\title{
The role of metabolism in direct and indirect defense towards two-spotted spider mite (Tetranychus urticae) in Capsicum spp.
}

Yuanyuan Zhang 
Thesis committee

\section{Promotor}

Prof. Dr Harro J. Bouwmeester

Professor of Plant Hormone Biology

University of Amsterdam

\section{Co-promotor}

Dr Iris F. Kappers

Researcher, Laboratory of Plant Physiology

Wageningen University and Research

\section{Other members}

Prof. Dr Joop A. van Loon, Wageningen University and Research

Prof. Dr Michel A. Haring, University of Amsterdam

Dr Petra M. Bleeker, ENZA zaden, Enkhuizen

Dr Mirka Macel, Radboud University Nijmegen

This research was conducted under the auspices of the Graduate School of Experimental Plant Sciences (EPS) 


\section{The role of metabolism in direct and indirect defense towards two-spotted spider mite (Tetranychus urticae) in Capsicum spp.}

\section{Yuanyuan Zhang}

Thesis

submitted in fulfilment of the requirements for the degree of doctor at Wageningen University and Research

by the authority of the Rector Magnificus

Prof. Dr A.P.J. Mol,

in the presence of the

Thesis Committee appointed by the Academic Board

to be defended in public

on Thursday 13 September

at 11 a.m. in the Aula. 
Yuanyuan Zhang

The role of metabolism in direct and indirect defense towards two-spotted spider mite (Tetranychus urticae) in Capsicum spp.

230 pages.

PhD thesis, Wageningen University and Research, Wageningen, NL (2018)

With references, with a summary in English

ISBN: 978-94-6343-340-2

DOI: https://doi.org/10.18174/458497 


\section{Contents}

Chapter 1

General introduction

Chapter 2

Exploring natural variation in metabolite-based defense against two-spotted spider mite in Capsicum spp

\section{Chapter 3}

61

Dynamic metabolic adaptations in Capsicum annuum upon two-spotted spider mite herbivory

Chapter 4

109

Combined transcriptome and metabolome analysis reveals induction and suppression of defense responses upon jasmonic acid and two-spotted spider mite herbivory in Capsicum annuum

Chapter 5

163

Characterization of the TPS gene family and transcriptomic insights into terpenoid biosynthesis upon spider-mite feeding in Capsicum annuum

Chapter 6

205

General discussion

Summary

Acknowledgements

Curriculum vitae 

Chapter 1 General introduction

Yuanyuan Zhang 
Plants exploit a multitude of mechanisms to defend themselves against herbivory in order to reduce damage and maintain fitness. They form morphological barriers, such as trichomes and a wax layer and constitutively produce defensive proteins and metabolites, such as phenolics and terpenes, as a first layer of constitutive defense. Upon herbivory, plants also produce defensive proteins and metabolites to repel or kill insects as induced defense (War et al., 2012, Sánchez-Sánchez and Morquecho-Contreras, 2017). These responses, which directly affect the herbivores' wellbeing and reduce the population of attackers, are defined as direct defense. In addition to diminishing herbivore number directly, plants emit volatiles upon herbivory (herbivore-induced-plant volatiles, HIPVs), which results in enhanced attractiveness to natural enemies (Dicke, 1999). The attraction of natural enemies, such as predatory mites and parasitoids, to minimize the number of herbivores, is called indirect defense (Takabayashi and Dicke, 1996, Pare and Tumlinson, 1999).

The exploitation of plant defense mechanisms, such as increasing host plant resistance or employing natural enemies as biological control agents, enables us to protect crops/plants in an environmentally friendly way. In this thesis, I focus on metabolite-based direct defense against two-spotted spider mites Tetranychus urticae Koch and indirect defense mediated by its natural enemy, the predatory mite Phytoseiulus persimilis in Capsicum species.

\section{Capsicum species}

Capsicum is a genus of the nightshade family, the Solanaceae (Walsh and Hoot, 2001). The Capsicum genus contains around 30 species that are mostly diploid with $2 n=24$, while a few of the non-domesticated species are $2 n=32$ (Wang and Bosland, 2006). Native to the Americas, Capsicum species have a thousands of years of history of domestication. Now it has become a worldwide cultivated and economically important vegetable crop in many countries. The world production of both fresh and dried pepper is about 36 million tonnes/year (Figure 1), which are mainly produced in Asian, American and European countries, such as China, Mexico, Turkey etc. (http:// www.fao.org).

Like in most cultivated crops, pests form the biggest threat to pepper production. Traditional crop protection means such as the use of pesticides harm the environment, humans and livestock. Besides, pests usually rapidly develop resistance to pesticides. Exploring genetic resources for new plant defense mechanisms and applying genetic approaches to introgress these into crops is therefore a new trend in crop protection. In literature, multiple 
herbivore-defense related proteins and metabolites have been identified in Capsicum. Defensive proteins, such as polyphenol oxidase (PPO) and trypsin inhibitor ( $\mathrm{TI})$ were shown to be induced by methyl jasmonate application and enhanced resistance to Spodoptera litura in sweet pepper (Tan et al., 2011). Wound-inducible Pin-II Proteinase inhibitors (PIs) in C. annuum are strongly elicited by mechanical wounding, the high cellular damage and herbivore-specific elicitors introduced by Lepidopteran insects (Helicoverpa armigera), as well as by aphids (Myzus persicae) (Mishra et al., 2012, Tamhane et al., 2009). The species-specific alkaloid, capsaicin (8-methyl-N-vanillyl-6-nonenamide), was shown not only to play an important role in plant defense but also to be a driving force for host adaptation by herbivores such as Helicoverpa assulta (Ahn et al., 2011). However, with the exception of capsaicin, most studies focus on metabolites important for the aroma of Capsicum fruits (Garcia-Mier et al., 2015), while much less studies report on defensive metabolites in the vegetative parts, important for plant defense, of Capsicum.

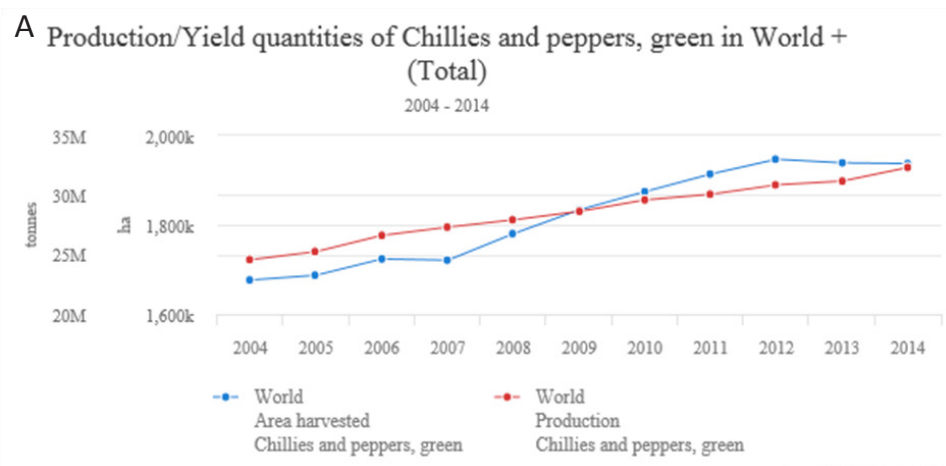

B

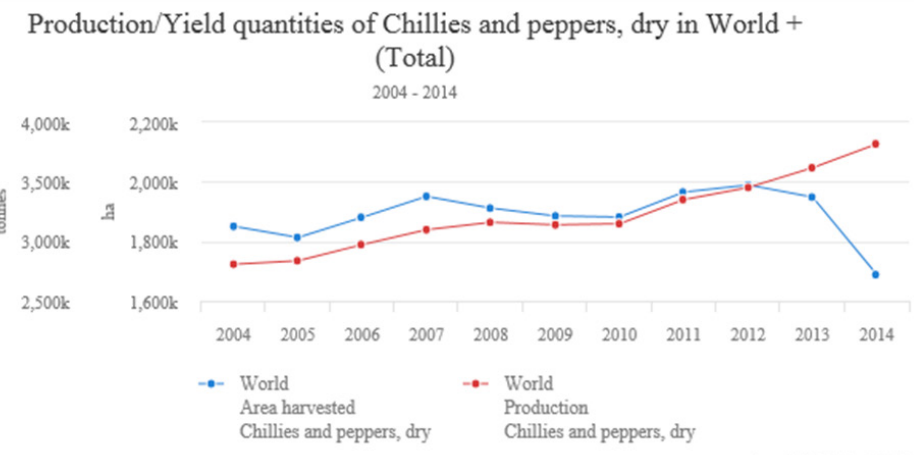

Figure 1. Global production of fresh (A) and dry (B) chilies and peppers between 20042014. Red line represents world production; Blue line represents world area harvested. 


\section{Two-spotted spider mites}

Spider mites are cell content feeding arthropods, a member of the Acari (mite) family Tetranychidae, which includes about 1,200 species (Bolland et al., 1998). The typical life cycle of spider mites consists of the egg, the larva, two nymphal stages and the adult stage. Depending on the temperature, spider mites hatch from the egg after 3 days and complete their development within 5 to 20 days. The adult females can live for 2 to 4 weeks and one individual female can produce several hundred eggs (Raworth et al., 2001). Spider mites form one of the most significant pests in agriculture, feeding on more than 1100 plant species, which results in great production losses, including in Capsicum. Spider mites inflict damage by puncturing the cells from which they subsequently suck the cell content. Damage is visible from the yellowing of leaves, the presence of areas with white spots consisting of punctured cells that do not contain chlorophyll anymore, and the presence of black spots consisting of fecal material (Figure 2). The short lifecycle and high fecundity allows spider mite to develop resistance to pesticides, which usually have a single mode of action, quickly. Therefore, biological control with natural enemies and/or the introduction of plant resistance consisting of multiple layers of defense would be a better way to control spider mites.

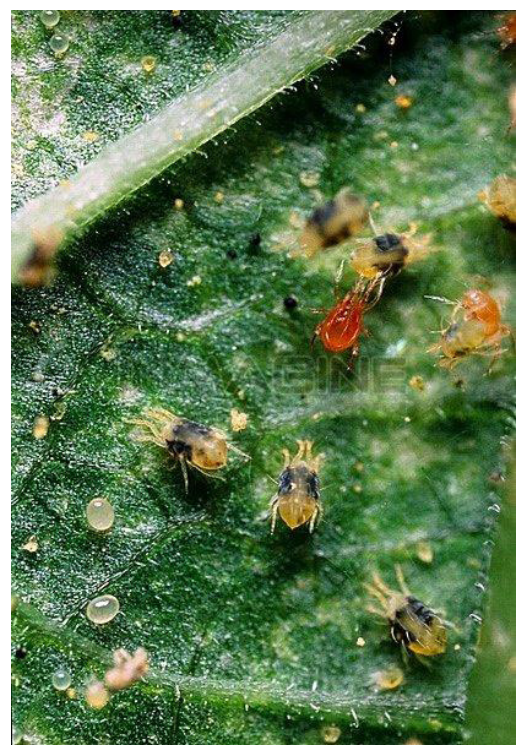

Figure 2. Two-spotted spider mites infested plants (picture from https://image.baidu. com)

Defense mechanisms against spider mites have been studied in many plant species. A study on tomato (Lycopersicon esculentum) suggested that the 
octadecanoid signaling pathway promotes resistance to a broad spectrum of cell content-feeding herbivores, including spider mites (Tetranychus urticae Koch) (Li et al., 2002). Spider mites induced proteinase inhibitor activity in tomato and activated the transcription of genes involved in jasmonate-, salicylate- and ethylene-regulated defense and increased biosynthesis of monoterpenes and diterpenes (Kant et al., 2004). Transcriptome analysis on Arabidopsis thaliana and L. esculentum revealed that genes involved in biosynthesis of JA, phenylpropanoids, flavonoids, and terpenoids were recruited for defense responses against spider mites in both species (Martel et al., 2015). In other species, multiple volatile terpenes have been identified as being involved in indirect defense to spider mites in lima bean (Phaseolus lunatus L.), such as (E)-4,8-dimethyl-1,3,7-nonatriene (DMNT), (S)-linalool and $(E, E)-4,8,12$-trimethyl-1,3,7,11-tridecatetraene (TMTT) (Li et al., 2018), as well as in cucumber (Cucumis sativus), such as (E,E)- $\alpha$-farnesene and (E)$\beta$-ocimene (Kappers et al., 2011).

\section{Signal transduction and defensive hormone regulating network}

In plants, changes occur in the transcriptome, proteome and metabolome upon recognition of herbivory (War et al., 2012) through compounds and/ or peptides in the oral secretion of the herbivores (Alborn et al., 1997, Halitschke et al., 2001) or their oviposition fluid (Hilfiker et al., 2014). These elicitors can activate mitogen-activated protein kinases (MAPKs), wounding-induced protein kinases (WIPKs), or salicylic acid (SA) induced protein kinases (SIPKs) and induce a cascade of defense responses. For instance, the tobacco hornworm (Manduca sexta) feeding on tobacco (Nicotiana attenuata) activates WIPKs and SIPKs in both the wounded as well as the unwounded leaves in the same plant (Wu et al., 2007). Nilaparvata lugens, a brown plant hopper, induced the expression of a putative MAPK, OmMKKI in wild rice, Oryza minuta Presl (You et al., 2007). Subsequent signal transduction induces defense related phytohormone pathways, such as jasmonic acid (JA), SA and ethylene, which play an important role in regulating plant defense responses to herbivores (Howe and Jander, 2008, Furstenberg-Hagg et al., 2013, War et al., 2012).

$\mathrm{JA}$ is the dominant hormone modulating responses to wounding, necrotrophic pathogens and a wide range of arthropod herbivores based on numerous laboratory and field studies (Pieterse et al., 2012, Howe and Jander, 2008). JA is an oxylipin signaling compound derived from $\alpha$-linolenic acid (18:3) ( $\alpha$-LeA) (Weber et al., 1997). JA signaling is activated by M. sexta caterpillars in tobacco (Schittko et al., 2000), spider mite T. urticae in tomato (Li et al., 2002) and Pieris rapae caterpillars and Frankliniella occidentalis thrips in Arabidopsis (Snoeren et al., 2011). Jasmonate deficient mutants showed 
compromised resistance to larvae of Bradysia impatiens in Arabidopsis (McConn et al., 1997) and to the lepidopteran predator Manduca sexta in tomato (Howe et al., 1996). The application of JA enhanced resistance against caterpillar herbivory by Spodoptera exigua, in tomato by causing production of toxic and antinutritional proteinase inhibitors and oxidative enzymes such as polyphenol oxidases (PPO) and peroxidases (POD) (Felton et al., 1989), as well as production of volatiles which attracted the natural enemy of the herbivore, Hyposoter exiguae (Thaler, 1999).

ET also plays a role in the complex signaling network in pathogen and herbivore induced defenses (Adie et al., 2007, Kunkel and Brooks, 2002). In general, ET co-regulates JA responsive genes and works synergistically with JA (Erb et al., 2012, Pieterse et al., 2012). The expression of protease inhibitors is regulated by both JA and ET in tomato. Application of the ET precursor, 1-amino-cyclopropane-1-carboxylic acid (ACC) to lima bean has been reported to enhance the JA induced volatile emission of detached leaves (Horiuchi et al., 2003). ET accumulated upon beet armyworm (S. exigua) feeding and promoted volatile emission induced by JA in maize (Schmelz et al., 2003). Significant overlap of defense related genes induced by both JA and ET were revealed by microarray analysis (Schenk et al., 2000). The expression of PDF1.2, for example, was inhibited in both the JA signalling coi1 mutant and the ET signaling ein 2 mutant (Penninckx et al., 1998, Thomma et al., 2001). Several transcription factors of the ETHYLENE RESPONSE FACTOR (ERF) family were identified as positive regulator of JA and ET signaling (Lorenzo et al., 2003, McGrath et al., 2005).

SA is a benzoic acid derivative that is mainly involved in the defense against biotrophic and hemi-biotrophic pathogens and regulates local and systemic acquired resistance (SAR) (Verma et al., 2016). Increased SA levels induced PATHOGENESIS RELATED (PR) proteins and conferred plants with enhanced resistance to a wide range of pathogens (van Loon et al., 2006, Chen et al., 1993). SA and JA act antagonistically in the defense against herbivores (Robert-Seilaniantz et al., 2011, Thaler et al., 2012). The key regulatory element in SA signaling is NON-EXPRESSOR OF PR GENE 1 (NPR1). A redox change induced by SA leads to the dissociation of the NPR1 complex. NPR1 monomers interact with the TGA transcription factor resulting in the expression of $P R$ genes (Mou et al., 2003, Wu et al., 2012). Several WRKY transcription factors also play an important role in SA signaling.

To defend against stresses in a cost-efficient manner, plants regulate their defense responses by fine-tuning multiple phytohormones according to different attackers (Pieterse et al., 2012). In Micro-Tom tomato, the leaf-chewing insects, larvae of S. litura and S. exigua, as well as cell-content feeder, 
the western flower thrips ( $F$. occidentalis) activated JA inducible genes while the two-spotted spider mite ( $T$. urticae) activated both JA-inducible and SA-inducible genes (Kawazu et al., 2012).

\section{Secondary metabolites in plant defense}

The definition of plant secondary metabolites is that they are metabolites that do not play a direct role in plant growth and development, but they may play an important role in the interaction of plants with other organisms (War et al., 2012, Pare and Tumlinson, 1999), because they may act as toxic/deterrent/anti-feedant or attractant compounds to herbivores and their natural enemies (Bennett and Wallsgrove, 1994). The major compound classes of secondary metabolites are alkaloids, phenolics and terpenoids.

The alkaloids is a widely distributed class of bioactive natural products found in many plant families, including Leguminosae (legumes), Liliaceae (lilies), Solanaceae (nightshade plants) and Amaryllidaceae (Furstenberg-Hagg et al., 2013, Howe and Jander, 2008). The true alkaloids are derived from amino acids and contain nitrogen in a heterocyclic ring. The ring structure includes pyridines, pyrroles, indoles, pyrrolidines, isoquinolines and piperidines (Ziegler and Facchini, 2008). Some alkaloids proved to be efficient feeding deterrents to herbivores (Rhodes, 1994). Caffeine, for example, is found in various plant species in which it has been demonstrated to be toxic to feeding insects (Detzel and Wink, 1993). The alkaloid demissine that was found in the wild potato Solanum demissum was shown to impart resistance to the Colorado potato beetle (Leptinotarsa decemlineata) and the potato leafhopper (Empoasca fabae) (Furstenberg-Hagg et al., 2013).

The phenolics are derived from the shikimic acid and/or malonic acid pathway and represent a large variety of secondary metabolites containing a phenol group. About 10,000 phenolics have been detected in plants, including coumarins, lignins, flavonoids, isoflavonoids and tanins. Phenolics were shown to repel feeding herbivores or to be toxic by inhibiting enzymes of the herbivores, but also serve as attractants to pollinators (Vogt, 2010).

The terpenoids are the largest class of plant secondary metabolites, with more than 40,000 compounds in the plant kingdom reported. Many terpenoids have been shown to be involved in direct and/or indirect defense. Conifers, for example, produce terpenoids upon insect induction (Keeling and Bohlmann, 2006). Pacific ponderosa pine (Pinus ponderosa) and white fir (Abies concolor) displayed increased monoterpene synthases activity upon tiger moth (Halisdota ingens) larva feeding (Litvak and Monson, 1998). The white pine weevil (Pissodes strobi) induced accumulation of traumatic resin 
rich in terpenoids by feeding on the stem of Sitka spruce (Picea sitchensis) (McKay et al., 2003, Miller et al., 2005). Several monoterpenes have been identified as directly toxic to bark beetles (Raffa and Smalley, 1995, Werner, 1995). Genetic engineering of Arabidopsis with a strawberry linalool/nerolidol synthase gene, FaNES1, resulted in the production of (E)-DMNT and $(3 S)-(E)$-nerolidol and this enhanced attraction of natural enemy of spider mites, P. persimilis (Kappers et al., 2005). Overexpression of TPS10 in Arabidopsis resulted in the emission of $(E)$ - $\beta$-farnesene and $(E)$ - $\alpha$-bergamotene, which caused attraction of females of the parasitoid Cotesia marginiventris (Schnee et al., 2006). The biosynthesis of the terpenes starts from the linear assemblage of different numbers of isopentenyl diphosphate molecules, isopentenyl diphosphate (IPP) and its isomer dimethylallyl diphosphate (DMAPP) (Wang and Ohnuma, 2000). These C5 precursors are produced in the mevalonate pathway or in the methylerythritol phosphate pathway (MEP) (Vranova et al., 2013). C10-prenyl diphosphates, geranyl diphosphate (GPP) (trans-configuration) or neryl diphosphate (NPP) (cis-configuration) are the substrates that are converted into monoterpenes by monoterpene synthases; the C15-prenyl diphosphates, farnesyl diphosphate (FPP) is converted into sesquiterpenes by sesquiterpene synthases; the C20-prenyl diphosphate, geranylgeranyl diphosphate (GGPP), is converted into diterpenes by diterpene synthases (Bohlmann et al., 1998). The plant terpene synthase (TPS) family has been studied in many plant species, including Arabidopsis (Aubourg et al., 2002), Citrus (Citrus sinensis) (Dornelas and Mazzafera, 2007), grapevine (Vitis vinifera) (Martin et al., 2010), tomato (Falara et al., 2011), and Eucalyptus (Eucalyptus grandis and E. globulus) (Külheim et al., 2015).

As mentioned above, compared with the great number of studies that analyze terpenoids in Capsicum fruits as a component contributing to aroma and flavor (Xiao et al., 2010, Martin et al., 2017), less research focused on terpenes in $C$. annuum as defensive compounds. Still, several terpenes, such as germacrene $A, T M T T$, linalool and $(E)-\beta$-ocimene, have been reported to be induced upon spider mite infestation in C. annuum (Van Den Boom et al., 2004). The pepper phytoalexin capsidiol was shown to play an important role in inducible defenses against fungi. Although key enzymes for biosynthesis of several terpenoids such as carotenoids (Mialoundama et al., 2010) and capsidiol (Back et al., 2000) have been isolated and characterized, most of the terpene biosynthetic genes that must be present in Capsicum spp. remain unknown. 


\section{Genetic variation in plant defense}

Many aspects drive plant diversity within populations, including reproduction, life-form and environment-plant interaction (Walker, 2006). Analyzing genetic variation facilitates identifying the multitude of factors underlying complex phenotypic traits, such as defensive responses to bacteria, fungi and herbivores. Genome-wide association studies (GWAS) pinpointed genes such as GLUCAN-SYNTHASE-LIKE 11 (GSL11) and TRICHOME BIREFRINGENCE-LIKE (TBL37) - that are involved in defense responses and cell wall integrity, respectively - affect the variation in the leaf microbial community in A. thaliana (Horton et al., 2014). The leucine rich repeat receptor-like protein $R / m 2$ was identified by mapping and explained the genetic variation in Brassica napus in resistance to the pathogen Leptosphaeria maculans (Larkan et al., 2014, Larkan et al., 2015). GWAS in Medicago truncatula identified a F-box protein coding gene and its promoter responsible for resistance to Aphanomyces euteiches (Bonhomme et al., 2014). Mapping using a maize recombinant inbred population identified genes that are involved in programmed cell death, defense response, ubiquitination, redox homeostasis, autophagy, calcium signalling, lignin biosynthesis and cell wall modification as playing a role in the hypersensitive response (HR) against pathogens (Olukolu et al., 2014). Genetic variation in plant defense against herbivores has been reported in multiple plant-herbivore combinations. Two Brassica oleracea cultivars differed in transcriptional responses to $P$. rapae attack, not only in timing but also in specific defense genes. The resistant genotype showed slower transcriptional changes than the susceptible one, but also specifically expressed genes encoding a putative glutathione S-transferase and a putative trypsin inhibitor (Broekgaarden et al., 2007). Wheat was reported with stronger constitutive enzyme activity of phenylalanine ammonia-lyase (PAL), polyphenol oxidase (PPO), and peroxidase (POD) in resistant cultivars. Although aphids (S. avenae) increased the activity of the three enzymes, PPO and POD showed higher increases in susceptible cultivars (Han et al., 2009). Cucumber accessions showed genetic variation in JA and spider mite (T. urticae) induced volatile emission resulting in different attractiveness towards predatory mites (P. persimilis). ( $E$ )- $\beta$-ocimene and TMTT positively correlated with attractiveness to P. persimilis while methyl salicylate, $\alpha$-patchoulene and geranyl isovalerate negatively correlated with predaceous attraction (Kappers et al., 2011, Kappers et al., 2010). Arabidopsis also displayed genetic variation in herbivore induced plant volatile emission upon P. rapae infestation (Snoeren et al., 2010).

Studies on genotypic diversity in Capsicum species provide knowledge how to use genetic resources for breeding optimization. Previously, analyses in 
semi-polar and volatile metabolites using untargeted approaches revealed 88 semi-polar metabolites in pepper fruits with a large proportion of flavonoid conjugates. Capsianosides were found highly abundant in $C$. annuum genotypes. Volatile variation corresponded well to the difference in pungency between accessions (Wahyuni et al., 2013). Metabolite quantitative trait locus (MQTL) analysis in ripe pepper fruits suggested the Ca-MYB12 transcription factor and the gene encoding flavone synthase (CaFS-2) as likely causative genes determining the variation in naringenin chalcone and flavone C-glycosides, respectively (Wahyuni et al., 2014). However, the semi-polar and volatile metabolites related with plant defenses were so far not studied in Capsicum spp. in any great detail.

\section{Integration of transcriptomics and metabolomics}

Plant-herbivore interactions involve complex signaling networks and largescale transcriptome as well as metabolome reprogramming. It's hard to understand such complex systems well by studying single or a limited number of elements separately (Jost et al., 2008). High-throughput omics techniques develop fast (e.g. genomics, proteomics, metabolomics, phenomics, etc.) and are more and more used to obtain more global insights in biological questions (Barah and Bones, 2015).

Transcriptomics. Insight in the changes in the expression of all genes of a certain species provides important information about how a phenotype arises. High-throughput transcript sequencing techniques allow us to detect genome-wide transcripts and facilitate understand how these profiles drive the biological processes going on in that organism/tissue/cell. From microarray chip detecting limited number of transcripts (Schena et al., 1995) to full transcriptome sequencing (RNA seq) (Gan et al., 2011), the technique of transcriptomics has developed fast and the cost have decreased. Furthermore, not only transcriptome sequencing but also whole genome sequencing of many model and non-model organisms have benefited from the development of next-generation sequencing technologies and provided the reference for transcriptome analysis (Egan et al., 2012). For those organism of which a reference genome is not available, de novo sequencing can also provide transcriptome profiles (Surget-Groba and Montoya-Burgos, 2010). Decades of experimental characterization of gene functions, archived in many gene and protein database, has facilitated the gene function prediction by sequence similarity. Along with the development of sequencing technologies, the development of various bioinformatics tools for gene clustering, co-expression analysis, gene ontology analysis allow transcriptome data to be analyzed stepwise. 
Metabolomics Secondary metabolites play an important role in plant defense (Bennett and Wallsgrove, 1994). Compared with genomic and transcript information, the metabolome potentially directly contributes to the defense phenotype. However, metabolite profiles mostly provide only a partial explanation of results obtained by transcriptome and proteome analyses (Fiehn, 2002). While targeted measurements of selected metabolites or pathways have been beneficial in confirming gene functions. Untargeted metabolite analysis approaches have been used without a priori knowledge of the outcome. Combining metabolomics and transcriptomics data provides corroborative evidence on different levels. For example, the most significant transcriptional and metabolic changes occurred in the first few hours after aphid infestation (Rhopalosiphum maidis) in maize (Zea mays). SA predominately regulated responses in aphid-infested maize, while JA was not involved. Benzoxazinoids were shown to be important for reducing aphid reproduction (Tzin et al., 2015). Comprehensive transcriptomics analysis uncovered the variation between resistant and susceptible $B$. napus to Sclerotinia sclerotiorum. A resistant line showed larger, in both number and fold change, differences in gene expression, including genes involved in MAPK signaling, WRKY transcriptional regulation, JA/ET signaling pathways, and in the biosynthesis of defense-related proteins and indolic glucosinolates (Wu et al., 2016).

\section{Research aim and Outline of this thesis}

In this thesis, I study the metabolite-based plant direct defense - against spider mites - and indirect defense - the attraction of a natural enemy, predatory mites - in Capsicum spp. I use multiple approaches to give a comprehensive overview of the defense mechanisms present in this genus. In Chapter 1, the General Introduction, I introduce the agronomic importance of Capsicum spp. and their herbivore problems as well as what defense mechanisms occur in plants and how these are regulated by plant hormones. In Chapter 2, I screened 22 genotypes of Capsicum spp. for their direct defense, using spider mite population development, and JA-induced indirect defense based on the attractiveness for predatory mites. I analyzed the endogenous and volatile metabolites using untargeted approaches and studied whether they explained the genetic variation in the two different defense types. In Chapter 3, I used two contrasting genotypes to reveal in the dynamic changes in the endogenous and volatile metabolome as well as defense related hormones during development of a spider mite population. In Chapter 4, I studied the transcriptome and metabolome changes in the same two genotypes upon spider mite infestation and JA induction. Compared with JA 
induction, spider mites induced both JA and SA signaling, but less genes involved in JA-induced metabolic pathways. The susceptible genotype showed more differently expressed genes but produced less metabolites compared with the resistant one. Flavonoids and terpenoids were found to be induced by JA and spider mites in both the transcript and metabolic level. In Chapter 5, I studied different characteristics of the terpene synthase gene family in Capsicum, including their phylogeny, their regulation by spider mites, and catalytic activity of selected number of them. Finally, in Chapter 6, the General Discussion, I discuss the results presented in the experimental chapters, I integrate and further discuss them in relation to the literature and discuss perspectives on hormone regulated transcription factors and the regulation of specialized secondary metabolites.

\section{Acknowledgements:}

I would like to thank Harro Bouwmeester and Iris Kappers for their comments on a previous version of this chapter. 


\section{References}

ADIE, B., CHICO, J. M., RUBIO-SOMOZA, I. \& SOLANO, R. 2007. Modulation of plant defenses by ethylene. Journal of Plant Growth Regulation, 26, 160-177.

AHN, S. J., BADENES-PEREZ, F. R. \& HECKEL, D. G. 2011. A host-plant specialist, Helicoverpa assulta, is more tolerant to capsaicin from Capsicum annuum than other noctuid species. Journal of Insect Physiology, 57, 1212-1219.

ALBORN, H. T., TURLINGS, T. C. J., JONES, T. H., STENHAGEN, G., LOUGHRIN, J. H. \& TUMLINSON, J. H. 1997. An Elicitor of Plant Volatiles from Beet Armyworm Oral Secretion. Science, 276, 945-949.

AUBOURG, S., LECHARNY, A. \& BOHLMANN, J. 2002. Genomic analysis of the terpenoid synthase (AtTPS) gene family of Arabidopsis thaliana. Molecular Genetics and Genomics, 267, Issue 6, pp 730-745.

BACK, K., NAH, J., LEE, S. B., SONG, J. H., SHIN, D. H. \& KIM, H. Y. 2000. Cloning of a sesquiterpene cyclase and its functional expression by domain swapping strategy. Molecules and Cells, 10, 220-225.

BARAH, P. \& BONES, A. M. 2015. Multidimensional approaches for studying plant defence against insects: from ecology to omics and synthetic biology. Journal of Experimental Botany, 66, 479-493.

BENNETT, R. N. \& WALLSGROVE, R. M. 1994. Secondary Metabolites in Plant Defense-Mechanisms. New Phytologist, 127, 617-633.

BOHLMANN, J., MEYER-GAUEN, G. \& CROTEAU, R. 1998. Plant terpenoid synthases: molecular biology and phylogenetic analysis. Proceedings of the National Academy of Sciences of the United States of America, 95, 4126-33.

BOLLAND, H. R., GUITERREZ, J. \& FLECHTMANN, C. H. W. 1998. World catalogue of the spider mite family (Acari:Tetranychidae).

BONHOMME, M., ANDRÃ@), O., BADIS, Y., RONFORT, J., BURGARELLA, C., CHANTRET, N., PROSPERI, J. M., BRISKINE, R., MUDGE, J. \& DEBÃCLLÃ@), F. 2014. High-density genome-wide association mapping implicates an F-box encoding gene in Medicago truncatula resistance to Aphanomyces euteiches. New Phytologist, 201, 1328-1342.

BROEKGAARDEN, C., POELMAN, E. H., STEENHUIS, G., VOORRIPS, R. E., DICKE, M. \& VOSMAN, B. 2007. Genotypic variation in genome-wide transcription profiles induced by insect feeding: Brassica oleracea--Pieris rapae interactions. Bmc Genomics, 8, 239.

CHEN, Z. X., SILVA, H. \& KLESSIG, D. F. 1993. Active Oxygen Species in the induction of plant systemic acquired-resistance by salicylic-acid. Science, 262, 1883-1886.

DETZEL, A. \& WINK, M. 1993. Attraction, deterrence or intoxication of bees ( Apis mellifera ) by plant allelochemicals. Chemoecology, 4, 8-18.

DICKE, M. 1999. Plant-Carnivore Interactions: Evolutionary and Ecological Consequences For Plant, Herbivores. In Abstract, 483-520.

DORNELAS, M. C. \& MAZZAFERA, P. 2007. A genomic approach to characterization of the Citrus terpene synthase gene family. Genetics and Molecular Biology, 30, 832840.

EGAN, A. N., SCHLUETER, J. \& SPOONER, D. M. 2012. Applications of next-generation se- 
quencing in plant biology. American Journal of Botany, 99, 175-185.

ERB, M., MELDAU, S. \& HOWE, G. A. 2012. Role of phytohormones in insect-specific plant reactions. Trends in Plant Science, 17, 250-259.

FALARA, V., AKHTAR, T. A., NGUYEN, T. T., SPYROPOULOU, E. A., BLEEKER, P. M., SCHAUVINHOLD, I., MATSUBA, Y., BONINI, M. E., SCHILMILLER, A. L. \& RL, L. 2011. The tomato terpene synthase gene family. Plant Physiology, 157, 770-789.

FELTON, G. W., DONATO, K., DEL VECCHIO, R. J. \& DUFFEY, S. S. 1989. Activation of plant foliar oxidases by insect feeding reduces nutritive quality of foliage for noctuid herbivores. Journal of Chemical Ecology, 15, 2667-2694.

FIEHN, O. 2002. Metabolomics--the link between genotypes and phenotypes. Plant Molecular Biology, 48, 155-171.

FURSTENBERG-HAGG, J., ZAGROBELNY, M. \& BAK, S. 2013. Plant defense against insect herbivores. Int J Mol Sci, 14, 10242-97.

GAN, X. C., STEGLE, O., BEHR, J., STEFFEN, J. G., DREWE, P., HILDEBRAND, K. L., LYNGSOE, R., SCHULTHEISS, S. J., OSBORNE, E. J., SREEDHARAN, V. T., KAHLES, A., BOHNERT, R., JEAN, G., DERWENT, P., KERSEY, P., BELFIELD, E. J., HARBERD, N. P., KEMEN, E., TOOMAJIAN, C., KOVER, P. X., CLARK, R. M., RATSCH, G. \& MOTT, R. 2011. Multiple reference genomes and transcriptomes for Arabidopsis thaliana. Nature, 477, 419-423.

GARCIA-MIER, L., JIMENEZ-GARCIA, S. N., GUEVARA-GONZALEZ, R. G., FEREGRINO-PEREZ, A. A., CONTRERAS-MEDINA, L. M. \& TORRES-PACHECO, I. 2015. Elicitor Mixtures Significantly Increase Bioactive Compounds, Antioxidant Activity, and Quality Parameters in Sweet Bell Pepper. Journal of Chemistry, 8.

HALITSCHKE, R., SCHITTKO, U., POHNERT, G., BOLAND, W. \& BALDWIN, I. T. 2001. Molecular interactions between the specialist herbivore Manduca sexta (Lepidoptera, Sphingidae) and its natural host Nicotiana attenuata. III. Fatty acid-amino acid conjugates in herbivore oral secretions are necessary and sufficient for herbivore-specific plant responses. Plant Physiology, 125, 711-717.

HAN, Y., WANG, Y., BI, J. L., YANG, X. Q., HUANG, Y., ZHAO, X., HU, Y. \& CAI, Q. N. 2009. Constitutive and Induced Activities of Defense-Related Enzymes in Aphid-Resistant and Aphid-Susceptible Cultivars of Wheat. Journal of Chemical Ecology, 35, 176-182.

HILFIKER, O., GROUX, R., BRUESSOW, F., KIEFER, K., ZEIER, J. \& REYMOND, P. 2014. Insect eggs induce a systemic acquired resistance in Arabidopsis. Plant Journal, 80, 1085-1094.

HORIUCHI, J. I., ARIMURA, G. I., OZAWA, R., SHIMODA, T., DICKE, M., TAKABAYASHI, J. \& NISHIOKA, T. 2003. Lima bean leaves exposed to herbivore-induced conspecific plant volatiles attract herbivores in addition to carnivores. Applied Entomology and Zoology, 38, 365-368.

HORTON, M. W., BODENHAUSEN, N., BEILSMITH, K., MENG, D., MUEGGE, B. D., SUBRAMANIAN, S., VETTER, M. M., VILHJÁLMSSON, B. J., NORDBORG, M., GORDON, J. I. \& BERGELSON, J. 2014. Genome-wide association study of Arabidopsis thaliana leaf microbial community. Nature Communications, 5, 5320.

HOWE, G. A. \& JANDER, G. 2008. Plant immunity to insect herbivores. Annual Review of Plant Biology, 59, 41-66. 
HOWE, G. A., LIGHTNER, J., BROWSE, J. \& RYAN, C. A. 1996. An octadecanoid pathway mutant (JL5) of tomato is compromised in signaling for defense against insect attack. Plant Cell, 8, 2067-2077.

JOST, J., HELBING, D., LHORINCZ, A. \& MIDDENDORF, M. 2008. Complexity in Biology, editorial. Theory in Biosciences, 127, 67-68.

KANT, M. R., AMENT, K., SABELIS, M. W., HARING, M. A. \& SCHUURINK, R. C. 2004. Differential timing of spider mite-induced direct and indirect defenses in tomato plants. Plant Physiology, 135, 483-495.

KAPPERS, I. F., AHARONI, A., VAN HERPEN, T., LUCKERHOFF, L. L. P., DICKE, M. \& BOUWMEESTER, H. J. 2005. Genetic engineering of terpenoid metabolism attracts, bodyguards to Arabidopsis. Science, 309, 2070-2072.

KAPPERS, I. F., HOOGERBRUGGE, H., BOUWMEESTER, H. J. \& DICKE, M. 2011. Variation in Herbivory-induced Volatiles Among Cucumber (Cucumis sativus L.) Varieties has Consequences for the Attraction of Carnivorous Natural Enemies. Journal of Chemical Ecology, 37, 150-60.

KAPPERS, I. F., VERSTAPPEN, F. W. A., LUCKERHOFF, L. L. P., BOUWMEESTER, H. J. \& DICKE, M. 2010. Genetic Variation in Jasmonic Acid- and Spider Mite-Induced Plant Volatile Emission of Cucumber Accessions and Attraction of the Predator Phytoseiulus persimilis. Journal of Chemical Ecology, 36, 500-12.

KAWAZU, K., MOCHIZUKI, A., SATO, Y., SUGENO, W., MURATA, M., SEO, S. \& MITSUHARA, I. 2012. Different expression profiles of jasmonic acid and salicylic acid inducible genes in the tomato plant against herbivores with various feeding modes. Arthropod-Plant Interactions, 6, 221-230.

KEELING, C. I. \& BOHLMANN, J. 2006. Genes, enzymes and chemicals of terpenoid diversity in the constitutive and induced defence of conifers against insects and pathogens. New Phytologist, 170, 657-675.

KÜLHEIM, C., PADOVAN, A., HEFER, C., KRAUSE, S. T., KÖlLnER, T. G., MYBURG, A. A., DEGENHARDT, J. \& FOLEY, W. J. 2015. The Eucalyptus terpene synthase gene family. BMC Genomics, 16, 450.

KUNKEL, B. N. \& BROOKS, D. M. 2002. Cross talk between signaling pathways in pathogen defense. Current Opinion in Plant Biology, 5, 325-331.

LARKAN, N. J., LYDIATE, D. J., YU, F., RIMMER, S. R. \& BORHAN, M. H. 2014. Co-localisation of the blackleg resistance genes RIm2 and LepR3 on Brassica napus chromosome A10. BMC Plant Biology,14,1(2014-12-31), 14, 1-9.

LARKAN, N. J., MA, L. S. \& BORHAN, M. H. 2015. The Brassica napus receptor-like protein RLM2 is encoded by a second allele of the LepR3/RIm2 blackleg resistance locus. Plant Biotechnology Journal, 13, 983-992.

LI, C. Y., WILLIAMS, M. M., LOH, Y. T., LEE, G. I. \& HOWE, G. A. 2002. Resistance of cultivated tomato to cell content-feeding herbivores is regulated by the octadecanoid-signaling pathway. Plant Physiology, 130, 494-503.

LI, F., LI, W., LIN, Y.-J., PICKETT, J. A., BIRKETT, M. A., WU, K., WANG, G. \& ZHOU, J.-J. 2018. Expression of lima bean terpene synthases in rice enhances recruitment of a beneficial enemy of a major rice pest. Plant, Cell \& Environment, 41, 111-120.

LITVAK, M. E. \& MONSON, R. K. 1998. Patterns of induced and constitutive monoterpene 
production in conifer needles in relation to insect herbivory. Oecologia, 114, 531540.

LORENZO, O., PIQUERAS, R., SANCHEZ-SERRANO, J. J. \& SOLANO, R. 2003. ETHYLENE RESPONSE FACTOR1 integrates signals from ethylene and jasmonate pathways in plant defense. Plant Cell, 15, 165-178.

MARTEL, C., ZHUROV, V., NAVARRO, M., MARTINEZ, M., CAZAUX, M., AUGER, P., MIGEON, A., SANTAMARIA, M. E., WYBOUW, N., DIAZ, I., VAN LEEUWEN, T., NAVAJAS, M., GRBIC, M. \& GRBIC, V. 2015. Tomato Whole Genome Transcriptional Response to Tetranychus urticae Identifies Divergence of Spider Mite-Induced Responses Between Tomato and Arabidopsis. Molecular Plant-Microbe Interactions, 28, 343361.

MARTIN, A., HERNANDEZ, A., ARANDA, E., CASQUETE, R., VELAZQUEZ, R., BARTOLOME, T. \& CORDOBA, M. G. 2017. Impact of volatile composition on the sensorial attributes of dried paprikas. Food Research International, 100, 691-697.

MARTIN, D. M., AUBOURG, S., SCHOUWEY, M. B., DAVIET, L., SCHALK, M., TOUB, O., LUND, S. T. \& BOHLMANN, J. 2010. Functional Annotation, Genome Organization and Phylogeny of the Grapevine (Vitis vinifera) Terpene Synthase Gene Family Based on Genome Assembly, FLcDNA Cloning, and Enzyme Assays. Bmc Plant Biology, 10, 22.

MCCONN, M., CREELMAN, R. A., BELL, E., MULLET, J. E. \& BROWSE, J. 1997. Jasmonate is essential for insect defense in Arabidopsis. Proceedings of the National Academy of Sciences of the United States of America, 94, 5473-5477.

MCGRATH, K. C., DOMBRECHT, B., MANNERS, J. M., SCHENK, P. M., EDGAR, C. I., MACLEAN, D. J., SCHEIBLE, W. R., UDVARDI, M. K. \& KAZAN, K. 2005. Repressor- and activator-type ethylene response factors functioning in jasmonate signaling and disease resistance identified via a genome-wide screen of Arabidopsis transcription factor gene expression. Plant Physiology, 139, 949-959.

MCKAY, S. A. B., HUNTER, W. L., GODARD, K. A., WANG, S. X., MARTIN, D. M., BOHLMANN, J. \& PLANT, A. L. 2003. Insect attack and wounding induce traumatic resin duct development and gene expression of (-)-pinene synthase in Sitka spruce. Plant Physiology, 133, 368-378.

MIALOUNDAMA, A. S., HEINTZ, D., JADID, N., NKENG, P., RAHIER, A., DELI, J., CAMARA, B. \& BOUVIER, F. 2010. Characterization of Plant Carotenoid Cyclases as Members of the Flavoprotein Family Functioning with No Net Redox Change. Plant Physiology, 153, 970-979.

MILLER, B., MADILAO, L. L., RALPH, S. \& BOHLMANN, J. 2005. Insect-induced conifer defense. White pine weevil and methyl jasmonate induce traumatic resinosis, de novo formed volatile emissions, and accumulation of terpenoid synthase and putative octadecanoid pathway transcripts in Sitka spruce. Plant Physiology, 137, 369-382.

MISHRA, M., MAHAJAN, N., TAMHANE, V. A., KULKARNI, M. J., BALDWIN, I. T., GUPTA, V. S. \& GIRI, A. P. 2012. Stress inducible proteinase inhibitor diversity in Capsicum annuum. Bmc Plant Biology, 12, 14.

MOU, Z., FAN, W. H. \& DONG, X. N. 2003. Inducers of plant systemic acquired resistance regulate NPR1 function through redox changes. Cell, 113, 935-944. 
OLUKOLU, B. A., WANG, G. F., VONTIMITTA, V., VENKATA, B. P., MARLA, S., JI, J., GACHOMO, E., CHU, K., NEGERI, A. \& BENSON, J. 2014. A Genome-Wide Association Study of the Maize Hypersensitive Defense Response Identifies Genes That Cluster in Related Pathways. Plos Genetics, 10, e1004562.

PARE, P. W. \& TUMLINSON, J. H. 1999. Plant volatiles as a defense against insect herbivores. Plant Physiology, 121, 325-331.

PENNINCKX, I. A. M. A., THOMMA, B. P. H. J., BUCHALA, A., METRAUX, J. P. \& BROEKAERT, W. F. 1998. Concomitant activation of jasmonate and ethylene response pathways is required for induction of a plant defensin gene in Arabidopsis. Plant Cell, 10, 2103-2113.

PIETERSE, C. M., VAN DER DOES, D., ZAMIOUDIS, C., LEON-REYES, A. \& VAN WEES, S. C. 2012. Hormonal modulation of plant immunity. Annu Rev Cell Dev Biol, 28, 489521.

RAFFA, K. F. \& SMALLEY, E. B. 1995. INTERACTION OF PRE-ATTACK AND INDUCED MONOTERPENE CONCENTRATIONS IN HOST CONIFER DEFENSE AGAINST BARK BEETLE FUNGAL COMPLEXES. Oecologia, 102, 285-295.

RAWORTH, D. A., GILLESPIE, D. R., ROY, M., THISTLEWOOD, H. M. A., MASON, P. G. \& HUBER, J. T. 2001. Tetranychus urticae Koch, twospotted spider mite (Acari: Tetranychidae).

RHODES, M. J. C. 1994. Physiological roles for secondary metabolites in plants: some progress, many outstanding problems. Plant Molecular Biology, 24, 1.

ROBERT-SEILANIANTZ, A., GRANT, M. \& JONES, J. D. G. 2011. Hormone Crosstalk in Plant Disease and Defense: More Than Just JASMONATE-SALICYLATE Antagonism. In: VANALFEN, N. K., BRUENING, G. \& LEACH, J. E. (eds.) Annual Review of Phytopathology, Vol 49. Palo Alto: Annual Reviews.

SÁNCHEZ-SÁNCHEZ, H. \& MORQUECHO-CONTRERAS, A. 2017. Chemical Plant Defense Against Herbivores.

SCHENA, M., SHALON, D., DAVIS, R. W. \& BROWN, P. O. 1995. Quantitative monitoring of gene-expression patterns with a complementary-dna microarray. Science, 270, 467-470.

SCHENK, P. M., KAZAN, K., WILSON, I., ANDERSON, J. P., RICHMOND, T., SOMERVILLE, S. C. \& MANNERS, J. M. 2000. Coordinated plant defense responses in Arabidopsis revealed by microarray analysis. Proceedings of the National Academy of Sciences of the United States of America, 97, 11655-11660.

SCHITTKO, U., PRESTON, C. A. \& BALDWIN, I. T. 2000. Eating the evidence? Manduca sexta larvae can not disrupt specific jasmonate induction in Nicotiana attenuata by rapid consumption. Planta, 210, 343-346.

SCHMELZ, E. A., ALBORN, H. T. \& TUMLINSON, J. H. 2003. Synergistic interactions between volicitin, jasmonic acid and ethylene mediate insect-induced volatile emission in Zea mays. Physiologia Plantarum, 117, 403-412.

SCHNEE, C., KOLLNER, T. G., HELD, M., TURLINGS, T. C. J., GERSHENZON, J. \& DEGENHARDT, J. 2006. The products of a single maize sesquiterpene synthase form a volatile defense signal that attracts natural enemies of maize herbivores. Proceedings of the National Academy of Sciences of the United States of America, 103, 1129-1134. 
SNOEREN, T. A. L., BROEKGAARDEN, C. \& DICKE, M. 2011. Jasmonates differentially affect interconnected signal-transduction pathways of Pieris rapae-induced defenses in Arabidopsis thaliana. Insect Science, 18, 249-258.

SNOEREN, T. A. L., KAPPERS, I. F., COLETTE, B., ROLAND, M., MARCEL, D. \& BOUWMEESTER, H. J. 2010. Natural variation in herbivore-induced volatiles inArabidopsis thaliana. Journal of Experimental Botany, 61, 3041-3056.

SURGET-GROBA, Y. \& MONTOYA-BURGOS, J. I. 2010. Optimization of de novo transcriptome assembly from next-generation sequencing data. Genome Research, 20, 1432-1440.

TAKABAYASHI, J. \& DICKE, M. 1996. Plant-carnivore mutualism through herbivore-induced carnivore attractants. Trends in Plant Science, 1, 109-113.

TAMHANE, V. A., GIRI, A. P., KUMAR, P. \& GUPTA, V. S. 2009. Spatial and temporal expression patterns of diverse Pin-II proteinase inhibitor genes in Capsicum annuum Linn. Gene, 442, 88-98.

TAN, C. W., LO, J. C., YADAV, J., RAVUIWASA, K. T. \& HWANG, S. Y. 2011. Methyl jasmonate induced responses in four plant species and its effect on Spodoptera litura Fab. performance. Journal of Asia-Pacific Entomology, 14, 263-269.

THALER, J. S. 1999. Jasmonate-inducible plant defences cause increased parasitism of herbivores. Nature, 399, 686-688.

THALER, J. S., HUMPHREY, P. T. \& WHITEMAN, N. K. 2012. Evolution of jasmonate and salicylate signal crosstalk. Trends in Plant Science, 17, 260-270.

THOMMA, B., PENNINCKX, I., BROEKAERT, W. F. \& CAMMUE, B. P. A. 2001. The complexity of disease signaling in Arabidopsis. Current Opinion in Immunology, 13, 63-68.

TZIN, V., FERNANDEZPOZO, N., RICHTER, A., SCHMELZ, E. A., SCHOETTNER, M., SCHÄFER, M., AHERN, K. R., MEIHLS, L. N., KAUR, H. \& HUFFAKER, A. 2015. Dynamic Maize Responses to Aphid Feeding Are Revealed by a Time Series of Transcriptomic and Metabolomic Assays. Plant Physiology, 169, 1727-43.

VAN DEN BOOM, C. E. M., VAN BEEK, T. A., POSTHUMUS, M. A., DE GROOT, A. \& DICKE, M. 2004. Qualitative and quantitative variation among volatile profiles induced by Tetranychus urticae feeding on plants from various families. Journal of Chemical Ecology, 30, 69-89.

VAN LOON, L. C., REP, M. \& PIETERSE, C. M. J. 2006. Significance of inducible defense-related proteins in infected plants. Annual Review of Phytopathology. Palo Alto: Annual Reviews.

VERMA, V., RAVINDRAN, P. \& KUMAR, P. P. 2016. Plant hormone-mediated regulation of stress responses. BMC Plant Biol, 16, 86.

VOGT, T. 2010. Phenylpropanoid Biosynthesis. Molecular Plant, 3, 2-20.

VRANOVA, E., COMAN, D. \& GRUISSEM, W. 2013. Network Analysis of the MVA and MEP Pathways for Isoprenoid Synthesis. In: MERCHANT, S. S. (ed.) Annual Review of Plant Biology, Vol 64. Palo Alto: Annual Reviews.

WAHYUNI, Y., BALLESTER, A. R., TIKUNOV, Y., VOS, R. C. H. D., PELGROM, K. T. B., MAHARIJAYA, A., SUDARMONOWATI, E., BINO, R. J. \& BOVY, A. G. 2013. Metabolomics and molecular marker analysis to explore pepper (Capsicum sp.) biodiversity. Metabolomics, 9, 130-144. 
WAHYUNI, Y., STAHL-HERMES, V., BALLESTER, A. R., VOS, R. C. H. D., VOORRIPS, R. E., MAHARIJAYA, A., MOLTHOFF, J., ZAMORA, M. V., SUDARMONOWATI, E. \& ARISI, A. C. M. 2014. Genetic mapping of semi-polar metabolites in pepper fruits ( Capsicum sp.): towards unravelling the molecular regulation of flavonoid quantitative trait loci. Molecular Breeding, 33, 503-518.

WALKER, T. 2006. Plant Diversity and Evolution. Genotypic and Phenotypic Variation in Higher Plants. Edited by R. J. Henry. Wallingford UK: CABI Publishing (2005), pp. 332, f65.00. ISBN 0-85199-904-2. Experimental Agriculture, 42, 121-121.

WALSH, B. M. \& HOOT, S. B. 2001. Phylogenetic relationships of Capsicum (Solanaceae) using DNA sequences from two noncoding regions: The chloroplast atpB-rbcL spacer region and nuclear waxy introns. International Journal of Plant Sciences, 162, 1409-1418.

WANG, D. \& BOSLAND, P. W. 2006. The genes of Capsicum. Hortscience A Publication of the American Society for Horticultural Science, 41, 1169-1187.

WANG, K. C. \& OHNUMA, S. 2000. Isoprenyl diphosphate synthases. Biochimica Et Biophysica Acta-Molecular and Cell Biology of Lipids, 1529, 33-48.

WAR, A. R., PAULRAJ, M. G., AHMAD, T., BUHROO, A. A., HUSSAIN, B., IGNACIMUTHU, S. \& SHARMA, H. C. 2012. Mechanisms of plant defense against insect herbivores. Plant Signal Behav, 7, 1306-20.

WEBER, H., VICK, B. A. \& FARMER, E. E. 1997. Dinor-oxo-phytodienoic acid: a new hexadecanoid signal in the jasmonate family. Proc Natl Acad Sci U S A, 94, 10473-8.

WERNER, R. A. 1995. Toxicity and Repellency of 4-Allylanisole and Monoterpenes from White Spruce and Tamarack to the Spruce Beetle and Eastern Larch Beetle (Coleoptera: Scolytidae). Environmental Entomology, 24, 372-379.

WU, J., HETTENHAUSEN, C., MELDAU, S. \& BALDWIN, I. T. 2007. Herbivory Rapidly Activates MAPK Signaling in Attacked and Unattacked Leaf Regions but Not between Leaves of Nicotiana attenuata. The Plant Cell, 19, 1096-1122.

WU, J., ZHAO, Q., YANG, Q., LIU, H., LI, Q., YI, X., CHENG, Y., GUO, L., FAN, C. \& ZHOU, Y. 2016. Comparative transcriptomic analysis uncovers the complex genetic network for resistance to Sclerotinia sclerotiorum in Brassica napus. Scientific Reports, 6, 19007.

WU, Y., ZHANG, D., CHU, J. Y., BOYLE, P., WANG, Y., BRINDLE, I. D., DE LUCA, V. \& DESPRES, C. 2012. The Arabidopsis NPR1 Protein Is a Receptor for the Plant Defense Hormone Salicylic Acid. Cell Reports, 1, 639-647.

XIAO, Z. B., ZHU, J. C., FENG, T., TIAN, H. X., YU, H. Y., NIU, Y. W. \& ZHANG, X. M. 2010. Comparison of volatile components in Chinese traditional pickled peppers using HS-SPME-GC-MS, GC-O and multivariate analysis. Natural Product Research, 24, 1939-1953.

YOU, M. K., OH, S. I., OK, S. H., CHO, S. K., SHIN, H. Y., JEUNG, J. U. \& SHIN, J. S. 2007. Identification of putative MAPK kinases in Oryza minuta and $\mathrm{O}$. sativa responsive to biotic stresses. Molecules \& Cells, 23, 108-114.

ZIEGLER, J. \& FACCHINI, P. J. 2008. Alkaloid biosynthesis: Metabolism and trafficking. Annual Review of Plant Biology, 59, 735-769. 


\title{
Chapter 2 Exploring natural variation in metabolite-based defense against spider mites in Capsicum spp.
}

\author{
Yuanyuan Zhang, Lidiya Sergeeva, Francel W. A. Verstappen, Harro J. \\ Bouwmeester \& Iris F. Kappers
}




\begin{abstract}
Spider mites are cosmopolitan distributed herbivores and attack a wide range of plants, including peppers. Here, we evaluated 22 Capsicum genotypes from eleven species ( $C$. annuum; $C$. chinense; $C$. baccatum; $C$. cardenasii; $C$. chacoense; $C$. eximium; $C$. frutescens; $C$. galapagoense; $C$. praetermissum; $C$. pubescens and $C$. tovarii) for their resistance to spider mites and predatory mite attractiveness. The selected Capsicum genotypes exhibited variation in spider mite resistance, based on offspring density, while less variation was observed in predatory mites attractiveness. To investigate the mechanisms underlying direct and indirect defense we analyzed the spider-mite induced endogenous metabolome and the jasmonic acid-induced plant volatile metabolome. Untargeted metabolomic analysis showed $47.1 \%$ of semi-polar endogenous metabolites varied between genotypes upon spider-mite infestation while $22.4 \%$ of volatile metabolite features varied among jasmonic acid induced genotypes. PCA based on both the volatile and endogenous metabolome suggested that instead of the global metabolome, specific metabolites may play an important role in plant direct and indirect defense. Explorative multivariate statistical analysis, including correlation analysis, multiple linear regression analysis and PLS-DA allowed the putative identification of defense related metabolites. Several semi-polar metabolites were identified as direct defense related based on spider mite oviposition. These compounds mostly belong to flavonoids, alkaloids and di- and triterpene glycosides. In addition, linalool and an isoform of TMTT were positively correlated with predatory mite attractiveness while 3-carene oxide, 1-isocyano-3-methyl-benzene and 1-octadecyne seem to repel predatory mites.
\end{abstract}




\section{Introduction}

Genetic variation within a species results from interactions between plant attributes such as reproduction, gene mutation, and environmental parameters such as biotic and abiotic stress selection and geographic isolation (Nevo and Beiles, 2011, Walker, 2006). Genetic variation is important to maintain the balance of ecology, ensuring plant populations to survive different stresses and providing genetic sources for evolution (Reed and Frankham, 2003, Nevo and Beiles, 2011). Studies on genetic variation help to reveal the structure of populations, gene flow, and the direction of evolution. Plant diversity was found in many plant physiological traits, as well as in proteins and DNA. Previous studies mainly focused on explaining plant diversity on DNA or protein level using various molecular techniques (Arnold and Emms, 1998, Byrne et al., 1998, Jarne and Lagoda, 1996, Nybom and Bartish, 2000, Mueller and Wolfenbarger, 1999, Huang and Han, 2014, Matsuda et al., 2015).

Plants exhibit an enormous diversity in metabolites regulated by both their genetic background and the environmental conditions they grow in (Harrigan et al., 2007). The interaction with herbivores is one of the most important effectors driving plant metabolite diversity. Because there is regional and temporal variation in herbivore pressure, natural variation in secondary metabolites is expected among different genotypes or accessions within a certain plant species or genus. In maize (Zea mays), considerable differences in leaf metabolites and activities of enzymes involved in primary metabolism were detected between lines (Canas et al., 2017) and in Arabidopsis, untargeted metabolomics showed only $13.4 \%$ of mass peaks were common to all 14 accessions analyzed (Keurentjes et al., 2006), revealing a strong intraspecific variation. The composition and level of major metabolites in fruits of pepper varied greatly between accessions, independent of species and geographical location (Wahyuni et al., 2011). Genetic variation in herbivore induced plant volatiles has also been reported in European poplar species (Caseys et al., 2015), Nicotiana attenuata (Li et al., 2015), Brassica nigra (Gols et al., 2009), Cucumis sativus (Kappers et al., 2011) and Arabidopsis thaliana (Snoeren et al., 2010).

The genus Capsicum belongs to the nightshade family Solanaceae and consists of approximately 35 species (Carrizog, 2013). Capsicum is native to the Americas and nowadays worldwide cultivated for its sweet or hot chili fruits used as vegetable or spice, respectively. The annual world production of both fresh and dried peppers is about 36 million tons (http://www.fao.org). The use of Capsicum as food for humans can be traced back to 6,000 years ago (Perry et al., 2007). After a long time of cultivating history, five species 
became domesticated and economically important, which include $C$. annuum, C. baccatum, C. chinense, C. frutescens, and C. pubescens (Pickersgill, 1997). The genetic variation in fruit traits has been extensively studied, including fruit shape, fruit disease resistance (Naegele et al., 2016) and fruit secondary metabolites (Wahyuni et al., 2013, Butcher et al., 2012), while hardly any knowledge is available about leaf traits in Capsicum in relation to herbivory. As healthy plants are important for proper fruit production, studying genetic variation with respect to plant resistance and susceptibility will provide physiological insights that together with genetic information can be exploited for plant breeding.

Herbivory can be a serious threat to plant growth and fruit production. Together with thrips and different aphid species, two-spotted spider mites are the most devastating pests in Capsicum cultivation (Kumar et al., 2001). Spider mites (Tetranychidae) can cause damage to many species of plants as they feed by puncturing the plant leaf cells and consuming the cell content leading to chlorotic spots (Raworth et al., 2001). The silk webbing, from which spider mites get their common name, helps to protect the colony from predators, such as predatory mites.

The high reproductive rate of spider mites helps to quickly adapt to chemical acaricides. Biological control of herbivores, using e.g. predatory mites has been proven successful to control spider-mite population settlement (Raworth et al., 2001). Although predatory mites including Phytoseiulus persimilis and Neoseiulus californicus, are known to be very effective predators of spider mite eggs and adults, they are blind and rely on olfactory cues to locate their prey (Prischmann, 2000, Lara and Hoddle, 2015). Knowledge on metabolites within the spider-mite induced volatile blend that are recognized by the predators can be helpful in breeding programs towards a higher success rate of prey-finding. Previously, multiple compounds within herbivore-induced volatile blends have been identified (War et al., 2011), for review see e.g. (Mumm and Dicke, 2010) and several of them have been associated with attractiveness to parasitoids and predators. $(E, E)$-4,8,12-trimethyltrideca-1,3,7,11-tetraene (TMTT) is induced by different herbivores in various plant species, including $A$. thaliana (Tholl et al., 2011), C. sativus (Kappers et al., 2011) and Medicago truncatula (Leitner et al., 2005) and was found to be attractive to Diadegma semiclausum parasitoid wasps (Snoeren et al., 2010) and to P. persimilis and N. californicus predatory mites (Kappers et al., 2011; Brillada et al., 2013). Other volatiles related with the attractiveness of various natural enemies and hence with indirect defence, include the benzoid compound methyl salicylate (MeSA), the homoterpene (E)-3,8-dimethyl-1,4,7-nonatriene (DMNT), the mono- 
terpene (E)- $\beta$-ocimene and multiple green leaf volatiles (GLVs) (Vore et al., 2011; Tieman et al., 2010; Tang et al., 2015; Hatano et al., 2015; Richter et al., 2016; Menzel et al., 2014; Allmann and Baldwin, 2010). Metabolic engineering facilitates the functional identification of these metabolites with respect to their role in indirect defense (Schnee et al., 2006, Kappers et al., 2005, Houshyani et al., 2013, Brillada et al., 2013). However, comprehensive knowledge on the role of the endogenous and the volatile metabolome in plant defense is still limited.

In Capsicum limited information is available about resistance mechanisms towards cell-feeding herbivores in general and to spider mites in particular. Spider-mite induced responses are mainly associated with jasmonic acid (JA) signaling (Martel et al., 2015, Kappers et al., 2010, Ament et al., 2004). Here, we explore the quantitative and qualitative variation in endogenous and volatile metabolites in Capsicum leaves upon spider-mite infestation and JA treatment, respectively, and correlate these to direct defense against the settlement of two-spotted spider mites (Tetranychus urticae) and to JA induced indirect defense based on volatile attractiveness towards $P$. persimilis predatory mites among 22 genetically distant genotypes, including several wild Capsicum and cultivated species.

\section{Material and Methods}

Plants and arthropods A total of 22 Capsicum genotypes were selected from the Centre for Genetic Resources, the Netherlands (CGN) and one of the Dutch Seed companies seed collections. Selection of genotypes was based on variations in species and geographical origins. Among selected species, Capsicum annuum is the most common and extensively cultivated of the five domesticated Capsicums. Seeds were germinated in potting compost and plants were grown in a greenhouse supplemented with high-pressure sodium lamps $\left(16: 8 \mathrm{~h}, 23: 18^{\circ} \mathrm{C} /\right.$ day : night, $50-60 \%$ relative humidity) for 5 weeks. Plants were transferred to a climate chamber $\left(16: 8 \mathrm{~h}, 24: 18^{\circ} \mathrm{C} /\right.$ day : night) two days prior to experiments.

Two-spotted spider mites, Tetranychus urticae Koch (Arachnida: Acari: Tetranychidae) (originally obtained from Koppert BV, Berkel and Rodenrijs, The Netherlands) were reared on lima bean plants (Phaseolus lunatus) for many generations and kept in a BugDorm-2120 insect tent $(96 \times 26,680$ $\mu \mathrm{m}$ aperture) on the window shelf in the lab $\left(22^{\circ} \mathrm{C}\right)$. To obtain synchronized mites, 300 mites were placed on a clean lima bean plant for $24 \mathrm{hrs}$ and subsequently removed. Newly emerged mites were considered to be of the 
same age and used for experiments.

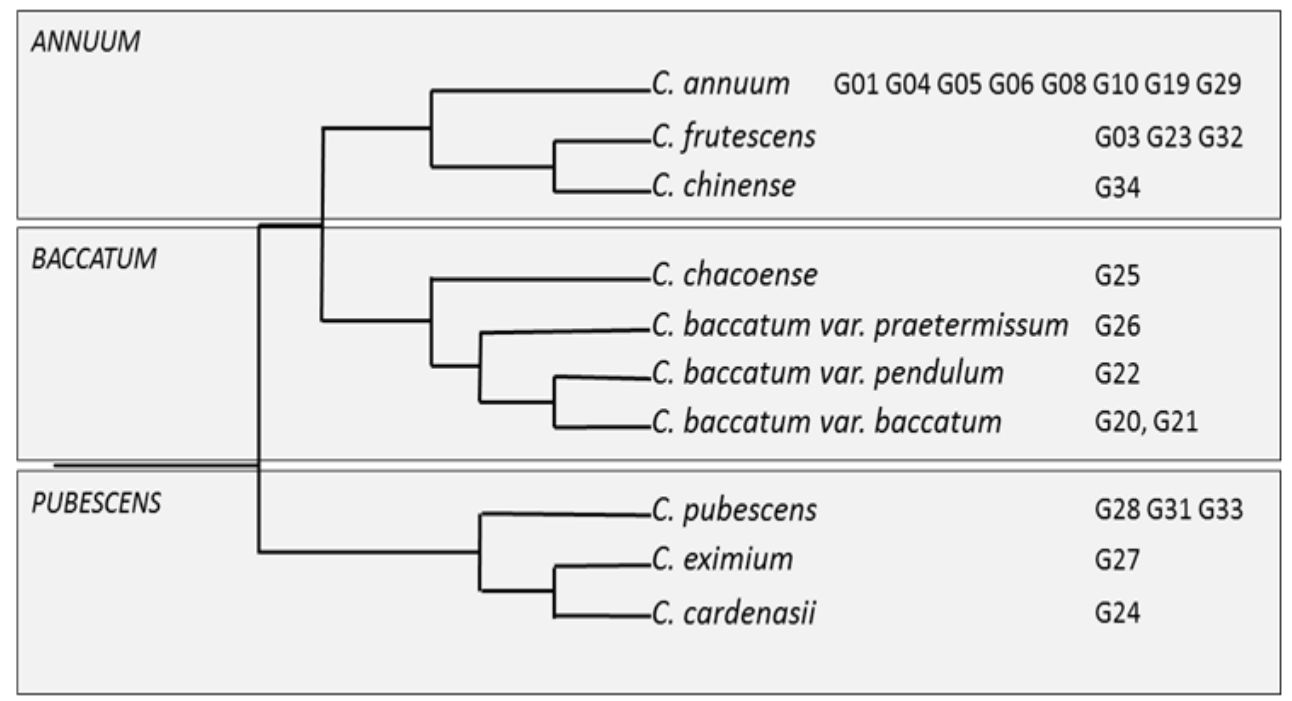

Figure 1. Phylogenetic tree of different Capsicum species used in this study. Each G-number represents a genotype, for detailed information about origins see Supplemental Table 1. Phylogenetic tree is based on (McLeod et al., 1982).

Predatory mites, Phytoseiulus persimilis were obtained from a standard rearing from Koppert BV (Berkel and Rodenrijs) and were delivered to the lab on the experimental day.

Spider mite oviposition on leaf discs and on whole plants For no-choice leaf disc assays one centimeter-diameter discs were taken from 5-week Capsicum leaves of similar ontological position using a hole puncher. Two synchronous adult female mites were placed on the abaxial side of each leaf disc. Leaf discs were incubated upside down on $0.5 \%$ water agar and placed in a climate chamber $\left(16: 8 \mathrm{~h}, 24: 18^{\circ} \mathrm{C} /\right.$ day:night at low light intensity). The number of eggs and nymphs that already hatched was counted after one week. For each genotype, three leaf discs were taken from each of three bioreplicate plants (nine leaf discs in total per genotype) and the experiment was repeated once.

To determine spider-mite oviposition and survival on whole plants, fiveweek old plants were infested with 50 adult spider mites each and kept in the climate chamber. The number of eggs, nymphs that already hatched and adult mites that were still alive was counted after one week. For each genotype, three individual plants were observed. 
Relative attractiveness of JA induced plants towards predatory mites Capsicum plants of the same developmental stage as used to estimate spider mite performance were used to determine their relative attractiveness to predatory mites upon induction. To ensure an equal degree of induction, JA was used to mimic herbivory. Plants were sprayed with $100 \mu \mathrm{M}$ JA solution (0.1\% Tween-20) in such a way droplets start falling the leaves. For each genotype, three plants were randomly placed in a climate chamber under similar conditions as described above and equal amounts of sawdust containing predatory mites were released 24 hours after spraying on multiple locations between plants in such a way that predators got equal access to each plant. Two days after introducing predatory mites, leaves were collected within a time period of 6 hours and the number of predatory mites on each plant was counted. Eggs of predatory mites were not counted. Leaves were subsequently scanned to determine the leaf area. Preferences are calculated as the number of predatory mites. $\mathrm{cm}^{-1}$ leaf area.

Statistical analysis of arthropod behavior Kruskal-Wallis test was applied to perform variation analysis of arthropod behavior data, followed by Dunn's post hoc test ( $P$ value $<0.1$ ) via SPSS 20.0 (SPSS 20.0, Chicago, II, USA).

Collection and analysis of volatile metabolites To compare the induced volatile blend of different genotypes, 5-week-old plants were sprayed with 100 $\mu \mathrm{M} J \mathrm{~A}$ (0.1\% Tween-20) 24 hours prior to headspace collection. Headspace was collected using a dynamic headspace sampling procedure in which 12 plants could be simultaneously trapped. Replicates from each genotype were divided among different batches. In the collecting system, a table top of stainless steel with notches was used to position pots with roots underneath the table surface while stems and leaves were above. A slide was used to close the notch as much as possible. In this way contamination by volatiles from pot and soil was minimized. The above shoot was placed under a $2.5 \mathrm{~L}$ glass jar. Purified air (Zero-air generator, Bronkhorst, The Netherlands) supplemented with $\mathrm{CO}_{2}$ to $400 \mathrm{ppm}$ and $\mathrm{H}_{2} \mathrm{O}$ to $60 \% \mathrm{RH}$ was introduced into the glass jar via a swage-lock connection in the table at a flow of 300 $\mathrm{ml} . \mathrm{min}^{-1}$. Volatiles released by the plant were collected on preconditioned (40 min at $280^{\circ} \mathrm{C}$ under a nitrogen flow) Tenax TA (20/35 mesh; Grace-Alltech, Deerfield, MI, USA) stainless steel cartridges at a flow of $200 \mathrm{ml} . \mathrm{min}^{-1}$. Volatiles were collected for 2 hours and afterwards Tenax cartridges were dried under a stream of nitrogen for $20 \mathrm{~min}$ at ambient temperature to remove water. Volatiles were resorbed from the cartridges with a Thermal Desorber TD100-xr (Unity, MARKES International) connected to a GC/Q-ToF (Agilent Technologies, CA, USA). Analytes were focused at $0^{\circ} \mathrm{C}$ on an electronically-cooled sorbent trap (Unity, Markes, Llantrisant, UK). Volatiles were 
transferred with split flow of $99 \mathrm{ml} \mathrm{min}^{-1}$ to the analytical column by rapid heating of the cold trap to $260^{\circ} \mathrm{C}$ for 3 minutes using a $7890 \mathrm{~B} \mathrm{GC}$-system for separation with a DB-5MS column of $30 \mathrm{~m}$ long a 0.250 diameter, $1 \mu \mathrm{m}$ film and a constant Helium flow of $1.2 \mathrm{ml} \mathrm{min}^{-1}$. (Agilent J\&W CC columns, Agilent Technologies, CA, USA). For each sample, the oven temperature was set at $40^{\circ} \mathrm{C}$ for 2 minutes to $280^{\circ} \mathrm{C}$ for 4 minutes followed by a linear thermal gradient of $10{ }^{\circ} \mathrm{C} \mathrm{min}^{-1}$ and held for $2.5 \mathrm{~min}$. The column effluent was ionized by electron impact ionization at $70 \mathrm{eV}$ and got detected with an Agilent Technologies 7200 accurate mass Q-Tof GC/MS. Mass spectra were acquired by scanning from $50-350 \mathrm{~m} / \mathrm{z}$ with a scan rate of 5 scans. $\mathrm{min}^{-1}$. Chromatograms were analyzed for the presence of plant derived compounds using the Software Agilent MassHunter Qualitive analyses B0700, NIST MS Search 2.2, version June 2014 , library and comparing retention indices with literature Adams, 1993. (Adams et al., 1993).

Analysis of leaf endogenous metabolites Four to five leaves of five-week old plants infested with 50 adult spider mites each for one week were flash-frozen in liquid nitrogen and lyophilized. Semi-polar endogenous metabolites were extracted as described previously by (De Vos et al., 2007) and analyzed by Synapt ultra-performance liquid chromatography coupled to Time of Flight mass spectrometry (Synapt UPLC-MS).

Briefly, $20 \mathrm{mg}$ lyophilized and finely ground leaf tissue was extracted with 2 $\mathrm{ml} 75 \% \mathrm{MeOH}$ (0.1\% formic acid) solution. Samples were homogenized for 5 seconds, sonicated for $15 \mathrm{~min}$ at maximum frequency $(40 \mathrm{kHz})$ in a water bath at ambient temperature, and centrifuged for $10 \mathrm{~min}$ at $5000 \mathrm{rpm}$. The supernatant was filtered using a $0.45 \mu \mathrm{m}$ inorganic membrane filter (Omnifix, Germany), fitted onto a disposable syringe and transferred into a $0.3 \mathrm{ml}$ LC-MS plastic vial. Aliquots of $10 \mu \mathrm{l}$ of each sample were combined to make a pooled sample that was used as quality control (QC), by analyzing it multiple times throughout the analyzing sequence in order to be able to correct for shifts in measurements.

The LC-Synapt QTOF-MS platform consisted of reversed phase liquid chromatography (Waters Alliance HPLC 2695) equipped with a luna C18 column including pre-column $\left(2.0 \times 4 \mathrm{~mm}^{2}\right)$ and an analytical column $(2.0 \times 150$ $\mathrm{mm}^{2}, 100 \AA$, particle size $3 \mu \mathrm{m}$; Phenomenex), a photodiode array detector (PDA) and a quadrupole time of flight mass spectrometry of the Synapt G2S (Waters, QTOF-Ultima) with negative electrospray ionization mode. Five $\mu \mathrm{L}$ of extracts were separated using a gradient of formic acid:water (1:1000, $\mathrm{v} / \mathrm{v}$; eluent $\mathrm{A}$ ) and formic acid:acetonitrile (1:1000, v/v; eluent B). Extracts were injected into HPLC at $0.19 \mathrm{~mL} \mathrm{~min}^{-1}$. The initial solvent composition consisted of $95 \%$ A and $5 \%$ B, increased linearly to $65 \%$ A and $35 \%$ B within 
$45 \mathrm{~min}$ and maintained for $2 \mathrm{~min}$. The column was washed with $25 \% \mathrm{~A}$ and $75 \%$ B for 15 min and equilibrated to $95 \%$ A and $5 \%$ B for 5 min before next injection. A collision energy of $10 \mathrm{eV}$ was used for full-scan LC-MS in the $\mathrm{m} / \mathrm{z}$ range 100-1500.

Data processing Metalign (Lommen, 2009) and MZ mine (Pluskal et al., 2010) were used for baseline correction, mass spectra extraction and mass signal alignment of raw data from LC-MS and GC-MS respectively. For LC-MS data, MSClust (Tikunov et al., 2012) was used for data reduction by unsupervised clustering and extracting putative metabolites mass spectra from ionwise chromatographic aligned data. The resulting reconstructed metabolite abundances were corrected for leaf area.

Principal Component Analysis (PCA) was performed on the reduced dataset to obtain an unsupervised overview of the whole dataset. Supervised clustering Partial Least Square Discriminant Analysis (PLS-DA) was performed to explain the membership of samples based on metabolites features using the R-based web online tool Metaboanalyst 3.0 (Xia and Wishart, 2016).

Individual metabolites were analyzed for significant changes among genotypes during infestation using one-way analysis of variance (ANOVA) (SPSS 20.0, Chicago, II, USA) followed by a Bonferroni post-hoc test and correction. Pearson correlation analysis and stepwise regression on quantitative metabolites and arthropod behaviors were performed by SPSS 20.0 (SPSS 20.0, Chicago, II, USA).

The resulting subset of mass signals and endogenous metabolites were putatively identified by comparing their accurate molecular weights with those from the KNApSAcK database (http://kanaya.naist.jp/KNApSAcK/) (Shinbo et al., 2006), taking possible adduct formations into account. For volatile metabolites putative identification was based on the NIST 98,Wiley 7th edition and in-house spectral libraries and by comparing their retention indices with those from the literature (Sparkman, 2005). For semi-quantification, the area under the curve of characteristic quantifier ions that were selected for each compound was determined.

\section{Results}

Relative susceptibility to spider mites based on offspring among different Capsicum genotypes

Capsicum genotypes (Figure 1, Supplemental Table 1) were characterized 
for oviposition of two-spotted spider mites on leaf discs and on whole plants (Table 2; Supplemental Tables 2, 3) to estimate the relative level of direct defense. As during the incubation time some of the eggs hatched into nymphs, the total offspring population consists of the sum of eggs and nymphs.

Significant variation in offspring was found among genotypes (Kruskal-Wallis test, sig. 0.00). The mean oviposition observed in the leaf disc assay ranged from 0.0 to 10.11 individuals per leaf disc. The four most resistant genotypes did not differ significantly from each other, nor did the two genotypes that had highest oviposition (Table 1). Nineteen genotypes were grouped into three clusters based on the total spider mite offspring. Genotypes 4, 6, 8 and 10 were classified as resistant, based on leaf disc assays, $R(I d)$, as only 0 or 1 individuals (eggs or nymphs) were counted after seven days; Genotypes 1, 3, 20, 21, 22, 23, 24, 25, 27, 28, 30, 32, 34 showed an intermediate relative direct defense response ( 2 to 8 individuals per leaf disc) and were classified as I(Id) (intermediate, leaf disc) while genotypes 19 and 29 had more than 9 individuals per leaf disc and hence a relative low level of direct defense, and were therefore classified as $S(I d)$ (susceptible, leaf disc).

Mechanical damage due to punching of leaf discs may have induced the formation of JA (Sun et al., 2011). JA induces changes in secondary metabolites (Ogura et al., 2002, Shekoufeh et al., 2014, De et al., 2012). To validate the responses found on leaf discs and to avoid a potential effect of mechanical-damage induced JA, direct defense was also determined based on spider mite offspring on whole plants (Table 1, Supplemental Table 3). The mean offspring after one week ranged from 0.33 to 86.67. Twenty-two genotypes were classified into three groups based on spider mite offspring on whole plants. Only genotype 33 was labeled as $R(w p)$ (resistant, whole plant), genotypes $1,4,6,8,10,19,20,22,23,24,25,26,27,28,29,30,31,32,34$ were labeled as I(wp) (intermediate, whole plant) and genotype 3 and 21 were labeled as S(wp) (susceptible, whole plant).

The correlation between the two oviposition assays was moderate (Spearman rank correlation coefficient 0.457 , Sig. (2-tailed) 0.049 ), mostly due to the shift of genotype 3 ( $C$. frutescens) from intermediate resistant in the leaf disc assay to susceptible in the whole plant assay, genotype 29 (C. annuum) from susceptible to intermediate and in particular genotype 8 (C. annuum) that showed a completely opposite response as it had lowest oviposition on leaf discs while it was classified within the five genotypes with highest oviposition on whole plants. 
Table 1. Spider-mite oviposition on Capsicum leaf discs and on whole plants. Oviposition of leaf discs was determined for nineteen Capsicum genotypes $(\mathrm{N}=9)$ and on whole plants for twenty-two genotypes $(\mathrm{N}=3)$. Within the same column scores with different letters differ significantly (Kruskal-Wallis test, Dunn's post hoc test; $P<0.1$ ).

\begin{tabular}{|c|c|c|c|c|c|}
\hline Genotype & Species & f disc assay ( & $V=9$ ) & Whole plant assay & $(\mathrm{N}=3)$ Mean $\pm \mathrm{SE} *$ \\
\hline 1 & C. annuum & $3.00 \pm 1.96$ & $a b$ & $9.33 \pm 2.19$ & $a b$ \\
\hline 3 & C. frutescens & $3.33 \pm 1.49$ & $a b$ & $57.67 \pm 3.76$ & b \\
\hline 4 & C. annuum & $0.78 \pm 0.40$ & a & $1.00 \pm 0.58$ & $a b$ \\
\hline 6 & C. annuum & $0.56 \pm 0.56$ & a & $7.67 \pm 2.40$ & $a b$ \\
\hline 8 & C. annuum & $0.56 \pm 0.34$ & a & $30.67 \pm 7.22$ & $a b$ \\
\hline 10 & C. annuum & $0.67 \pm 0.33$ & a & $1.33 \pm 1.33$ & $a b$ \\
\hline 19 & C. annuum & $9.33 \pm 2.06$ & $b$ & $23.67 \pm 2.03$ & $a b$ \\
\hline 20 & C. baccatum & $7.33 \pm 3.37$ & $a b$ & $9.33 \pm 1.45$ & $a b$ \\
\hline 21 & C. baccatum & $6.33 \pm 1.51$ & $a b$ & $86.67 \pm 6.94$ & $b$ \\
\hline 22 & C. baccatum & $4.22 \pm 1.18$ & $a b$ & $9.67 \pm 1.76$ & $a b$ \\
\hline 23 & C. frutescens & $3.22 \pm 0.94$ & $a b$ & $9.00 \pm 2.31$ & $a b$ \\
\hline 24 & C. cardenasii & $5.89 \pm 1.33$ & $a b$ & $45.67 \pm 6.33$ & $a b$ \\
\hline 25 & C. chacoense & $5.89 \pm 1.25$ & $a b$ & $19.00 \pm 2.08$ & $a b$ \\
\hline 26 & C. praetermissum & - & & $38.00 \pm 9.45$ & $a b$ \\
\hline 27 & C. eximium & $3.89 \pm 1.17$ & $a b$ & $7.00 \pm 1.16$ & $a b$ \\
\hline 28 & C. pubescens & $1.67 \pm 0.44$ & $a b$ & $2.33 \pm 0.88$ & $a b$ \\
\hline 29 & C. annuum & $10.11 \pm 1.97$ & $\mathrm{~b}$ & $11.00 \pm 2.65$ & $a b$ \\
\hline 30 & C. galapagoense & $4.78 \pm 0.88$ & $a b$ & $12.00 \pm 1.73$ & $a b$ \\
\hline 31 & C. frutescens & - & & $8.33 \pm 2.03$ & $a b$ \\
\hline 32 & C. frutescens & $7.78 \pm 1.96$ & $a b$ & $14.00 \pm 2.31$ & $a b$ \\
\hline 33 & C. pubescens & - & & $0.33 \pm 0.33$ & $\mathrm{a}$ \\
\hline 34 & C. chinense & $2.89 \pm 1.74$ & $a b$ & $15.00 \pm 1.73$ & $a b$ \\
\hline
\end{tabular}




\section{Biodiversity of metabolites in leaves of Capsicum related to spider-mite susceptibility}

The composition of endogenous secondary metabolites in Capsicum leaves was investigated in seventeen genotypes (genotypes 20, 23, 28, 30 and 33 were not included because of bad germination or pathogen infestation) and correlated with spider mite susceptibility. Both induced and constitutively present endogenous metabolites could play a role in resistance to spider mites and be responsible for variation in defense. Untargeted metabolic profiling of plants infested with spider mites or plants that were left non-treated using LC-MS resulted in on average 4756 mass signals per sample. Since individual chemical compounds give rise to more than one fragment upon ionization and to reduce complexity, 344 reconstructed metabolites were generated based on the chromatographic distance and the pattern similarity between mass peaks to be representative for each putative compound (Supplemental Table 4). These reconstructed metabolites were used for further statistical analyses, using a chemometric approach, meaning that chemical compounds were not annotated before statistical analysis.

Of 344 reconstructed metabolites identified by LC-MS, 242 metabolites varied among Capsicum genotypes in spider-mite-infested plants while 153 metabolites varied among Capsicum genotypes in non-treated plants (ANOVA, $p \leq 0.05$ ) (Supplemental Table 5). Of the reconstructed metabolites, 209 $(60.8 \%)$ showed a significant genotype effect. ANOVA also indicated a strong adaptation of the leaf metabolome upon spider mite infestation as more than $42.4 \%$ of the reconstructed metabolites changed significantly upon infestation. In addition, 162 (47.1\%) of the reconstructed metabolites varied due to genotype-spider mite infestation interaction. Hence, the variation observed in our dataset is the result of both metabolic differences present in different genotypes and metabolic responses to spider mite infestation. Both contribute to the genotypic variation found in spider-mite induced endogenous metabolomes of which the genotypic background is of greater importance than spider mite infestation. 
Table 2: Number of reconstructed endogenous metabolites analysed by LC-MS affected by spider-mite infestation and genotype background in Capsicum (ANOVA, significance threshold FDR=0.05)

No. of reconstructed metabolites

Total ANOVA tested

Significant Genotype background effect

Significant Spider-mite infestation effect

Significant infestation $\mathrm{X}$ genotype interaction
344

$209(60.8 \%)$

$146(42.4 \%)$

$162(47.1 \%)$
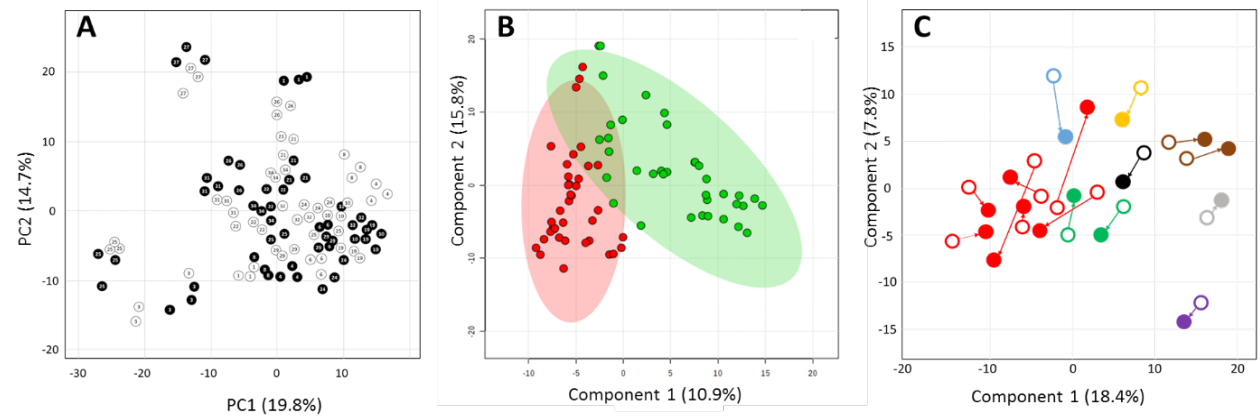

Figure 2. Semi-polar endogenous metabolites in Capsicum leaves. A: Principal component analysis (PCA) clustering based on reconstructed metabolites, axes 1 and 2 explain 19.8\% and $14.7 \%$ of the total variation, respectively. Genotypes are depicted using numbers as indicated in Table 1 with black number in open circles indicating non-infested plants and white numbers in black circles infested spider-mite infested plants; B: Partial least square discriminant analysis (PLS-DA) clustering based on reconstructed metabolites separating spider-mite infested plants (green circles) from non-infested plants (red circles), axes 1 and 2 explain $10.9 \%$ and $15.8 \%$ of total variation respectively. Area's indicate $95 \%$ confidence region; C: PLS-DA clustering based on reconstructed metabolites separating genotypes that were spider-mite infested from non-infested plants, axes 1 and 2 explain $18.4 \%$ and $7.8 \%$ of total variation respectively. Circles indicate the average position for a specific genotype and arrows were drawn to visualize connections between non-infested plants (open circles) and those infested with spider mites (closed circles). Colours indicate different Capsicum species: red: $C$. annuum; green: $C$. baccatum; blue: $C$. cardenassi; purple: $C$. chacoense; orange: $C$. chinense; grey $C$. eximium; brown: $C$. frutescens; black: $C$. praetermissum.

PCA was conducted on 344 reconstructed metabolites. The first two components explained $34.5 \%$ of the total variation, but did not separate infested from non-infested plants (Figure 2A). PLS-DA using infestation as discriminant, indicated that metabolomes of spider-mite infested plants were 
distinctive from those left uninfested (Figure 2B) and based on underlying variable importance in projection (VIP) scores, 26 reconstructed metabolite features were found responsible for the majority of variation. All of them varied among genotypes (Supplemental Table 5). Consistent with ANOVA analysis, Capsicum plants exhibited substantial variation in their endogenous secondary metabolome across genotypes and directions of metabolic adaptations to spider-mite infestation differed for different genotypes resulting in clear separations between infested and non-treated plants for individual genotypes as indicated by PLS-DA using both genotype and infestation as discriminants (Figure 2C). Both magnitudes and directions of responses in the metabolome upon spider-mite infestation differ between genotypes.
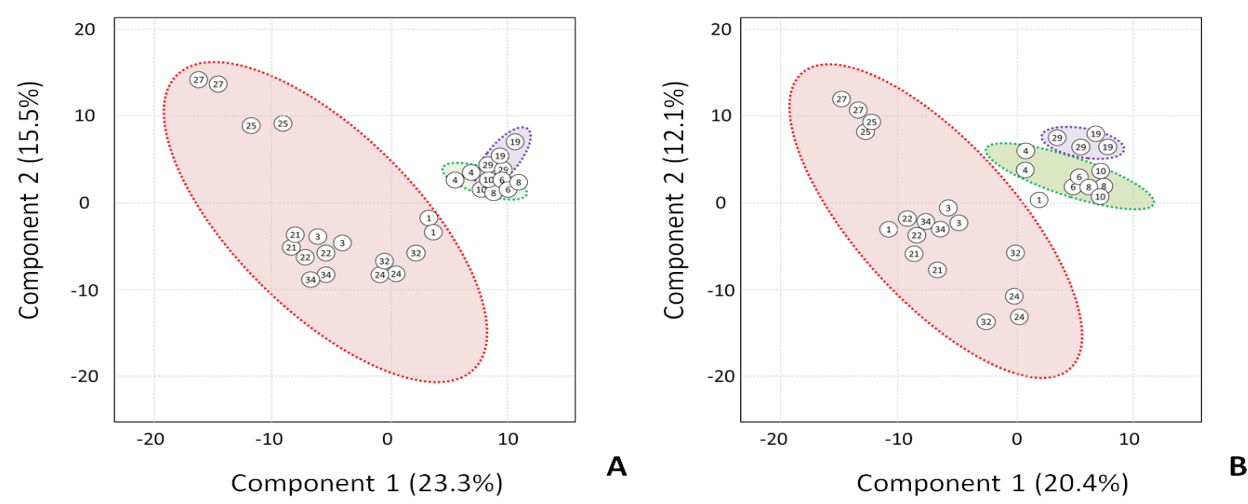

Figure 3. PLS-DA of reconstructed endogenous metabolites in non-infested $(A)$ or spider-mite infested (B) plants of seventeen Capsicum genotypes. Numbers represent genotypes as indicated in Table 1. Direct defense levels are based on spider mite offspring on leaf discs: with G4, G6, G8 and G10 as resistant, G1, G3, G21, G22, G24, G25, G27, G32 and G34 as intermediate and G19 and G29 as susceptible. PC1 and PC2 explain 23.3\% and $15.5 \%$ and $20.4 \%$ and $12.1 \%$, respectively, of the total variation in non-infested and in spider-mite infested plants, respectively.

Subsequently, PLS-DA was conducted on the same data set of endogenous metabolites using the level of susceptibility based on oviposition to determine whether specific metabolites could contribute to the variation found in direct defense (Figure 3). Based on least squares, PLS-DA highlighted 31 and 15 important variables (corresponding with reconstructed metabolites) explaining the membership of genotypes in different classes in non-infested and spider-mite infested plants, respectively (Supplementary Table 6). Thirteen of the identified variables overlapped between the constitutive and induced metabolomes. 
The putative defense related metabolites present in infested plants were further investigated using Pearson correlation analysis with spider mite offspring on leaf discs (Table 3). Two metabolites putatively identified as an alkaloid and lignan both negatively correlated with spider mite offspring ( $r$ $=-0.827, r=-0.677$ ) suggesting they may have a role in defense. In contrast, a flavonoid and a peptide positively correlated with spider mite offspring ( $r=0.743, r=0.712$ ) suggesting that their presence may be beneficial for spider mite oviposition or that these compounds accumulated upon infestation. The alkaloid and lignan like compound were indeed found in higher amounts in the more resistant genotypes while the putative flavonoid and peptide were found in higher amounts in more susceptible genotypes.

In addition to individual metabolites that can affect defense, there might also be an interaction between individual metabolites. Backward-stepwise regression was conducted to investigate the contribution of all candidate metabolites to direct defense against spider mites. Fourteen metabolites significantly $(P<0.05)$ affected spider mite offspring in the linear model, either in a positive or negative direction (Table 3). Compared with Pearsons' correlation analysis, two of those 14 metabolites showed high correlation with spider mite offspring. An alkaloid-like compound (putative annotation: thalfinine) showed a strong negative correlation with spider mites ( $r$ $=-0.827)$ with the largest negative standardized coefficient $(\beta=-0.726)$. In contrast, the flavonoid-like compound (petunidin 3-(4"'-p-coumaryl rutinoside)) positively correlated with spider mite number $(r=0.712)$ and showed a positive standardized coefficient $(\beta=0.107)$.

Among the features that were selected based on PLS-DA (VIP weight $\geq 2$ ) using different classes of direct defense level upon spider-mite infestation (Figure 3B), a reconstructed metabolite was also identified in the regression analysis of spider mite offspring number against metabolites, and putatively identified as a diterpene glycoside, i.e. capsianoside III (C50H84O26). Capsianosides are commonly identified in C. annuum fruits (Lee et al., 2007, Izumitani et al., 1990) and the fraction of jalapeno pepper fruit extract (C. annuum var. annuum) which contains capsianosides was found to have antibacterial activity (Bacon et al., 2017).

A similar approach, i.e. PLS-DA (Supplemental Figure 1), Pearson's correlation analysis and stepwise regression, was also performed using the spider-mite induced metabolome and spider mite offspring on whole plants. The analysis resulted in 34 VIPs with a weight $\geq 2.0,22$ metabolite features with correlation coefficient $|r| \geq 0.5$ and 18 metabolite features in the regression model (Supplemental Table 6). Five metabolites with $|r| \geq 0.5$ and VIP $\geq 2.0$ anda single metabolite from the regression model with $|r| \geq 0.5$ 
were putatively annotated based on their molecular weight (Table 3).

Table 3. Endogenous metabolites highly correlated with spider mite offspring on leaf discs (Id) based on Pearson correlation analysis.

\begin{tabular}{|c|c|c|c|c|c|}
\hline $\begin{array}{l}\text { Metabol- } \\
\text { ic Feature }\end{array}$ & $\begin{array}{l}\text { Chemical } \\
\text { class }\end{array}$ & $\begin{array}{l}\text { Correlation } \\
\text { coefficient }\end{array}$ & $\begin{array}{l}\text { Putative identi- } \\
\text { fication }\end{array}$ & $\begin{array}{l}\text { Chemical for- } \\
\text { mula }\end{array}$ & $\begin{array}{l}\text { Mo- } \\
\text { lecular } \\
\text { Weight } \\
\text { (D) }\end{array}$ \\
\hline 316 & Alkaloids & $\begin{array}{c}-0.827 / \beta \\
-0.726 \\
\end{array}$ & Thalfinine & $\mathrm{C} 39 \mathrm{H} 42 \mathrm{~N} 2 \mathrm{O} 8$ & 666.29 \\
\hline 2703 & $\begin{array}{l}\text { Lignan oligo- } \\
\text { saccharide } \\
\text { ester }\end{array}$ & -0.677 & Rupestrin C & C35H40O19 & 764.22 \\
\hline 799 & Flavonoids & -0.664 & $\begin{array}{c}\text { 3',4',5,7-Tetra- } \\
\text { hydroxyflavone; } \\
\text { 7-O-(6-O-Ace- } \\
\text { tyl-?-D-glucopy- } \\
\text { ranoside) }\end{array}$ & $\mathrm{C} 23 \mathrm{H} 22 \mathrm{O} 12$ & 490.11 \\
\hline 4273 & $\begin{array}{l}\text { Triterpenoid } \\
\text { saponins }\end{array}$ & -0.637 & Conyzasaponin C & $\mathrm{C} 68 \mathrm{H} 110 \mathrm{O} 34$ & 1470.69 \\
\hline 657 & Flavonoids & -0.506 & Sanggenon G & $\mathrm{C} 40 \mathrm{H} 38011$ & 694.24 \\
\hline 2354 & $\begin{array}{l}\text { Depsipep- } \\
\text { tides }\end{array}$ & 0.504 & Kulolide-2 & C43H65N5O9 & 795.48 \\
\hline 138 & $\begin{array}{l}\text { Cyanogenic } \\
\text { glycosides }\end{array}$ & 0.575 & $\begin{array}{c}\text { Prunasin } \\
\text { 3',6'-di-Ogallate }\end{array}$ & $\mathrm{C} 28 \mathrm{H} 25 \mathrm{NO} 14$ & 599.13 \\
\hline 284 & $\begin{array}{l}\text { Glycosylated } \\
\text { nucleotide }\end{array}$ & 0.58 & 3',5'-Cyclic GMP & C10H12N507P & 345.05 \\
\hline 731 & $\begin{array}{l}\text { Withano- } \\
\text { lide-type ste- } \\
\text { roids }\end{array}$ & 0.581 & Cilistol A & $\mathrm{C} 28 \mathrm{H} 4005$ & 456.29 \\
\hline 2713 & Flavonoids & $\begin{array}{c}0.712 / \beta \\
0.107\end{array}$ & Petunidin & С37H39O18 & 771.21 \\
\hline 2899 & Peptides & 0.743 & Oligomycin E & $\mathrm{C} 45 \mathrm{H} 72 \mathrm{O} 13$ & 820.50 \\
\hline
\end{tabular}

No overlap was found in reconstructed metabolites that were selected from ranking genotypes for resistance to spider mites based on leaf discs or on whole plants, although similar classes of compounds were identified, including flavonoids and triterpene glycosides. 
Table 4. Endogenous metabolites highly correlated with spider mite offspring on whole plant (wp) based on Pearson correlation analysis.

\begin{tabular}{|c|c|c|c|c|c|}
\hline $\begin{array}{l}\text { Centro- } \\
\text { type }\end{array}$ & $\begin{array}{l}\text { Chemical } \\
\text { Class }\end{array}$ & $\begin{array}{c}\text { Putative } \\
\text { Metabo- } \\
\text { lites }\end{array}$ & $\begin{array}{l}\text { Correlation coef- } \\
\text { ficient }\end{array}$ & $\begin{array}{l}\text { Chemical } \\
\text { formula }\end{array}$ & $\begin{array}{l}\text { Molecular } \\
\text { Weight (D) }\end{array}$ \\
\hline 655 & Flavonoids & $\begin{array}{c}0.721 / \mathrm{VIP} \\
2.41\end{array}$ & $\begin{array}{l}\text { 5,7-Dihydroxyfla- } \\
\text { vone }\end{array}$ & $\mathrm{C} 21 \mathrm{H} 18010$ & 430.09 \\
\hline 1595 & Flavonoids & $\begin{array}{c}0.721 / \mathrm{VIP} \\
2.29\end{array}$ & $\begin{array}{c}3^{\prime}, 44^{\prime}, 5,6,7-P e n t a- \\
\text { hydroxyflavone }\end{array}$ & $\mathrm{C} 26 \mathrm{H} 28 \mathrm{O} 15$ & 580.14 \\
\hline 3012 & - & $\begin{array}{l}0.72 / \mathrm{VIP} \\
2.31\end{array}$ & $\begin{array}{c}\text { O25-Me, } \\
\text { 2-O-[?-D-glu- } \\
\text { copyrano- } \\
\text { syl-(1?6)-?-D-glu- } \\
\text { copyranoside] }\end{array}$ & $\mathrm{C} 42 \mathrm{H} 64 \mathrm{O} 17$ & 840.41 \\
\hline 3123 & Triterpene & $\begin{array}{c}0.702 / \mathrm{VIP} \\
2.44\end{array}$ & Rotundioside $\mathrm{O}$ & $\mathrm{C} 48 \mathrm{H} 76 \mathrm{O} 17$ & 924.51 \\
\hline 3138 & Saponins & $\begin{array}{c}0.721 / \mathrm{VIP} \\
2.98\end{array}$ & Abutiloside $\mathrm{H}$ & C46H75NO17 & 913.50 \\
\hline 3635 & Saponins & $\begin{array}{c}0.719 / \mathrm{VIP} \\
2.43\end{array}$ & $\begin{array}{c}\text { Acanthopanaxo- } \\
\text { side A }\end{array}$ & С60H94O27 & 1246.90 \\
\hline 4262 & Saponins & $\begin{array}{c}0.72 / \mathrm{VIP} \\
2.31\end{array}$ & Aster saponin Hd & $\mathrm{C} 62 \mathrm{H} 98030$ & 1322.61 \\
\hline 4414 & $\begin{array}{l}\text { Triterpene } \\
\text { glycosides }\end{array}$ & $\begin{array}{c}0.719 / \mathrm{VIP} \\
2.38\end{array}$ & $\begin{array}{l}\text { Achlioniceoside } \\
\text { A1 }\end{array}$ & С60H96O34S2 & 1424.52 \\
\hline 4037 & $\begin{array}{l}\text { Triterpene } \\
\text { glycosides }\end{array}$ & $\begin{array}{l}0.723 / \\
\beta 0.843\end{array}$ & Gleditsioside I & $\mathrm{C} 68 \mathrm{H} 110033$ & 1454.69 \\
\hline
\end{tabular}

\section{Relative indirect defense, predatory mite attractiveness among different Capsicum genotypes}

Attractiveness towards predatory mites among Capsicum genotypes was determined using plants induced by JA to ensure an equal level of induction. The number of attracted predatory mites among the genotypes varied from none to 1.2 predatory mites per $\mathrm{cm}^{2}$ leaf area (Table 4) but the differences were not significant (Kruskal-Wallis test), due to the large variation between replicates. Nevertheless, genotypes were classified as either relatively attractive when more than 2 predatory mites. $\mathrm{cm}^{-2}$ were found on the leaves (level 1), medium attractive when between 0.5 to 2 mites. $\mathrm{cm}^{2}$ (level 2) predatory mites were detected or less attractive when the number of predatory mites detected was less than 0.5 mite. $\mathrm{cm}^{-2}$ leaf area (level 3). 
Table 5. Relative indirect defense of Capsicum genotypes to predatory mites. Number of predatory mites attracted to Capsicum plants induced with jasmonic acid, $24 \mathrm{~h}$ prior to release of predatory mites. Genotypes are classified as attractive (level 1), medium attractive (level 2) or less attractive (level 3).

\begin{tabular}{|c|c|c|}
\hline Genotype & $\begin{array}{c}\text { Nr. of predatory mites. } \mathrm{cm}^{-2} \\
\text { leafMean } \pm \mathrm{SE}\end{array}$ & Attractively level \\
\hline 1 & $0.67 \pm 0.33$ & 2 \\
\hline 3 & $0.33 \pm 0.33$ & 3 \\
\hline 4 & $0 \pm-$ & 3 \\
\hline 6 & $0 \pm-$ & 3 \\
\hline 8 & $1.33 \pm 0.67$ & 2 \\
\hline 10 & $3.00 \pm 0.58$ & 1 \\
\hline 19 & $0.50 \pm 0.41$ & 3 \\
\hline 21 & $0.67 \pm 0.67$ & 2 \\
\hline 22 & $2.67 \pm 2.19$ & 1 \\
\hline 24 & $0.67 \pm 0.67$ & 2 \\
\hline 25 & $1.67 \pm 0.67$ & 2 \\
\hline 28 & $2.33 \pm 0.89$ & 1 \\
\hline 29 & $1.33 \pm 0.33$ & 2 \\
\hline 31 & $2.67 \pm 0.33$ & 1 \\
\hline 32 & $1.33 \pm 0.88$ & 2 \\
\hline 33 & $1.67 \pm 0.33$ & 2 \\
\hline 34 & $0.50 \pm 0.41$ & 3 \\
\hline
\end{tabular}

\section{JA induced volatile metabolite analysis}

To study whether the variation within the relative level of indirect defense across genotypes could be related to volatile metabolites, JA-induced volatiles of eighteen Capsicum genotypes were collected using a dynamic head- 
space collection method and analyzed by GC-MS. In total, 5319 metabolite fragments were retrieved (Supplemental Table 7). Feature reduction was not performed because of un-optimized reduction software. Overall, $1213(22.4 \%)$ of the features significantly varied among genotypes (one-way ANOVA, $p<0.05$ ) (Supplemental Table 8).

The 5319 metabolite features were then subjected to PCA to outline genotypic variation in JA-induced volatile metabolites. Almost $48 \%$ of the total variation present within the eighteen Capsicum genotypes can be explained by the first two PCs (Figure 4A). Interestingly, PC1 separates the majority of genotypes from $\mathrm{G} 28, \mathrm{G} 31$ and $\mathrm{G} 33$, which are all $C$. pubescens. A PLS-DA using the classification of genotypes within their phylogenic complex ( $A N N$ UUM, BACCATUM and PUBESCENS clade, Figure 1) confirms the chemo-diversity in (JA-induced) volatiles between genotypes (Figure 4B). Genotypes within the PUBESCENS and BACCATUM complex clearly separate from those within the ANNUUM complex. An exception is G24, C. cardenasii, which on basis of its JA-induced volatile blend clusters more with the genotypes of the BACCATUM complex.
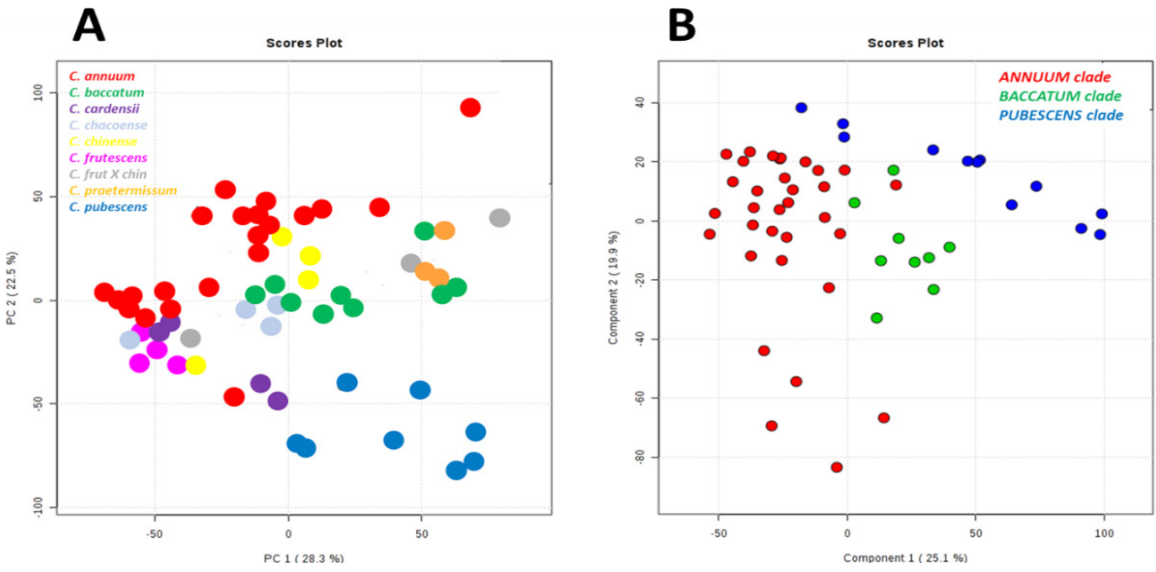

Figure 4. A. PCA plot of JA-induced volatiles of 18 color coded Capsicum genotypes, red, C. annuum; green, $C$. baccatum; purple, $C$. cardenasii; light blue, $C$. chacoense; yellow, $C$. chinense; pink, $C$. frutescens; grey, $C$. frut. $X$ chin.; orange, $C$. praetermissum; dark blue, C. pubescens. B: PLS-DA plot of these same genotypes, classified according to their phylogenic origin, red: genotypes that are part of the ANNUUM clade, green: BACCATUM clade, blue: PUBESCENS clade (see also Fig. 1).

The majority of $m / z$ fragments responsible for this separation originated from specific sesquiterpenes, including $\gamma$-himachalene and $\delta$-Amorphene that are abundant in pubescens while absent or very low in annuum genotypes. In contrast, green leaf volatiles (Z)-3-hexen-1-ol, 2-methyl-propanal- 
oxime, ethyl benzoate and benzoic acid are abundant in annuum genotypes while absent or very low in pubescens. Furthermore, (Z)-methyl dihydro jasmonate, methyl-epi-jasmonate and (1-butylhexyl)-benzene are low in baccatum compared to annuum genotypes (Supplemental Table 7).

Subsequently, to learn whether any of the volatile compounds could be related with predatory mite preferences, PLS-DA was performed on $\mathrm{m} / \mathrm{z}$ features using classification of genotypes as less attractive, medium attractive and high attractive as shown in Table 4. Two hundred and fifty-three $\mathrm{m} / \mathrm{z}$ features were identified as important variables for the variation in attractiveness among the genotypes (Figure 5). While genotypes that attracted low or medium numbers of predatory mites could not be separated, those that attracted highest number of predatory mites did (Figure 5A). Therefore, we visualized $\mathrm{m} / \mathrm{z}$ features that are responsible for the separation between attractive genotypes versus those that were less attractive (low or medium in Table 4) using a Volcano plot to enable visual identification of those $\mathrm{m} / \mathrm{z}$ features that display large magnitude changes that are also statistically significant (Figure 5B).

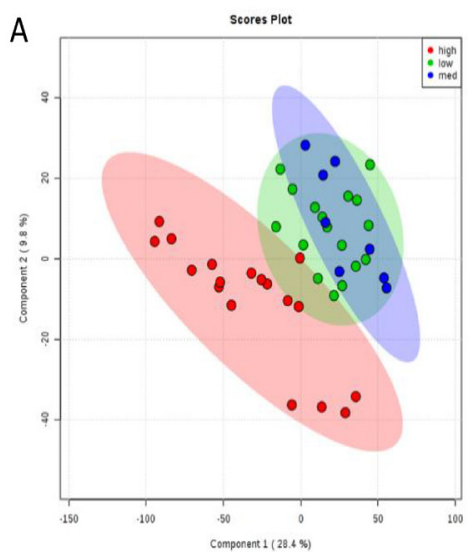

B

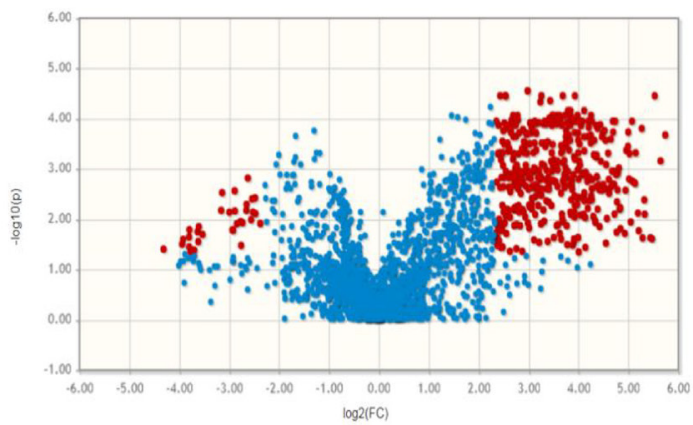

Figure 5. A. PLS-DA plot of JA-induced volatiles of 18 Capsicum genotypes, that are color coded on basis of their relative attractiveness towards predatory mites, red: most attractive, blue medium attractive and green: least attractive, The first two components explain $38.2 \%$ of the variation. B. Volcano plot depicting significance versus fold-change on the $y$ and $x$ axes, respectively of attractive genotypes versus less attractive genotypes (medium and least attractive combined). $m / z$ features that are significantly $(-\log 10(p)>1.5)$ higher or lower (log2(fold-change) $>2.5$ ) in attractive genotypes are depicted in red, while those not significantly different are depicted in blue.

Features that were 5-fold or more present in the volatile blend of attractive genotypes compared to less attractive genotypes predominantly belong to the sesquiterpenes, including $\gamma$-himachalene (Retention Time $(R T)=20.12$ ), 
$\beta$-copaene (RT=19.56), $\alpha$-copaene $(R T=19.91), \quad$ longifolene $(R T=19.29)$, $\beta$-guaiene $(R T=19.65)$ and three unidentified sesquiterpenes. Furthermore, putatively identified hexyl-2-methylbutyrate and hexyl-2-methyl but-2enoate were also positively associated with higher attractiveness towards predatory mites. Only few $\mathrm{m} / \mathrm{z}$ features were negatively associated with attractiveness and include benzyl alcohol $(\mathrm{RT}=12.99)$ and an oxidized monoterpene $(\mathrm{C} 10 \mathrm{H} 180)$ which is putatively annotated as 4-thujanol $(\mathrm{RT}=13.12)$, and of which the amounts were lower in the blend of spider-mite infested plants compared to non-infested plants.

Furthermore, Pearsons' correlation analysis between $\mathrm{m} / \mathrm{z}$ features and relative attraction of predatory mites revealed eighteen $\mathrm{m} / \mathrm{z}$ features that correlated with the number of attracted predatory mites, and that were shown to originate from five volatile metabolites. Among these, linalool $(\mathrm{C} 10 \mathrm{H} 180)$ and TMTT $(\mathrm{C} 16 \mathrm{H} 26)$ positively correlated with predatory mite attraction while 3-carene oxide $(\mathrm{C} 10 \mathrm{H} 16 \mathrm{O}), 1$-isocyano-3-methyl-benzene $(\mathrm{C} 8 \mathrm{H} 7 \mathrm{~N})$ and 1-Octadecyne $(\mathrm{C} 18 \mathrm{H} 34)$ were found negatively affecting predatory mite attraction. In addition, TMTT and 1-isocyano-3-methyl-benzene were also identified as VIP in PLS-DA in which the relative attraction was used as discriminant (Supplemental Table 10; Table 6; $|r|>0.5$ ).

Table 6. Volatile metabolites highly correlated with attracted predatory mites based on Pearson correlation analysis.

\begin{tabular}{c|c|c|c|c}
\hline $\begin{array}{c}\text { Reten- } \\
\text { tion time }\end{array}$ & Chemical class & $\begin{array}{c}\text { Correlation coef- } \\
\text { ficient }\end{array}$ & $\begin{array}{c}\text { Putative Metab- } \\
\text { olites }\end{array}$ & $\begin{array}{c}\text { Chemical fo- } \\
\text { mula }\end{array}$ \\
\hline 13.59 & $\begin{array}{c}\text { Oxygenated Mono- } \\
\text { terpene }\end{array}$ & -0.51 & 3-Carene oxide & $\mathrm{C} 10 \mathrm{H} 16 \mathrm{O}$ \\
14.05 & Monoterpene & 0.56 & Linalool & $\mathrm{C} 10 \mathrm{H} 18 \mathrm{O}$ \\
14.84 & $\begin{array}{c}\text { Heterocyclic com- } \\
\text { pound }\end{array}$ & $-0.52 /$ VIP 2.59 & $\begin{array}{c}\text { Benzene, 1-isocy- } \\
\text { ano-3-methyl- }\end{array}$ & $\mathrm{C} 8 \mathrm{H} 7 \mathrm{~N}$ \\
17.30 & long chain alkane & -0.51 & 1-Octadecyne & $\mathrm{C} 18 \mathrm{H} 34$ \\
17.50 & Sesquiterpene & $0.55 /$ VIP 3.12 & -TMTT & $\mathrm{C} 16 \mathrm{H} 26$ \\
\hline
\end{tabular}

\section{Positive correlation between metabolite-based direct and indirect defense}

To characterize a possible relation between direct and indirect defenses in Capsicum genotypes were ranked on basis of spider mite offspring on the whole plants as well as the number of attracted predatory mites upon JA induction. The number of predatory mites which were attracted by JA-induced plants negatively correlated with spider mite offspring in the whole 
plant assay (Figure 6).

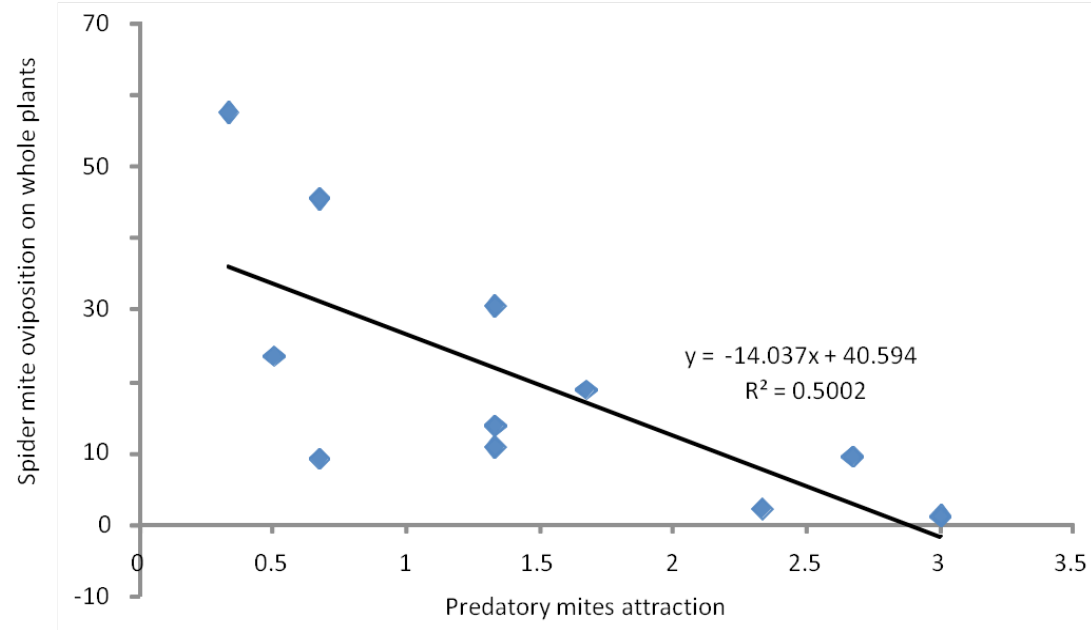

Figure 6. Correlations between direct and indirect defenses in Capsicum spp. Genotypes were ranked on basis of their average relative attractiveness towards predatory mites (X-axis) and average spider mite oviposition ( $Y$-axis). $R^{2}=0.50$.

\section{Discussion}

Secondary metabolites play an important role in complex plant traits such as defense to herbivorous arthropods and attraction of natural enemies (Wilson et al., 2012). Phytochemical diversity among genotypes within plant species directs the biodiversity of the higher trophic levels, herbivorous arthropods and their natural enemies (Richards et al., 2015). Therefore, studying genetic variation in plant defense and the corresponding metabolomes is an important approach to quantify the interaction between herbivores and natural enemies, and could provide insight in how the ecological biodiversity is controlled by the lower tropic level, the plant. Plants defense responses to arthropods proceed mainly through the JA signaling pathway (Furstenberg-Hagg et al., 2013) (Bari and Jones, 2009). Besides its role in direct defense, JA also plays an important role in volatile-mediated indirect defenses of plants, which results in increased attractiveness towards parasitoids and predators of the herbivores (War et al., 2012) (Heil, 2015). Exogenous application of JA induced similar but not identical volatile metabolites in lima bean (Phaseolus lunatus) and cucumber (Cucumis sativus L.). In both species, the JA induced volatile blend significantly attracted predatory mites (Phytoseiulus persimilis), the natural enemy of spider mites (Tetranychus urticae) (Dicke et al., 1999, Kappers et al., 2011). 


\section{Genotypic variation}

In the present study, spider-mite induced secondary metabolites and JA induced volatiles were analyzed to characterize metabolome variation among 19 Capsicum genotypes selected from diverse geographic regions and genomic background (Table 1). The direct and indirect defense variation among these Capsicum genotypes was described based on the spider-mite oviposition rate and predatory mite attractiveness (Table 2, Table 3, Table 4). There was significant variation in direct defense against spider mites among the genotypes (Table 1) and multivariate analysis (PCA, PLS-DA), stepwise regression and Pearson's correlation analysis were applied to explore the relation between corresponding metabolomes of the different genotypes and defense traits. Indeed, the data indicate that endogenous metabolomes of both spider-mite infested and control plants exhibited large variation among genotypes but in different classes of secondary metabolites. However, the variation found in the level of direct defense could not be fully explained by the global metabolome of either spider-mite infested or control plants, indicating an outweighed role of certain metabolites.

\section{Defensive metabolites}

While both methods used to measure spider mite performance show more or less a parallel defense level among most of the genotypes included, the identification of metabolites that relate with the number of spider mites was not accordant. Likely explanations could be the large difference in number of spider mites used in both methods and a low resolution due to limited replicates and genotypes. Mechanical damage due to punching of leaf discs may have induced the formation of JA (Sun et al., 2011). JA induces changes in secondary metabolites (Ogura et al., 2002, Shekoufeh et al., 2014, De et al., 2012) and hence the level of resistance in the leaf discs could be altered before spider mites were introduced to the discs While the use of leaf discs to determine relative resistance towards a specific pest could be time and space efficient, validation of results using whole plants should not be neglected.

Specific metabolites were identified to be potentially involved in defense to spider mites. In this study, defensive metabolites were defined as negatively correlating with spider mite offspring, or being (partly) responsible for the variation found in the metabolomes of resistant and susceptible genotypes. When metabolomes were related to spider-mite offspring on leaf discs, several alkaloids, triterpenes and flavonoids were found to be correlated to spider mite performance (Table 2). While compound identification is only based on comparison of the accurate mass of the selected metabolites with those 
within the KEGG database, their putative identification gives indications of their possible defensive function. Five metabolites were found negatively correlated with spider mite number, including an alkaloid (thalfinine), which was also found to be a negative effector in the regression model, a lignan (rupestrin C), and a triterpenoid saponin (conyzasaponin C), while six metabolites were positively related with the number of spider mites including a flavonoid (petunidin) which was identified using regression. Thalfinine was found in the roots of Thalictrum minus and was shown to be active against Mycobacterium smegmatis (Liao et al., 1978), but whether it is defensive against spider mites still requires further confirmative studies; The lignan oligosaccharide ester, rupestrin C like compound was found in Eritrichium rupestre (Suo et al., 2006) but not previously reported in Capsicum. Lignans play an important role in plant defense against pathogens by thickening the secondary cell wall (Bagniewska-Zadworna et al., 2014) which could probably enable defense deterring spider mites from feeding. The triterpenoid saponin compound conyzasaponin C was previously identified in the aerial parts of Conyza blinii (Su et al., 2001). Triterpenoid saponins accumulate in plant cells in response to biotic and abiotic elicitors and are associated with anti-bacterial, anti-fungal and insect resistance (Yendo et al., 2010). Our study also suggest multiple flavonoids and some peptides to positively correlate with spider mites offspring, inclduing the flavonoid, petunidin. Petunidin was found to have antioxidant activity in Phaseolus vulgaris L. (Dwivedi et al., 2016) and we hypothesize that it accumulaties in the infested leaves as result of proceeding damage caused by spider mite feeding.

When spider mite offspring in whole plants was used as proxy for the level of direct defense, we mainly identified several flavonoids and triterpene saponins that were positively correlated with the number of spider mites, and all identified as important to describe the variation found in defense. Notably, saponins including those with a triterpenoid aglycon, are present in a great many plant species and have proved defense against several fungi (Osbourn, 1996) and herbivores (Szakiel et al., 2011). In Medicago sativa, the total content of saponins as well as the level of individual saponins including medicagenic acid bidesmoside and soyasaponin I, significantly increased in foliage of alfalfa damaged by chewing caterpillars of $S$. littoralis (Agrell et al., 2003). Even though, saponins in plants are described to function as deterrents, toxins and digestibility inhibitors related with herbivory defense (Francis et al., 2002, Wittstock and Gershenzon, 2002), none of the triterpenoids saponins detected in Capsicum negatively affected the number of spider mites. Therefore, we conclude that spider mites induce the production of triterpenoid saponins in Capsicum but are more or less resistant to these compounds. 
Similarly, our data also revealed large genotypic variation in volatile metabolites of JA treated Capsicum plants as almost $23 \%$ of the metabolite differed among different genotypes. Even though significant variation in predatory mite attractiveness was absent in our study due to the large variation among replicates, we tried to identify the volatile metabolites that can be related to attractiveness (Table 5). Linalool, a monoterpene, positively correlated with predatory mite attractiveness in Capsicum and was previously reported to increase attractiveness to the predator Geocoris pallens in N. attenuate plants (Kessler and Baldwin, 2001) and to predatory mites, P. persimilis in C. sativus L. (Kappers et al., 2011).The JA- inducible sesquiterpene TMTT was also positively related with predatory mite attractiveness. TMTT is a wel-known volatile compound that is often part of flower volatile blends and in many species reported to increasse upon herivory, including tomato L. esculentum (Ament et al., 2004) and A. thaliana (Snoeren et al., 2010). In this study, the variation found in the attraction of predators to JA induced volatiles was not obvious among genotypes, although the JA induced volatile metabolomes did differ among individual genotypes as well between Capsicum species. However, these species-specified volatile blends did not explain the variation found in attraction. As we introduced predatory mites within the plants and recorded their presence on the leaves, not only the volatile blend but also physical traits will determine the final preferences of the predators. We conclude that only a few volatile metabolites play a role in indirect defense in Capsicum, and that possibly accessibility or other parameters could be of influence.

\section{Relationship between direct and indirect defense}

Due to physiological and ecological costs, most plant defense theories expect a trade-off between different defensive traits. Many studies support that there is likely a trade-off between direct defense and indirect defense. For example, the amount of cyanogenesis, a direct defense trait, negatively correlated with the release of JA-induced volatiles, which function as indirect defense signals in lima bean (Phaseolus lunatus)(Ballhorn et al., 2008). Also in willow, there is a trade-off between signal-based induced indirect defense to ladybeetles (Aiolocaria hexaspilota) and direct defense to willow leaf beetles (Plagiodera versicolora) (Yoneya et al., 2012). However, our results suggest a synergism between direct defense and JA-induced indirect defense instead of a commonly expected trade-off. A number of studies is consistent with our results. Studies proved that there is no conflict between direct and indirect defense in a highly specialized tritrophic system among brassicaceous plant species, the herbivore Pieris brassicae L. and a gregarious endoparasitoid, Cotesia glomerata L. (Gols et al., 2008). There was 
also no trade-off been found between direct defense to cerambycid beetles (Tetraopes tetraophthalmus) and indirect defenses based on the attraction of beneficial nematodes (Heterorhabditis bacteriophora) in milkweed root (Asclepias syriaca) (Rasmann et al., 2011).The authors suggested that direct and indirect defense mechanisms may either not share limiting resources or they may independently promote defense (Rasmann et al., 2011). Either trade-off or complication effects were observed between direct and indirect defense in different plant species, however it's difficult to define different types of defensive traits and the mechanisms underlying these traits mostly remain unrevealed. In this study, genotypes which attracted more predatory mites upon JA induction may possess a stronger JA regulated defense response, resulting in both more attractive volatile metabolites and a stronger direct defense to spider mites. A meta-analysis of 31 studies on covariation of different defensive traits in plant genotypes suggested that there was no overall negative or positive association between different defensive traits founds in various plants and the relationship between defensive traits is more depending on the types of co-occurring defenses. Significant positive correlations were found between individual compounds belonging to the same biochemical group (Koricheva et al., 2004). Thus, we conclude that JA-induced indirect defense are more likely associated with direct defense by sharing the same group of metabolites.

\section{Conclusions}

This study examined the genotypic variation in endogenous as well as volatile metabolites of a range of Capsicum genotypes using untargeted LC- and GC-MS analyses and explored the relationship between these metabolites and plant direct and indirect defense. Capsicum genotypes exhibited large variation in metabolites as well as in direct and to some extent also indirect defense towards spider mites. We found a number of metabolites correlating, positively as well as negatively, with both defense mechanisms. These metabolites form an interesting reservoir for improving defense in Capsicum. This warrants further work on their unambiguous identification and field evaluation. To fully explore and utilize the value of these metabolites, further analysis is required. Our study supports the notion that studying wild species can provide new genetic resources that can help to regain crop resistance that was lost during the long history of domestication based on yield production and flavor. 


\section{Acknowledgements:}

We would like to thank Bert Schipper for help with LC-MS measurements, and Marit Rutten and Rens van Essen for performing bioassays with spider mites and predatory mites. 


\section{References}

AGRELL, J., OLESZEK, W., STOCHMAL, A., OLSEN, M. \& ANDERSON, P. 2003. Herbivore-induced responses in alfalfa (Medicago sativa). Journal of Chemical Ecology, 29, 303320.

AMENT, K., KANT, M. R., SABELIS, M. W., HARING, M. A. \& SCHUURINK, R. C. 2004. Jasmonic acid is a key regulator of spider mite-induced volatile terpenoid and methyl salicylate emission in tomato. Plant Physiology, 135, 2025-2037.

ARNOLD, M. L. \& EMMS, S. K. 1998. Molecular Markers, Gene Flow, and Natural Selection, Springer US.

BACON, K., BOYER, R., DENBOW, C., O'KEEFE, S., NEILSON, A. \& WILLIAMS, R. 2017. Antibacterial activity of jalapeno pepper (Capsicum annuum var. annuum) extract fractions against select foodborne pathogens. Food Science \& Nutrition, 5, 730-738.

BAGNIEWSKA-ZADWORNA, A., BARAKAT, A., LAKOMY, P., SMOLINSKI, D. J. \& ZADWORNY, M. 2014. Lignin and lignans in plant defence: Insight from expression profiling of cinnamyl alcohol dehydrogenase genes during development and following fungal infection in Populus. Plant Science, 229, 111-121.

BALLHORN, D. J., KAUTZ, S., LION, U. \& HEIL, M. 2008. Trade-offs between direct and indirect defences of lima bean (Phaseolus lunatus). Journal of Ecology, 96, 971-980.

BARI, R. \& JONES, J. D. G. 2009. Role of hormones in plant defense responses. Plant Molecular Biology, 69, 473-488.

BRILLADA, C., NISHIHARA, M., SHIMODA, T., GARMS, S., BOLAND, W., MAFFEI, M. E. \& ARIMURA, G. I. 2013. Metabolic engineering of the C 16 homoterpene TMTT in Lotus japonicus through overexpression of ( $E, E$ )-geranyllinalool synthase attracts generalist and specialist predators in different manners. New Phytologist, 200, 1200-11.

BUTCHER, J. D., CROSBY, K. M., YOO, K. S., PATIL, B. S., IBRAHIM, A. M. H., LESKOVAR, D. I. \& JIFON, J. L. 2012. Environmental and genotypic variation of capsaicinoid and flavonoid concentrations in Habanero (capsicum Chinense) peppers. University of Newcastle Upon Tyne, 21, 509-518.

BYRNE, PARRISH \& MORAN 1998. Nuclear RFLP diversity in Eucalyptus nitens. Heredity, 81, 225-233.

CANAS, R. A., YESBERGENOVA-CUNY, Z., SIMONS, M., CHARDON, F., ARMENGAUD, P., QUILLERE, I., CUKIER, C., GIBON, Y., LIMAMI, A. M., NICOLAS, S., BRULE, L., LEA, P. J., MARANAS, C. D. \& HIREL, B. 2017. Exploiting the Genetic Diversity of Maize Using a Combined Metabolomic, Enzyme Activity Profiling, and Metabolic Modeling Approach to Link Leaf Physiology to Kernel Yield. Plant Cell, 29, 919-943.

CARRIZOG, C. 2013. Wild Capsicums: identification and in situ analysis of Brazilian species.

CASEYS, C., STRITT, C., GLAUSER, G., BLANCHARD, T. \& LEXER, C. 2015. Effects of Hybridization and Evolutionary Constraints on Secondary Metabolites: The Genetic Architecture of Phenylpropanoids in European Populus Species. Plos One, 10, 23.

DE, G. N., GHOLAMI, A., GOORMACHTIG, S. \& GOOSSENS, A. 2012. Transcriptional machineries in jasmonate-elicited plant secondary metabolism. Trends in Plant Science, 17, 349-359.

DE VOS, R. C., MOCO, S., LOMMEN, A., KEURENTJES, J. J., BINO, R. J. \& HALL, R. D. 2007. Untargeted large-scale plant metabolomics using liquid chromatography coupled to mass spectrometry. Nature Protocols, 2, 778-91. 
DICKE, M., GOLS, R., LUDEKING, D. \& POSTHUMUS, M. A. 1999. Jasmonic Acid and Herbivory Differentially Induce Carnivore-Attracting Plant Volatiles in Lima Bean Plants. Journal of Chemical Ecology, 25, 1907-1922.

DWIVEDI, S. L., UPADHYAYA, H. D., CHUNG, I.-M., DE VITA, P., GARCÍA-LARA, S., GUAJARDO-FLORES, D., GUTIÉRREZ-URIBE, J. A., SERNA-SALDÍVAR, S. O., RAJAKUMAR, G., SAHRAWAT, K. L., KUMAR, J. \& ORTIZ, R. 2016. Exploiting Phenylpropanoid Derivatives to Enhance the Nutraceutical Values of Cereals and Legumes. Frontiers in Plant Science, 7.

FRANCIS, G., KEREM, Z., MAKKAR, H. P. S. \& BECKER, K. 2002. The biological action of saponins in animal systems: a review. British Journal of Nutrition, 88, 587-605.

FURSTENBERG-HAGG, J., ZAGROBELNY, M. \& BAK, S. 2013. Plant defense against insect herbivores. Int J Mol Sci, 14, 10242-97.

GOLS, R., DAM, N. M. V., RAAIJMAKERS, C. E., DICKE, M. \& HARVEY, J. A. 2009. Are population differences in plant quality reflected in the preference and performance of two endoparasitoid wasps? Oikos, 118, 733-742.

GOLS, R., WITJES, L. M. A., LOON, J. J. A. V., POSTHUMUS, M. A., DICKE, M. \& HARVEY, J. A. 2008. The effect of direct and indirect defenses in two wild brassicaceous plant species on a specialist herbivore and its gregarious endoparasitoid. Entomologia Experimentalis Et Applicata, 128, 99-108.

HARRIGAN, G. G., MARTINO-CATT, S. \& GLENN, K. C. 2007. Metabolomics, metabolic diversity and genetic variation in crops. Metabolomics, 3, 259-272.

HEIL, M. 2015. Herbivore-induced plant volatiles: targets, perception and unanswered questions. New Phytologist, 204, 297-306.

HOUSHYANI, B., ASSAREH, M., BUSQUETS, A., FERRER, A., BOUWMEESTER, H. J. \& KAPPERS, I. F. 2013. Three-step pathway engineering results in more incidence rate and higher emission of nerolidol and improved attraction of Diadegma semiclausum. Metabolic Engineering, 15, 88-97.

HUANG, X. \& HAN, B. 2014. Natural variations and genome-wide association studies in crop plants. Annual Review of Plant Biology, 65, 531-551.

IZUMITANI, Y., YAHARA, S. \& NOHARA, T. 1990. NOVEL ACYCLIC DITERPENE GLYCOSIDES, CAPSIANOSIDES-A-F AND CAPSIANOSIDES-I-V FROM CAPSICUM PLANTS - SOLANACEOUS STUDIES .16. Chemical \& Pharmaceutical Bulletin, 38, 1299-1307.

JARNE, P. \& LAGODA, P. J. 1996. Microsatellites, from molecules to populations and back. Trends in Ecology \& Evolution, 11, 424-9.

KAPPERS, I. F., AHARONI, A., VAN HERPEN, T., LUCKERHOFF, L. L. P., DICKE, M. \& BOUWMEESTER, H. J. 2005. Genetic engineering of terpenoid metabolism attracts, bodyguards to Arabidopsis. Science, 309, 2070-2072.

KAPPERS, I. F., HOOGERBRUGGE, H., BOUWMEESTER, H. J. \& DICKE, M. 2011. Variation in Herbivory-induced Volatiles Among Cucumber (Cucumis sativus L.) Varieties has Consequences for the Attraction of Carnivorous Natural Enemies. Journal of Chemical Ecology, 37, 150-160.

KAPPERS, I. F., VERSTAPPEN, F. W. A., LUCKERHOFF, L. L. P., BOUWMEESTER, H. J. \& DICKE, M. 2010. Genetic Variation in Jasmonic Acid- and Spider Mite-Induced Plant Volatile Emission of Cucumber Accessions and Attraction of the Predator Phytoseiulus persimilis. Journal of Chemical Ecology, 36, 500-12.

KESSLER, A. \& BALDWIN, I. T. 2001. Defensive function of herbivore-induced plant volatile 
emissions in nature. Science, 291, 2141-2144.

KEURENTJES, J. J. B., FU, J., VOS, C. H. R. D., LOMMEN, A., HALL, R. D., BINO, R. J., PLAS, L. H. W. V. D., JANSEN, R. C., VREUGDENHIL, D. \& KOORNNEEF, M. 2006. The genetics of plant metabolism. Nature Genetics, 38, 842-9.

KORICHEVA, J., NYKÄNEN, H. \& GIANOLI, E. 2004. Meta-analysis of trade-offs among plant antiherbivore defenses: are plants jacks-of-all-trades, masters of all? American Naturalist, 163, E64-E75.

KUMAR, K. P., REDDY, D. J. \& NARENDRANATH, V. V. 2001. Bio-efficacy of selected insecticides against pest complex in chilli (Capsicum annuum Linn). Pesticide Research Journal.

LARA, J. R. \& HODDLE, M. S. 2015. Past, Present, and Future: Biological Control of Spider Mites on California-Grown Avocados, Springer International Publishing.

LEE, J. H., KIYOTA, N., IKEDA, T. \& NOHARA, T. 2007. Acyclic diterpene glycosides, capsianosides C, D, E, F and III, from the fruits of hot red pepper Capsicum annuum L. Used in Kimchi and their revised structures. Chemical \& Pharmaceutical Bulletin, $55,1151-1156$.

LEITNER, M., BOLAND, W. \& MITHÖFER, A. 2005. Direct and Indirect Defences Induced by Piercing-Sucking and Chewing Herbivores in Medicago truncatula. New Phytologist, 167, 597-606.

LI, D. P., BALDWIN, I. T. \& GAQUEREL, E. 2015. Navigating natural variation in herbivory-induced secondary metabolism in coyote tobacco populations using MS/MS structural analysis. Proceedings of the National Academy of Sciences of the United States of America, 112, E4147-E4155.

LIAO, W. T., BEAL, J. L., WU, W. N. \& DOSKOTCH, R. W. 1978. Alkaloids of Thalictrum XXVI. New hypotensive and other alkaloids from Thalictrum minus race B. Lloydia, 41, 257-270.

LOMMEN, A. 2009. MetAlign: interface-driven, versatile metabolomics tool for hyphenated full-scan mass spectrometry data preprocessing. Analytical Chemistry, 81, 3079.

MARTEL, C., ZHUROV, V., NAVARRO, M., MARTINEZ, M., CAZAUX, M., AUGER, P., MIGEON, A., SANTAMARIA, M. E., WYBOUW, N., DIAZ, I., VAN LEEUWEN, T., NAVAJAS, M., GRBIC, M. \& GRBIC, V. 2015. Tomato Whole Genome Transcriptional Response to Tetranychus urticae Identifies Divergence of Spider Mite-Induced Responses Between Tomato and Arabidopsis. Molecular Plant-Microbe Interactions, 28, 343361.

MATSUDA, F., NAKABAYASHI, R., YANG, Z., OKAZAKI, Y., YONEMARU, J. I., EBANA, K., YANO, M. \& SAITO, K. 2015. Metabolome-genome-wide association study dissects genetic architecture for generating natural variation in rice secondary metabolism. The Plant Journal, 81, 13-23.

MCLEOD, M. J., GUTTMAN, S. I. \& ESHBAUGH, W. H. 1982. Early Evolution Of Chili Peppers (Capsicum). Economic Botany, 36, 361-368.

MUELLER, U. G. \& WOLFENBARGER, L. L. 1999. AFLP genotyping and fingerprinting. Trends Ecol Evol, 14, 389-394.

MUMM, R. \& DICKE, M. 2010. Variation in natural plant products and the attraction of bodyguards involved in indirect plant defense. Canadian Journal of Zoology-Revue Canadienne De Zoologie, 88, 628-667.

NAEGELE, R. P., MITCHELL, J. \& HAUSBECK, M. K. 2016. Genetic Diversity, Population Struc- 
ture, and Heritability of Fruit Traits in Capsicum annuum. Plos One, 11, e0156969.

NEVO, E. \& BEILES, A. 2011. Genetic variation in nature. Scholarpedia, 6, 8821.

NYBOM, H. \& BARTISH, I. V. 2000. Effects of life history traits and sampling strategies on genetic diversity estimates obtained with RAPD markers in plants. Perspectives in Plant Ecology, Evolution and Systematics, 3, 93-114.

OGURA, Y., ISHIHARA, A. \& IWAMURA, H. 2002. Changes in secondary metabolites by treatments with jasmonic acid and abscisic acid in barley. Journal of Occupational \& Organizational Psychology, 75, 489\&ndash;509.

OSBOURN, A. 1996. Saponins and plant defence - A soap story. Trends in Plant Science, 1, 4-9.

PERRY, L., DICKAU, R., ZARRILLO, S., HOLST, I., PEARSALL, D. M., PIPERNO, D. R., BERMAN, M. J., COOKE, R. G., RADEMAKER, K. \& RANERE, A. J. 2007. Starch Fossils and the Domestication and Dispersal of Chili Peppers (Capsicum spp. L.) in the Americas. Science, 315, 986-988.

PICKERSGILL, B. 1997. Genetic resources and breeding of Capsicum spp. Euphytica, 96, 129133.

PLUSKAL, T., CASTILLO, S., VILLAR-BRIONES, A. \& OREŠIČ, M. 2010. MZmine 2: Modular framework for processing, visualizing, and analyzing mass spectrometry-based molecular profile data. Bmc Bioinformatics, 11, 395.

PRISCHMANN, D. A. 2000. Biological control of spider mites (Acari: Tetranychidae) on grape emphasizing regional aspects. Spider mites -- Biological control -- Oregon.

RASMANN, S., ERWIN, A. C., HALITSCHKE, R. \& AGRAWAL, A. A. 2011. Direct and indirect root defences of milkweed (Asclepias syriaca): trophic cascades, trade-offs and novel methods for studying subterranean herbivory. Journal of Ecology, 99, 16-25.

RAWORTH, D. A., GILLESPIE, D. R., ROY, M., THISTLEWOOD, H. M. A., MASON, P. G. \& HUBER, J. T. 2001. Tetranychus urticae Koch, twospotted spider mite (Acari: Tetranychidae).

REED, D. H. \& FRANKHAM, R. 2003. Correlation between Fitness and Genetic Diversity. Conservation Biology, 17, 230-237.

RICHARDS, L. A., DYER, L. A., FORISTER, M. L., SMILANICH, A. M., DODSON, C. D., LEONARD, M. D. \& JEFFREY, C. S. 2015. Phytochemical diversity drives plant-insect community diversity. Proceedings of the National Academy of Sciences of the United States of America, 112, 10973-8.

SCHNEE, C., KOLLNER, T. G., HELD, M., TURLINGS, T. C. J., GERSHENZON, J. \& DEGENHARDT, J. 2006. The products of a single maize sesquiterpene synthase form a volatile defense signal that attracts natural enemies of maize herbivores. Proceedings of the National Academy of Sciences of the United States of America, 103, 1129-1134.

SHEKOUFEH, E., SOGHRA, R. \& ABDOLLAH, G. P. 2014. THE EFFECT OF DIFFERENT CONCENTRATION OF JASMONIC ACID ON SECOND METABOLITES CONTENT IN THYMUS VULGARIS L.

SHINBO, Y., NAKAMURA, Y., ALTAF-UL-AMIN, M., ASAHI, H., KUROKAWA, K., ARITA, M., SAITO, K., OHTA, D., SHIBATA, D. \& KANAYA, S. 2006. KNApSAcK: A Comprehensive Species-Metabolite Relationship Database, Springer Berlin Heidelberg.

SNOEREN, T. A. L., KAPPERS, I. F., COLETTE, B., ROLAND, M., MARCEL, D. \& BOUWMEESTER, H. J. 2010. Natural variation in herbivore-induced volatiles inArabidopsis thaliana. Journal of Experimental Botany, 61, 3041-3056. 
SPARKMAN, O. D. 2005. Identification of Essential Oil Components by Gas Chromatography/Mass Spectroscopy, Robert P. Adams (Ed.). Allured Publishing Corporation, New York (1995), 469, ISBN: 0-931710-42-1. Journal of the American Society for Mass Spectrometry, 16, 1902-1903.

SU, Y., GUO, D., H, LIU, J., ZHENG, J., KOIKE, K. \& NIKAIDO, T. 2001. Four new triterpenoid saponins from Conyza blinii. Journal of Natural Products, 64, 32.

SUN, X. L., CAI, X. M., CHUN-LEI, M. A., WANG, G. C. \& CHEN, Z. M. 2011. Kinetics of Polyphenol Oxidase Activity in Tea Leaves Induced by Exogenous Application of MeJA and Mechanical Damage. Acta Botanica Boreali-Occidentalia Sinica, 31, 1805-1810.

SUO, M. R., YANG, J. S. \& LIU, Q. H. 2006. Lignan oligosaccharide esters from Eritrichium rupestre. Journal of Natural Products, 69, 682-684.

SZAKIEL, A., PACZKOWSKI, C. \& HENRY, M. 2011. Influence of environmental biotic factors on the content of saponins in plants. Phytochemistry Reviews, 10, 493-502.

THOLL, D., SOHRABI, R., HUH, J. H. \& LEE, S. 2011. The biochemistry of homoterpenes Common constituents of floral and herbivore-induced plant volatile bouquets. Phytochemistry, 72, 1635.

TIKUNOV, Y. M., LAPTENOK, S., HALL, R. D., BOVY, A. \& VOS, R. C. H. D. 2012. MSClust: a tool for unsupervised mass spectra extraction of chromatography-mass spectrometry ion-wise aligned data. Metabolomics, 8, 714-718.

WAHYUNI, Y., BALLESTER, A.-R., SUDARMONOWATI, E., BINO, R. J. \& BOVY, A. G. 2011. Metabolite biodiversity in pepper (Capsicum) fruits of thirty-two diverse accessions: Variation in health-related compounds and implications for breeding. Phytochemistry, 72, 1358-1370.

WAHYUNI, Y., BALLESTER, A. R., SUDARMONOWATI, E., BINO, R. J. \& BOVY, A. G. 2013. Secondary metabolites of Capsicum species and their importance in the human diet. Journal of Natural Products, 76, 783-793.

WALKER, T. 2006. Plant Diversity and Evolution. Genotypic and Phenotypic Variation in Higher Plants. Edited by R. J. Henry. Wallingford UK: CABI Publishing (2005), pp. 332, f65.00. ISBN 0-85199-904-2. Experimental Agriculture, 42, 121-121.

WAR, A. R., PAULRAJ, M. G., AHMAD, T., BUHROO, A. A., HUSSAIN, B., IGNACIMUTHU, S. \& SHARMA, H. C. 2012. Mechanisms of plant defense against insect herbivores. Plant Signal Behav, 7, 1306-20.

WAR, A. R., SHARMA, H. C., PAULRAJ, M. G., WAR, M. Y. \& IGNACIMUTHU, S. 2011. Herbivore induced plant volatiles: their role in plant defense for pest management. Plant Signaling \& Behavior, 6, 1973-8.

WILSON, J. S., FORISTER, M. L., DYER, L. A., O'CONNOR, J. M., BURLS, K., FELDMAN, C. R., JARAMILLO, M. A., MILLER, J. S., RODRÍGUEZ-CASTAÑEDA, G. \& TEPE, E. J. 2012. Host conservatism, host shifts and diversification across three trophic levels in two Neotropical forests. Journal of Evolutionary Biology, 25, 532-546.

WITTSTOCK, U. \& GERSHENZON, J. 2002. Constitutive plant toxins and their role in defense against herbivores and pathogens. Current Opinion in Plant Biology, 5, 300-307.

XIA, J. \& WISHART, D. S. 2016. Using MetaboAnalyst 3.0 for Comprehensive Metabolomics Data Analysis, John Wiley \& Sons, Inc.

YENDO, A. C. A., COSTA, F. D., GOSMANN, G. \& FETT-NETO, A. G. 2010. Production of Plant Bioactive Triterpenoid Saponins: Elicitation Strategies and Target Genes to Improve Yields. Molecular Biotechnology, 46, 94-104. 
YONEYA, K., UEFUNE, M. \& TAKABAYASHI, J. 2012. An Apparent Trade-Off between Direct and Signal-Based Induced Indirect Defence against Herbivores in Willow Trees. Plos One, 7, 7.

Supplemental Tables and Figures

Supplemental files to this chapter can be downloaded from:

<http://www.wageningenseedlab.nl/thesis/yuanyuanzhang/>http://www.wageningenseedlab.nl/thesis/yuanyuanzhang/

<http://www.wageningenseedlab.nl/thesis/vuanyuanzhang/Sl/>http://www.wageningenseedlab.nl/thesis/yuanyuanzhang/SI/

Supplemental Table 1. ANOVA analysis $(P \leq 0.05)$ on the two-spotted spider mites oviposition on leaf discs $(n=9)$ among nineteen Capsicum genotypes or on whole plants $(n=$ 3) among 22 Capsicum genotypes followed by a Bonferroni post-hoc test and correction.

Supplemental Table 2.The offspring number (the sum of nymphs and eggs number) of two-spotted spider mites on leaf discs $(n=9)$ among nineteen Capsicum genotypes.

Supplemental Table 3. The offspring number (the sum of nymphs and eggs number) of two-spotted spider mites on whole plants $(n=3)$ among 22 Capsicum genotypes.

Supplemental Table 4. Endogenoues metabolite features in 17 Capsicum genotypes of both infested plants(in) and non-treated plants(con). Genotypes are labeled with 1 to 34 , two replicates for each treatment.

Supplemental Table 5. One-way ANOVA analysis $(P \leq 0.05)$ on endogenous metabolites features among 17 Capsicum genotypes. CON are non-treated plants and TSSM are spider mites infested plants for one week.

Supplemental Table 6. Endogenous metabolite features with Variable importance in projection (VIP) $\geq 2.0$ by PLS-DA, metabolite features with Correlation coefficiency $|r| \geq 0.5$ by Pearson correlation analysis and metabolite features in stepwise regression based on spider mites offspring on leaf discs (Id) or whole plants (wp).

Supplemental Table 7. Voltile metabolite features $(\mathrm{m} / \mathrm{z})$ of different genotypes (column) represented by numbers in retaintion time (row). Three replicates were measured for each genotype, labelled by $a, b$ or c respectively.

Supplemental Table 8. One-way ANOVA analysis ( $P \leq 0.05)$ on volatile metabolites features among 19 Capsicum genotypes.

Supplemental Table 10. Volatile Metabolite features with Variable importance in projection (VIP) $\geq 2.0$ by PLS-DA, metabolite features with Correlation coefficiency $|r| \geq 0.5$ by Pearson correlation analysis. 


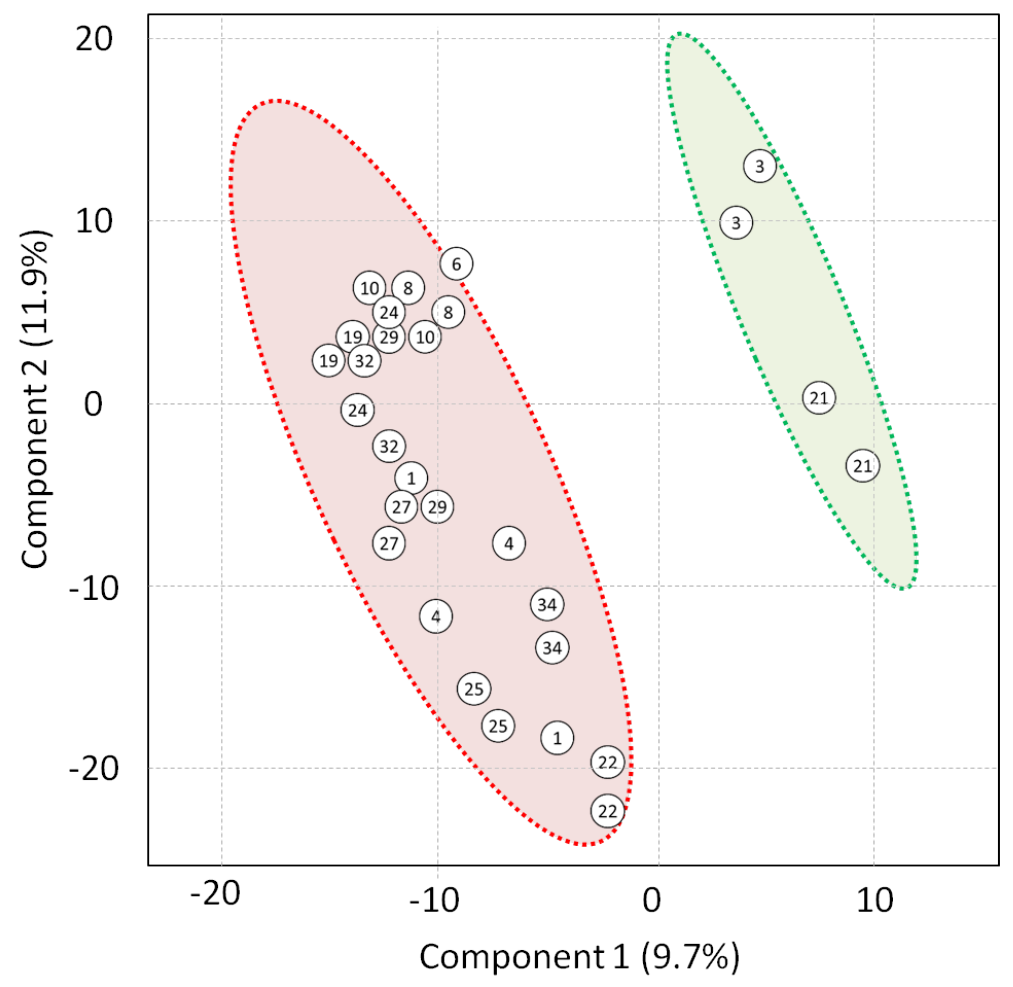

Supplementary Figure 1. PLS-DA of reconstructed endogenous metabolites in spider-mite infested plants of twenty-two Capsicum genotypes. Numbers represent genotypes as indicated in Table 1 . Direct defense levels are based on spider mite offspring on whole plants: with G4, G6, G8 and G10 as resistant, G1, G3, G21, G22, G24, G25, G27, G32 and G34 as intermediate and G19 and G29 as susceptible. PC1 and PC2 explain $23.3 \%$ and $15.5 \%$ and $20.4 \%$ and $12.1 \%$, respectively, of the total variation in non-infested and in spider-mite infested plants, respectively. 


\section{Chapter 3 Dynamic metabolic adaptations in Capsicum annuum upon two-spotted spider mite herbivory}

Yuanyuan Zhang, Kristyna Flokova, Harro J. Bouwmeester and Iris F. Kappers 


\begin{abstract}
Adaptation of the metabolome forms an important defense layer for plants against herbivores. The type of changes that occur largely depend on the plant and herbivore species that interact. Here, we use untargeted and targeted metabolomics to monitor the metabolic responses in Capsicum leaves upon spider mite infestation. We analyzed two genotypes - that varied in their susceptibility towards spider mites - for their endogenous and volatile secondary metabolite profiles during the first period of spider-mite infestation. Furthermore, stress-related phytohormones and genes involved in hormonal signaling pathways were analyzed. Based on the results, we conclude that recognition of the attacker coincides with a transient increase in jasmonic acid followed by a gradual increase in salicylic acid. We show that several terpenoids are being induced by spider mites, both in the volatile as well as in the non-volatile metabolome, which may play a role in the attraction of their natural enemy, predatory mites, as well as in direct defenses against the spider mites, respectively.
\end{abstract}




\section{Introduction}

The co-existence of plants with multiple natural attackers drove the evolution of a dynamic and complex signaling network and an array of different strategies to respond to herbivore attack. Defensive plant traits can be constitutive such as the presence of thorns, trichomes and toxic metabolites (War et al., 2012) or can be induced upon herbivore attack (Kessler and Baldwin, 2002). Induced plant defenses against herbivores are sophisticated and require herbivore elicitor perception, signal transduction, and induction of the expression of defensive genes (Furstenberg-Hagg et al., 2013). The changes in gene expression, proteins and metabolites are regulated in a temporally and spatially dynamic pattern (Liu et al., 2016, Barah and Bones, 2015, Ehlting et al., 2008). The induced changes in gene expression can result in the production of defensive metabolites and toxic proteins that constitute a direct defense, reducing herbivore fitness and reproduction (Howe and Jander, 2008) and/or the production and release of volatile metabolites that mediate indirect defenses, that is the attraction of natural enemies of the herbivores (Dicke and Baldwin, 2010).

Yield loss due to herbivory is a big problem in modern agriculture. Chemical control, which is still the major approach applied to protect crops, has negative drawbacks as it does not only threaten the environment but may also result in development of resistance of the herbivorous arthropods towards these chemicals (Pedigo and Rice, 2009). Enhancing the natural resistance of crops by genetic and breeding techniques and the use of natural enemies for biological control can be a sustainable and more environmental friendly solution. Therefore, understanding the mechanisms of plant defenses against herbivores is essential for improving plant performance under conditions with herbivory.

The secondary metabolite signature of a plant is the combined result of signal transduction and gene expression and directly determines the state of both direct and indirect defense (Bennett and Wallsgrove, 1994, Pickett and Khan, 2016). Multiple biochemical classes of secondary metabolites were proven to be associated with herbivore defenses in different plant species, including cyanogenic glucosides, glucosinolates, benzoxazinoids, non-protein amino acids, alkaloids, phenolics and terpenoids (Bennett and Wallsgrove, 1994). Specific alkaloids and flavonoids accumulated more in a resistant Senecio line compared to a susceptible line upon thrips infestation (Leiss et al., 2009). Analyzing natural variation of the metabolome in Barbarea vulgaris plants revealed specific saponins positively correlated with resistance towards flea beetle (Phyllotreta nemorum) (Kuzina et al., 2009). A combined transcriptome and metabolome analysis in rice indicated that 
multiple phenylpropanoids and terpenoids are involved in defense against the rice stem borer, Chilo suppressalis (Liu et al., 2016). Terpenes, green leaf volatiles and nitrogen-containing compounds released from foliage of black poplar (Populus nigra) upon gypsy moth (Lymantria dispar) caterpillar feeding were found to be essential for attracting parasitic Hymenoptera (McCormick et al., 2014). Predatory mites Phytoseiulus persimilis were more attracted to cucumber genotypes emitting relatively higher mono-, sesquiand homoterpenes in their Tetranychus urticae spider-mite induced volatile blend (Kappers et al., 2010, Kappers et al., 2011).

Fine-tuning of the different defense responses is necessary as the use of metabolites in plant resistance may have negative impact on other physiological traits, such as biomass and reproductive fitness (Rasmann et al., 2015). The timing and magnitude of the resistance response is primarily regulated by phytohormones of which salicylic acid and jasmonic acid are the predominant phytohormones involved in plant-herbivore interactions (Verma et al., 2016, Erb et al., 2012). Jasmonic acid (JA) and its derivatives are oxylipins. Biosynthesis starts from the conversion of linolenic acid to 12-oxo-phytodienoic acid (OPDA) in chloroplast membranes, which then undergoes a reduction and three rounds of oxidation to form JA. Conjugation with the amino acid isoleucine results in the bioactive derivative, JA-Ile, which is generally thought to be responsible for JA signaling (Turner et al., 2002). JAs regulate a wide range of processes in plants, ranging from growth and photosynthesis to reproductive development (Erb et al., 2012). In particular, JAs are critical both for recognition and regulation of plant defenses against herbivores, necrotrophic pathogens and wounding. Increased JA and JA-Ile concentrations result in adaptation of the primary metabolic signature (Tytgat et al., 2013) and reallocation of primary metabolites to fuel the metabolic reprogramming needed to enhance plant defences (Zhou et al., 2015) for instance to increased terpene accumulation leading to enhanced resistance towards herbivores (Garms et al., 2008) (Li et al., 2015).

Salicylic acid (SA) is a phenolic compound mediating plant growth and development, photosynthesis, transpiration, ion uptake and transport and induces specific changes in leaf anatomy and chloroplast structure (Pieterse et al., 2012). SA predominantly mediates local and systemic plant defense responses against pathogens (Rivas-San Vicente and Plasencia, 2011) and some piercing/sucking herbivores (Walling, 2009, Meldau et al., 2012). SA induces the accumulation of primary metabolites including various amino acids (proline, serine, threonine and alanine) and carbohydrates (glucose, mannose, fructose and cellobiose) in bentgrass (Agrostis stolonifera) (Li et al., 2017). SA pre-treatment on micro propagated Uncaria tomentosa plant- 
lets resulted in increased production of monoterpenoid oxindole alkaloids, flavonoids and phenolic compounds (Sanchez-Rojo et al., 2015).

Capsicum belongs to the Solanaceae family. Native to the Americas, Capsicum species have thousands of years of history of domestication. Nowadays it has become a worldwide cultivated crop and is economically important in many countries as a fruit vegetable (https://en.wikipedia.org/wiki/Capsicum). Two-spotted spider mites (Tetranychus urticae Koch) are cell-content feeding arthropods, member of the Acari (mite) family Tetranychidae (Bolland et al., 1997) and generally live on the abaxial side of leaves of plants, where they may spin protective silk webs. The cosmopolitan spider mites attack a wide range of plant species including peppers and cause high production losses. The typical life cycle of spider mites includes eggs, a larval stage, two nymphal stages and an adult stage. Depending on temperature, spider mites hatch from eggs within 3 days and can complete their development within 5 to 20 days. The adult females can live for 2 to 4 weeks and one individual female can produce several hundred eggs (Raworth et al., 2002).

To determine the dynamics of adaptation in the leaf metabolome during spider-mite infestation, endogenous and volatile metabolites as well as stress-related phyhormones and their corresponding marker genes were traced in two genotypes of Capsicum annuum with different susceptibility to spider mites.

\section{Materials and Methods}

\section{Plant Material and Arthropods}

Seeds of Capsicum (Capsicum annuum, Genotype 8 (G8); Genotype 29 (G29); Capsicum chacoense, Genotype 25 (G25)) were germinated and grown in a greenhouse under long day conditions of which the light was supplemented with high-pressure sodium lamps $\left(16: 8 \mathrm{~h}, 23: 18^{\circ} \mathrm{C} /\right.$ day : night, $50-60 \%$ relative humidity) for 5 weeks. Plants were transferred to a climate chamber (16: $8 \mathrm{~h}, 24: 18^{\circ} \mathrm{C} /$ day : night) two days prior to experiments.

Two-spotted spider mites, Tetranychus urticae Koch (Arachnida: Acari: Tetranychidae) (originally obtained from Koppert BV, Berkel and Rodenrijs, The Netherlands) were reared on lima bean plants (Phaseolus lunatus) for many generations and kept in a BugDorm-2120 insect tent $(96 \times 26,680 \mu \mathrm{m}$ aperture) on the window shelf in the $\operatorname{lab}\left(22^{\circ} \mathrm{C}\right)$.

Predatory mites, Phytoseiulus persimilis were obtained from a standard 
rearing from Koppert BV (Berkel and Rodenrijs, The Netherlands) and were delivered to the lab on the experimental day.

\section{Experimental set-up}

Capsicum annuum plants of a similar developing stage (five weeks old, in vegetative stage) were placed in a climate chamber two days before infestation for adaptation. For $\mathrm{G} 29,33$ plants were infested with 50 spider mites on each plant and 21 plants were left non-treated as control plants. Adult spider mites with two spots clearly visible and of similar size were transferred to the upper leaf surface of the plants using a fine brush. All of mites' transferring was done within 1 hour in the morning and the day of infestation was recorded as the first day of the experiment (Day 0). All plants were placed in an insect-gauze tent to prevent contamination. Infested and control plants were kept in two separate chambers with identical conditions.

Plants of G29 were sampled at different time points after introducing spider mites: i.e. 6 hours, 3, 6, 9, 1016 and 20 days post infestation (hpi / dpi). On each of these time points, the headspace of three spider mite-infested plants and three non-treated plants was collected. Three leaves of different ontogenic positions from three other plants that were either infested with spider mites or were left non-treated were harvested and flash-frozen in liquid nitrogen for RNA extraction, endogenous metabolites and phytohormone analyses. After sample collection, the number of spider mites present on the left leaves was counted and leaves were scanned to determine leaf area.

For G8, an inverted approach was used, i.e. plants were infested with approximately 300 spider mites on each plant, 3, 18 hours, 1, 4, 8 and 15 days before sampling. In total, 36 plants were infested and 6 were left uninfested. All plants were sampled on the same day. For endogenous metabolites and phytohormone analyses, three replicates were used and volatile metabolites were collected from three separate plants in each time point. Leaves for headspace collection were weighted for fresh weight.

\section{Development of spider-mite population}

For G29 plants, the spider-mite population was evaluated in each of the above indicated time points. Leaves from different ontogenic positions (top, middle and bottom) of three plants were collected to homogenize for possible variation in the spider-mite population due to localization and analyzed for the number of spider mites, including adults, nymphs and eggs. 


\section{Predatory mite attraction}

For G29 plants, predatory mite attraction was evaluated in each of the time points. The relative attractiveness of spider-mite infested plants to predatory mites was evaluated using 5-day spider-mite infested Capsicum chacoense (G25) plants as reference. On each experimental day three spider mite-infested $\mathrm{G} 29$ (7, 13 or $17 \mathrm{dpi}$ ) and three $\mathrm{G} 25$ (5 dpi) plants were alternately placed in a BugDorm-2120 insect tent and approximately 100 predatory mites were released equally between the plants at different positions to ensure equal accesses to each plant $24 \mathrm{hrs}$ prior counting. The number of predatory mites was counted on 3 different leaves of each of the plants and normalized by leaf area. Relative preferences on each time point were statistically tested using a student $T$ test $(P<0.1)$.

\section{Leaf endogenous secondary metabolites}

Semi-polar endogenous metabolites were extracted according to the protocol described by (De Vos et al., 2007) and analyzed by liquid chromatography coupled to mass spectrometry (LC-MS). Frozen leaf samples were grinded into a fine powder in liquid nitrogen and lyophilized overnight. Twenty $( \pm 1) \mathrm{mg}$ of lyophilized leaf material from each sample was extracted with 2 $\mathrm{ml} 75 \% \mathrm{MeOH}$ (0.1\% formic acid) solution. Samples were homogenized for 5 seconds, sonicated for $15 \mathrm{~min}$ at maximum frequency $(40 \mathrm{kHz})$ in a water bath at room temperature, and centrifuged for $10 \mathrm{~min}$ at $5000 \mathrm{rpm}$. The supernatant was filtered using a $0.45 \mu \mathrm{m}$ inorganic membrane filter (Omnifix, Germany), fitted onto a disposable syringe and transferred into a $0.3 \mathrm{~mL}$ LC-MS plastic vial. Ten $\mu$ l of supernatant was taken from each sample and combined to make a quality control sample (QC), that was injected multiple times throughout the sequence in order to be able to correct for time shifts. Due to availability of platforms, extracts of G29 were analyzed by a LC-QTOFMS platform, while extracts of G8 were analyzed by LC-Orbitrap-MS.

The LC-Synapt QTOF-MS platform consisted of reversed phase liquid chromatography (Waters Alliance HPLC 2695) equipped with a luna C18 column including pre-column $\left(2.0 \times 4 \mathrm{~mm}^{2}\right)$ and an analytical column $(2.0 \times 150$ $\mathrm{mm}^{2}, 100 \AA$, particle size $3 \mu \mathrm{m}$; Phenomenex), a photodiode array detector (PDA) and a quadrupole time of flight mass spectrometry of the Synapt G2S (Waters, QTOF-Ultima) with negative electrospray ionization mode. Five $\mu \mathrm{L}$ of extracts were separated using a gradient of formic acid : water (1: 1000, v/v; eluent A) and formic acid : acetonitrile (1:1000, v/v; eluent B). Extracts were injected into HPLC at a flow rate of $0.19 \mathrm{~mL} \mathrm{~min} \mathrm{~m}^{-1}$. The initial solvent composition consisted of $95 \% A$ and $5 \%$ B, increased linearly to $65 \%$ $A$ and $35 \% \mathrm{~B}$ within $45 \mathrm{~min}$ and maintained for $2 \mathrm{~min}$. The column was then 
washed with $25 \% \mathrm{~A}$ and $75 \% \mathrm{~B}$ for $15 \mathrm{~min}$ and equilibrated to $95 \% \mathrm{~A}$ and $5 \%$ $B$ for 5 min before the next injection. A collision energy of $10 \mathrm{eV}$ was used for full-scan LC-MS in the $\mathrm{m} / \mathrm{z}$ range $100-1,500$.

The LC-Orbitrap-MS consisted of an Accela U-HPLC equipped with a $1.7 \mu \mathrm{m}$ AQUITY UPLC BEH C18 column (2.1 x 150 mm; Waters), an Accela photodiode array (PDA) detector and an lon trap-Orbitrap FTMS hybrid mass spectrometer (Thermo Fisher Scientific) with negative electrospray ionization mode at a source voltage of $4.5 \mathrm{kV}$. Five $\mu \mathrm{L}$ of extracts were injected and separated with a linear 20 min gradient of $5-35 \%$ acetonitrile (acidified with $0.1 \mathrm{FA}$ ) at a flow rate of $400 \mu \mathrm{L} \mathrm{min}^{-1}$ similar as described above. The column was washed and equilibrated before next injection.

\section{Volatile secondary metabolites}

The headspace of infested plants and control plants was collected using a dynamic sampling procedure with adaptations (Kappers et al., 2011). Plants were placed on a lower shelf with a second shelf with notches above in such a way that pot with roots were placed under the second shelf and shoot and leaves above.

During the collection, above parts of plants were enclosed by a $2.5 \mathrm{~L}$ glass jar. Inlet air was pre-treated using a zero-air generator (Bronkhorst, The Netherlands) and supplemented with $\mathrm{CO}_{2}$ to $400 \mathrm{ppm}$ and a $\mathrm{RH}$ of $50 \%$. Inlet air was introduced via Teflon tubing into the glass jar with $300 \mathrm{ml} . \mathrm{min}^{-1}$. Volatiles were collected on pre-conditioned Tenax TA (200 mg, 20/35 mesh; Grace-Alltech, Deerfield, MI, USA) in stainless steel liners (Markes, Llantrisant, UK) connected to the outlet of the system at a flow of $200 \mathrm{ml} \cdot \mathrm{min}^{-1}$. The slight overpressure minimizes contamination of background odors. Headspaces were collected from 11.00 AM to $13.00 \mathrm{PM}$. After collection, Tenax liners were dry-purged with nitrogen for $30 \mathrm{ml} \mathrm{min}^{-1}$ for $30 \mathrm{~min}$ at ambient temperature before GC-MS analysis. Fresh weights of leaves were determined immediately after the collection.

Headspace samples were analyzed with a Thermo Trace GC Ultra (Thermo Fisher Scientific, Waltham, MA, USA) connected to a Thermo Trace DSQ (Thermo Fisher Scientific, Waltham, MA, USA) quadrupole mass spectrometer (GC-MS). Volatiles were desorbed using a thermal desorption system at $250^{\circ} \mathrm{C}$ for $3 \mathrm{~min}$ (Model Ultra Markes Llantrisant, UK) with a helium flow of $30 \mathrm{ml} \mathrm{min}{ }^{-1}$. Analytes were focused at $3^{\circ} \mathrm{C}$ on an electronically-cooled sorbent trap (Unity, Markes, Llantrisant, UK). Volatiles were transferred in splitless mode to the analytical column (Rtx-5 ms, $30 \mathrm{~m}, 0.25 \mathrm{~mm}$ i.d., 1.0 $\mu \mathrm{m}$ film thickness, Restek, Bellefonte, PA, USA) by rapid heating of the cold 
trap to $250^{\circ} \mathrm{C}$. The $\mathrm{GC}$ was held at an initial temperature of $40^{\circ} \mathrm{C}$ for 3.5 min followed by a linear thermal gradient of $10^{\circ} \mathrm{C} \mathrm{min}^{-1}$ to $280^{\circ} \mathrm{C}$, and held for $2.5 \mathrm{~min}$ with a column flow of $1 \mathrm{ml} \mathrm{min}^{-1}$. The column effluent was ionized by electron impact ionization at $70 \mathrm{eV}$. Mass spectra were acquired by scanning from $45-400 \mathrm{~m} / \mathrm{z}$ with a scan rate of 3 scans s$^{-1}$. Compounds were identified by using the deconvolution software AMDIS (version 2.64, NIST, USA) and MassHunter, Unknown Analysis (c) Agilent Techologies, Inc 2008, in combination with NIST 98 and Wiley 7th edition spectral libraries. For relative quantification, characteristic quantifier ions were selected for each compound.

\section{Statistical analysis of metabolic data}

For all chromatography-MS platforms (LC-MS for endogenous metabolites and GC-MS for volatile metabolites) Metalign software (Lommen, 2009) was used for baseline correction, mass spectra extraction and mass signal alignment. MSClust (Tikunov et al., 2012) was used for data reduction by unsupervised clustering and extracting putative reconstructed metabolites (centrotypes, centrotype factor $>0.7$ ) from mass spectra by ion-wise chromatographic alignment of the data using the subtractive fuzzy clustering method.

Principal Component Analysis was performed on the reduced dataset to obtain an overview of the whole dataset using GeneMath XT 2.0 after log2 transformation and noise subtraction (Hendriks et al., 2005). The first few principal components (PCs) explain most of the variance in the original data, and we used it to visualize differences of the total metabolite profile during spider-mite infestation in both genotypes. Hierarchical cluster analysis was applied to depict the similarities of the samples using Pearson Correlation and UPGMA method. Individual metabolites were analyzed for significant changes upon infestation using a T-test (SPSS 15.0, Chicago, II, USA). The selected endogenous metabolites were putatively annotated based on their molecular weight using the knapsack database (http://kanaya.naist. $\mathrm{jp} / \mathrm{knapsack}$ jsp/top.html) and in case of volatile metabolites by comparing mass spectra and retention indices with NIST,WILEY \& ADAMS databases (Wiley, 2016, NIST, 2011).

\section{Stress-related phytohormones}

The analysis of endogenous stress-related plant hormones - SA, JA, cis-OPDA and JA-lle - was performed according Floková and co-workers (Floková et al., 2014) with modifications. Frozen plant tissue was grinded to fine powder in liquid nitrogen and lyophilized. Aliquots of $7 \mathrm{mg}( \pm 0.05)$ of dry weight 
were extracted in $1 \mathrm{ml}$ of ice cold $10 \%$ methanol/water (v/v) and homogenized using a MM 301 vibration mill at a frequency of $27 \mathrm{~Hz}$ for 3 min (Retsch $\mathrm{GmbH} \&$ Co. KG, Haan, Germany) in the presence of zirconium oxide homogenization beads. At this stage, stable isotope-labelled internal standard $\left[{ }^{2} \mathrm{H}_{4}\right]-\mathrm{SA},\left[{ }^{2} \mathrm{H}_{6}\right]-\mathrm{JA},\left[{ }^{2} \mathrm{H}_{5}\right]$-cis-OPDA and $\left[{ }^{2} \mathrm{H}_{2}\right]-\mathrm{JA}$-lle were added to each sample in order to validate quantification. Samples were further extracted for 30 min by constant shaking $(200 \mathrm{rpm})$ at $4^{\circ} \mathrm{C}$. Plant extracts were centrifuged (13000 rpm/ $10 \mathrm{~min} / 4^{\circ} \mathrm{C}$ ) and collected supernatants were purified using Strata X (30 mg/3 cc, Phenomenex) columns, activated with $1 \mathrm{ml}$ of methanol, water and $1 \mathrm{ml}$ of the extraction solvent. Loaded samples were washed with $3 \mathrm{ml}$ of water and compounds of the interest were eluted with $3 \mathrm{ml}$ of $80 \%$ methanol/water ( $\mathrm{v} / \mathrm{v})$. The solvent was evaporated to dryness under a stream of nitrogen and dried samples were stored at $-20^{\circ} \mathrm{C}$ until UPLC-MS/ MS analysis. The Acquity UPLC ${ }^{\circledR}$ System (Waters, Milford, MA, USA) coupled to a triple quadrupole mass spectrometer Xevo ${ }^{\text {TM }}$ TQ S (Waters MS Technologies, Manchester, UK) was employed to determine endogenous levels of plant hormones. Dried samples were reconstituted in $60 \mu \mathrm{l}$ of mobile phase and injected on reverse phase based column Acquity UPLC ${ }^{\circledR} \mathrm{CSH}^{\mathrm{TM}} \mathrm{C} 18 ; 2.1$ $x 100 \mathrm{~mm} ; 1.7 \mu \mathrm{m}$ (Waters, Ireland) at a flow rate of $0.4 \mathrm{ml} \mathrm{min}{ }^{-1}$. Separation was performed at $40^{\circ} \mathrm{C}$ by 9 min binary gradient elution using $15 \mathrm{mM}$ formic acid/ water $(A)$ and acetonitrile (B) with following conditions: 0-1 min isocratic elution at $15 \% \mathrm{~B}(\mathrm{v} / \mathrm{v}), 1-7$ min linear gradient to $60 \% \mathrm{~B}, 7-9$ min linear gradient to $80 \%$ B and $9-10$ min logarithmic gradient to $100 \%$ B. Finally, the column was washed with $100 \%$ acetonitrile and equilibrated for initial conditions ( $2 \mathrm{~min}$ ). The effluent was introduced into electrospray ion source of tandem mass spectrometer operating at following settings: source/desolvation temperature $\left(120 / 550^{\circ} \mathrm{C}\right)$, cone/desolvation gas flow $\left(147 / 650 \mathrm{~L} \mathrm{~h} \mathrm{~h}^{-1}\right)$, capillary voltage $(3 \mathrm{kV})$, cone voltage $(25-30 \mathrm{~V})$, collision energy $(10-25 \mathrm{eV})$ and collision gas flow $0.25 \mathrm{ml} \mathrm{min}^{-1}$. Compounds were quantified in multiple reaction monitoring mode (MRM) using standard isotope dilution method (Supplemental Table 1, 2). The MassLynx ${ }^{\mathrm{TM}}$ software (version 4.1, Waters, Milford, MA, USA) was used to control the instrument, acquire and process MS data.

\section{Gene expression}

\section{Reference gene selection and stability evaluation in a time course}

Four candidate reference genes were selected based on the available literature of commonly used reference genes in RT-qPCR studies in Capsicum, Arabidopsis and tomato (Wan et al., 2011, Dekkers et al., 2012, Kim et al., 2003), including glyceraldehyde-3-phosphate dehydrogenase (GAPDH), actin (ACT), ubiquitin (Kubigsteltig et al., 1999) and ribosomal protein L2 (RPL2) 
( $L \varnothing v d a l$ and Lillo, 2009). The complete coding sequences of selected genes from tomato (NCBI, http://www.ncbi.nlm.nih.gov/) were blasted against the Capsicum annuum translated nucleotide database (http://peppersequence. genomics.cn/page/species/download.jsp). The sequences with highest similarity were selected as putative orthologues of the above mentioned genes.

Primers were designed using Primer-Blast (NCBI, http://www.ncbi.nlm.nih. gov/tools/primer-blast/index.cgi?LINK LOC=BlastHome) with melting temperature (Schaller et al.) of $58-62^{\circ} \mathrm{C}$, primer lengths of $18-22 \mathrm{bp}$ and product lengths of 70-200bp. The specificity of the primers was evaluated based on melting curve analysis. Primer sequences are in supplemental Table 3.1.

Real Time quantitative Polymerase Chain Reactions (RT-qPCR) were prepared in duplicate in a total volume of $45 \mu \mathrm{l}$, containing $2 \mu \mathrm{l}$ of cDNA template, $4.5 \mu \mathrm{l}$ of forward primer and reverse primer ( $3 \mu \mathrm{M}), 22.5 \mu \mathrm{l}$ of iQSYBR Green Supermix (BIO-RAD) and $11.5 \mu$ of fresh MilliQ water. Each mixture was separated into 2 wells as technical replicates with $20 \mu \mathrm{l}$ of mixture in each well. The following qPCR program was used for all PCR reactions: $95^{\circ} \mathrm{C}$ for $3 \mathrm{~min}$, followed by 40 cycles of $95^{\circ} \mathrm{C}$ for $15 \mathrm{~s}$ and $60^{\circ} \mathrm{C}$ for $30 \mathrm{~s}$. Melting curves were obtained after this program by heating from 65 to $95^{\circ} \mathrm{C}$, increasing the temperature stepwise by $0.5^{\circ} \mathrm{C}$ every 5 s (Ribeiro et al., 2014).

The reference genes were ranked and selected for their stability using $C$. annuum G29 time series materials using the online software RefFinder (https://archive.is/wRrsF\#selection-423.0-423.9) (Andersen et al., 2004). Ranking results are provided in Supplemental Table 3.2.

\section{Functional gene expression of stress-related phytohormone signaling pathways}

$\beta$-chitinase (chiB) and plant defensin (PDF1.2) were selected as marker genes of the JA/ Ethylene pathway and lipoxygenase 2 (LOX2) were selected as JA marker genes (Abe et al., 2008, De Vos et al., 2005, Lorenzo and Solano, 2005). SA-inducible genes, pathogenesis-related protein 1 (PR1) and glucan 1,3-beta-glucosidase (BGL) were selected as SA marker genes. The complete coding sequences of mRNA of orthologues from Arabidopsis thaliana (NCBI, http://www.ncbi.nlm.nih.gov/) were blasted against the Capsicum annuum translated nucleotide database (http://peppersequence. genomics.cn/page/species/download.jsp). The sequences that showed the highest similarity were selected for primer design with Primer-Blast in NCBI. Primer sequences are in Supplemental Table 4. 


\section{RNA extraction and cDNA synthesis}

Samples were ground into fine powder in liquid nitrogen using a pestle and mortar. Total RNA was extracted from $100 \mathrm{mg}$ fresh weight of each sample using $1 \mathrm{ml}$ TriPure (Roche, Mannheim, Germany), cleaned with the RNeasy Plant Mini Kit (Qiagen, USA) and genomic DNA was digested using RNaseFree DNase Set (Qiagen, USA) according to the manufacturer's instructions. RNA integrity was estimated by $1.0 \%$ agarose gel electrophoresis. RNA concentration and quality were measured spectrophotometrically using a NanoDrop ND-1000 spectrophotometer (Thermo scientific, USA). RNA samples with an $A_{260} / A_{280}$ and $A_{260} / A_{230}$ ratio ranging from 1.8 to 2.2 were used for subsequent analysis. One $\mu \mathrm{g}$ of total RNA was used for reverse-transcription reaction to synthesize CDNA using the iScriptTM CDNA synthesis kit (BioRad, Hercules, CA, USA) at $42^{\circ} \mathrm{C}$ for $30 \mathrm{~min}$ followed by $85^{\circ} \mathrm{C}$ for $5 \mathrm{~min}$ to inactivate RTase. The cDNA was diluted to $200 \mu \mathrm{l}$ with fresh MQ water for use in RT-qPCR reactions as described above. $\Delta \Delta C_{T}$ was calculated as follows: $\Delta \Delta \mathrm{C}_{\mathrm{T}}=\Delta \mathrm{C}_{\mathrm{T}}$ (Target) $-\Delta \mathrm{C}_{\mathrm{T}}$ (Reference). The expression fold change was calculated by $2^{-\Delta \Delta C T}$ (Kenneth et al., 2001). 


\section{Results and Discussion}

To get insight in the time frame in which metabolome changes in $C$. annuum are induced, genotype 29 (G29) was infested with spider mites and after different time points, volatile and endogenous metabolites were analyzed. Furthermore, responses in stress-related phytohormones were studied, both at the chemical level as well as with regard to the expression of genes responsible for the biosynthesis of these phytohormones. To eliminate metabolic changes resulting from plant development, we studied a second C. annuum genotype (G8) via an inverted approach by infesting plants at different time points and collecting all samples at the same time to validate whether hormone and metabolome adaptations occur within the same timeframe and are of the same order of magnitude.

\section{Genotype 29}

\section{Spider mite population development during 19 days after infestation in Capsicum}

To reveal the time frame in which a spider mite population develops on Capsicum leaves, adults, nymphs and eggs were counted at different time points after spider mites were introduced to Capsicum (G29) plants. The number of spider mites decreased during the first 3 dpi probably due to transition of spider mites from lima bean to Capsicum. The adult density was 0.4 mites per $\mathrm{cm}^{-2}$ leaf area while no eggs or nymphs were found yet. From 6 to 16 $\mathrm{dpi}$, the total number of individuals increased 4 fold compared to $3 \mathrm{dpi}$, as result of new egg deposition. The total density of eggs and nymphs was 0.79 per $\mathrm{cm}^{-2}$ compared with an adult density of $1.99 \times 10^{-2} \mathrm{~cm}^{2}$. After 16 days, the population number declined probably as the first introduced adult spider mites died because of aging. The number of new hatched nymphs and eggs slowly increased during the first 16 days (Figure 1, Sup Table 5). The total population of spider mites at the end of our experimental period ( $20 \mathrm{dpi}$ ) was lower than at the onset of the experiment, suggesting that this genotype is quite resistant to spider mites or spider mites did not successfully adapt to this $C$. annuum genotype within this time frame.

\section{Semi-polar endogenous metabolites in leaves infested by spider mites}

To reveal how and which endogenous secondary metabolites in Capsicum leaves alter during the settlement of spider mites, an untargeted metabolomics approach based on LC-MS data was applied. Processing the raw data from the LC-MS platform for baseline correction, mass signal extraction and redundancy reduction by mass pattern similarity (centrotype factor $>0.7$ ), 
resulted in a dataset consisting of 115 metabolite features (Sup Table 6) which was subjected to different multivariate analyses including hierarchical clustering analysis (HCA) and principal component analysis (PCA).

As a starting point for data analysis, HCA based on all 115 metabolite features was performed to explore the data (Figure 2A). HCA suggests that the leaf metabolome of similar developmental stages shows high similarity, independently of whether infested by spider mites or left un-infested, while the leaf metabolomes of early time points was different from those of the later time points.

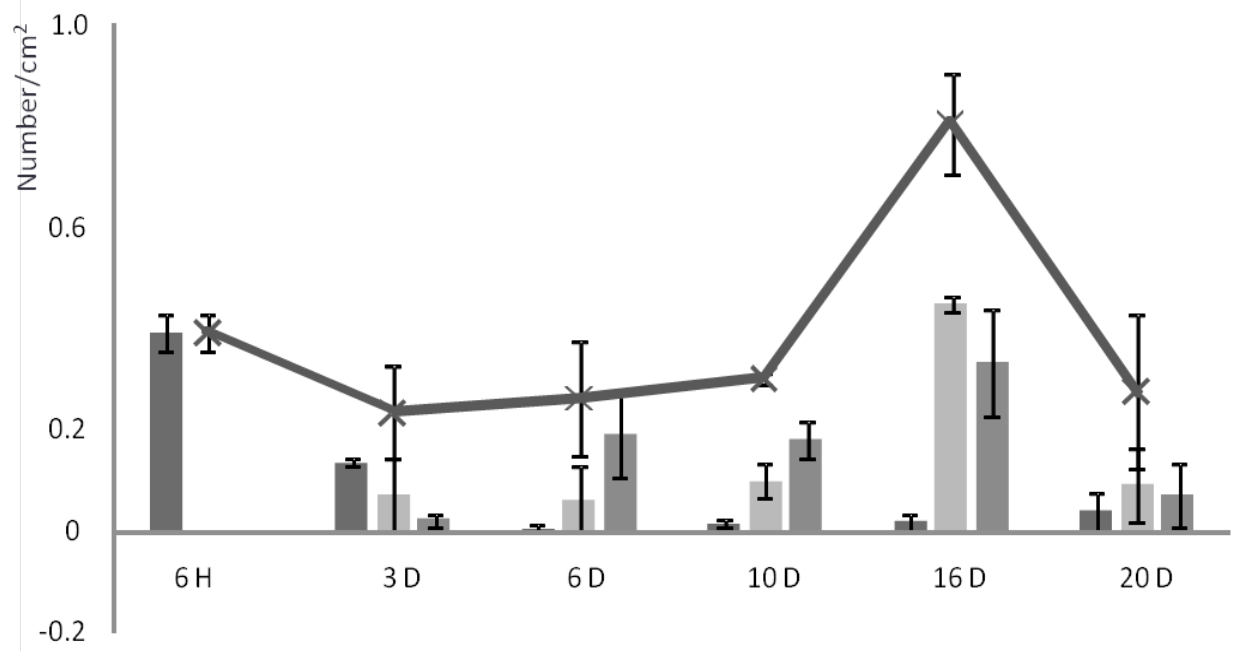

Adults Nymphs $\quad$ Eggs Population

Figure 1. Spider mite population density $\left(/ \mathrm{cm}^{2}\right)$ during 20 days post infestation in $\mathbf{G 2 9}$. Dark grey bars represent adult density; Light gray bars represent nymph density; Grey bars represent egg density. The line represents the total population density (Sum of spider mite adults, nymphs and eggs). Error bars represent the mean \pm SE of $n=3$ biological replicates.

The results of PCA are consistent with HCA (Figure 2B), as most of the variation in the leaf metabolome could be attributed to the age of the leaves. There is a clear shift in the composition of the leaf metabolome from $6 \mathrm{~h}$ to $3,6,10,16$ and $20 \mathrm{dpi}$, mostly along the first PC, and independent from spider mite infestation (PC1 19.3\% of total variation). The second PC explained $13.8 \%$ of the total variation and mainly discriminates spider-mite infested leaves from those of similar age that were not infested. In all cases, except for $6 \mathrm{dpi}$ we see a downward shift in the position in the PCA upon spider mite infestation. 


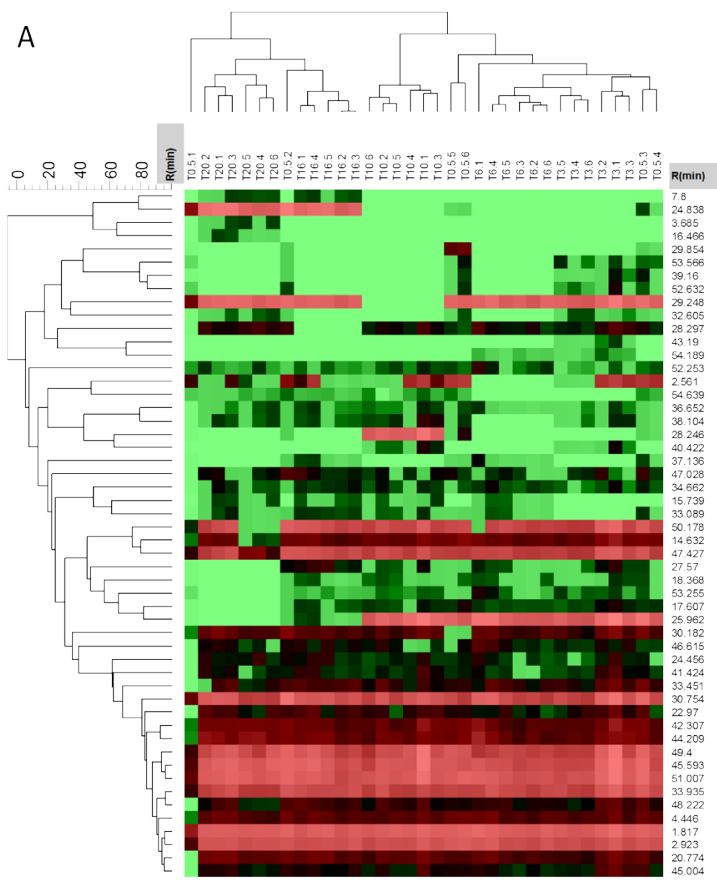

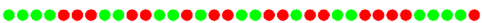

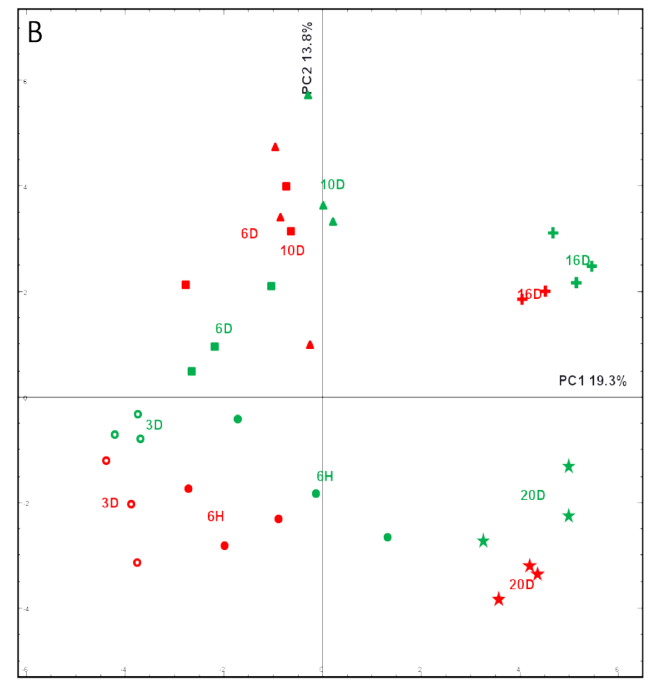

C

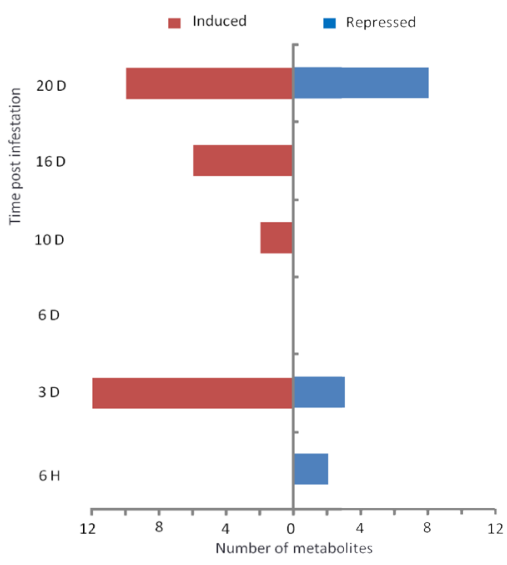

Figure 2. A. Hierarchical clustering analysis (HCA) of metabolome data of Capsicum leaves during $\mathbf{2 0}$ days post infestation detected by LC-MS platform. Green and red dots represent control and infested plants respectively; T0.5 represent samples of 6 hours post infestation (hpi), T3, 6, 10, 16, 20 represent samples of 3, 6, 10, 16, 20 days post infestation (dpi). B. Principal component analysis (PCA) based on the same dataset. PC1 explains $19.3 \%$ and PC2 explains $13.8 \%$ of the total variation. Green and red represent control and infested plants respectively, closed circles represent data points for $6 \mathrm{hpi}$, open circles, squares, triangles, crosses, stars represent 3, 6, 10, 16, 20 dpi respectively. Centralities of three rep- 
licates were labeled as 6H, 3D, 6D, 10D, 16D, 20D; C. Number of endogenous metabolites that were significantly induced or repressed (T-test $\mathrm{P}<0.05$, |Fold change $\mid(\mathrm{FC})>1.5$ ) upon spider mite infestation in each time point compared with control plants of similar developmental stage.

Using Student's T-test to compare the metabolite profiles of spider-mite infested leaves with those of non-infested leaves of the same age, we found that spider mites significantly induced $12,2,6$ and 10 metabolites $(P<0.05$, $\mid$ Fold change $\mid>1.5$ ) at 3, 10, 16 and $20 \mathrm{dpi}$, respectively while 2, 3 and 9 metabolites were repressed by spider mites at $6 \mathrm{~h}$, and 3 and $20 \mathrm{dpi}$, respectively (Figure 2C).

Six hours after the onset of infestation no semi-polar metabolites were found to be increased while 2 putative triterpenoid compounds were found to be decreased by spider mites (Table 1). Three days later, when spider mites had been clearly feeding as chlorotic spots became visible, we found more compounds significantly altered, among which several triterpene glycosides, flavonoids and an alkaloid that were found to be 9- to 27-fold induced upon mite feeding, while a carotenoid and two diterpenes were found to be 2 - to 4-fold decreased three days after onset of infestation.

No metabolites were found to be significantly different in spider-mite infested plants from those in non-infested plants on day 6 . The observed number of spider mites suggests that the initially introduced spider mite adults disappeared, likely as a result of death and hence little feeding activity occurred until $6 \mathrm{dpi}$, which probably resulted in very small metabolic changes. New population build-up started with the emergence of nymphs from the first deposited eggs and the damage inflicted by the feeding of the nymphs coincides with the increase of a putative alkaloid and a diterpene glycoside on $10 \mathrm{dpi}$ and six different compounds on $16 \mathrm{dpi}$. While the total number of individual spider mites counted on day 20 decreased, the number of significantly altered compounds increased, including 10 that were present in higher concentrations and 9 that decreased. Interestingly, members of similar biochemical classes of compounds, such as putative diterpene glycosides and triterpene glycosides showed different responses during the time of infestation. For example, a Capsianoside III like compound (diterpene glycoside) decreased $3 \mathrm{dpi}$, while other putative diterpene glycosides increased 10 and $16 \mathrm{dpi}$ (Table 1). It suggests that the biosynthesis and catabolism of metabolites belonging to a similar biochemical group are not necessarily regulated similar in response to a given biotic stress. 
Table 1. Spider-mite induced and repressed endogenous metabolites during 20 days post infestation in Capsicum annuum G29 as detected by LC-MS platform (T-test $p<0.05$ ).

\begin{tabular}{|c|c|c|c|c|c|c|}
\hline Time & $\begin{array}{l}\text { Biochemical } \\
\text { class }\end{array}$ & $\begin{array}{l}\text { TSSM/ } \\
\text { CON }\end{array}$ & KEGG ID & Putative Metabolite & Formula & $\begin{array}{c}\text { MW } \\
\text { (Dalton) }\end{array}$ \\
\hline \multirow[t]{2}{*}{$6 \mathrm{hpi}$} & $\begin{array}{l}\text { Triterpene } \\
\text { saponin }\end{array}$ & 0.17 & C00041305 & Acanthopanaxoside B & $\mathrm{C} 61 \mathrm{H} 98 \mathrm{O} 27$ & 1262.29 \\
\hline & - & 0.03 & C00042667 & Lanceolitol A7 & $\mathrm{C} 31 \mathrm{H} 58011$ & 606.38 \\
\hline \multirow{15}{*}{$3 d p i$} & Flavonoids & 27.39 & - & $\begin{array}{l}\text { 6,8-Dihexosyl-4',5-dihy- } \\
\text { droxy-7-methoxyflavone }\end{array}$ & $\mathrm{C} 28 \mathrm{H} 30 \mathrm{O} 15$ & 606.15 \\
\hline & - & 22.56 & C00006177 & Schaftoside & $\mathrm{C} 26 \mathrm{H} 28 \mathrm{O} 14$ & 565.15 \\
\hline & - & 21.45 & C00047170 & Amaroxocane A & C5H88017S3 & 1116.52 \\
\hline & $\begin{array}{l}\text { Triterpene } \\
\text { glycoside }\end{array}$ & 21.00 & C00032813 & Chiisanoside & $\mathrm{C} 48 \mathrm{H} 74 \mathrm{O} 19$ & 954.46 \\
\hline & - & 17.58 & - & $\begin{array}{c}\text { 3,4',5,7-Tetrahy- } \\
\text { droxy-3',5'-dimethoxyfla- } \\
\text { vylium }\end{array}$ & С39H41O19(+) & 812.21 \\
\hline & $\begin{array}{l}\text { Triterpene } \\
\text { saponin }\end{array}$ & 16.54 & C00037718 & Randiasaponin I & $\mathrm{C} 41 \mathrm{H} 61014$ & 777.42 \\
\hline & $\begin{array}{l}\text { Steroid } \\
\text { Glycoside }\end{array}$ & 16.46 & C00046181 & Namonin A & C57H84O26 & 1184.51 \\
\hline & - & 15.00 & C00033109 & Latifoloside K & $\mathrm{C} 53 \mathrm{H} 84 \mathrm{O} 21$ & 1056.52 \\
\hline & Triterpene & 11.27 & C00032813 & Chiisanoside & $\mathrm{C} 48 \mathrm{H} 74 \mathrm{O} 19$ & 954.46 \\
\hline & $\begin{array}{l}\text { Iso- } \\
\text { prenoid-de- } \\
\text { rived Lac- } \\
\text { tone }\end{array}$ & 9.87 & - & Tylosin B & C47H73NO18 & 939.47 \\
\hline & - & 9.64 & - & $\begin{array}{c}\text { Glaudelsine; O6-Me, N-de- } \\
\text { Et, N-formyl }\end{array}$ & C36H46N2O11 & 682.30 \\
\hline & $\begin{array}{l}\text { Triterpene } \\
\text { glycoside }\end{array}$ & 9.13 & C00039704 & Maesasaponin IV3 & $\mathrm{C} 62 \mathrm{H} 98 \mathrm{O} 28$ & 1290.59 \\
\hline & Carotenoid & 0.58 & C00000913 & Phytofluene & $\mathrm{C} 40 \mathrm{H} 62$ & 542.29 \\
\hline & $\begin{array}{l}\text { Nor-diter- } \\
\text { penoid }\end{array}$ & 0.44 & C00028627 & mycalolide B & C52H74N4O17 & 1026.47 \\
\hline & $\begin{array}{l}\text { Diterpene } \\
\text { glycoside }\end{array}$ & 0.23 & C00029908 & Capsianoside III & $\mathrm{C} 50 \mathrm{H} 84 \mathrm{O} 26$ & 1100.51 \\
\hline \multirow{3}{*}{$\begin{array}{l}10 \\
\text { dpi }\end{array}$} & Alkaloids & 1.71 & C00039920 & Pahayokoide A & $\begin{array}{c}\mathrm{C} 72 \mathrm{H}- \\
105 \mathrm{~N} 13 \mathrm{O} 20\end{array}$ & 1471.74 \\
\hline & $\begin{array}{l}\text { Nucleo- } \\
\text { tide-glyco- } \\
\text { side }\end{array}$ & 1.70 & C00001514 & UDP-D-glucose & $\begin{array}{c}\mathrm{C} 15 \mathrm{H}- \\
\text { 24N2O17P2 }\end{array}$ & 566.05 \\
\hline & $\begin{array}{l}\text { Diterpene } \\
\text { glycoside }\end{array}$ & 1.12 & C000XXXX & Capsianoside II & $\mathrm{C} 50 \mathrm{H} 84 \mathrm{O} 25$ & 1085.19 \\
\hline
\end{tabular}




\begin{tabular}{|c|c|c|c|c|c|c|}
\hline \multirow{7}{*}{$\begin{array}{l}16 \\
d p i\end{array}$} & $\begin{array}{l}\text { Diterpene } \\
\text { glycoside }\end{array}$ & 3.21 & C000XXXX & Capsianoside D & $\mathrm{C} 82 \mathrm{H} 134038$ & 1727.92 \\
\hline & Triterpene & 2.38 & C00040895 & Beciumecine 2 & $\mathrm{C} 63 \mathrm{H} 102 \mathrm{O} 31$ & 1354.27 \\
\hline & Flavonoid & 2.37 & C00005548 & $\begin{array}{l}\text { Isorhamnetin 3-O-rutino- } \\
\text { side }\end{array}$ & $\mathrm{C} 28 \mathrm{H} 32 \mathrm{O} 16$ & 625.17 \\
\hline & - & 2.19 & - & Unknown & - & - \\
\hline & - & 2.11 & C00046181 & Namonin A & $\mathrm{C} 57 \mathrm{H} 84 \mathrm{O} 26$ & 1184.51 \\
\hline & - & 1.93 & - & Unknown & - & - \\
\hline & Amino acid & 1.86 & C00043378 & Cervinin & $\mathrm{C} 56 \mathrm{H} 82$ & 1187.62 \\
\hline \multirow{18}{*}{20} & Terpenoid & 40.25 & C00034899 & Swietephragmin C & $\mathrm{C} 37 \mathrm{H} 46 \mathrm{O} 12$ & 682.30 \\
\hline & - & 25.72 & - & Unknown & - & - \\
\hline & Flavonoid & 14.97 & C00008139 & $\begin{array}{l}\text { Pinocembrin 7-O-ne- } \\
\text { opesperidoside 2"'"-o-ac- } \\
\text { etate }\end{array}$ & $\mathrm{C} 29 \mathrm{H} 34 \mathrm{O} 14$ & 606.19 \\
\hline & Terpenoid & 13.75 & C00049771 & $16,23,24$-Triketomelianin B & $\mathrm{C} 41 \mathrm{H} 52 \mathrm{O} 10$ & 704.34 \\
\hline & $\begin{array}{l}\text { Phenolic } \\
\text { compound }\end{array}$ & 7.15 & - & $\begin{array}{l}\text { 2,3,6-Trigalloylglucose; } \\
\text { ?-D-Pyranose-form, Me } \\
\text { glycoside }\end{array}$ & $\mathrm{C} 28 \mathrm{H} 26 \mathrm{O} 18$ & 650.10 \\
\hline & Flavonoid & 6.36 & C00009370 & Mongolicain A & $\mathrm{C} 62 \mathrm{H} 46 \mathrm{O} 37$ & 1382.30 \\
\hline & Flavonoid & 4.01 & C00009220 & $\begin{array}{c}\text { [3-O-Galloylepicate- } \\
\text { chin-(4beta->6)]2-epicate- } \\
\text { chin-3-gallate }\end{array}$ & $\mathrm{C} 66 \mathrm{H} 50030$ & 1323.28 \\
\hline & $\begin{array}{l}\text { Steroid } \\
\text { Glycoside }\end{array}$ & 2.97 & C00033179 & Marstomentoside Q & $\mathrm{C} 71 \mathrm{H} 108 \mathrm{O} 27$ & 1392.66 \\
\hline & Alkaloid & 2.56 & C00039920 & Pahayokoide A & $\begin{array}{c}\mathrm{C} 72 \mathrm{H}- \\
105 \mathrm{~N} 13 \mathrm{O} 20\end{array}$ & 1471.74 \\
\hline & $\begin{array}{l}\text { Phenolic } \\
\text { compound }\end{array}$ & 2.49 & - & Thonningianin B & С35H30O17 & 722.07 \\
\hline & Amino acid & 0.19 & C00043378 & Cervinin & $\mathrm{C} 56 \mathrm{H} 82$ & 1187.62 \\
\hline & $\begin{array}{l}\text { Carbohy- } \\
\text { drate }\end{array}$ & 0.16 & C00046875 & Reiniose A & $\mathrm{C} 34 \mathrm{H} 42 \mathrm{O} 18$ & 739.23 \\
\hline & Steroid & 0.14 & C00038796 & Clathsterol & C38H66O15S2 & 826.36 \\
\hline & $\begin{array}{l}\text { Carbohy- } \\
\text { drate }\end{array}$ & 0.12 & C00018529 & Trestatin A & C56H94N2O40 & 1434.74 \\
\hline & $\begin{array}{l}\text { Steroid } \\
\text { glycoside }\end{array}$ & 0.12 & C00033179 & Marstomentoside $\mathrm{Q}$ & $\mathrm{C} 71 \mathrm{H} 108 \mathrm{O} 27$ & 1392.66 \\
\hline & Alkaloid & 0.11 & C00001654 & Mesaconitine & $\mathrm{C} 33 \mathrm{H} 45 \mathrm{NO} 11$ & 630.93 \\
\hline & Flavonoid & 0.07 & C00006039 & $\begin{array}{c}\text { Myrice- } \\
\text { tin 3-(6"-galloylgalactoside }\end{array}$ & $\mathrm{C} 28 \mathrm{H} 24 \mathrm{O} 17$ & 632.13 \\
\hline & Amino acid & 0.03 & - & Destruxin A3 & $\mathrm{C} 29 \mathrm{H} 47 \mathrm{~N} 507$ & 565.33 \\
\hline
\end{tabular}

There was little overlap in the metabolite profiles of leaves between different time points during plant development which suggests high dynamics in metabolite profiles during leaf development. The increase in the size of 
the spider mite population seems to precede the increase in the metabolic differences between control and spider-mite infested plants, as the largest number of metabolites found to be altered ( 3 and $20 \mathrm{dpi}$ ) was found consecutively the time points at which the highest numbers of mites were present ( $6 \mathrm{hpi}, 16 \mathrm{dpi})$. Although plants used for assessment of mite performance were all in vegetative stage, leaves used for leaf disc experiments and metabolome analysis were taken from different ontogenic positions and combined. Possibly, this had a quenching effect on the analysis of the magnitude of metabolome adaptation and/or mite performance. Future experiments could take this into account using leaves from a similar ontogenic position.

\section{Predatory mite attractiveness}

To gain insight if and how the indirect defense level alters upon spider-mite infestation in Capsicum plants, the attractiveness of plants towards predatory mites was analyzed at three different time points after spider mite infestation. As attractiveness is a relative trait, it was determined relative to the attractiveness of 5-day spider-mite infested $C$. chachoense plants (Genotype 25$)$.

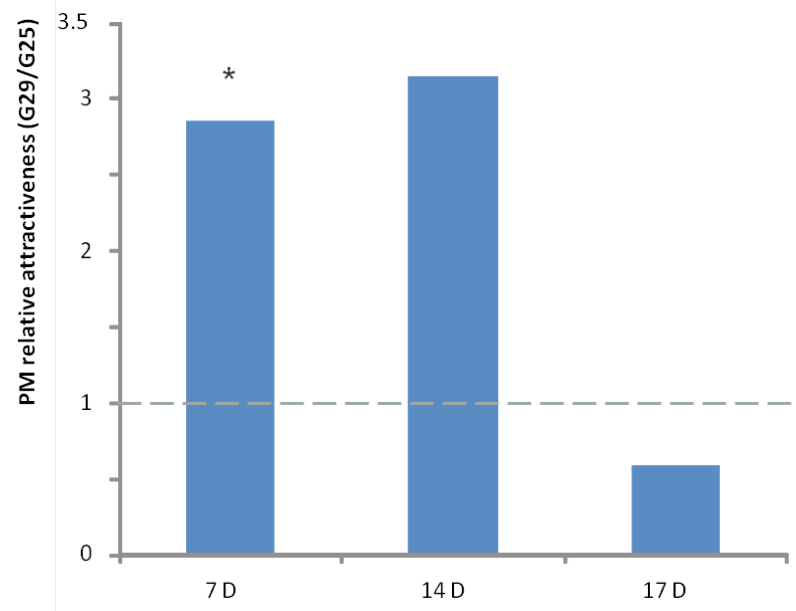

Figure 3. Relative attractiveness of Capsicum annuum G29 plants towards predatory mites (PM) at 7, 14, 17 dpi with two-spotted spider mites relative to 5-day spider-mite infested plants of Capsicum annuum $\mathbf{G 2 5}, \mathbf{N}=\mathbf{3}$. The dotted line indicates where predatory mites do not show preference for either odour source. 
Relative to reference $\mathrm{G} 25$, spider mite-infested $\mathrm{G} 29$ plants were significantly more attractive to predatory mites at $7 \mathrm{dpi}$ (Figure 3, Sup Table 7). With progressing infestation during the experiment the relative attractiveness of G29 plants decreased. While at $14 \mathrm{dpi} \mathrm{G29}$ plants were still more attractive, although not significant anymore, at $17 \mathrm{dpi}, \mathrm{G} 29$ plants attracted clearly less predatory mites than $\mathrm{G} 25$ plants.

\section{Spider-mite induced volatile metabolites in $\mathbf{6 2 9}$}

According to HCA of the volatile metabolites emitted from spider-mite infested and non-infested plants, those from later stages of infestation did not cluster together or separate from earlier stages, in contrast to the HCA pattern based on endogenous metabolites (Figure 4A, Sup Table 8). A PCA based on the same data suggests that both aging of the leaves and spider-mite infestation resulted in alteration of the volatile metabolome (Figure $4 \mathrm{~B})$. Along the first PC ( $12.5 \%$ of total variation), there were metabolite changes between $6 \mathrm{~h}, 3 \mathrm{dpi}$ and $6 \mathrm{dpi}$, but not between $6 \mathrm{~h}$ and $20 \mathrm{dpi}$, or between 3 and 10, $16 \mathrm{dpi}$. Along the second PC (9.4\% of total variation), there was little change between $6 \mathrm{~h}$ and $3 \mathrm{dpi}$, as well as between 6,10 and $20 \mathrm{dpi}$. The metabolic variation between non-infested and spider-mites infested plants occurs along both PC1 and PC2. PLS-DA analysis using infestation as discriminant showed separation of the volatile blends of non-infested plants from those infested with spider mites (Figure 4C) of which several metabolites were suggested to contribute for the separation. Among them, the homoterpene $(3 E, 7 E)-4,8,12$-trimethyltrideca-1,3,7,11-tetraene (TMTT) was identified as the compound most responsible for this separation and it was LOG2 $(2,84)$ higher present in the volatile blend of mite-infested plants in general.

The comparison between volatile metabolites emitted by non-treated control and spider-mite infested plants showed that 57, 12, 13, 13, 9 and 12 metabolite features significantly changed upon spider mite infestation at $6 \mathrm{hpi}$, $3,6,10,16$, and 20 dpi respectively (Figure 4D). Multiple terpenoids, and green leaf volatiles were either induced or repressed (Table 2 ). The fact that the highest number of volatiles, including (Z)- $\beta$--ocimene and linalool, was altered in the first 6 hours after infestation is probably due to the handling of plants as mechanical damage also results in the production of green leaf volatiles and volatile terpenes (Piesik et al., 2010). The number of volatile metabolites did indeed decrease within the first 3 days of infestation and less volatiles were found increased at later stages of infestation; especially 20 days after infestation, most volatiles were repressed. This could explain the decreased attractiveness of plants at $20 \mathrm{dpi}$ to predatory mites. 
A
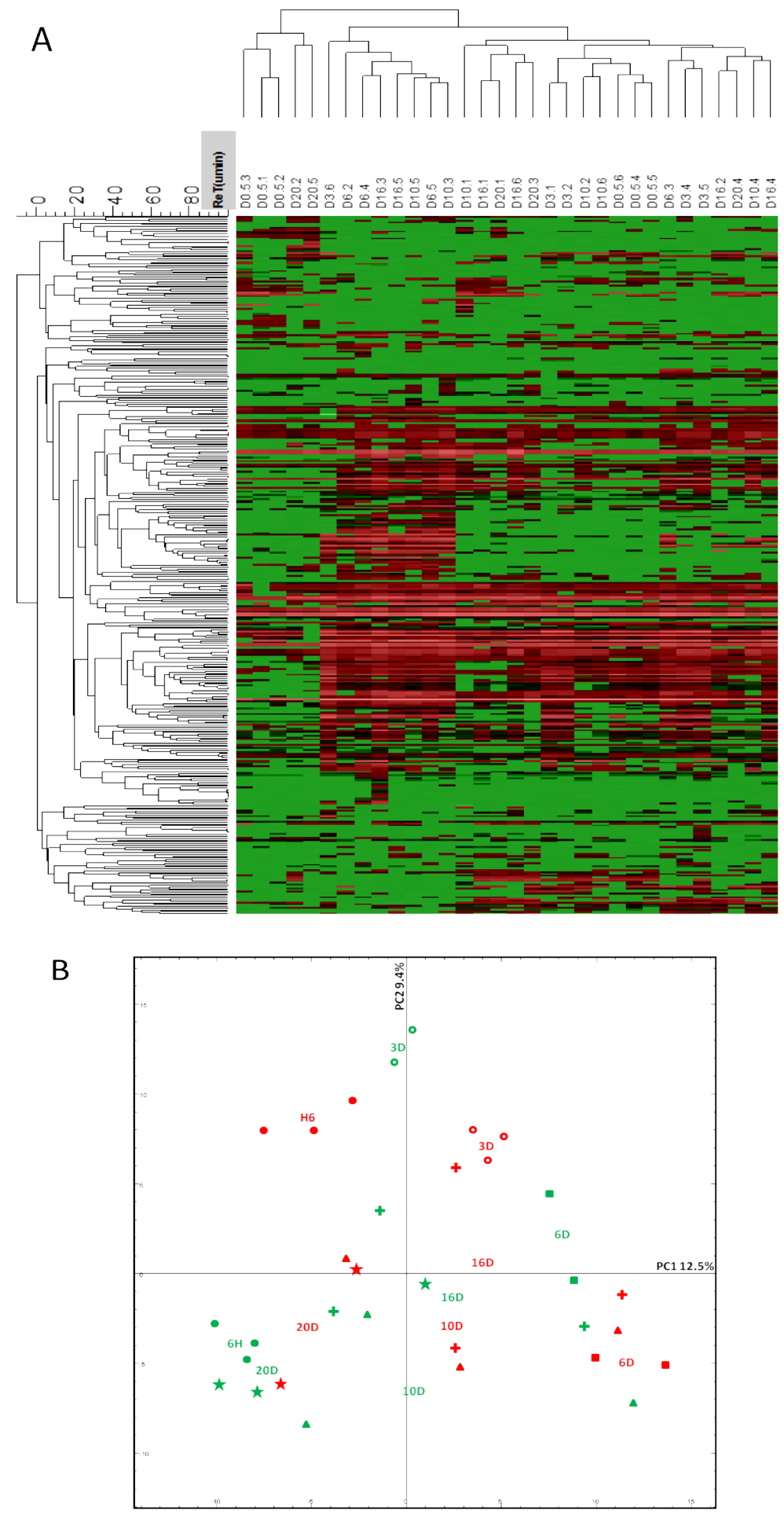


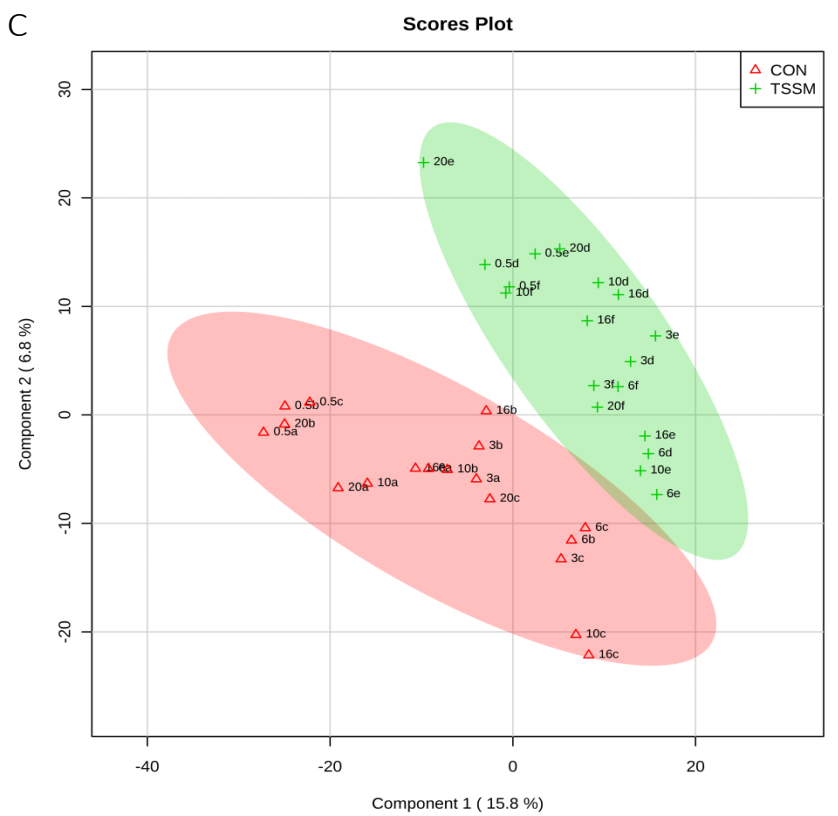

D

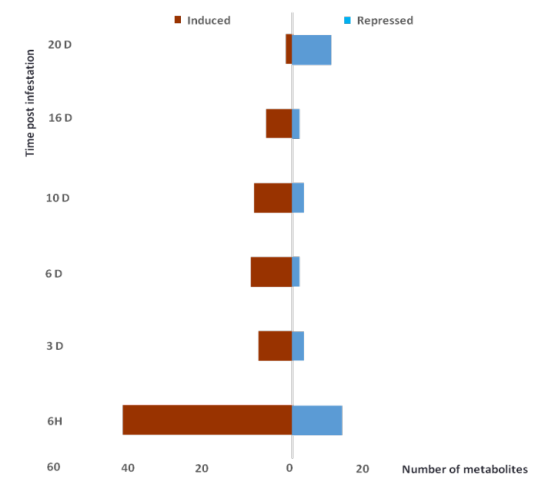


Figure 4. A. Hierarchical Clustering Analysis (HCA) of the volatile metabolome of Capsicum annuum G29 leaves during different time post infestation with two spotted spider mites as detected by GC-MS platform; B. Principal Component Analysis (PCA). PC1 explained 12.5\%; PC2 explained $9.4 \%$ of the total variation; Green and red represent non-infested control and spider-mite infested plants respectively; Closed circles represent 6 hpi, open circles, squares, triangles, crosses, stars represent 3, 6, 10, 16, 20 dpi respectively. Centralities of three replicates were labeled as 6H, 3D, 6D, 10D, 16D, 20D; C. Partial Least Square Discrimination Analysis (PLS-DA) Red triangles represent control plants, $\mathrm{N}=3$, replicates were described by $a, b, c$; Green crosses represent spider-mite infested plants. $N=3$, replicates were described by d, e, f; D. Number of volatile metabolites that were significantly induced or repressed (T-test $P<0.05,|F C|>1.5)$ upon TSSM infestation in each time point compared with control plants of similar developmental stage.

Table 2. Spider-mite induced and repressed volatile metabolites in genotype 29 during different days post infestation detected by GC-MS platform (T-test $\mathrm{P}<0.05,|\mathrm{FC}|>1.5$ ) 


\begin{tabular}{|c|c|c|c|c|c|c|}
\hline Time & $\operatorname{Ret}(\min )$ & Metabolite & Formula & MW & CAS & TSSM /CON \\
\hline \multirow{22}{*}{$6 h p i$} & 5.28 & Oxanamide & $\mathrm{C} 8 \mathrm{H} 15 \mathrm{NO} 2$ & 157 & $126-93-2$ & 6.61 \\
\hline & 8.78 & Trimethybenzene & $\mathrm{C} 9 \mathrm{H} 12$ & 120 & $108-67-8$ & 604.61 \\
\hline & 8.90 & $\begin{array}{l}\text { 7,7-Dimethylnor- } \\
\text { bornadiene }\end{array}$ & $\mathrm{C} 9 \mathrm{H} 12$ & 120 & $68757-94-8$ & 230.92 \\
\hline & 9.11 & $\begin{array}{l}\text { 1,3,5-Trimethy } \\
\text { Benzene }\end{array}$ & $\mathrm{C} 9 \mathrm{H} 12$ & 120 & $108-67-8$ & 15.40 \\
\hline & 9.30 & $\begin{array}{c}\text { 6-methyl-5-Hepten- } \\
\text { 2-one }\end{array}$ & $\mathrm{C} 8 \mathrm{H} 140$ & 126 & $110-93-0$ & 2.48 \\
\hline & 9.36 & $\begin{array}{l}\text { 1,3,5-Trimethyben- } \\
\text { zene }\end{array}$ & $\mathrm{C} 9 \mathrm{H} 12$ & 120 & $108-67-8$ & 36.82 \\
\hline & 9.51 & $\begin{array}{l}\text { cis-3-hexenyl ace- } \\
\text { tate }\end{array}$ & $\mathrm{C} 8 \mathrm{H} 14 \mathrm{O} 2$ & 142 & $3681-71-8$ & 261.60 \\
\hline & 9.87 & $\begin{array}{c}\text { 1-meth- } \\
\text { yl-4-(1-methyle- } \\
\text { thenyl)-Cyclohexene }\end{array}$ & $\mathrm{C} 10 \mathrm{H} 16$ & 136 & $138-86-3$ & 5.36 \\
\hline & 10.10 & Unknown & - & - & - & 4.02 \\
\hline & 10.12 & 2-ethyl hexanol & $\mathrm{C} 8 \mathrm{H} 18 \mathrm{O}$ & 130 & $104-76-7$ & 448.47 \\
\hline & 10.29 & $(E)$ - $\beta$-Ocimene & $\mathrm{C} 10 \mathrm{H} 16$ & 136 & $3779-61-1$ & 3.26 \\
\hline & 10.48 & $\alpha$-Pinene & $\mathrm{C} 10 \mathrm{H} 16$ & 136 & $127-91-3$ & 51.89 \\
\hline & 11.31 & Linalool & $\mathrm{C} 10 \mathrm{H} 18 \mathrm{O}$ & 154 & $78-70-6$ & 516.40 \\
\hline & 11.33 & Unknown & - & - & - & 1116.41 \\
\hline & 11.41 & $\begin{array}{c}\text { (E)-4,8-Dimethyl- } \\
\text { 1,3,7-nonatriene } \\
\text { (DMNT) }\end{array}$ & $\mathrm{C} 11 \mathrm{H} 18$ & 150 & $21214-62-0$ & 7.14 \\
\hline & 12.67 & p-Menthane & $\mathrm{C} 10 \mathrm{H} 16 \mathrm{O} 2$ & 168 & $96-08-2$ & 247.94 \\
\hline & 17.55 & $\begin{array}{l}\text { Nerolidol-epoxyac- } \\
\text { etate }\end{array}$ & $\mathrm{C} 17 \mathrm{H} 28 \mathrm{O} 4$ & 296 & NA & 258.42 \\
\hline & 17.77 & $\begin{array}{c}(E, E)-4,8,12- \\
\text { trimethyl- } \\
1,3(E), 7(E), 11-T r i- \\
\text { decatetraene } \\
(\mathrm{TMTT})\end{array}$ & $\mathrm{C} 16 \mathrm{H} 26$ & 218 & NA & 3.84 \\
\hline & 9.51 & $\begin{array}{l}\text { cis-3-Hexenyl ac- } \\
\text { etate }\end{array}$ & $\mathrm{C} 8 \mathrm{H} 14 \mathrm{O} 2$ & 142 & $3681-71-8$ & 0.01 \\
\hline & 11.03 & $\begin{array}{c}\text { Methyl } 12,15-O c t a- \\
\text { decadiynote }\end{array}$ & С19H30O2 & 290 & 57156-95-3 & 0.18 \\
\hline & 11.48 & $\begin{array}{l}\text { 1,1-Dimethyl-3-me- } \\
\text { thylidene-2-vinylcy- } \\
\text { clohexane }\end{array}$ & $\mathrm{C} 11 \mathrm{H} 18$ & 150 & $95452-08-7$ & 0.03 \\
\hline & 15.54 & $\begin{array}{l}\text { 1-Chloro octade- } \\
\text { cane }\end{array}$ & $\mathrm{C} 18 \mathrm{H} 37 \mathrm{Cl}$ & 288 & $3386-33-2$ & 0.01 \\
\hline
\end{tabular}




\begin{tabular}{|c|c|c|c|c|c|c|}
\hline \multirow{4}{*}{$3 d p i$} & 14.37 & 9-Octadecenoic acid & $\mathrm{C} 18 \mathrm{H} 34 \mathrm{O} 2$ & 282 & $112-80-1$ & 94.76 \\
\hline & 19.39 & Unknown & - & - & - & 76.10 \\
\hline & 11.08 & $\begin{array}{l}\text { 6-Methyl octade- } \\
\text { cane }\end{array}$ & $\mathrm{C} 19 \mathrm{H} 40$ & 268 & $10544-96-4$ & 5.01 \\
\hline & 16.84 & $\begin{array}{l}\text { 5a-Cholestan-3a-ol, } \\
\text { 2-methylene- }\end{array}$ & $\mathrm{C} 28 \mathrm{H} 48 \mathrm{O}$ & 400 & 22599-96-8 & 0.24 \\
\hline \multirow[b]{2}{*}{$6 \mathrm{dpi}$} & 28.97 & n-Dotriacontane & $\mathrm{C} 32 \mathrm{H} 66$ & 450 & $544-85-4$ & 3.74 \\
\hline & 16.84 & $\begin{array}{c}\text { 5a-Choles- } \\
\text { tan-3a-ol,2-meth- } \\
\text { ylene }\end{array}$ & $\mathrm{C} 28 \mathrm{H} 48 \mathrm{O}$ & 400 & 22599-96-8 & 0.02 \\
\hline \multirow{4}{*}{ 10dpi } & 10.10 & (Z)- $\beta$-Ocimene & $\mathrm{C} 10 \mathrm{H} 16$ & 136 & $10 / 8 / 6874$ & 6.59 \\
\hline & 13.13 & Limonene dioxide 4 & $\mathrm{C} 10 \mathrm{H} 16 \mathrm{O} 2$ & 168 & NA & 170.40 \\
\hline & 19.14 & Unknown & - & - & - & 105.71 \\
\hline & 21.65 & $\begin{array}{c}\text { Tetracyclopropane } \\
\text { derivative of methyl } \\
\text { arachidonate }\end{array}$ & $\mathrm{C} 25 \mathrm{H} 42 \mathrm{O} 2$ & 374 & 56051-53-7 & 287.23 \\
\hline \multirow{4}{*}{ 16hpi } & 8.78 & Trimethylbenzene & $\mathrm{C} 9 \mathrm{H} 12$ & 120 & $108-67-8$ & 5.68 \\
\hline & 12.06 & Unknown & - & - & - & 108.29 \\
\hline & 14.37 & 9-Octadecenoic acid & $\mathrm{C} 18 \mathrm{H} 34 \mathrm{O} 2$ & 282 & $112-80-1$ & 165.38 \\
\hline & 17.55 & $\begin{array}{l}\text { Nerolidol-epoxyac- } \\
\text { etate }\end{array}$ & $\mathrm{C} 17 \mathrm{H} 28 \mathrm{O} 4$ & 296 & NA & 111.09 \\
\hline \multirow{7}{*}{$20 \mathrm{hpi}$} & 5.28 & Oxanamide & $\mathrm{C} 8 \mathrm{H} 15 \mathrm{NO} 2$ & 157 & $126-93-2$ & 6.61 \\
\hline & 7.19 & $\begin{array}{l}\text { 4-Penten-1-ol, } \\
\text { 3-methyl- }\end{array}$ & $\mathrm{C} 6 \mathrm{H} 12 \mathrm{O}$ & 100 & $51174-44-8$ & 0.01 \\
\hline & 10.12 & 2 ethyl hexanol & $\mathrm{C} 8 \mathrm{H} 180$ & 130 & $104-76-7$ & 0.00 \\
\hline & 10.73 & trans-2-Nonenol & $\mathrm{C} 9 \mathrm{H} 180$ & 142 & $31502-14-4$ & 0.00 \\
\hline & 11.31 & Linalool & $\mathrm{C} 10 \mathrm{H} 180$ & 154 & $78-70-6$ & 0.00 \\
\hline & 11.34 & Unknown & - & - & - & 0.00 \\
\hline & 12.41 & 2-Decen-1-ol,(Z) & $\mathrm{C} 10 \mathrm{H} 20 \mathrm{O}$ & 156 & - & 0.00 \\
\hline
\end{tabular}

\section{Plant defense related phytohormones in genotype 29}

Phytohormones mediate the downstream signaling after perception of herbivore-specific signals during herbivore attack. We analyzed the dynamics of phytohormone levels (Figure 5) and transcripts of genes involved in their biosynthesis or signaling (Figure 6) as result of spider-mite infestation. 

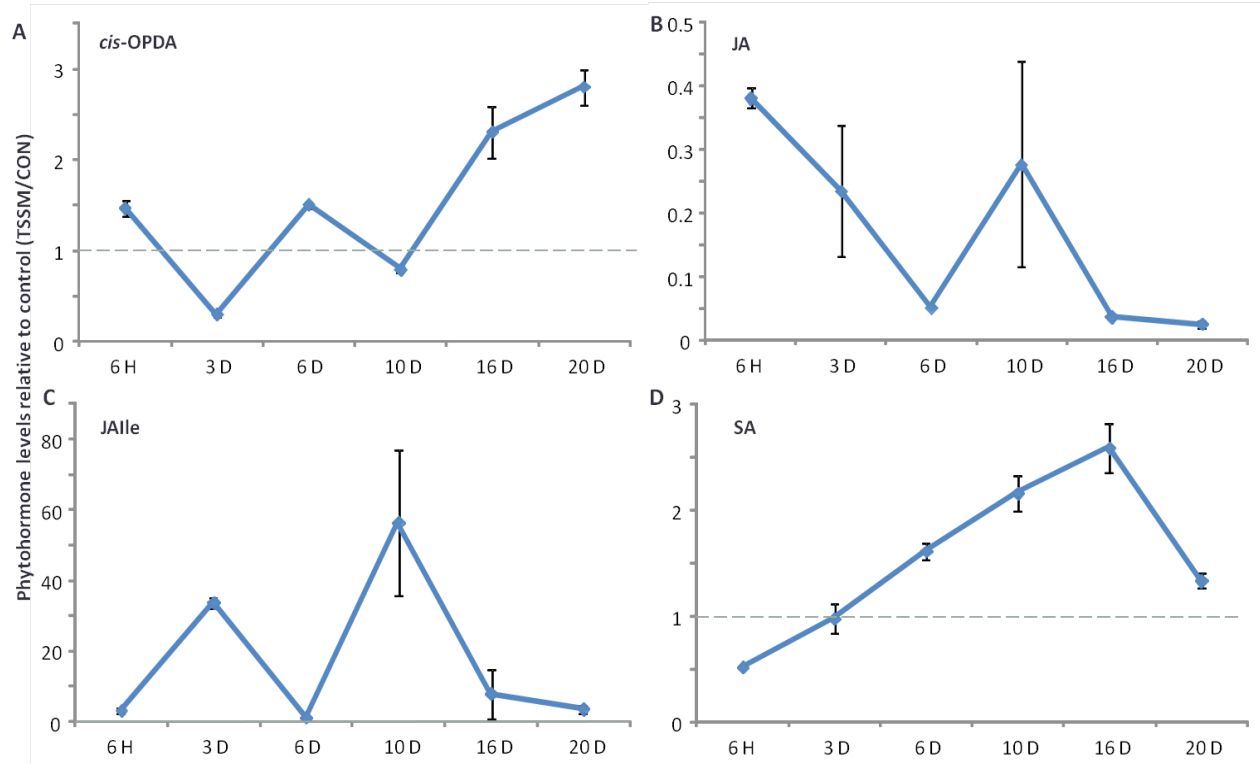

Figure 5. Fold change (FC) differences in defensive phytohormones detected in spider-mite infested plants (TSSM) compared with non-infested control plants (CON) of Capsicum annuum $\mathbf{G 2 9}$ at 6 hours, and 3, 6, 10, 16, 20 days post infestation (dpi). A, FC of cis-OPDA; B, FC of JA; C, FC of JA-Ile; D, FC of SA. Error bars represent the mean \pm SE of $N=3$ biological replicates.

Lipoxygenases (LOXs) catalyze the oxygenation of fatty acids and thus provide the substrate for cis-OPDA biosynthesis (Mueller, 1997). In Arabidopsis, cis-OPDA is transformed into jasmonic acid (JA) through one step of reduction catalyzed by OPDA reductase (OPR3) (Biesgen and Weiler, 1999) and three steps of $\beta$-oxidation (Turner et al., 2002), catalyzed by three core enzymes, namely ACYL-COA OXIDASE (ACX) (comprising ENOYL-COA HYDRATASE and $\beta$-HYDROXY-ACYL-COA DEHYDROGENASE) and 3-KETOACYL-COA-THIOLASE (Wasternack and Hause, 2013). An increase in cis-OPDA level upon spider-mite infestation relative to non-infested leaves was detected as early as 6 hours after introduction of mites, and subsequently dropped below the level in control plants at $3 \mathrm{dpi}$. Thereafter, the amount of cis-OPDA in infested leaves steadily increased relative to the amount in non-infested leaves with a transient dip at $10 \mathrm{dpi}$ (Figure 5A). LOX2 expression in infested leaves was repressed at the beginning of the infestation ( $6 \mathrm{hrs}$ ) but increased at 3 , 10 and $16 \mathrm{dpi}$ when compared with the levels in non-infested leaves (Figure 6A). As evidenced by the production of cis-OPDA and expression of LOX2, the JA biosynthetic pathway was induced by spider mites at least at 3 and 16 dpi, corresponding with the moments that most feeding mites, i.e. nymphs and adults, were present on the leaves (Figure 1). Remarkably, the amount of JA in infested plants was lower than that in control plants (Figure 5B) 
although, with the exception of $6 \mathrm{~h}$, it still mirrors the pattern of JA-lle. The absolute amounts of JA were highest in young non-infested plants (1097.75 $\mathrm{pmol} / \mathrm{g}$ D.W. dry weight at $6 \mathrm{hpi}$ and decreased to $863.04 \mathrm{pmol} / \mathrm{g}$ D.W. at 20 dpi. Also in soybean plants, JA levels were highest in young leaves (Creelman \& Mullet, 1995). JA is conjugated to isoleucine to form JA-lle by JASMONATE RESISTANT 1 (JAR1) in Arabidopsis and JAR4 in Solanum nigrum (Staswick and Tiryaki, 2004, VanDoorn et al., 2011). It is counter-intuitive that JA seems to be repressed by spider mite infestation. However, if the conversion from JA to JA-lle is increased by spider mites (more than that of OPDA to JA), more active JA-lle can be produced, while the concentration of JA is lower.
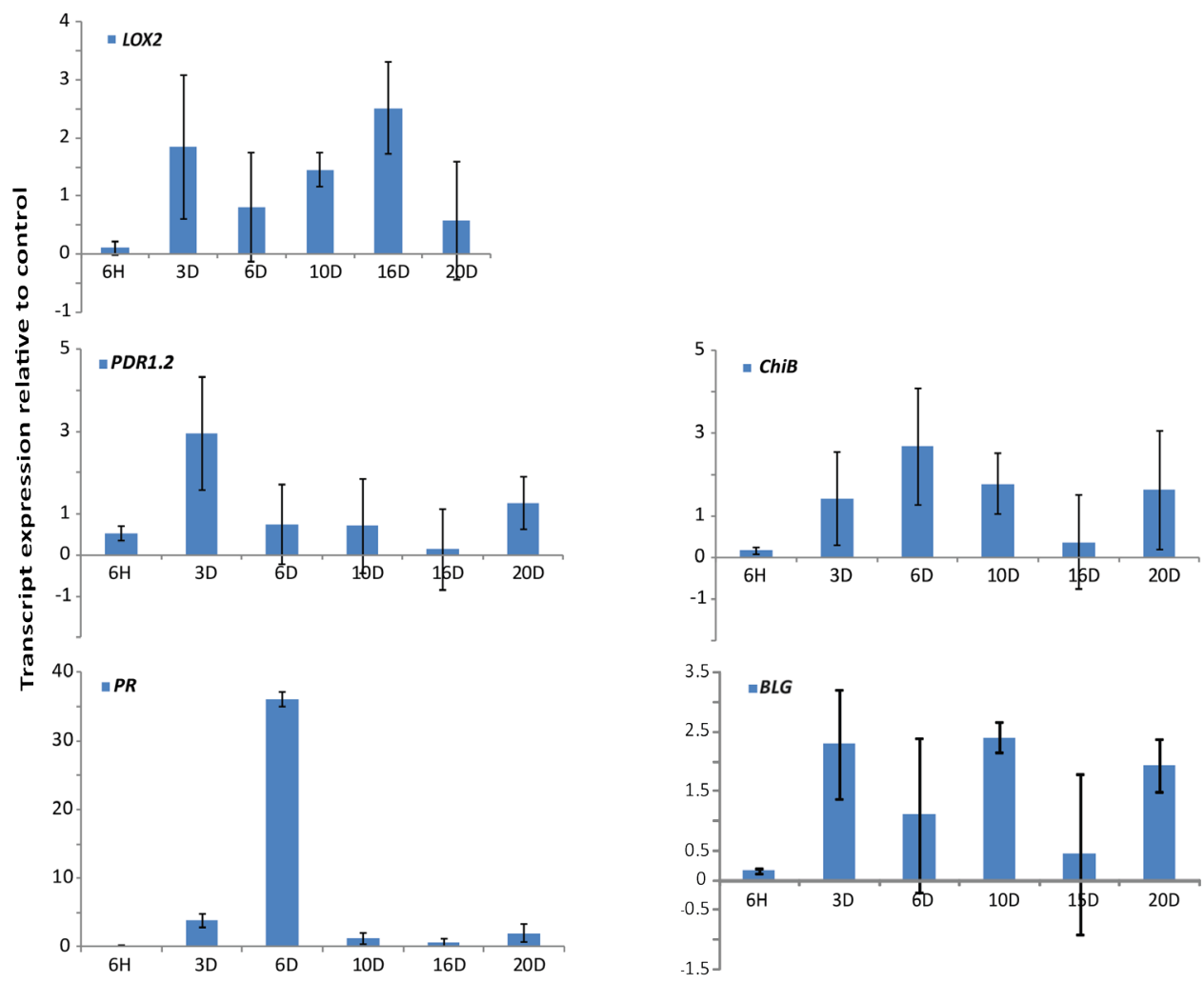

Figure 6. Gene expression of selected marker genes for the JA, SA and JA/ET pathway during $\mathbf{2 0}$ days post spider mite infestation as determined by qPCR. $Y$ axis indicates expression relative to that of RPL2 as calculated by $2^{-\triangle \Delta C T}$ method; $L O X 2$ is a marker for JA biosynthesis, ChiB and PDR1.2 are marker genes for JA/ET response, $P R$ and $B L G$ are marker genes for SA response. Error bars represent the mean \pm SE of $N=3$ biological replicates.

Both ChiB and PDR 1.2 are genes responsive to either JA and/or ET. Transcripts of both genes were found to be suppressed at 6 hpi while Chib was induced at $3 \mathrm{dpi}$ and PDR1.2 was induced at $6 \mathrm{dpi}$. JA-lle has an essential role in jasmonate signaling. Studies on Nicotiana attenuata showed that 
leaf wounding remarkably increased the amount of JA-lle. In addition, JAIle mediates the degradation of JA transcription factor repressor, jasmonate ZIM-domain (JAZ) via CORONATINE INSENSITIVE 1 (COI1) F-box protein rather than JA, MeJA or cisOPDA and leads to the activation of JA responsive genes (Thines et al., 2007). JA-lle production was induced by spider mites from the onset of infestation and reached a maximum at $10 \mathrm{dpi}$ with a level of $240.74 \mathrm{pmol} / \mathrm{g} \mathrm{D.W}$. compared with $4.26 \mathrm{pmol} / \mathrm{g} \mathrm{D.W}$. in non-infested plants (Sup Table 1). Interestingly, at $6 \mathrm{dpi}$ on which there were few feeding mites, the JA-lle amount dropped to the amounts in non-infested plants.

SA initially decreased upon spider mite infestation, followed by a gradual increase during the following 16 days. After 20 days of infestation, SA dropped back to approximately the amount of non-infested leaves of the same age (3092.77 pmol/g D.W.). For SA responsive genes, BGL was found upregulated 3, 6 and 20 dpi while $P R$ was significantly induced 6 dpi with a 36-fold change compared to control plants. The SA level coincided with spider-mite development and might indicate that the level of SA is positively correlated with the number of spider mites. As SA is known to have a predominant role in mediating local and systemic plant defense responses against pathogens (Rivas-San Vicente and Plasencia, 2011), a possible explanation for the induction of SA after spider-mite infestation might be the introduction of pathogen infestation brought in by spider mites as suggested by Alba and co-workers (Alba et al., 2015) or the presence of bacterial endosymbionts or their effectors in the saliva of the spider mites (Vacante, 2013). SA marker genes $B L G$ and $P R$ were also induced 3 and 6 dpi respectively showing that $\mathrm{SA}$ signaling is indeed induced by spider mites and/or their endosymbionts.

\section{Defensive phytohormones changes in genotype 8}

Considering that the detected changes in the metabolome due to spider mite infestation was relatively small compared to the variation due to the plant development, we performed an inverted approach to analyze the metabolic responses to spider mites in another genotype. Genotype (G8) was selected as it is more susceptible to spider mites, based on the results presented in chapter 2 of this thesis and infested with a higher density of spider mites (> 300) to ensure the changes in the metabolome were detectable. The spider mites were released on Capsicum plants 15 days, 8 days, 4 days, 1 day, 18 hours or 3 hours before harvesting the leaves and one group of plants was left uninfested. Leaf samples of similar ontogeny were collected within one hour on the same day, so that the effect of leaf development stage was excluded. 
With progressing infestation, cis-OPDA increased during the first 8 days compared with control plants $(P<0.05)$ and then slightly decreased at day 15 (Figure 7). In contrast, both JA and JA-lle transiently increased from 3 hours of infestation onwards until $1 \mathrm{dpi}$ and decreased afterwards until day 15. While the amount of JA returned to the basal level that is also present in non-infested plants $\left(0.62 \mathrm{pmol} \mathrm{mg}^{-1}\right)$, that of JA-lle remained at a 4.02 -fold higher level. This difference between JA and JA-lle was also found in genotype 29 , and is indicative for a dynamic and high flux in the conversion of JA into JA-Ile in response to herbivore infestation.
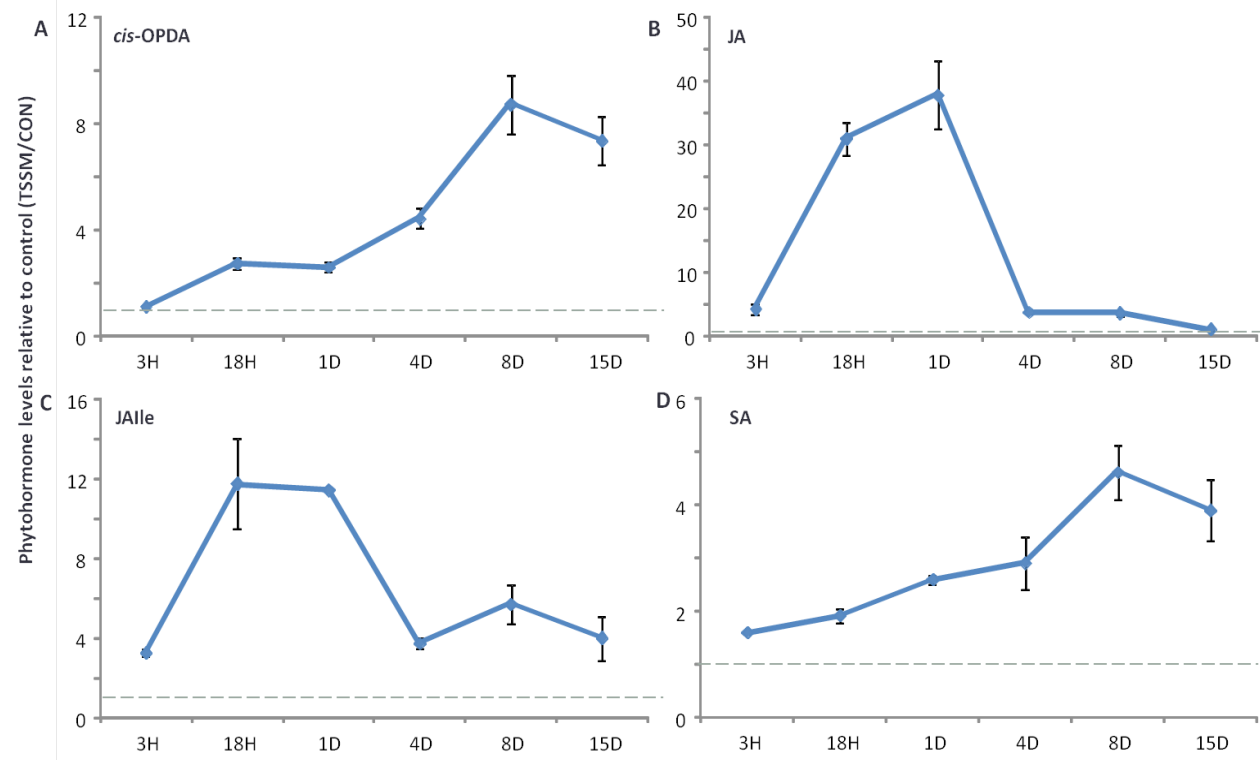

Figure 7. Fold change (FC) differences in defensive phytohormones in spider-mite infested plants (TSSM) relative to non-infested control plants (CON) of G8 at 3, 18 hours (H), and $1,4,8,15$ days (D) post infestation (dpi). A, FC of cis-OPDA; B, FC of JA; C, FC of JAlle; D, FC of SA. Error bars represent the mean \pm SE of $n=3$ biological replicates.

Interestingly, the increased cis-OPDA does not necessarily correlate directly with the amount of JA nor JA-Ile. Spider mites induced a transient upregulation of JA biosynthesis as visualized by increased cis-OPDA, JA and JA-lle levels in the first 18 hours of infestation. Afterwards, levels of JA related compounds decreased while SA accumulated (Figure 7). The production of SA was similar to that of cis-OPDA, continuously increasing from 3 hours post infestation until $8 \mathrm{dpi}$ when it reached the peak level with a fold change of 4.6 (Figure 7). In genotype 29, the production of SA seemed to be dependent on the spider mite population density (Figure 1, 5). In genotype 8 , the production of SA correlates nicely with the level of cis-OPDA, suggesting that increasing spider mite damage results in increased JA biosynthesis 
(cis-OPDA) while at the same time spider mite feeding induces SA signaling. The disconnected correlation between cis-OPDA and products downstream such as JA and JA-lle suggests genes downstream in JA biosynthesis are repressed, possibly by SA. A recent study in Arabidopsis showed that pathogen-mediated SA accumulation resulted in lower JA levels, as SA inhibited CATALASE2 (CAT2) which was shown to promote JA biosynthetic enzyme ACX2/ACX3 activity via direct interaction (Yuan et al., 2017).

\section{Endogenous metabolite profile in genotype 8}

After raw data alignment and reduction, 134 variables representing endogenous metabolites were generated for multivariate analysis (Sup Table 9). Based on HCA, early time points, 3 and $18 \mathrm{~h}$ post-infestation, clustered together with non-treated control samples and separated from later time points, indicating that spider-mite induced metabolome adaptation from 1 dpi onwards (Figure 8A). In accordance with HCA, PCA shows that metabolome profiles of leaves that were spider-mite infested for 3 and 18 hours and untreated plants separated from those that were infested for 1, 4, 8 and $14 \mathrm{dpi}$ along PC1 (25.9\% of total variation). However, PCA analysis also shows that within 3 and $18 \mathrm{~h}$ after introduction of spider mites the overall metabolome already differs from the non-treated leaves (Figure 8B) as they clustered separately from non-infested control samples along PC2 (12.3\% of total variation), suggesting that the recognition of the mites by the plant, but more likely the technical handling of transferring is visible in the endogenous metabolite profile. 

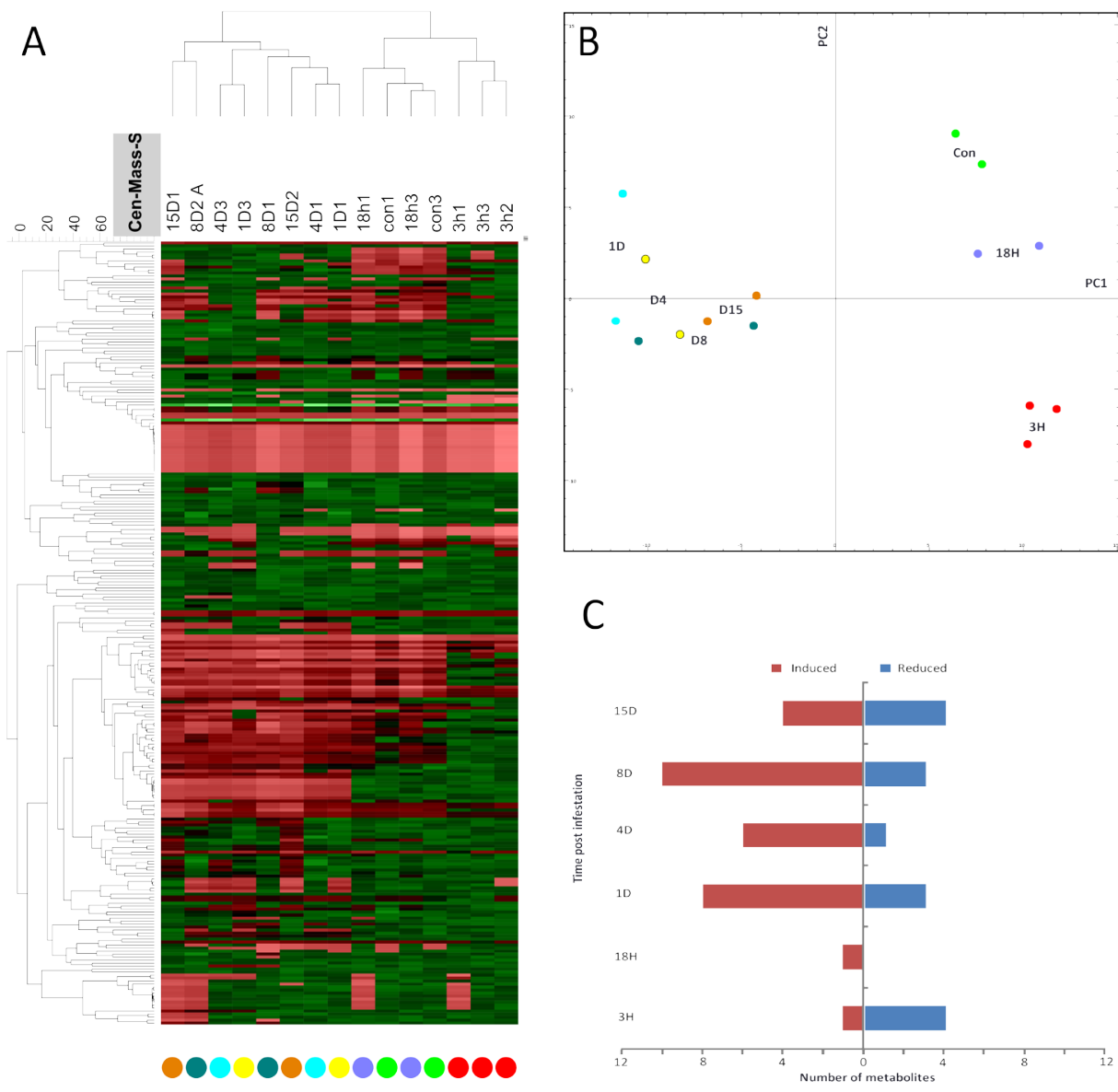

Figure 8. A. Hierarchical clustering analysis (HCA) of endogenous metabolome data of Capsicum annuum $\mathbf{G 8}$ leaves during 15 days post infestation with spider mites. Light green, red, puple, blue, yellow, dark green and orange dots represent control plants and spider-mite infested plants for 3, 18 hours, 1, 4, 8, 15 days. Dots colours correspond to dots in Figure 8B; B. Principal component analysis (PCA) based on the same dataset. PC1 explained $25.9 \%$ and $P C 2$ explained $12.3 \%$ of the total variation; $C$. Number of endogenous metabolites that were significantly induced or repressed (T-test $\mathrm{P}<0.05,|\mathrm{FC}|>1.5$ ) upon spider mite infestation in each time point compared with control plants of similar developmental stage. 
Table 3. Spider mites induced / repressed endogenous metabolites during 15 days post infestation detected by LC-MS platform (T-test $\mathrm{p}<0.05,|\mathrm{FC}|>1.5$ )

\begin{tabular}{|c|c|c|c|c|c|c|}
\hline Time & Chemical Class & $\begin{array}{l}\text { TSSM/ } \\
\text { CON }\end{array}$ & KEGG ID & Metabolite & Formula & $\begin{array}{l}\text { Mo- } \\
\text { lecular } \\
\text { weight }\end{array}$ \\
\hline \multirow{5}{*}{$3 \mathrm{hpi}$} & Flavonoids & 3.33 & - & beta-Carotene & $\mathrm{C} 40 \mathrm{H} 56$ & 536.44 \\
\hline & Flavonoids & 0.00 & C00007053 & Derricidin & $\mathrm{C} 2 \mathrm{OH} 20 \mathrm{O} 3$ & 308.14 \\
\hline & Alkaloids & 0.28 & C00026003 & Pandicine & $\begin{array}{l}\mathrm{C} 44 \mathrm{H}- \\
50 \mathrm{~N} 4 \mathrm{O} 7\end{array}$ & 746.37 \\
\hline & $\begin{array}{l}\text { Steroidal Gly- } \\
\text { cosides }\end{array}$ & 0.09 & C00032708 & Anguivioside B & $\mathrm{C} 48 \mathrm{H} 74 \mathrm{O} 20$ & 970.48 \\
\hline & $\begin{array}{l}\text { Flavonoid de- } \\
\text { rivatives }\end{array}$ & 0.09 & C00033287 & Paniculoside & $\mathrm{C} 26 \mathrm{H} 42 \mathrm{O} 9$ & 498.28 \\
\hline $\begin{array}{l}18 \\
\text { hpi }\end{array}$ & Flavonoids & 6.29 & C00006764 & $\begin{array}{l}\text { Pelargonidin 3-glu- } \\
\text { coside-5-(6"'-malo- } \\
\text { nylglucoside) }\end{array}$ & $\mathrm{C} 30 \mathrm{H} 33018$ & 681.17 \\
\hline \multirow{11}{*}{$1 \mathrm{dpi}$} & $\begin{array}{l}\text { Cylopeptide } \\
\text { alkaloids }\end{array}$ & $\infty$ & C00028949 & Rugosanine A & $\begin{array}{c}\mathrm{C} 30 \mathrm{H}- \\
43 \mathrm{~N} 5 \mathrm{O} 7\end{array}$ & 585.32 \\
\hline & $\begin{array}{l}\text { Macrocycli } \\
\text { lactones }\end{array}$ & $\infty$ & C00018809 & Tetranactin & C44H72O12 & 792.50 \\
\hline & Glycosides & $\infty$ & C00016679 & Altromycin $\mathrm{F}$ & $\begin{array}{l}\mathrm{C} 47 \mathrm{H}- \\
59 \mathrm{NO} 17\end{array}$ & 909.38 \\
\hline & Steriods & $\infty$ & & $\begin{array}{l}\text { 13-Hydroxy-16- } \\
\text { kauren-19-oic acid }\end{array}$ & С38H60018 & 804.38 \\
\hline & Triterpenes & $\infty$ & C00044760 & Fomlactone A & $\mathrm{C} 33 \mathrm{H} 50 \mathrm{O} 5$ & 526.37 \\
\hline & Flavonoids & 84.79 & - & $\begin{array}{l}\text { 3',4',5,7-Tetrahy- } \\
\text { droxyflavone }\end{array}$ & $\mathrm{C} 43 \mathrm{H} 44 \mathrm{O} 26$ & 976.21 \\
\hline & Flavonoids & 8.06 & - & $\begin{array}{c}\text { 7-O-[L-Rham- } \\
\text { nopyrano- } \\
\text { syl-(1,2)-6"-O-mal- } \\
\text { onyl]-D-glucopyra- } \\
\text { noside] }\end{array}$ & С30H32O18 & 680.16 \\
\hline & Glycosides & 2.18 & C00034894 & Specioside & $\mathrm{C} 24 \mathrm{H} 28012$ & 508.16 \\
\hline & - & 0.00 & - & $\begin{array}{l}\text { 1,2-Diacylglyc- } \\
\text { erol 3-(6-de- } \\
\text { oxy-6-sulfo-?-D-glu- } \\
\text { copyranosides) }\end{array}$ & $\mathrm{C} 43 \mathrm{H} 76012 \mathrm{~S}$ & 816.51 \\
\hline & $\begin{array}{c}\text { Cyclic depsi- } \\
\text { peptides }\end{array}$ & 0.00 & C00028547 & Majusculamide C & $\begin{array}{c}\mathrm{C} 50 \mathrm{H}- \\
80 \mathrm{~N} 8012\end{array}$ & 984.59 \\
\hline & Xanthenes & 0.02 & C00035833 & Griffipavixanthone & $\mathrm{C} 36 \mathrm{H} 28012$ & 652.16 \\
\hline
\end{tabular}




\begin{tabular}{|c|c|c|c|c|c|c|}
\hline \multirow{7}{*}{4 dpi } & $\begin{array}{l}\text { Cylopeptide } \\
\text { alkaloidS }\end{array}$ & $\infty$ & C00028949 & Rugosanine $A$ & $\begin{array}{c}\mathrm{C} 30 \mathrm{H}- \\
43 \mathrm{~N} 5 \mathrm{O} 7\end{array}$ & 585.36 \\
\hline & Terpenes & $\infty$ & - & 2-Octaprenylphenol & $\mathrm{C} 38 \mathrm{H} 54 \mathrm{O}$ & 526.42 \\
\hline & Flavonoids & 77.95 & - & $\begin{array}{l}\text { 3',4',5,7-Tetrahy- } \\
\text { droxyflavone }\end{array}$ & $\mathrm{C} 43 \mathrm{H} 44 \mathrm{O} 26$ & 976.21 \\
\hline & Flavonoids & 9.65 & - & $\begin{array}{c}\text { 7-O-[L-Rham- } \\
\text { nopyrano- } \\
\text { syl-(1,2)-6"-O-mal- } \\
\text { onyl]-D-glucopyra- } \\
\text { noside] }\end{array}$ & С30Н32O18 & 680.16 \\
\hline & Steroids & 7.65 & C00003575 & Collettiside III & $\mathrm{C} 45 \mathrm{H} 72 \mathrm{O} 16$ & 868.48 \\
\hline & $\begin{array}{l}\text { Steroidal Gly- } \\
\text { cosides }\end{array}$ & 1.98 & C00030553 & Isotubocaposigenin & $\mathrm{C} 30 \mathrm{H} 44 \mathrm{O} 6$ & 500.31 \\
\hline & Xanthenes & 0.01 & C00035833 & Griffipavixanthone & $\mathrm{C} 36 \mathrm{H} 28012$ & 652.16 \\
\hline \multirow{13}{*}{$8 \mathrm{dpi}$} & Diterpenes & $\infty$ & - & $\begin{array}{l}\text { 13-Hydroxy-16- } \\
\text { kauren-19-oic acid }\end{array}$ & $\mathrm{C} 38 \mathrm{H} 60018$ & 804.38 \\
\hline & Flavonoids & $\infty$ & C00004444 & $\begin{array}{l}\text { Tricin 7-O-be- } \\
\text { ta-D-glucopyrano- } \\
\text { side }\end{array}$ & - & - \\
\hline & Glycosides & $\infty$ & C00007245 & GDP-L-fucose & $\begin{array}{c}\mathrm{C} 16 \mathrm{H}- \\
25 \mathrm{~N} 5 \mathrm{O} 15 \mathrm{P} 2\end{array}$ & 589.08 \\
\hline & Flavonoids & $\infty$ & C00036260 & 28-Nortyphasterol & $\mathrm{C} 27 \mathrm{H} 48 \mathrm{O} 3$ & 420.36 \\
\hline & Terpenes & $\infty$ & - & 2-Octaprenylphenol & $\mathrm{C} 38 \mathrm{H} 540$ & 526.42 \\
\hline & Steriods & $\infty$ & C00044760 & Fomlactone A & $\mathrm{C} 33 \mathrm{H} 50 \mathrm{O} 5$ & 526.37 \\
\hline & Flavonoids & 81.19 & - & $\begin{array}{c}\text { 3',4',5,7-Tetrahy- } \\
\text { droxyflavone }\end{array}$ & $\mathrm{C} 43 \mathrm{H} 44 \mathrm{O} 26$ & 976.21 \\
\hline & Unknown & 3.57 & C00018428 & $\begin{array}{c}\text { 16,17-Dihydrorifa- } \\
\text { mycin S }\end{array}$ & $\begin{array}{l}\mathrm{C} 37 \mathrm{H}- \\
47 \mathrm{NO} 12\end{array}$ & 697.31 \\
\hline & - & 3.57 & - & Unknown & - & - \\
\hline & $\begin{array}{l}\text { Steriod glyco- } \\
\text { sides }\end{array}$ & 3.43 & C00030553 & Isotubocaposigenin & $\mathrm{C} 30 \mathrm{H} 44 \mathrm{O} 6$ & 500.31 \\
\hline & $\begin{array}{l}\text { Diglyceride } \\
\text { glycoside }\end{array}$ & 0.11 & - & $\begin{array}{l}\text { 1,2-Diacylglyc- } \\
\text { erol 3-(6-de- } \\
\text { oxy-6-sulfo-?-D-glu- } \\
\text { copyranosides) }\end{array}$ & $\mathrm{C} 43 \mathrm{H} 76 \mathrm{O} 12 \mathrm{~S}$ & 816.51 \\
\hline & Alkloids & 0.06 & C00040894 & Baccatin VII & $\mathrm{C} 36 \mathrm{H} 52 \mathrm{O} 14$ & 708.34 \\
\hline & Xanthenes & 0.01 & C00035833 & Griffipavixanthone & $\mathrm{C} 36 \mathrm{H} 28012$ & 652.16 \\
\hline
\end{tabular}




\begin{tabular}{|c|c|c|c|c|c|c|}
\hline \multirow{7}{*}{} & Terpenes & $\infty$ & - & 2-Octaprenylphenol & C38H540 & 526.42 \\
\cline { 2 - 7 } & Glycosides & $\infty$ & C00007245 & GDP-L-fucose & $\begin{array}{c}\text { C16H- } \\
25 \mathrm{~N} 5015 \mathrm{P} 2\end{array}$ & 589.08 \\
\cline { 2 - 7 } & Unknown & 4.20 & C00018428 & $\begin{array}{c}16,17-\text {-Dihydrorifa- } \\
\text { mycin S }\end{array}$ & $\begin{array}{c}\text { C37H- } \\
47 \mathrm{NO} 12\end{array}$ & 697.31 \\
\cline { 2 - 7 } dpi & - & 4.20 & - & Unknown & - & - \\
\cline { 2 - 7 } & Xanthenes & 0.01 & C00035833 & Griffipavixanthone & C36H28O12 & 652.16 \\
\cline { 2 - 7 } & Alkaloids & 0.00 & C00026003 & Pandicine & $\begin{array}{c}\text { C44H- } \\
50 N 407\end{array}$ & 746.37 \\
\cline { 2 - 7 } & Alkloids & 0.00 & C00040894 & Baccatin VII & C36H52O14 & 708.34 \\
\cline { 2 - 7 } & $\begin{array}{c}\text { Cyclic depsi- } \\
\text { peptides }\end{array}$ & 0.00 & C00028547 & Majusculamide C & $\begin{array}{c}\text { C50H- } \\
80 N 8012\end{array}$ & 984.59 \\
\hline
\end{tabular}

Three hours after introducing spider mites, a single compound was induced $(p<0.05)$ while four were repressed by spider mites. The only metabolite significantly different at $18 \mathrm{hrs}$ was a putative flavonoid (7-O-[L-Rhamnopyranosyl-(1,2)-6"-O-malonyl]-D-glucopyranoside]). As infestation progressed, the number of significantly induced metabolites increased to 8, 6, 10, 4 at $1,4,8$ and $15 \mathrm{dpi}$ while the number of repressed metabolites was $3,1,3,4$ (Figure 8C).

As JA regulates secondary metabolite biosynthesis under biotic stresses and enhances the resistance to herbivores and pathogens (Afrin et al., 2015, Bennett and Wallsgrove, 1994), we expect that metabolites that positively correlate with the production of JA are potentially defensive compounds. We classified endogenous metabolites as detected by the LCMS platform and phytohormones as analyzed by UPLC-MS/MS, into nine clusters using a self-organizing map (SOM, Supplemental Figure 1). The metabolite cluster in which most reconstructed metabolite members showed a pattern correlating with JA production (correlation coefficient $>0.5$ ) among time (Figure 9A) include putative triterpenes, glycosides and peptides. Reconstructed metabolite members in cluster B (Figure 9B) which particularly accumulate during later stages $(1,4,8,15 \mathrm{dpi})$ compared with the early stages $(3,18 \mathrm{~h}$ post infestation), include several flavonoids and steroidal conjugates (Figure 9B), and display a pattern that correlates with the amount of SA and cis-OPDA (correlation coefficient $>0.5$ ). It could be that the metabolic changes in this cluster are the result of the infestation and positively correlate with infestation level as SA is positively related with infestation level as previously detected for $\mathrm{G} 29$ plants. 


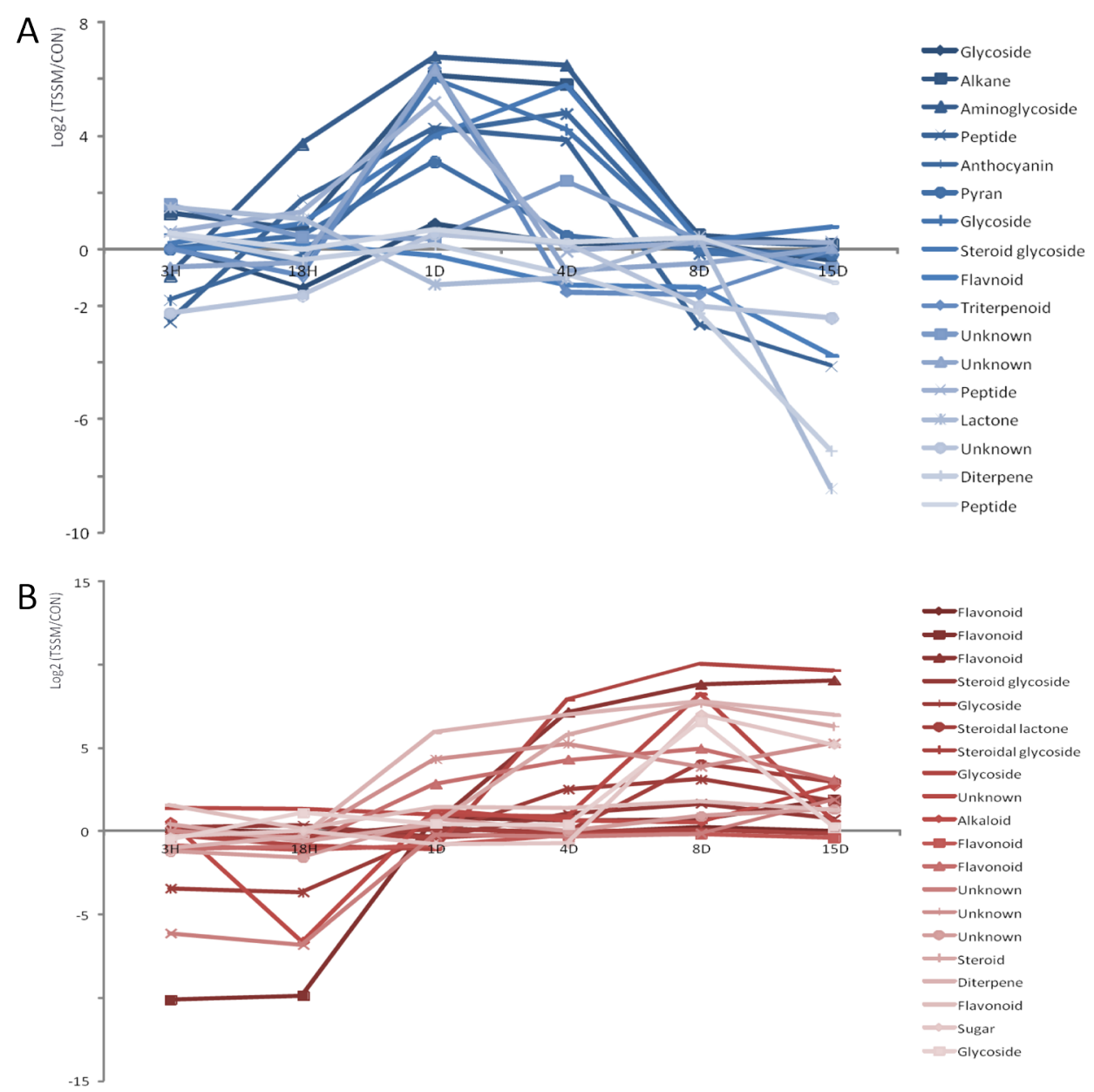

Figure 9. Endogenous metabolites selected based Self-Organizing Map (SOM) in genotype 8 during 15 days post infestation. A. Metabolites positively correlated with JA (Correlation coefficiency>0.5); B Metabolites distance is calculated by Pearson Correlation. $Y$ axis indicates Log2 transformed relative ion intensity of spider mites (TSSM) infested samples and non-treated samples (CON).

\section{Volatile metabolite profiles in genotype 8}

Volatile metabolites emitted by G8 plants infested with spider mites for 1, 7 or 14 days as well as those from non-treated plants were collected at the same time. Seventy-five metabolites were detected by GC-MS upon manual alignment by retention time (Supplementary Table 10) and sixty-nine of them were putatively annotated as known compounds including terpenoids and green leaf volatiles. Both HCA and PCA indicated that volatile blends altered after spider-mite infestation. Besides, volatile emission also changed according to the duration of infestation. Four metabolites, namely TMTT, 
indole, methyl salicylate (MeSA) and geranylacetone were significantly induced $(P<0.05)$ by spider mites at 1 dpi (Table 4). While after 7 days of infestation clear damage was visible on the leaves that was inflicted by spider mites, no emitted volatiles were detected that were significantly altered compared with non-treated plants. Longer infestation (14 dpi) resulted in increasing visible damage but only a single green leaf volatile, (Z)-4-Hexen-1-ol, was significantly induced by spider mites (Table 4). As also found for spider-mite infested leaves of genotype 29 plants, emission of volatile metabolites was both quantitatively and qualitatively higher in early than in later stages of infestation (Table 1, 4), consistent with JA accumulation in the early stages of infestation.

TMTT was identified in maize, tomato, lima bean, medicago and cucumber upon attack by different herbivore species (Degenhardt and Gershenzon, 2000, Kant et al., 2004, Arimura et al., 2000, Arimura et al., 2008, Bouwmeester et al., 1999). Several studies have suggested that TMTT contributed to the attraction of herbivore predators (Mumm et al., 2008, Kappers et al., 2005). Methyl salicylate (MeSA) is also a herbivore induced plant volatile (HIPV) involved in plant direct and indirect defense (Gadino et al., 2012, Mallinger et al., 2011, Tang et al., 2015). JA has been shown to be a key regulator of TMTT and MeSA emission in tomato upon spider-mite infestation (Ament et al., 2004). TMTT, MeSA and indole were found to be produced by maize in a primed state of herbivore infestation and thought to be responsible for systematic signaling within the plants as well as a warning signal for neighboring plants for coming attacks (Erb et al., 2015). JA induced the production of monoterpene indole alkaloids which are derived from the indole and iridoid pathway in Catharanthus roseus (Patra et al., 2018). Whether JA is involved in inducing the indole pathway directly remains unknown (Van et al., 2015) but, vice versa, indole increased the herbivore-induced production of JA-lle and ABA in maize (Erb et al., 2015). 
A

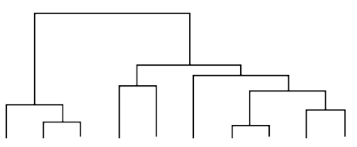

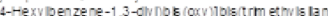

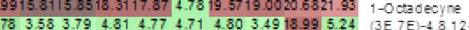

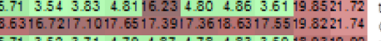

3E 7 E-43.12-Trmernyrnoca-1.3.7.11-terraene

$5.713 .523 .714 .794 .874 .78 \quad 4.83 \quad 3.5918 .9319 .90$

(anc-3-ter en-1-ol trinyogacetate

$5.7815 .8015 .974 .904 .784 .754 .753 .53 \quad 3.745 .26$ Oloutyl phenalate

$5.6814 .8214 .214 .78 \quad 4.85 \quad 4.75 \quad 4.88 \quad 3.58 \quad 3.825 .30$ Hexasloxane, tetradecamethy-

$5.6714 .3714 .094 .88 \quad 4.794 .794 .87 \quad 3.52 \quad 3.525 .22$ Unknown

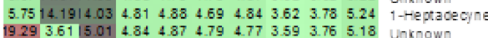

$6.9514 .31 / 4.534 .824 .814 .694 .84 \quad 3.55 \quad 3.765 .30$ Heptane 1-chloro-

$6.6214 .2814 .13 \quad 4.814 .894 .694 .783 .56 \quad 3.775 .23 \quad 1-0$ tadecyne

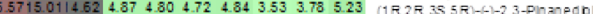

$6.6915 .0614 .68 \quad 4.82 \quad 4.37 \quad 4.72 \quad 4.853 .55 \quad 3.775 .30$ unknown

$17.5215 .8916 .12 \quad 4.824 .804 .714 .853 .553 .345 .31$ p-Cresol

$9.3717 .8017 .43 \quad 4.844 .854 .784 .843 .593 .745 .26$ texadecanolcack menylester

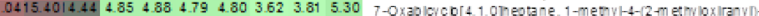

$7.6516 .4615 .25 \quad 4.844 .884 .76 \quad 4.793 .55 \quad 3.735 .23$ Etranol 2-prenoxy-

$8.1117 .0516 .094 .88 \quad 4.82 \quad 4.76 \quad 4.853 .56 \quad 3.75 \quad 5.24$ Dlenylphtnate

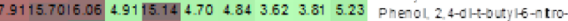

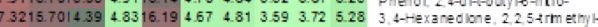

$16.6114 .32 / 4.12 \quad 4.8316 .08 \quad 4.794 .793 .493 .765 .19$ 3-Menylyclopentyl aceate

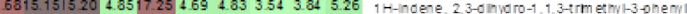

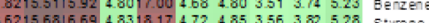

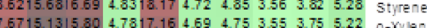

$7.5415 .1515 .8504 .7817 .164 .694 .753 .55 \quad 3.755 .22$ o-Xylene

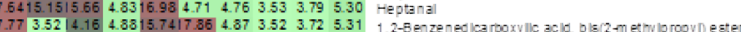

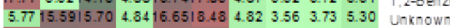

$7.8915 .4316 .17 \quad 4.8517 .0117 .114 .813 .62 \quad 3.315 .20$ 1-Hexangl z-emyl

72517.2715 .2349015 .8217694 .823 .493 .785 .25 teotasloxane, hesageoan any-

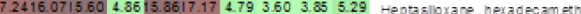

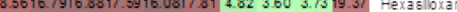

$5.7815 .0514 .4918 .2615 .564 .704 .843 .55 \quad 3.765 .25$ 1 1 H-Pymole 1-memyl-

9.1316 .36169819 .4518 .9818 .1418 .563 .563 .725 .22 Phenacylldene dlacenate

$16.9414 .3715 .0617 .7516 .434 .714 .863 .55 \quad 3.85 \quad 5.29$ Ethybenzene

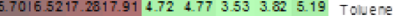

3.6016 .3316 .7117 .9318 .014 .724773 .583 .755 .26 treptanone $26-4 \mathrm{mernyt}$

$17.8315 .1116 .8318 .2416 .8517 .154 .83 \quad 3.613 .775 .22$ phenacylldene dacetate

$89116.1716 .6817 .2617 .9017 .544 .32 \quad 3.56 \quad 3.815 .23$ 1-Tetradecyne

.

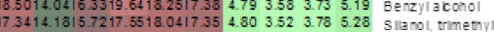

$178219.96 \mid 5.3619 .1515 .4418 .6120 .6418 .7619 .445 .26$ 2-Emymexylsalnyame

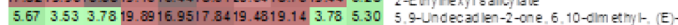

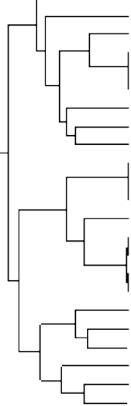

16.6417.19/5.04 4.8915.6417 2018.1517.59 3.33 5.26 Heptaslloxane, hexadecam ethyl-

20.661822182719 .431815189919 .6713 .603 .355 .26 Gyoloterras loxane octam ernyl-

8.8616 .3516 .5917 .9917 .8517 .7318 .5117 .313 .735 .21 Octanal

92317.1217 .2618 .7618 .6018 .0318 .6117 .603 .765 .28 1-Trlethylillibxyhedtadecane

5.083 .504 .3417 .5715 .314 .6817 .9517 .153 .755 .26 Benzylaenzoate

17.7915 .4917 .9515 .804 .7418 .5717263 .735 .22 lsopropylpalmiate

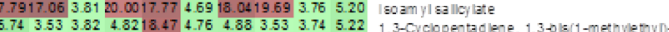

5.773 .503 .804 .8315 .274 .704 .753 .533 .765 .26 texadecane

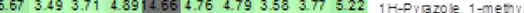

$5.73 \quad 3.523 .76 \quad 17.6116 .454 .804 .8217 .523 .725 .21$ Lnk-own

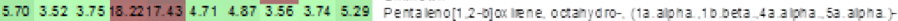

5.683 .613 .7417 .4317 .104 .804 .873 .573805 .22 Hexana

$5.743 .513 .7018 .5415 .634 .754 .803 .58 \quad 3.735 .27$ Bengenacetambe N-all

$5.763 .613 .7018 .5114 .964 .804 .873 .53 \quad 3.815 .24$ cyobentene, 3-methy|-

$23.2120 .62: 0.6422 .3920 .2321 .6021 .6420 .9120 .3321 .36$ Gyclotrk lloxane hexamethy-

1.1618 .4018 .7320 .1520 .3220 .5021 .1020 .6419 .5320 .79 1.9-Nonanedbo

2.0519 .5219 .3120 .9521 .1420 .6520 .7820 .01189321 .20 1-Teradecyne

$5.683 .593 .7219 .0116 .45 \quad 4.7118 .72 \quad 3.003 .8519 .44$ Propanold acld, 4 -hex en-1-19lester

6.8515 .7014 .6322 .0120 .134 .7721 .3318 .803 .3419 .63 t-Hexen-1-01 $\left(z-z_{-1}\right.$

8.3216 .5915 .5520 .0518 .1213 .0018 .9318 .0333 .2019 .80 5-Hepten-2-0ne. 6 -meny- 


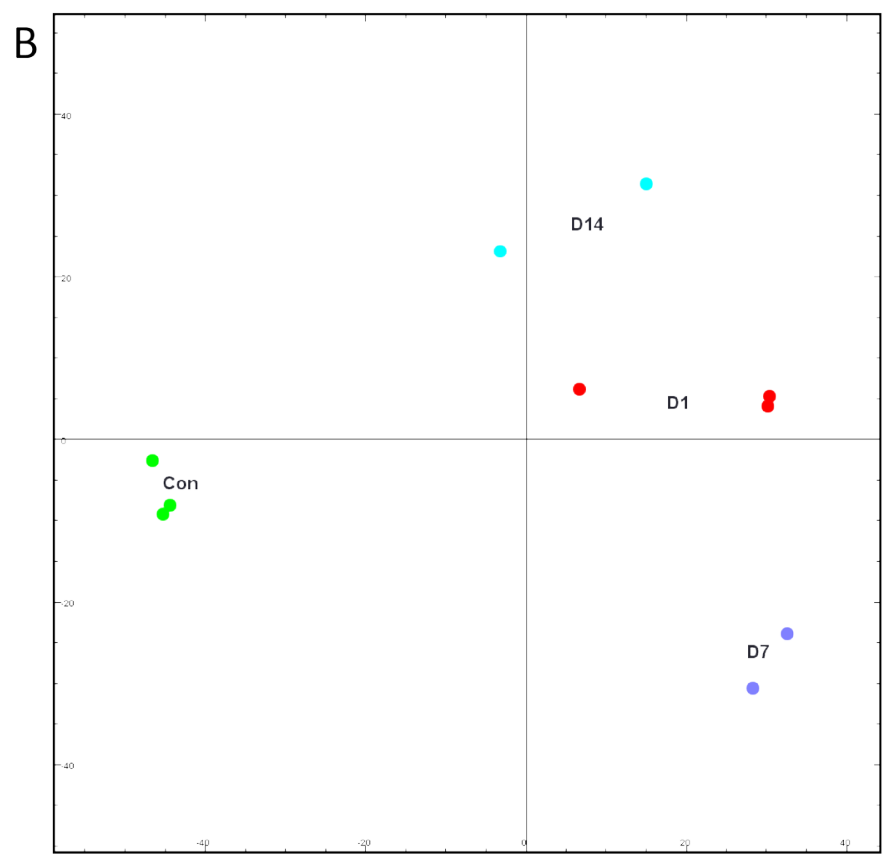

Figure 10 A. B. Hierarchical clustering analysis (HCA) of volatile metabolome data of Capsicum leaves during 15 days post infestation detected by GC-MS platform. Green, red, purple, blue dots represent control plants (CON) and spider-mite infested plants for $1,7,14$ days post infestation (D1, D7, D14); B. Principal component analysis (PCA) based on the same dataset. PC1 explained $48.4 \%$ and PC2 $15.6 \%$ of the total variation;

\section{Comparison between genotypes}

In genotype 29 , the number of endogenous metabolite that changed in response to spider mite infestation was highest at 3 and 20 dpi while volatile metabolites were predominantly induced at 6 hpi (Figure 2). Responding metabolites included alkaloids, flavonoids, di- and triterpenes within the endogenous metabolites and mono- and sesquiterpenes within volatile metabolites (Table 1, 2). Although the total spider mite population slowly increased during the first 16 day after infestation (Figure 1), the number of feeding individuals was highest at the beginning of the experiment, followed by a decline due to departing or dying adult mites, while at the later stage of the experiment, the population started to settle from new hatching eggs. Plants attracted more predatory mites in the early period of infestation, suggesting that predatory mite attractiveness is associated with the number of actively feeding mites instead of the total population. Indeed, more volatile metabolites that were previously described to be associated 
with predator attractiveness, including TMTT, MeSA and other terpenes (Kappers et al., 2011) were present in higher amounts during the early stages of infestation (Table 2, 4).

Table 4. Spider-mite induced and repressed volatile metabolites in genotype 8 during 15 days post infestation detected by GC-MS platform (T-test $p<0.05,|F C|>1.5$ )

\begin{tabular}{|c|c|c|c|c|c|c|}
\hline \multirow{2}{*}{ Time } & $\begin{array}{c}\text { RT } \\
(\mathrm{min})\end{array}$ & Metabolite & $\begin{array}{c}\text { Chemical } \\
\text { fomula }\end{array}$ & $\begin{array}{c}\text { Chemical } \\
\text { class }\end{array}$ & $\begin{array}{c}\mathrm{MW} \text { g/ } \\
\mathrm{mol}\end{array}$ & TSSM/CON \\
\hline \multirow{2}{*}{$1 \mathrm{dpi}$} & 20.91 & $\mathrm{TMTT}$ & $\mathrm{C} 16 \mathrm{H} 26$ & $\begin{array}{c}\text { Sesquiter- } \\
\text { pene }\end{array}$ & 218.384 & 381944.49 \\
\cline { 2 - 7 } & 17.38 & Indole & $\mathrm{C} 8 \mathrm{H} 7 \mathrm{~N}$ & Benzopryrrole & 117.151 & 164858.88 \\
\cline { 2 - 7 } & 15.83 & $\begin{array}{c}\text { Methyl salic- } \\
\text { ylate }\end{array}$ & $\mathrm{C} 8 \mathrm{H} 8 \mathrm{O} 3$ & Phenols & 152.149 & 151572.86 \\
\cline { 2 - 7 } & 19.29 & $\begin{array}{c}\text { Geranylace- } \\
\text { tone }\end{array}$ & $\mathrm{C} 13 \mathrm{H} 22 \mathrm{O}$ & $\begin{array}{c}\text { Terpene ke- } \\
\text { tone }\end{array}$ & 194.318 & 20287.38 \\
\hline $7 \mathrm{dpi}$ & $\mathrm{NONE}$ & - & - & - & - & - \\
\hline $\begin{array}{c}14 \\
\mathrm{dpi}\end{array}$ & 9.50 & $\begin{array}{c}(Z)-4-\mathrm{Hexen}- \\
\text { 1-ol }\end{array}$ & $\mathrm{C} 6 \mathrm{H} 120$ & Enol & 100.161 & 41.82 \\
\hline
\end{tabular}

Spider mites induced the production of both of JA and SA (Figure 5, 6). Interestingly, the total spider mite population, including eggs positively correlated with the production of SA (Pearson Correlation 0.58). In Arabidopsis, the oviposition by the Large White butterfly Pieris brassicae also activated the SA pathway and triggered the accumulation of SA (Schmiesing et al., 2016, Hilfiker et al., 2014). There is a consistent correlation between SA and cis-OPDA as well as LOX2, indicating that both SA production and upstream of JA biosynthesis positively correlated with spider mite population development. Positive correlations were also found between JA and its amino acid conjugate JA-Ile as well as with JA-regulated pathway genes, PDR1.2, ChiB but not between cis-OPDA and JA or JA-lle.

In genotype 8 , to eliminate the effect of plant development, all traits were measured on the same day, with infestation occurring at the indicated time points before the analysis and with a higher number of spider mites. The most obvious change in endogenous metabolites was already visible at $1 \mathrm{dpi}$ (Figure 7). However, no specific metabolites that were significantly induced or repressed were found in common between different time points, even though the metabolome profiles of plants at 1, 4, 8, and 15 dpi were similar according to multivariate analysis (Table 3, Figure $8 \mathrm{~A}, \mathrm{~B}$ ). No metabolites significantly altered upon spider mite infestation were found in common between both genotypes either, probably because that metabolite production 
in response to spider mites was a highly dynamic process and the emission of volatile blends change rapidly through infestation processing as well as between genotypes. Compared with G29, we found much less significantly qualitatively changed volatile metabolites, but the defense-related volatile metabolites were mostly induced $1 \mathrm{dpi}$, and not in the later stages of infestation, consistent with G29 (Table 4).

Even though the two genotypes were analyzed within different time scales and infested with different spider mite intensities, there are overlapping responses. Spider mites induced quantitatively the most endogenous metabolites in the early stages of infestation, such as 3 dpi for G29 and 1 dpi for G8, although not as early as several hours post infestation. Outstanding significantly induced metabolites include several flavonoids, di- and triterpenoidglycoside conjugates (Table 1,3 ). The defensive-related volatile TMTT was identified among the induced volatiles in the early stages of infestation in both genotypes (Table 2, 4).

A comparable, positive correlation between JA and JA-lle was observed in both genotypes, suggesting a linear relationship between them (Figure 5, 7). On the contrary, no positive correlation was found between JA and its precursor cis-OPDA. Interestingly, a consistent correlation between SA and cis-OPDA was observed in our results. In Arabidopsis, SA strongly antagonizes the JA signaling pathway, resulting in the down regulation of a large set of JA-responsive genes (Leonreyes et al., 2010). On the other hand, the majority of JA biosynthetic genes are induced by JA (Turner et al., 2002). We conclude that the damage inflicted by spider-mite infestation results in a transient increase in JA and JA-lle followed by a consistent production of SA. This increased SA might be repressing the formation of JA and JA-Ile because JA and JA-lle decreased while JA precursor cis-OPDA accumulated, as SA kept increasing. However, the increased production of cis-OPDA and upregulated or not-downregulated expression of LOX2 upon spider-mite infestation suggested that not all steps in the JA biosynthetic pathway were repressed by SA.

\section{Conclusions}

High resolution mass spectrometry based metabolomics was applied to identify metabolites involved in plant direct and indirect defense in two Capsicum annuum genotypes. Multivariate statistical analysis suggests that both the endogenous and volatile metabolome altered through plant developmental stages as well in response to spider mite infestation. Significantly 
changed metabolites include terpenoids, alkaloids and flavonoids. Stress-related phytohormones and genes involved in the hormone biosynthetic and signaling pathways revealed a transiently induced JA pathway followed by repressed JA signaling and continuously increasing SA signaling upon progression of spider-mite infestation in Capsicum.

Secondary metabolites and stress-related phytohormones are of great importance in plant defense. Other studies have mostly focused on targeted metabolite changes upon herbivory attack. In the present study, we applied untargeted analysis on both the endogenous and the volatile metabolome in a time dependent manner, in combination with plant hormone analysis. Capsicum responds to spider-mite infestation by instantaneous $\mathrm{JA}$ production as early as 3 hours post infestation and this is accompanied by an increase in secondary metabolite - both volatile as well as non-volatile - production. This response is followed by an continuous increase in SA concentration and a decrease in JA signaling. The results provide a comprehensive overview of the dynamic metabolic and phytohormone changes that occur during infestation. To further reveal the underlying mechanisms, plant material of $3 \mathrm{dpi}$ was selected for transcriptome and metabolome analysis in chapter 4.

\section{Acknowledgements:}

We would like to thank Robert Hall for providing suggestions on metabolome analysis, Desalegn W. Etalo, Carmen Diez Simon and Yury Tikunov for helping with metabolome data analysis and discussion, Bert Schipper for performing endogenous metabolite measurements and Francel Verstappen for performing volatile metabolite measurements. 


\section{References}

ABE, H., OHNISHI, J., NARUSAKA, M., SEO, S., NARUSAKA, Y., TSUDA, S. \& KOBAYASHI, M. 2008. Function of jasmonate in response and tolerance of Arabidopsis to thrip feeding. Plant and Cell Physiology, 49, 68-80.

AFRIN, S., HUANG, J.-J. \& LUO, Z.-Y. 2015. JA-mediated transcriptional regulation of secondary metabolism in medicinal plants. Science Bulletin, 60, 1062-1072.

ALBA, J. M., SCHIMMEL, B. C., GLAS, J. J., ATAIDE, L. M., PAPPAS, M. L., VILLARROEL, C. A., SCHUURINK, R. C., SABELIS, M. W. \& KANT, M. R. 2015. Spider mites suppress tomato defenses downstream of jasmonate and salicylate independently of hormonal crosstalk. New Phytol, 205, 828-40.

AMENT, K., KANT, M. R., SABELIS, M. W., HARING, M. A. \& SCHUURINK, R. C. 2004. Jasmonic acid is a key regulator of spider mite-induced volatile terpenoid and methyl salicylate emission in tomato. Plant Physiology, 135, 2025-2037.

ANDERSEN, C. L., JENSEN, J. L. \& ORNTOFT, T. F. 2004. Normalization of real-time quantitative reverse transcription-PCR data: A model-based variance estimation approach to identify genes suited for normalization, applied to bladder and colon cancer data sets. Cancer Research, 64, 5245-5250.

ARIMURA, G., OZAWA, R., SHIMODA, T., NISHIOKA, T., BOLAND, W. \& TAKABAYASHI, J. 2000. Herbivory-induced volatiles elicit defence genes in lima bean leaves. Nature, 406, 512-515.

ARIMURA, G. I., GARMS, S., MAFFEI, M., BOSSI, S., SCHULZE, B., LEITNER, M., MITHOEFER, A. \& BOLAND, W. 2008. Herbivore-induced terpenoid emission in Medicago truncatula: concerted action of jasmonate, ethylene and calcium signaling. Planta, 227, 453-464.

BARAH, P. \& BONES, A. M. 2015. Multidimensional approaches for studying plant defence against insects: from ecology to omics and synthetic biology. J Exp Bot, 66, 479-93.

BENNETT, R. N. \& WALLSGROVE, R. M. 1994. Secondary Metabolites in Plant Defense-Mechanisms. New Phytologist, 127, 617-633.

BIESGEN, C. \& WEILER, E. W. 1999. Structure and regulation of OPR1 and OPR2, two closely related genes encoding 12-oxophytodienoic acid-10,11-reductases from Arabidopsis thaliana. Planta, 208, 155-165.

BOUWMEESTER, H. J., VERSTAPPEN, F. W. A., POSTHUMUS, M. A. \& DICKE, M. 1999. Spider mite-induced (3S)-(E)-nerolidol synthase activity in cucumber and lima bean. The first dedicated step in acyclic C11-homoterpene biosynthesis. Plant Physiology, 121, 173-180.

DE VOS, M., VAN OOSTEN, V. R., VAN POECKE, R. M. P., VAN PELT, J. A., POZO, M. J., MUELLER, M. J., BUCHALA, A. J., METRAUX, J. P., VAN LOON, L. C., DICKE, M. \& PIETERSE, C. M. J. 2005. Signal signature and transcriptome changes of Arabidopsis during pathogen and insect attack. Molecular Plant-Microbe Interactions, 18, 923-937.

DE VOS, R. C., MOCO, S., LOMMEN, A., KEURENTJES, J. J., BINO, R. J. \& HALL, R. D. 2007. Untargeted large-scale plant metabolomics using liquid chromatography coupled to mass spectrometry. Nature Protocols, 2, 778-91.

DEGENHARDT, J. \& GERSHENZON, J. 2000. Demonstration and characterization of (E)-nerolidol synthase from maize: a herbivore-inducible terpene synthase participating in (3E)-4,8-dimethyl-1,3,7-nonatriene biosynthesis. Planta, 210, 815-822.

DEKKERS, B. J. W., WILLEMS, L., BASSEL, G. W., VAN BOLDEREN-VELDKAMP, R. P., LIGTERINK, 
W., HILHORST, H. W. M. \& BENTSINK, L. 2012. Identification of Reference Genes for RT-qPCR Expression Analysis in Arabidopsis and Tomato Seeds. Plant and Cell Physiology, 53, 28-37.

DICKE, M. \& BALDWIN, I. T. 2010. The evolutionary context for herbivore-induced plant volatiles: beyond the 'cry for help'. Trends in Plant Science, 15, 167-175.

EHLTING, J., CHOWRIRA, S. G., MATTHEUS, N., AESCHLIMAN, D. S., ARIMURA, G. \& BOHLMANN, J. 2008. Comparative transcriptome analysis of Arabidopsis thaliana infested by diamond back moth (Plutella xylostella) larvae reveals signatures of stress response, secondary metabolism, and signalling. BMC Genomics, 9, 154.

ERB, M., MELDAU, S. \& HOWE, G. A. 2012. Role of phytohormones in insect-specific plant reactions. Trends in Plant Science, 17, 250-259.

ERB, M., VEYRAT, N., ROBERT, C. A. M., XU, H., FREY, M., TON, J. \& TURLINGS, T. C. J. 2015. Indole is an essential herbivore-induced volatile priming signal in maize. Nature Communications, 6, 10.

FLOKOVÁ, K., TARKOWSKÁ, D., MIERSCH, O., STRNAD, M., WASTERNACK, C. \& NOVAK, O. 2014. UHPLC-MS/MS based target profiling of stress-induced phytohormones.

FURSTENBERG-HAGG, J., ZAGROBELNY, M. \& BAK, S. 2013. Plant defense against insect herbivores. Int J Mol Sci, 14, 10242-97.

GADINO, A. N., WALTON, V. M. \& LEE, J. C. 2012. Evaluation of methyl salicylate lures on populations of Typhlodromus pyri (Acari: Phytoseiidae) and other natural enemies in western Oregon vineyards. Biological Control, 63, 48-55.

GARMS, S., BOLAND, W. \& ARIMURA, G. 2008. Early herbivore-elicited events in terpenoid biosynthesis. Plant Signal Behav, 3, 418-9.

HENDRIKS, M. M. W. B., CRUZ-JUAREZ, L., DE BONT, D. \& HALL, R. D. 2005. Preprocessing and exploratory analysis of chromatographic profiles of plant extracts. Analytica Chimica Acta, 545, 53-64.

HILFIKER, O., GROUX, R., BRUESSOW, F., KIEFER, K., ZEIER, J. \& REYMOND, P. 2014. Insect eggs induce a systemic acquired resistance in Arabidopsis. Plant Journal, 80, 10851094.

HOWE, G. A. \& JANDER, G. 2008. Plant immunity to insect herbivores. Annu Rev Plant Biol, 59, 41-66.

KANT, M. R., AMENT, K., SABELIS, M. W., HARING, M. A. \& SCHUURINK, R. C. 2004. Differential timing of spider mite-induced direct and indirect defenses in tomato plants. Plant Physiology, 135, 483-495.

KAPPERS, I. F., AHARONI, A., VAN HERPEN, T., LUCKERHOFF, L. L. P., DICKE, M. \& BOUWMEESTER, H. J. 2005. Genetic engineering of terpenoid metabolism attracts, bodyguards to Arabidopsis. Science, 309, 2070-2072.

KAPPERS, I. F., HOOGERBRUGGE, H., BOUWMEESTER, H. J. \& DICKE, M. 2011. Variation in Herbivory-induced Volatiles Among Cucumber (Cucumis sativus L.) Varieties has Consequences for the Attraction of Carnivorous Natural Enemies. Journal of Chemical Ecology, 37, 150-160.

KAPPERS, I. F., VERSTAPPEN, F. W. A., LUCKERHOFF, L. L. P., BOUWMEESTER, H. J. \& DICKE, M. 2010. Genetic Variation in Jasmonic Acid- and Spider Mite-Induced Plant Volatile Emission of Cucumber Accessions and Attraction of the Predator Phytoseiulus persimilis. Journal of Chemical Ecology, 36, 500-12.

KESSLER, A. A. \& BALDWIN, I. T. 2002. PLANT RESPONSES TO INSECT HERBIVORY: The 
Emerging Molecular Analysis. Annual Review of Plant Biology, 53, 299-328.

KIM, B. R., NAM, H. Y., KIM, S. U., KIM, S. I. \& CHANG, Y. J. 2003. Normalization of reverse transcription quantitative-PCR with housekeeping genes in rice. Biotechnology Letters, 25, 1869-1872.

KUBIGSTELTIG, I., LAUDERT, D. \& WEILER, E. W. 1999. Structure and regulation of the Arabidopsis thaliana allene oxide synthase gene. Planta, 208, 463-71.

KUZINA, V., EKSTROM, C. T., ANDERSEN, S. B., NIELSEN, J. K., OLSEN, C. E. \& BAK, S. 2009. Identification of Defense Compounds in Barbarea vulgaris against the Herbivore Phyllotreta nemorum by an Ecometabolomic Approach. Plant Physiology, 151, 1977-1990.

LEISS, K. A., CHOI, Y. H., ABDEL-FARID, I. B., VERPOORTE, R. \& KLINKHAMER, P. G. L. 2009. NMR Metabolomics of Thrips (Frankliniella occidentalis) Resistance in Senecio Hybrids. Journal of Chemical Ecology, 35, 219-229.

LEONREYES, A., DOES, D. V. D., LANGE, E. S. D., DELKER, C., WASTERNACK, C., WEES, S. C. M. V., RITSEMA, T. \& PIETERSE, C. M. J. 2010. Salicylate-mediated suppression of jasmonate-responsive gene expression in Arabidopsis is targeted downstream of the jasmonate biosynthesis pathway. Planta, 232, 1423-1432.

LI, R., TEE, C. S., JIANG, Y. L., JIANG, X. Y., VENKATESH, P. N., SAROJAM, R. \& YE, J. 2015. A terpenoid phytoalexin plays a role in basal defense of Nicotiana benthamiana against Potato virus X. Sci Rep, 5, 9682.

LI, Z., YU, J., PENG, Y. \& HUANG, B. 2017. Metabolic pathways regulated by abscisic acid, salicylic acid and gamma-aminobutyric acid in association with improved drought tolerance in creeping bentgrass (Agrostis stolonifera). Physiol Plant, 159, 42-58.

LIU, Q., WANG, X., TZIN, V., ROMEIS, J., PENG, Y. \& LI, Y. 2016. Combined transcriptome and metabolome analyses to understand the dynamic responses of rice plants to attack by the rice stem borer Chilo suppressalis (Lepidoptera: Crambidae). BMC Plant Biology, 16, 259.

LOMMEN, A. 2009. MetAlign: Interface-Driven, Versatile Metabolomics Tool for Hyphenated Full-Scan Mass Spectrometry Data Preprocessing. Analytical Chemistry, 81, 3079-3086.

LORENZO, O. \& SOLANO, R. 2005. Molecular players regulating the jasmonate signalling network. Current Opinion in Plant Biology, 8, 532-540.

LøVDAL, T. \& LILLO, C. 2009. Reference gene selection for quantitative real-time PCR normalization in tomato subjected to nitrogen, cold, and light stress. Analytical Biochemistry, 387, 238-242.

MALLINGER, R. E., HOGG, D. B. \& GRATTON, C. 2011. Methyl Salicylate Attracts Natural Enemies and Reduces Populations of Soybean Aphids (Hemiptera: Aphididae) in Soybean Agroecosystems. Journal of Economic Entomology, 104, 115-124.

MCCORMICK, A. C., IRMISCH, S., REINECKE, A., BOECKLER, G. A., VEIT, D., REICHELT, M., HANSSON, B. S., GERSHENZON, J., KOLLNER, T. G. \& UNSICKER, S. B. 2014. Herbivore-induced volatile emission in black poplar: regulation and role in attracting herbivore enemies. Plant Cell and Environment, 37, 1909-1923.

MELDAU, S., ULLMAN-ZEUNERT, L., GOVIND, G., BARTRAM, S. \& BALDWIN, I. T. 2012. MAPK-dependent JA and SA signalling in Nicotiana attenuata affects plant growth and fitness during competition with conspecifics. Bmc Plant Biology, 12, 213.

MUELLER, M. J. 1997. Enzymes involved in jasmonic acid biosynthesis. Physiologia Planta- 
rum, 100, 653-663.

MUMM, R., POSTHUMUS, M. A. \& DICKE, M. 2008. Significance of terpenoids in induced indirect plant defence against herbivorous arthropods. Plant Cell and Environment, 31, 575-585.

NIST 2011. Nist/EPA/Nih Mass Spectral Library 2011 (Update). National Institute of Standards and Technology.

PATRA, B., PATTANAIK, S., SCHLUTTENHOFER, C. \& YUAN, L. 2018. A network of jasmonate-responsive bHLH factors modulate monoterpenoid indole alkaloid biosynthesis in Catharanthus roseus. New Phytologist, 217, 1566-1581.

PEDIGO, L. P. \& RICE, M. E. 2009. Entomology and Pest Management, Pearson Prentice Hall.

PICKETT, J. A. \& KHAN, Z. R. 2016. Plant volatile-mediated signalling and its application in agriculture: successes and challenges. New Phytologist, 212, 856-870.

PIESIK, D., LYSZCZARZ, A., TABAKA, P., LAMPARSKI, R., BOCIANOWSKI, J. \& DELANEY, K. J. 2010. Volatile induction of three cereals: influence of mechanical injury and insect herbivory on injured plants and neighbouring uninjured plants. Annals of Applied Biology, 157, 425-434.

PIETERSE, C. M., VAN DER DOES, D., ZAMIOUDIS, C., LEON-REYES, A. \& VAN WEES, S. C. 2012. Hormonal modulation of plant immunity. Annu Rev Cell Dev Biol, 28, 489521.

RASMANN, S., CHASSIN, E., BILAT, J., GLAUSER, G. \& REYMOND, P. 2015. Trade-off between constitutive and inducible resistance against herbivores is only partially explained by gene expression and glucosinolate production. Journal of Experimental Botany, $66,2527-2534$.

RIBEIRO, P. R., DEKKERS, B. J. W., FERNANDEZ, L. G., DE CASTRO, R. D., LIGTERINK, W. \& HILHORST, H. W. M. 2014. Identification of reference genes for gene expression studies during seed germination and seedling establishment in Ricinus communis L. Seed Science Research, 24, 341-352.

RIVAS-SAN VICENTE, M. \& PLASENCIA, J. 2011. Salicylic acid beyond defence: its role in plant growth and development. J Exp Bot, 62, 3321-38.

SANCHEZ-ROJO, S., CERDA-GARCIA-ROJAS, C. M., ESPARZA-GARCIA, F., PLASENCIA, J., POGGI-VARALDO, H. M., PONCE-NOYOLA, T. \& RAMOS-VALDIVIA, A. C. 2015. Longterm response on growth, antioxidant enzymes, and secondary metabolites in salicylic acid pre-treated Uncaria tomentosa microplants. Biotechnology Letters, 37, 2489-2496.

SCHALLER, F., BIESGEN, C., MUSSIG, C., ALTMANN, T. \& WEILER, E. W. 2000. 12-oxophytodienoate reductase 3 (OPR3) is the isoenzyme involved in jasmonate biosynthesis. Planta, 210, 979-984.

SCHMIESING, A., EMONET, A., GOUHIER-DARIMONT, C. \& REYMOND, P. 2016. Arabidopsis MYC Transcription Factors Are the Target of Hormonal Salicylic Acid/Jasmonic Acid Cross Talk in Response to Pieris brassicae Egg Extract. Plant Physiology, 170, 24322443.

STASWICK, P. E. \& TIRYAKI, I. 2004. The Oxylipin Signal Jasmonic Acid Is Activated by an Enzyme That Conjugates It to Isoleucine in Arabidopsis. The Plant Cell, 16, 21172127.

TANG, F., FU, Y. Y. \& YE, J. R. 2015. The effect of methyl salicylate on the induction of direct and indirect plant defense mechanisms in poplar (Populus $x$ euramericana 'Nanlin 
895'). Journal of Plant Interactions, 10, 93-100.

THINES, B., KATSIR, L., MELOTTO, M., NIU, Y., MANDAOKAR, A., LIU, G., NOMURA, K., HE, S. Y., HOWE, G. A. \& BROWSE, J. 2007. JAZ repressor proteins are targets of the SCF(COI1) complex during jasmonate signalling. Nature, 448, 661-5.

TIKUNOV, Y. M., LAPTENOK, S., HALL, R. D., BOVY, A. \& DE VOS, R. C. H. 2012. MSClust: a tool for unsupervised mass spectra extraction of chromatography-mass spectrometry ion-wise aligned data. Metabolomics, 8, 714-718.

TURNER, J. G., ELLIS, C. \& DEVOTO, A. 2002. The jasmonate signal pathway. Plant Cell, 14, S153-S164.

TYTGAT, T. O. G., VERHOEVEN, K. J. F., JANSEN, J. J., RAAIJMAKERS, C. E., BAKX-SCHOTMAN, T., MCINTYRE, L. M., VAN DER PUTTEN, W. H., BIERE, A. \& VAN DAM, N. M. 2013. Plants Know Where It Hurts: Root and Shoot Jasmonic Acid Induction Elicit Differential Responses in Brassica olracea. Plos One, 8, 14.

VACANTE, V. 2013. The mites as vectors of pathogens of plant. Protezione Delle Colture.

VAN, M. A., STEENSMA, P., SCHWEIZER, F., POLLIER, J., GARIBOLDI, I., PAYNE, R., VANDEN, B. R., MIETTINEN, K., ESPOZ, J. \& PURNAMA, P. C. 2015. The bHLH transcription factor BIS1 controls the iridoid branch of the monoterpenoid indole alkaloid pathway in Catharanthus roseus. Proceedings of the National Academy of Sciences of the United States of America, 112, 8130.

VANDOORN, A., BONAVENTURE, G., SCHMIDT, D. D. \& BALDWIN, I. T. 2011. Regulation of jasmonate metabolism and activation of systemic signaling in Solanum nigrum: COI1 and JAR4 play overlapping yet distinct roles. New Phytologist, 190, 640-652.

VERMA, V., RAVINDRAN, P. \& KUMAR, P. P. 2016. Plant hormone-mediated regulation of stress responses. Bmc Plant Biology, 16.

WALLING, L. L. 2009. Chapter 13 Adaptive Defense Responses to Pathogens and Insects, Elsevier Science \& Technology.

WAN, H. J., YUAN, W., RUAN, M. Y., YE, Q. J., WANG, R. Q., LI, Z. M., ZHOU, G. Z., YAO, Z. P., ZHAO, J., LIU, S. J. \& YANG, Y. J. 2011. Identification of reference genes for reverse transcription quantitative real-time PCR normalization in pepper (Capsicum annuum L.). Biochemical and Biophysical Research Communications, 416, 24-30.

WAR, A. R., PAULRAJ, M. G., AHMAD, T., BUHROO, A. A., HUSSAIN, B., IGNACIMUTHU, S. \& SHARMA, H. C. 2012. Mechanisms of plant defense against insect herbivores. Plant Signal Behav, 7, 1306-20.

WASTERNACK, C. \& HAUSE, B. 2013. Jasmonates: biosynthesis, perception, signal transduction and action in plant stress response, growth and development. An update to the 2007 review in Annals of Botany. Annals of Botany, 111, 1021-1058.

WILEY, M. 2016. Wiley Registry of Mass Spectral Data, 11th Edition. Proteomics.

YUAN, H.-M., LIU, W.-C. \& LU, Y.-T. 2017. CATALASE2 Coordinates SA-Mediated Repression of Both Auxin Accumulation and JA Biosynthesis in Plant Defenses. Cell Host \& Microbe, 21, 143-155.

ZHOU, S. Q., LOU, Y. R., TZIN, V. \& JANDER, G. 2015. Alteration of Plant Primary Metabolism in Response to Insect Herbivory. Plant Physiology, 169, 1488-1498. 


\section{Supplemental Tables}

Supplemental files to this chapter can be downloaded from:

<http://www.wageningenseedlab.nl/thesis/vuanyuanzhang/>http://www.wageningenseedlab.nl/thesis/vuanyuanzhang/

<http://www.wageningenseedlab.nl/thesis/yuanyuanzhang/Sl/>http://www.wageningenseedlab.nl/thesis/vuanyuanzhang/SI/

Supplemental Table 1. Hormone levels in G29 during 20 days post infestation;

Supplemental Table 2. Hormone levels in G8 during 15 days post infestation;

Supplemental Table 3.1 Primer sequences of seleted reference genes; 3.2 Ranking order of seleted reference genes with multiple methods;

Supplemental Table 4. Primer sequences of maker genes;

Supplemental Table 5. Spider mites population development in $\mathbf{G} 29$ during 20 days post infestation.

Supplemental Table 6. Output from Metalign alignment and MSclust classification of ion intensity from LC-QToF-MS metabolite profiling in genotype 29;

Supplemental Table 7. Predatory mites attracted by $\mathbf{G} 29$ and $\mathbf{G} 25$ during 20 days post infestation.

Supplemental Table 8. Output from Metalign alignment and MSclust classification of ion intensity from GC-QToF-MS metabolite profiling in genotype 29;

Supplemental Table 9. Output from Metalign alignment and MSclust classification of ion intensity from LC-orbitrap-MS metabolite profiling in genotype 8;

Supplemental Table 10. GC-MS data from of genotype 8. 


\section{Chapter 4 Combined transcriptome and metabolome analysis reveals induction and suppression of defense responses upon JA and two-spotted spider mite herbivory in Capsicum annuum}

Yuanyuan Zhang, Jan van Haarst, Harro Bouwmeester \& Iris Kappers 


\section{Abstract}

Plants regulate defense responses towards herbivory through fine-tuning of defense related plant hormone production, which results in the expression of defense genes as well as the production of secondary metabolites. Multiple studies have shown that jasmonic acid (JA), as an essential plant stress hormone, plays a key role in plant-herbivorous arthropod interaction. Two-spotted spider mite (Tetranychus urticae Koch, TSSM) is a commonly reported pest threat for many crops including pepper (Capsicum spp.), and severely reduces yield. For a better control of this pest, insight into the molecular mechanisms underlying the defense responses against spider mites is required. In this study, we compared herbivore and JA-induced changes in the transcriptome of two Capsicum annuum genotypes that differ in their susceptibility to spider mites. Multivariate analysis and a weighted gene co-expression network based on RNA-seq data revealed distinct transcriptome profiles for spider mite and JA induction and relatively similar transcriptional responses between the two genotypes for a given treatment. Gene ontology and pathway analysis showed that JA mainly induced JA signaling, metabolic processes and responses to wound and abiotic stress and repressed photosynthesis, while spider mites induced both JA and salicylic acid (SA) signaling and responses to multiple stresses including wound and fungus/bacterium. Compared with exogenous JA application, spider mites induced few differentially expressed genes (DEGs) involved in metabolic processes except for genes involved in the phenylpropanoid pathway and lipid metabolic process. Spider mites induced mainly pathogen-related defense responses including the activation of WRKY transcription factors and pathogenesis related (PR) gene expression likely as a result of SA signaling. Untargeted analysis of endogenous secondary metabolites on the same samples confirmed that JA induced more extensive changes in metabolism than spider-mite infestation, resulting for example in a higher production of terpenoids and flavonoids. Between genotypes, the more resistant genotype exhibited the higher increase in JA and produced more volatile and non-volatile secondary metabolites upon spider-mite infestation, which could explain the stronger defense. We discuss the implications of the simultaneous induction of JA and SA signaling by spider mites. Our data provide a direct comparison between spider mites and JA induced responses at both the transcriptome and metabolome level and give a comprehensive insight into the hormone-regulated, metabolite-based induced defense against spider mites in pepper. 


\section{Introduction}

Plants have evolved multiple mechanisms to defend themselves against herbivores and pathogens. Constitutively present leaf surface waxes, toxic secondary metabolites and morphological structures such as trichomes and thorns, form the first barrier in plants to prevent herbivore attack (Furstenberg-Hagg et al., 2013). Should these barriers not be sufficient, upon herbivore feeding, plants can produce defensive proteins and secondary metabolites that are toxic or anti-nutritional to affect the herbivore's growth and reproduction directly. In addition to this induced direct defense, arthropod herbivory also results in the release of herbivore-induced plant volatiles (HIPVs) that attract natural enemies of the herbivores, thus protecting the plant indirectly (Yamawo et al., 2012, Kappers et al., 2005, War et al., 2012, Gols, 2014). Ubiquitous or species-specific plant secondary metabolites belonging to different chemical classes such as phenolics, terpenoids and green leaf volatiles play a key role in these direct and indirect defenses (Cheynier et al., 2013, Tholl, 2015, Scala et al., 2013, Snoeren et al., 2010).

Plants can distinguish herbivore presence from mechanical damage by recognizing herbivore oral secretions or oviposition fluids (Bandoly et al., 2015, Little et al., 2007). These elicitors, together with the damage caused by the herbivore, trigger electrical signals and change the $\mathrm{Ca}^{2+}$ homeostasis. Subsequently, signal transduction through kinases such as $\mathrm{Ca}^{2+}$-binding protein kinases (CDPKs) and mitogen-activated protein kinases (MAPKs) is followed by downstream defense responses regulated through hormone signaling pathways (Furstenberg-Hagg et al., 2013). Jasmonic acid (JA), ethylene (ET) and salicylic acid (SA) are the three major plant hormones involved in plant defense responses to biotic stress, including various pathogens and arthropod herbivores (Bari and Jones, 2009). Both the individual hormones as well as the crosstalk between them play an essential role in fine-tuning of the defense responses to specific attackers (Kawazu et al., 2012).

ET is involved in many plant developmental processes such as ripening, and leaf and flower senescence. Furthermore, it is involved in reactions towards biotic and abiotic stresses (Bleecker and Kende, 2000). A rapid increase in ET production is detectable upon interaction of plants with pathogens including bacteria, fungi and viruses and this corresponds with the regulation of several plant defense genes (Grennan, 2008, Huang et al., 2016). These genes are involved in different processes, such as the hypersensitive response (HR) and the production of phytoalexins (Fan et al., 2000, Bouchez et al., 2007), pathogenesis-related (PR) proteins and proteinase inhibitors (Tornero et al., 1994, Tornero et al., 1997, Van Kan et al., 1995, Diaz et al., 2002). Carmine spider mite (Tetranychus cinnabarinus Boisduval) feeding 
caused an increase in ethylene production by $40 \%$ within the first 3 days of infestation in tomato leaves (Kielkiewicz, 2002).

SA accumulates upon pathogen infection and is generally known to mediate plant defense responses against biotrophic and hemi-biotrophic pathogens including systemic acquired resistance (SAR) (Durrant and Dong, 2004). Application of exogenous SA and its derivative, acetylsalicylic acid, induced the expression of pathogenesis-related $(P R)$ genes and enhanced the resistance to pathogens in tobacco cv. Xanthi-nc (White, 1979, Verma et al., 2016). NON-EXPRESSOR OF PR GENES1 (NPR1), a master transcriptional co-regulator in the SA signaling pathway is also regulated by the cellular redox state (Fu and Dong, 2013). NPR1 activates SA-dependent gene transcription by binding to transcription factors of the TGA family (Wang et al., 2006). Several WRKY transcription factors are also involved in downstream transcriptional responses to SA (Eulgem and Somssich, 2007, Kloth et al., 2016).

Jasmonates (JAs) are lipid-derived signaling molecules mediating multiple aspects of plant development such as lateral/adventitious root formation, trichome formation, flower development and leaf senescence as well as plant responses to various biotic and abiotic stresses (Wasternack and Hause, 2013). JAs predominantly have a role in the response to wounding (Creelman et al., 1992), herbivores (Howe and Jander, 2008) and necrotrophic pathogens (Glazebrook, 2005). Biosynthesis of JA starts with the oxygenation of $\alpha$-linolenic acid (18:3) ( $\alpha$-LeA) that is released from chloroplast membranes (Weber et al., 1997) catalyzed by LIPOXYGENASES (LOXs) (Schaller, 2001). The produced hydroperoxy-octadecatrienoic acid undergoes several enzymatic steps including dehydration, stereospecific cyclization and reduction catalyzed by ALLENE OXIDE SYNTHASE (AOS) (Laudert et al., 2000, Kubigsteltig et al., 1999), ALLENE OXIDE CYCLASE (AOC) (Ziegler et al., 2000) and 12-OXOPHYTODIENOATE REDUCTASE (OPR3), respectively (Schaller et al., 2000), which is followed by three rounds of $\beta$-oxidation to form JA (Turner et al., 2002). JA is conjugated to the amino acid leucine to form the bioactive JA-lle (Staswick and Tiryaki, 2004, Kang et al., 2006). In response to wounding or herbivory, JA-lle accumulates and is perceived by the CORONATINE-INSENSITIVE 1 (COI1), an F-box protein that forms a Skp1/ Cullin/F-box complex (Xie et al., 1998), which then recruits JASMONATE ZIM DOMAIN (JAZ) proteins for degradation by the $26 \mathrm{~S}$ proteasome (Thines et al., 2007, Yan et al., 2007). In unstimulated conditions, JAZ represses BASIC HELIX-LOOP-HELIX (bHLH) transcription factors including MYC2, MYC3 and MYC4 with co-repressor TOPLESS and the adaptor protein NOVEL INTERACTOR OF JAZ (NINJA). Upon stress, degradation of JAZ releases MYC2 which can then bind to JA responsive elements (G-boxes) in the promoters of JA 
regulated genes (Fernandez-Calvo et al., 2011, Pauwels et al., 2010). In Arabidopsis thaliana, MYC2 positively regulates expression of wound-responsive genes such as VEGETATIVE STORAGE PROTEIN (VSP) 1 and 2, TYROSINE AMINOTRANSFERASE (TAT) and LOX (Lorenzo et al., 2004). MYC2 enhances the production of flavonoids, also in Medicago truncatula (Adolfsson et al., 2017) and is required for the JA-mediated tolerance to the generalist herbivore Helicoverpa armigera (Dombrecht et al., 2007). In addition to MYC-regulated JA responses, APETALA2/ETHYLENE RESPONSE FACTOR (AP2/ERF) domain transcription factors are involved in JA signaling in co-regulation with ET. ERF1 and OCTADECANOID-RESPONSIVE ARABIDOPSIS59 (ORA59) are induced by both JA and ET, requiring both signaling pathways in a COI independent way (Lorenzo et al., 2003, Kazan and Manners, 2013). ERF1 and ORA29 positively regulate expression of PLANT DEFENSIN1.2 (PDF1.2) and increase resistance to pathogens (Lorenzo et al., 2003, Pre et al., 2008). MYC2 works as negative regulator of pathogen defensive genes, including PDF1.2, BASIC CHITINASE (CHIB) and PATHOGENESIS-RELATED GENE 4/HEVEIN-LIKE GENE (PR4/HEL) probably mediated by suppression of ERF1 (Dombrecht et al., 2007). JA has been identified as the responsible hormone for the accumulation of several different classes of bioactive secondary metabolites (Memelink et al., 2001, Gundlach et al., 1992).

Unlike the synergism between JA and ET, SA regulates biotic stress responses antagonistically with the JA signaling pathway (Bari and Jones, 2009, Erb et al., 2012, Furstenberg-Hagg et al., 2013). In tomato, JA-induced wound responses were inhibited by acetylsalicylic acid supporting the antagonistic relation between the JA and SA pathway (Doherty et al., 1988). Bypassing JA biosynthesis by exogenous application of methyl-JA in a JA biosynthesis deficient mutant aos/dde2 did not affect SA mediated suppression of JA responsive genes PDF1.2 and VSP in A. thaliana (Leon-Reyes et al., 2010). In A. thaliana, WRKY transcription factors are essential for mediating the crosstalk between JA and SA (Spoel et al., 2003). Overexpression of the NPR1-independent transcription factor WRKY7O resulted in constitutive expression of SA induced pathogenesis-related genes and increased resistance to virulent pathogens while antisense suppression of WRKY7O activated JA responsive/COI independent genes (Li et al., 2004).

Capsicum annuum, including sweet and hot peppers, belongs to the nightshade family Solanaceae, and is a worldwide grown and economically important vegetable crop (Carrizo García et al., 2016)(http://www.fao.org). As for many other crops, herbivorous pests are a major threat to Capsicum production. The two-spotted spider mite, Tetranychus urticae Koch, is a cell-content sucking arthropod and has been reported to infest over 200 
plant species, especially within the Solanaceae family (Fasulo and Denmark, 2016), including Capsicum. Predatory mites, Phytoseiulus persimilis, feed on spider mite adults as well as on their eggs and can use the odour emitted by infested plants as a cue to locate their prey (Dicke et al., 1991).

To obtain a comprehensive insight into the defense responses of sweet pepper against two-spotted spider mites and how the stress-related hormones, especially JA, play a role in herbivory-induced defenses, we present here a comparative, genome-wide, transcriptome analysis upon spider-mite infestation and JA treatment in two $C$. annuum genotypes that differ in spider mite susceptibility. The corresponding metabolome and defense-related plant hormone profiles were analyzed to underpin the analysis of the transcriptome defense responses.

\section{Material and methods}

\section{Plants, arthropods and experimental set up}

Two-spotted spider mites (Tetranychus urticae Koch) were originally obtained from Koppert (Berkel and Rodenrijs, The Netherlands) and propagated on lima bean plants (Phaseolus lunatus) for many generations. Predatory mites, Phytoseiulus persimilis were obtained from a standard rearing from Koppert and were delivered to the lab on the experimental day.

Seeds of Capsicum annuum varieties Vania (Inbred line, Genotype 8) and Ta Pien Chiao (Land race, Genotype 29) were incubated on wet filter paper in a Petri dish at $23^{\circ} \mathrm{C}$ for 6 to 7 days until cotyledons emerged. Seedlings were transferred to $7 \times 7 \times 8 \mathrm{~cm}$ plastic pots filled with compost and grown for 5 weeks in a greenhouse $\left(16: 8 \mathrm{~h}, 23: 18^{\circ} \mathrm{C} /\right.$ day : night, $50-60 \%$ relative humidity) located at Wageningen, The Netherlands. Five-week old plants were infested with about 300 adult spider mites for 3 days or treated with JA (100 $\mu \mathrm{M}, 0.01 \%$ Tween-80) for 6 or 24 hours prior to harvest or left untreated. JA was applied by spraying leaves with a fine mist until drops fell of the leaves. Leaves from different ontogenic positions from each plant were pooled together as one bio replicate and powdered in liquid nitrogen. Three independent biological replicates were generated for each treatment as well as for untreated controls. The same samples were used for RNA isolation (two replicates due to budget considerations), analysis of endogenous metabolites and stress-related phytohomones. 


\section{Spider mite population}

In a separate batch of infested Capsicum plants, the number of spider mite adults, eggs and nymphs on leaves of 3 individual plants were counted after 3 days of infestation to evaluate plant resistance to spider mites.

\section{Olfactometer assays with predatory mites}

A Y-tube olfactometer (Takabayashi and Dicke, 1992) was used to determine preferences of predatory mites. The airflow through each olfactometer arm was set at a rate of $3.0 \mathrm{l} / \mathrm{min}$. Adult predators were individually introduced at the start point of the $\mathrm{Y}$-tube. The behaviour of each predator was observed for 5 minutes. The observation was terminated when a predator crossed the finish line which was pre-set on each arm of the Y-tube. Predators that did not reach the finish line (no choice) within $5 \mathrm{~min}$ were excluded from the statistical analysis. Each comparison of odors was tested four times using 20 individual adults per replicate. Choices of predatory mites between odor sources were analyzed with two-sided binominal tests to determine whether the distribution of the predators' choice was significantly different from 50:50. Predators that did not make a choice within 5 mins were excluded from the statistical analysis.

\section{RNA-isolation, library preparation and sequencing}

About $100 \mathrm{mg}$ of tissue of each sample was used for total RNA extraction with TriPure (Roche, Mannheim, Germany). The extracted total RNAs were cleaned with the RNeasy Plant Mini Kit (Qiagen, USA) and genomic DNA was digested using RNase-Free DNase (Qiagen, USA) according to the manufacturer's instructions. RNA integrity was evaluated by $1.0 \%$ agarose gel electrophoresis. Total RNA for RNA-seq library construction was quantified (Thermo scientific Nanodrop 2000, Wilmington, USA) and samples with a concentration above $300 \mathrm{ng} / \mu \mathrm{l}, \mathrm{A}_{260} / \mathrm{A}_{280}$ values between 1.8 to 2.0 and $\mathrm{A}_{260} \mathrm{~J}$ $A_{230}$ values between 2.0 to 2.2 were sent for cDNA library construction and sequencing (Bioscience, Plant Research International, WUR, Wageningen, The Netherlands).

Transcriptome libraries were constructed using the TruSeq ${ }^{\mathrm{TM}}$ RNA sample Prep Kit (Illumina, CA, USA). Sequencing was conducted using Illumina HiSeq ${ }^{\mathrm{TM}} 2500$ (Illumina, CA, USA) platform and produced 9 to 20 million-bp pairedend reads per sample. Reads were filtered with the program Trimmomatic (Bolger et al., 2014) to remove the adaptor sequences, empty reads, short reads ( $<25 \mathrm{bp}$ ), reads with an $\mathrm{N}$ ratio greater than $10 \%$ and low quality sequences, all of which negatively affect the bioinformatics analysis. 


\section{Quality control and Mapping}

Quality control was performed with FastQC (http://www.bioinformatics. babraham.ac.uk/projects/fastqc) and clean reads were generated in FASTQ format. Clean reads were mapped to the Capsicum annuum L Zunla-1 reference genome (http://peppersequence.genomics.cn/page/species/index. jsp) with CLC Genomics Server 7.0.3 (Mortazavi et al., 2008). Transcript assembly, quantification, normalisation and differential expression analysis were performed with CLC Genomics Server 7.0.3 using the default settings for RNA-Seq mapping and analysis, and using quantile normalization.

\section{Function annotation of Capsicum annuum L Zunla-1 sequences}

Capsicum annuum L Zunla-1 sequences were downloaded from the Pepper Genome Database (release 2.0, Pepper Institute, Zunyi Academy of Agricultural Science). Assembled sequences were putatively annotated using NCBI-blast- 2.2 in case of $>90 \%$ identity and an E-value of $<0.00001$.

\section{Gene expression analysis}

The RNA-Seq reads were mapped to the assembled sequences to calculate the read counts for each unigene. Only paired-end reads paired with unique locations were calculated as expression values of the assembled unigenes. Transcript levels of each unigene were calculated and normalized as the reads per kilobase of transcript per million mapped reads (RPKM). Genes that were differentially expressed between different experimental conditions (differently expressed genes, DEGs) were filtered at a threshold of Log2 transformed fold change (treatment / control) $>1.5$ or $<-1.5$ and $P<$ 0.05 after Benjamini and Hochberg false discovery rate correction, (Benjamini and Hochberg, 1995).

\section{Cluster analysis}

RPKM expression values of DEGs under different experimental conditions were analyzed in a multidimensional way using GeneMaths XT (Applied Maths, 2010). The expression values were Log2 transformed and Hierarchical Clustering Analysis (HCA) was performed based on Log2 transformed data. The distance was calculated using Pearson Correlation and summarized with UPGMA (Unweighted Pair Group Method with Arithmetic Mean) method. Principle Component Analysis (PCA) was performed after HCA with both row and column data subtracted with the average of that row or column. 


\section{Gene enrichment analysis}

DEGs discovered in our experiment were mapped to GO terms in the general gene ontology database (Du et al., 2010) with homolog to Capsicum annuum.L_Zunla-1 genes in A. thaliana. All the Capsicum genes were blasted against $A$. thaliana genome using the CLC Workbench (QIAGEN Bioinformatics).

\section{Gene co-expression network analysis}

Pearson correlation coefficients were calculated between DEGs to build a co-expression network using Cytoscape 3.3.0. A threshold correlation of 0.85 (negative or positive) was used to get a minimum number of edges while retaining maximum nodes.

\section{Stress-related plant hormones}

The analysis of endogenous stress-related plant hormones - SA, JA, its biosynthetic precursor cis-OPDA and the biologically active metabolite JA-lle - was performed according to Floková et al. (Floková et al., 2014) with modifications. Frozen plant tissue was ground to a fine powder in liquid nitrogen and lyophilized. Aliquots of $7 \mathrm{mg}$ of dry weight were extracted in $1 \mathrm{ml}$ of ice cold $10 \%$ methanol/water (v/v) and homogenized using an MM 301 vibration mill at a frequency of $27 \mathrm{~Hz}$ for 3 min (Retsch GmbH \& Co. KG, Haan, Germany) in the presence of zirconium oxide homogenization beads. At this stage, stable isotope-labelled internal standards $\left[{ }^{2} \mathrm{H}_{4}\right]-\mathrm{SA},\left[{ }^{2} \mathrm{H}_{6}\right]-\mathrm{JA},\left[{ }^{2} \mathrm{H}_{5}\right]$-cisOPDA and $\left[{ }^{2} \mathrm{H}_{2}\right]-J A-l l e$ were added to each sample for quantification. Samples were further extracted for $30 \mathrm{~min}$ by constant shaking $(200 \mathrm{rpm})$ at $4^{\circ} \mathrm{C}$. Plant extracts were centrifuged $\left(13000 \mathrm{rpm} / 10 \mathrm{~min} / 4^{\circ} \mathrm{C}\right)$ and supernatants purified using Strata $X(30 \mathrm{mg} / 3 \mathrm{cc}$, Phenomenex) columns, activated with $1 \mathrm{ml}$ of methanol, $1 \mathrm{ml}$ of water and $1 \mathrm{ml}$ of the extraction solvent. Loaded samples were washed with $3 \mathrm{ml}$ of water and compounds of interest eluted with $3 \mathrm{ml}$ of $80 \%$ methanol/water $(\mathrm{v} / \mathrm{v})$. The solvent was evaporated to dryness under a stream of nitrogen and dried samples were stored at $-20^{\circ} \mathrm{C}$ until UPLC-MS/MS analysis. The Acquity UPLC ${ }^{\circledR}$ System (Waters, Milford, MA, USA) coupled to a triple quadrupole mass spectrometer Xevo ${ }^{\mathrm{TM}} \mathrm{TQ}-\mathrm{S}$ (Waters MS Technologies, Manchester, UK) was employed to determine endogenous levels of plant hormones. Dried samples were reconstituted in $60 \mu \mathrm{l}$ of mobile phase and injected on reverse phase based column Acquity UPLC $^{\circledR} \mathrm{CSH}^{\mathrm{TM}} \mathrm{C} 18 ; 2.1 \times 100 \mathrm{~mm} ; 1.7 \mu \mathrm{m}$ (Waters, Ireland) at a flow rate of $0.4 \mathrm{ml} \mathrm{min}{ }^{-1}$. Separation was performed at $40^{\circ} \mathrm{C}$ using a 9 min binary gradient elution using $15 \mathrm{mM}$ formic acid/ water (A) and acetonitrile (B) with following conditions: 0-1 min isocratic elution at $15 \% \mathrm{~B}(\mathrm{v} / \mathrm{v}), 1-7$ min linear 
gradient to $60 \%$ B, 7-9 min linear gradient to $80 \%$ B and 9-10 min logarithmic gradient to $100 \%$ B. Finally, the column was washed with $100 \%$ acetonitrile and equilibrated for initial conditions ( $2 \mathrm{~min}$ ). The eluent was introduced into the electrospray ion source of a tandem mass spectrometer operating at following settings: source/desolvation temperature $\left(120 / 550^{\circ} \mathrm{C}\right)$, cone/ desolvation gas flow $\left(147 / 650 \mathrm{~L} \mathrm{~h}^{-1}\right)$, capillary voltage $(3 \mathrm{kV})$, cone voltage (25-30 V), collision energy (10-25 eV) and collision gas flow $0.25 \mathrm{ml} \mathrm{min}^{-1}$. Compounds were quantified in multiple reaction monitoring mode (MRM) using standard isotope dilution method. The MassLynx ${ }^{\mathrm{TM}}$ software (version 4.1, Waters, Milford, MA, USA) was used to control the instrument, and acquire and process MS data.

\section{Volatile metabolites}

The headspace of spider-mite infested, JA-treated and non-treated control plants was collected using a dynamic headspace sampling procedure. In this setup a table surface of stainless steel with notches was used to position pots with roots underneath the table surface while stems and leaves were above. In this way contamination by volatiles from pot and soil was minimized. The shoot was placed under a $2.5 \mathrm{~L}$ glass jar. Inlet air was pre-treated using a zero-air generator (Bronkhorst, The Netherlands) and supplemented with $\mathrm{CO}_{2}$ to $400 \mathrm{ppm}$ and a $\mathrm{RH}$ of $50 \%$. Inlet air was introduced via Teflon tubing into the glass jar at $300 \mathrm{ml} . \mathrm{min}^{-1}$. Volatiles were collected on pre-conditioned Tenax TA (200 mg, 20/35 mesh; Grace-Alltech, Deerfield, MI, USA) in stainless steel liners (Markes, Llantrisant, UK) connected to the outlet of the system at a flow of $200 \mathrm{ml}^{\mathrm{min}} \mathrm{m}^{-1}$. The slight overpressure minimizes contamination by background odors from the chamber. Volatiles were collected for 2 hours and afterwards Tenax cartridges were dry-purged with nitrogen for $30 \mathrm{ml} \mathrm{min}^{-1}$ for $30 \mathrm{~min}$ at ambient temperature before GC-MS analysis. Fresh weights of leaves were determined immediately after the collection for weight correction.

Volatiles were resorbed from the cartridges with a Thermal Desorber TD100xr (Unity, MARKES International) connected to a GC/Q-ToF (Agilent Technologies, CA, USA). Analytes were focused at $0^{\circ} \mathrm{C}$ on an electronically-cooled sorbent trap (Unity, Markes, Llantrisant, UK). Volatiles were transferred with split flow of $99 \mathrm{ml} \mathrm{min}^{-1}$ to the analytical column by rapid heating of the cold trap to $260^{\circ} \mathrm{C}$ for 3 minutes using a $7890 \mathrm{~B}$ GC-system for separation with a DB-5MS column of $30 \mathrm{~m}$ long a 0.250 diameter, $1 \mu \mathrm{m}$ film and a constant Helium flow of $1.2 \mathrm{ml} \mathrm{min}^{-1}$. (Agilent J\&W CC columns, Agilent Technologies, CA, USA). For each sample, the oven temperature was set at $40^{\circ} \mathrm{C}$ for 2 minutes to $280^{\circ} \mathrm{C}$ for 4 minutes followed by a linear thermal gradient of $10{ }^{\circ} \mathrm{C}$ $\mathrm{min}^{-1}$ and held for $2.5 \mathrm{~min}$. The column effluent was ionized by electron im- 
pact ionization at $70 \mathrm{eV}$ and got detected with an Agilent Technologies 7200 accurate mass Q-Tof GC/MS. Mass spectra were acquired by scanning from $50-350 \mathrm{~m} / \mathrm{z}$ with a scan rate of 5 scans. $\mathrm{min}^{-1}$. Chromatograms were analyzed for the presence of plant derived compounds using using the deconvolution software AMDIS (version 2.64, NIST, USA) / MassHunter, Unknown Analysis (C) Agilent Techologies, Inc 2008, in combination with NIST 98 and Wiley 7th edition spectral libraries. For relative quantification, characteristic quantifier ions were selected for each compound. Data files generated from GC-MS platform were processed with mzmine (mzmine.github.io/) for baseline correction, mass spectra extraction and mass signal alignment.

\section{Endogenous semi-polar secondary metabolites}

Semi-polar endogenous metabolites were analyzed by Synapt ultra-performance liquid chromatography coupled to Time of Flight mass spectrometry (Synapt UPLC-MS). From the same lyophilized leaf material as used for plant hormone analysis $20 \mathrm{mg}$ was extracted with $2 \mathrm{ml} \mathrm{75 \%} \mathrm{MeOH}(0.1 \%$ formic acid) solution (De Vos et al., 2007). Samples were homogenized for 5 seconds and sonicated for 15 min at maximum frequency $(40 \mathrm{kHz})$ in a water bath at ambient temperature, and centrifuged for $10 \mathrm{~min}$ at $5000 \mathrm{rpm}$. The supernatant was filtered using a $0.45 \mu \mathrm{m}$ inorganic membrane filter (Omnifix, Germany), fitted onto a disposable syringe and transferred into a $0.3 \mathrm{ml}$ LC-MS plastic vial. Aliquots of $10 \mu$ of each sample were combined to make a quality control sample (QC), which was analyzed multiple times throughout the analyzing sequence in order to be able to correct for shifts in retention times.

The LC-Synapt QTOF-MS platform consisted of reversed phase liquid chromatography (Waters Alliance HPLC 2695) equipped with a luna C18 column including pre-column $\left(2.0 \times 4 \mathrm{~mm}^{2}\right)$ and an analytical column $(2.0 \times 150$ $\mathrm{mm}^{2}, 100 \AA$, particle size $3 \mu \mathrm{m}$; Phenomenex), a photodiode array detector (PDA) and a quadrupole time of flight mass spectrometry of the Synapt G2S (Waters, QTOF-Ultima) with negative electrospray ionization mode. Five $\mu \mathrm{L}$ of extracts were separated using a gradient of formic acid:water (1:1000, $\mathrm{v} / \mathrm{v}$; eluent $A$ ) and formic acid:acetonitrile (1:1000, v/v; eluent B). Extracts were injected into HPLC at $0.19 \mathrm{~mL} \mathrm{~min}^{-1}$. The initial solvent composition consisted of $95 \% A$ and $5 \% B$, increased linearly to $65 \% A$ and $35 \%$ B within $45 \mathrm{~min}$ and maintained for $2 \mathrm{~min}$. The column was washed with $25 \% \mathrm{~A}$ and $75 \%$ B for 15 min and equilibrated to $95 \%$ A and $5 \%$ B for 5 min before next injection. A collision energy of $10 \mathrm{eV}$ was used for full-scan LC-MS in the $\mathrm{m} / \mathrm{z}$ range $100-1,500$. The mixture was divided into 5 vials to make 5 replicates with maximum volume $180 \mu \mathrm{l}$ to prevent overflow during injection. Data files generated from LC-MS platform were processed with Metalign 
software (Lommen, 2009) for baseline correction, mass spectra extraction and mass signal alignment. MSClust (Tikunov et al., 2012) was used for data reduction by unsupervised clustering and extracting putative metabolite from mass spectra from ion-wise chromatographic alignment data. Principal Component Analysis was performed on the reduced dataset to obtain an overview of the whole dataset using GeneMath XT 2.0 after log2 transformation and noise subtraction (Hendriks et al., 2005). Individual metabolites were analyzed for significant changes upon infestation using a t-test (SPSS 15.0, Chicago, II, USA). The selected endogenous metabolites were putatively annotated based on their molecular weight using the knapsack database (http://kanaya.naist.jp/knapsack jsp/top.html). Multivariate analysis of volatile and non-volatile metabolites was performed using the R-based online tool, MetaboAnalyst 3.0 (Xia and Wishart, 2002). 


\section{Results}

\section{Comparison of spider mite performance and predatory mite attractiveness in two Capsicum annuum genotypes}

Two genotypes that were previously shown to be distinctive in their relative direct defense to spider mites as well as in their relative indirect defense with respect to attractiveness towards predatory mites were selected from 22 genotypes from different geographic origins for further analysis. To compare the initial resistance level of these two genotypes, we determined the spider mite population development (number of adults, eggs and nymphs) 4 days after placing female adults on the whole plant. More spider mites survived and produced more eggs on genotype 8. Especially, more eggs developed into young nymphs on leaves of genotype 8 with 13.1 nymphs per leaf on average compared to 6.2 nymphs per leaf on genotype $29(P=0.039)$.

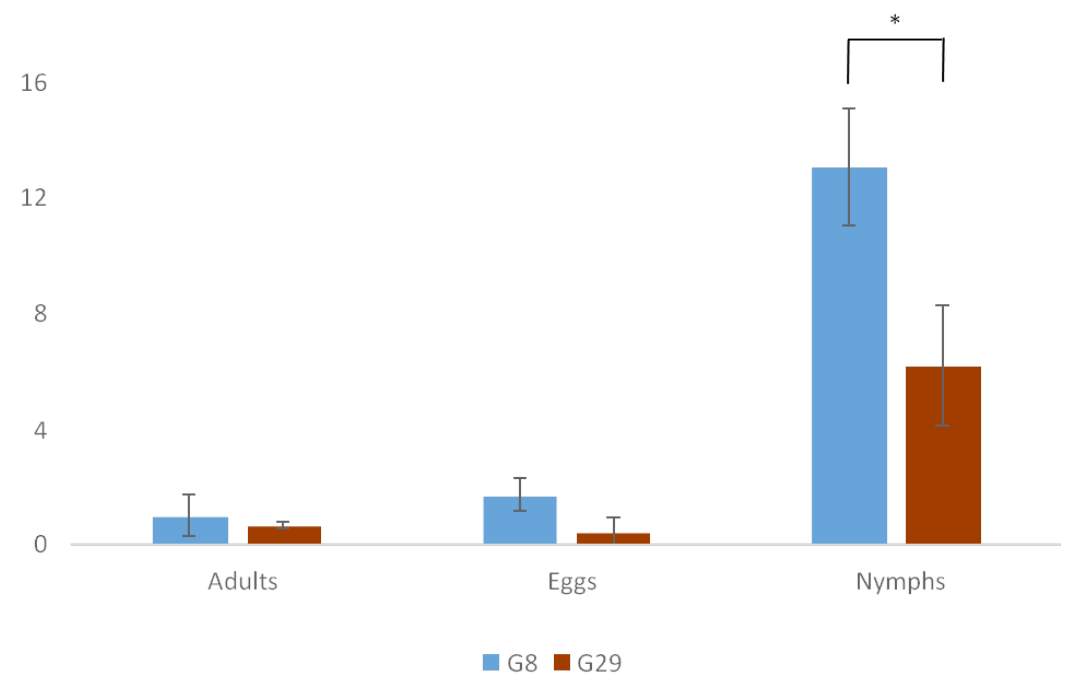

Figure 1. Spider mite population including adults, eggs and nymphs (per leaf), 4 days after infestation on Capsicum plants. Data are means ( \pm SE) of 3 replicates and were tested for significance using a one-tailed T-Test with equal variation. The significance is indicated by asterisks. ${ }^{*}, \mathrm{P}<0.05$.

The attractiveness of spider-mite induced volatiles towards predatory mites was compared between both genotypes using a Y-tube olfactometer. After 3 days of spider-mite infestation, the odors of infested plants of both genotypes attracted more predatory mites than non-infested plants (Figure 2). Although not significantly different, the volatile blend of spider-mite infested genotype 8 plants attracted more than $60 \%$ of the predatory mites relative to the blend of genotype 29 plants. 


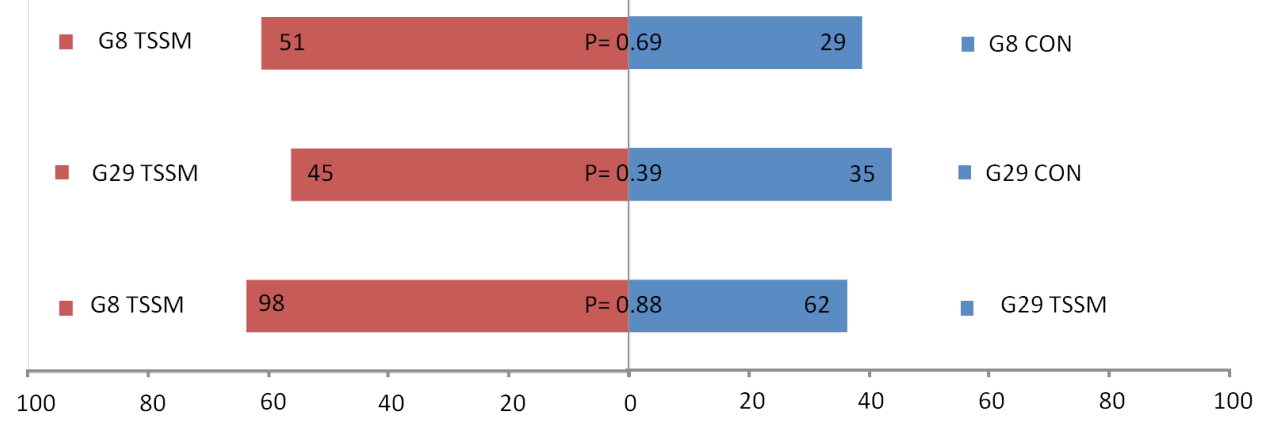

Figure 2. Numbers of predatory mites that were attracted to odors of spider-mite infested $\boldsymbol{C}$. annuum plants in a two-choice olfactometer. Four replicates were used in the comparison between spider-mite infested (TSSM) with non-infested control (CON) plants in each genotype. Eight replicates were used in the comparison between spider-mite infested plants of both genotypes. Twenty individual adult mites were tested within one comparison out of four/eight replicates ( $X^{2}$ test, $P$ value).

\section{Defense-related plant hormones}

To identify the changes in defense-related plant hormones upon spider-mite infestation, we measured SA, cis-OPDA, JA and JA-Ile in plants of both genotypes that were infested with spider mites for 3 days or were left uninfested. A two-way ANOVA was conducted to examine the effect of spider-mite infestation and genotype on hormone levels. In both genotypes, cis-OPDA, JA, JA-lle and SA significantly increased upon spider-mite infestation (Figure 3 ), suggesting that spider mites induced the production of both JA and SA in Capsicum. Significant differences between the two genotypes were found in amounts of cis-OPDA ( $P=0.046), \mathrm{JA}(P=0.012)$ and SA $(P=0.008)$, but not in the amount of JA-Ile $(P=0.200)$. Plants of the two genotypes responded differently to spider mites in terms of SA level, as indicated by the significant interaction between spider-mite infestation and genotype $(P=0.025)$. No significant differences between genotypes were found in the accumulation of cis-OPDA or JA-lle under control conditions (T-test; $P>0.05$ ), while the concentrations of JA and SA were 325.3-fold $(P=0.000)$ and 1.64-fold $(P=$ 0.0373 ) higher in genotype 8 than in genotype 29. Upon spider-mite infestation, genotype 8 contained 1.95 -fold more $(P=0.0349)$ SA than genotype 29 , while for the other hormones analyzed, no differences between spider mite infested plants of both genotypes were detected $(P>0.05)$. Interestingly, there was a significantly higher fold change in JA upon spider-mite infestation in genotype 29 (Supplementary Figure 1), due to the relatively low constitutive JA production. 

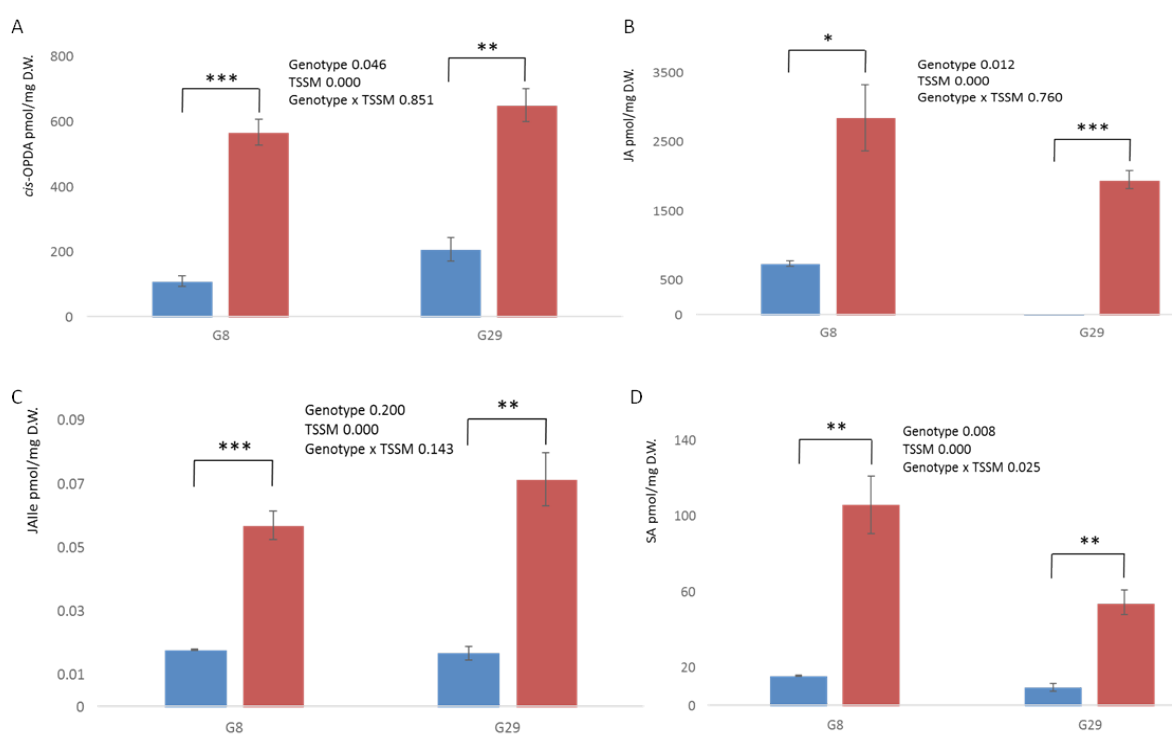

Figure 3. The amount of cis-OPDA, JA, JA-lle and SA in spider mite infested Capsicum leaves of Genotype 8 and 29. Data represent the average $( \pm S E)$ concentration of cis-OPDA (A), JA (B), JA-Ile (C), and SA (D) in Capsicum leaves of genotype 8 (G8) and genotype 29 (G29) after 3 days of spider-mite infestation (red bars) or non-treated control (blue bars). The significance of the effect of genotype, treatment (spider mites) and the interaction between genotype and treatment is depicted by P-values from two-way analysis of variance. The significance between spider-mite infested and control plants is depicted by $P$ values obtained using the two-tailed T-Test with equal variance and indicated by asterisks. ***, $\mathrm{P}<0.001 ;{ }^{* *}, \mathrm{P}<0.01 ; *, \mathrm{P}<0.05$. ns, non significant.

\section{Global transcriptome changes upon spider-mite infestation and JA treat- ment in two Capsicum genotypes}

JA has been identified as the paramount plant hormone regulating plant defense against herbivores (Erb et al., 2012, Verma et al., 2016). To characterize the mechanism of spider-mite induced defense responses and disentangle the role that plant hormones in general and JA in particular play in this process, we compared the JA-induced transcriptome response with that induced by spider-mite infestation in the two genotypes. To cover the relatively transient response induced by JA, two time points ( 6 and $24 \mathrm{hrs}$ ) of JA-induction were analyzed while one time point ( 3 days) of spider-mite infestation was used.

Principal Component Analysis (PCA) of all detected transcripts (normalized to RPKM) showed that the first PC explains $13.5 \%$ of the total variation and separates the two genotypes from each other, while samples of different experimental conditions separate along the second PC (10.6\%) (Figure 4). The 
PCA shows that genotypes that differ in their susceptibility towards spider mites have different transcriptome profiles regardless of whether they are infested or not. Furthermore, the transcriptome response to spider mites is clearly different from that to JA.

To reduce the complexity of the data set, we selected the 1955 genes that were differentially expressed (DEGs) in at least one experimental condition compared to the corresponding non-treated control and had an absolute Log2 transformed fold change (FC) $>1.5$ and a Benjamini-Yekutieli false discovery rate (FDR) adjusted $P$ value $<0.05$.

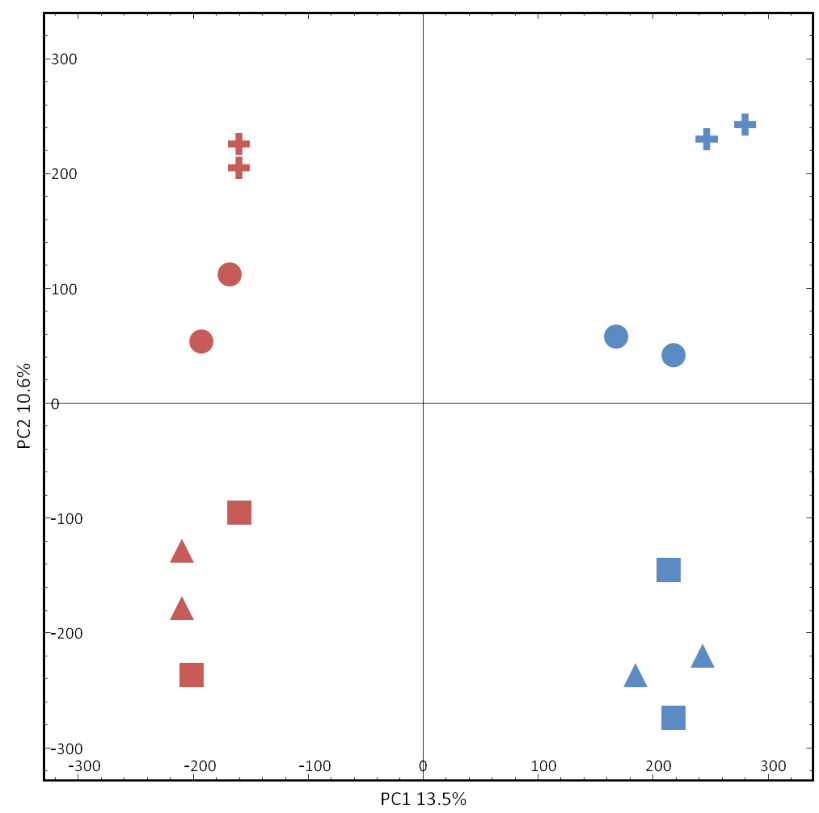

Figure 4. Transcriptional changes upon spider-mite infestation or JA application in two Capsicum annuum genotypes. Principal Component Analysis (score plot) of all transcripts (RPKM values) detected in leaves of Capsicum annuum. Data points represent the different samples. Blue color represents Genotype 8, red represents Genotype 29. Circles represent non-treated samples, crosses represent samples infested by spider mites for 3 days, squares and triangles represent samples induced by JA for 6 or 24 hours, respectively. The first PC explains $13.5 \%$ and the second PC $10.6 \%$ of the total variation.

To further explore the transcriptional changes, a co-expression network was constructed based on the expression profiles of the 1955 DEGs across treatments (Figure 5). Transcriptional interactions with an absolute Pearson Correlation Coefficient $\geq 0.85$ were selected to generate a co-expression network according to the node-edge ratio (Supplemental data, Table 3) with 87978 edges and 1917 nodes that were scale free over three orders 
of magnitude.
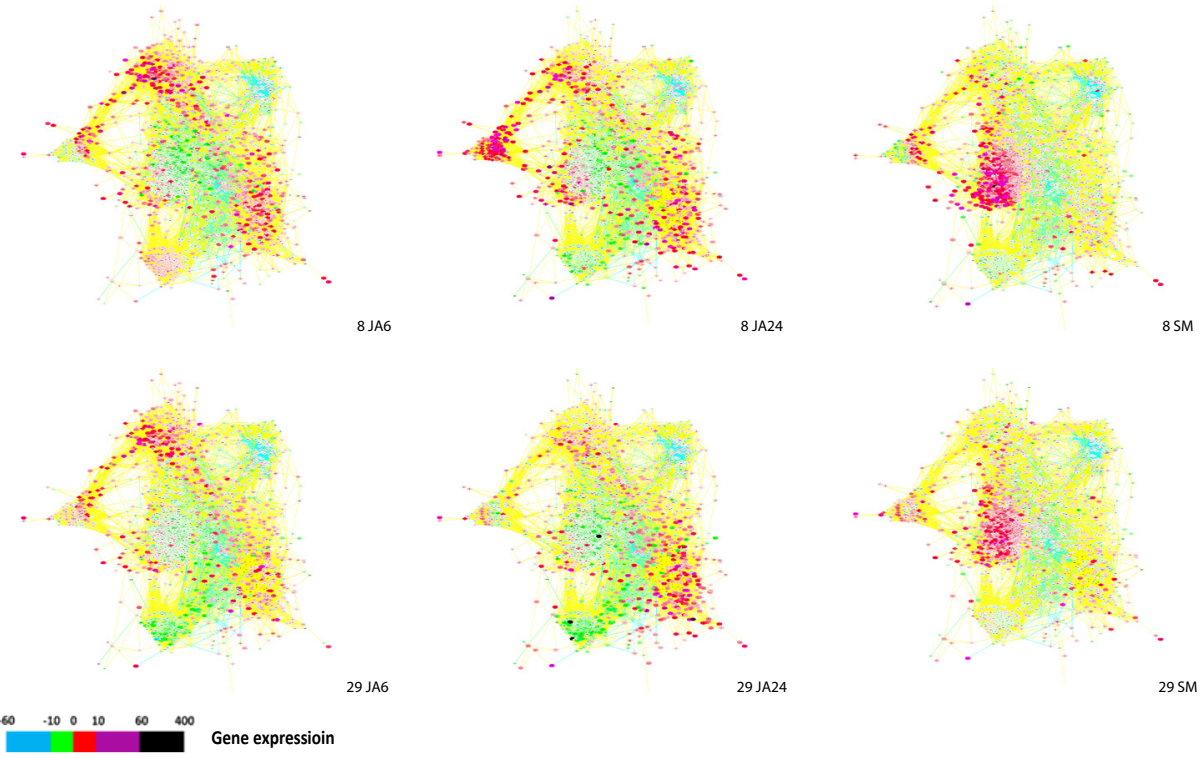

Gene expressioin

Figure 5. Gene co-expression network of transcriptomes of Capsicum leaves infested with spider mites for three days or treated with JA for $\mathbf{6}$ or $\mathbf{2 4}$ hours. The network is visualized using the organic layout in Cytoscape. Nodes are labeled with a gene function identifier (The Pepper Genome Database (release 2.0)), diamonds indicate significant $P$ values $>0.05$, circles indicate significant $P$ values $\leq 0.05$, and different colors represent expression fold changes relative to non-treated plants. Edges represent a measure for the correlation coefficient between two nodes, with positive correlations depicted in yellow and negative correlations in blue. A high resolution version of this figure is available in Supplemental Figure 5.

The co-expression network shows the overall responses to spider mites and $J A$ in both genotypes. Consistent with Figure 4, the network shows that spider mites induce and repress different clusters of transcripts compared to JA in both genotypes while transcript profiles upon JA or spider-mite induction were more or less comparable between the genotypes (Figure 5).

\section{JA induced responses in Capsicum}

To reduce the complexity and explain JA and spider-mite induced responses at the functional level, we performed Gene Ontology (GO) analysis based on homology of Capsicum DEGs to $A$. thaliana genes and their function. GO enrichment showed that JA predominantly induced genes associated with 'metabolic process', 'response to jasmonic acid', 'response to fungus', 'osmotic stress', 'salt stress', 'water deprivation', 'wounding', 'oxidative stress' and 'response to cadmium ion' (Figure 6, Supplemental Table 2). 


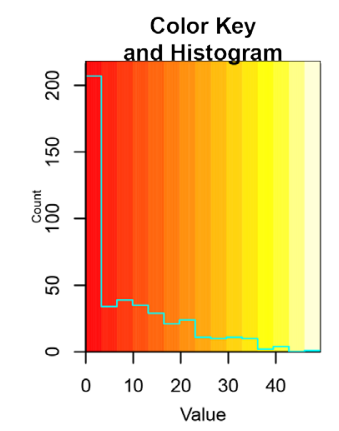

\section{GO heatmap}

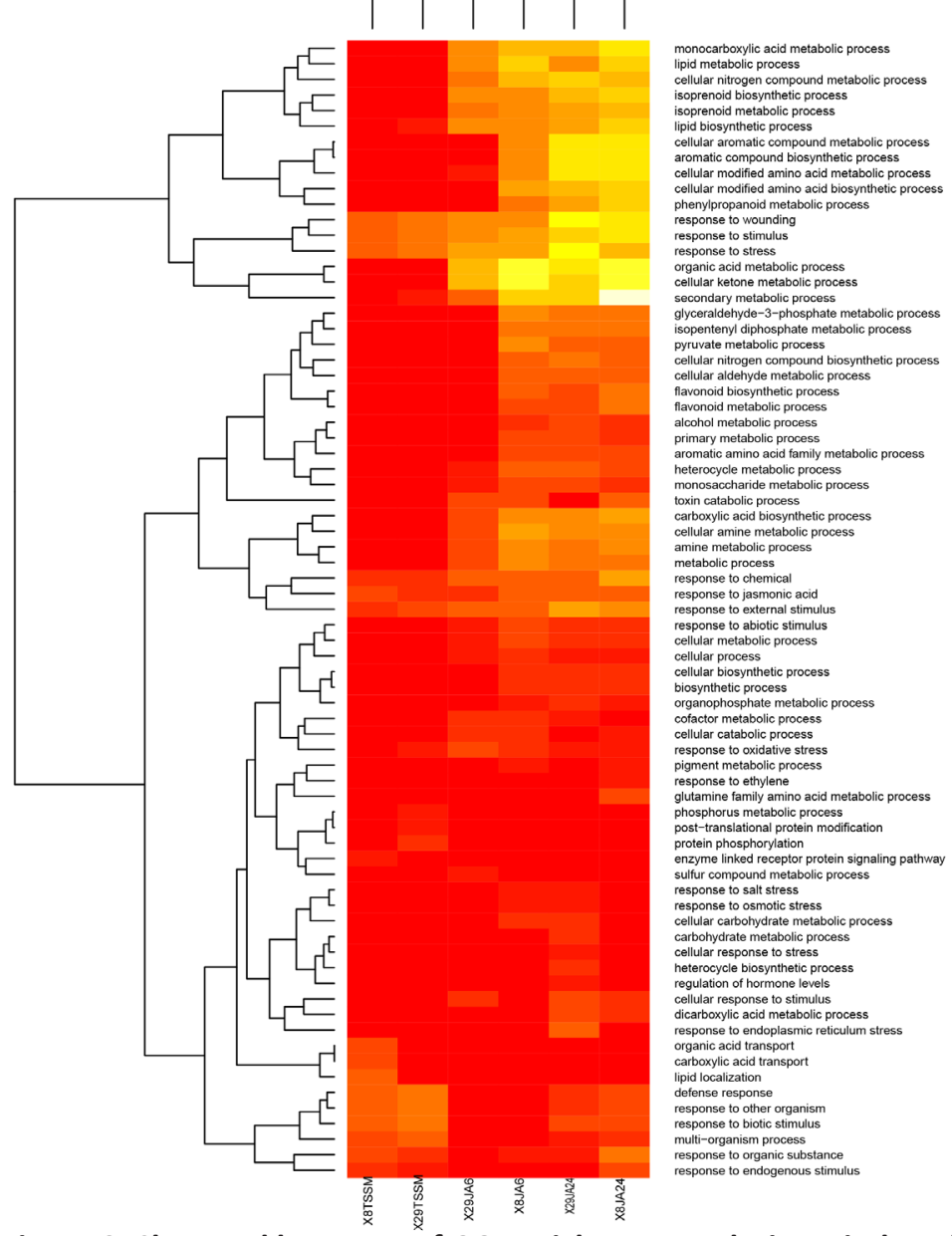

Figure 6. Clustered heatmap of GO enrichment analysis on induced genes in each condition. The color intensity indicates the level of enrichment. Enrichment value are calculated by -Log10 transformed FDR adjusted $P$ values. $X$ indicates Genotype.

Genes involved in the JA biosynthetic pathway were upregulated including ALLENE OXIDE SYNTHASE (AOS) (Capana03g003512, Capana11g000038), LIPOXYGENASE 2.1 (LOX2.1) (Capana01g001574, Capana01g001577, Capana01g001578) and JASMONIC ACID CARBOXYL METHYLTRANSFERASE (JMT) 
(Capana04g000320) (Supplementary Table 3). Furthermore, genes related to JA signaling including JASMONATE-ZIM-DOMAIN PROTEIN 3 (JAZ3) (Capana01g003720) and multiple JA responsive genes such as PROTEASE INHIBITOR (PI; Capana01g000282, Capana10g001469), BASIC CHITINASE (CHIB) (Capana03g000779, Capana07g001180, Capana07g001653), PROTEIN PATHOGENESIS-RELATED PROTEIN 4 (PR4; Capana08g001236) and BASIC PR1-LIKE PROTEIN (Capana08g002192) were also induced.

JA induced genes involved in multiple primary metabolic processes including 'isopentenyl diphosphate biosynthetic pathways', 'fatty acid metabolic process', 'glutamine amino acid metabolic process', 'aromatic amino acid metabolic process' and several secondary metabolic processes, including 'terpenoid biosynthetic pathway', 'phenylpropanoid biosynthetic pathway' and 'flavonoid biosynthetic pathway' (Figure 6; Supplemental Table 2). For induced biosynthetic genes, functional annotation by blasting against the $\mathrm{NCBI}$ non-redundant protein database suggested that Capsicum gene Capana04g002602 has high homology to $(E, E)$-geranyl linalool synthase in potato (Solanum tuberosum, E-value 0) and tomato (Solanum lycopersicum, E-value 0) (Falara et al., 2014). Geranyl linalool can be converted into a C16-homoterpene $(E, E)$-4,8,12-trimethyltrideca-1,3,7,11-tetraene (TMTT) by a cytochrome P450 monooxygenase, CYP82G1 (At3g25180) in A. thaliana (Snoeren et al., 2010). Multiple cytochrome P450 encoding genes positively co-expressed with Capana04g002602 (Correlation Coefficient $>0.85$ ), suggesting one of them is probably involved in the production of TMTT. TMTT is induced by various herbivores and has been demonstrated to be attractive for predators in many plant species including $A$. thaliana (Snoeren et al., 2010), cucumber (Kappers et al., 2011)M - and tomato (Ament et al., 2004). Furthermore, geranyl linalool is the precursor of non-volatile diterpenes, for the biosynthesis of which also conversion by cytochrome P450s is required (Falara et al., 2014). Another JA induced gene, Capana03g001804, shows homology to CAFFEIC ACID 3-O-METHYLTRANSFERASE (COMT) from Nicotiana attenuata (OIT03318, E value 2e-140). COMT catalyses multi-step methylations in the lignin and flavonoid biosynthetic pathway (Do et al., 2007). The JA-induced Capana12g000350 encoded protein has high homology to CHALCONE SYNTHASE (CHS) in Lochroma cyaneum (AIY22756.1, E value 0), which catalyses the condensation of 4-coumaroyl-CoA and malonyl-CoA to form the flavonoid naringenin chalcone (Coburn et al., 2015).

The early JA-response ( $6 \mathrm{~h}$ treatment) resulted in the induction of 211 transcripts and repression of 85 transcripts in genotype 29 (Figure 7). The induced transcripts include genes involved in 'amino acid derivatives biosynthetic pathway', 'fatty acids biosynthetic pathway' and 'isoprenoids biosynthetic 
pathway'. As the response process further develops, the number of up-regulated and down-regulated genes increased to 325 and 126, respectively, 24 hours after JA induction. Expression of genes involved in 'flavonoid biosynthetic pathways' and 'phenylpropanoid biosynthetic pathways' which are biosynthetically downstream of 'amino acid derivatives metabolic process' was induced. Furthermore, 'terpenoid biosynthetic pathway', biosynthetically downstream of 'isoprenoid biosynthetic pathway' was induced after 24 hours of JA induction, but not yet after 6 hours. Gene transcripts repressed upon 6 as well as 24 hours JA-induction showed enrichment in 'response to light stimulus' and 'photosynthesis'.

In genotype 8 , early overall transcriptional changes to JA treatment were stronger than in genotype 29 , while after 24 hours both genotypes showed a comparable response (Figure 7). The 'terpenoid biosynthetic pathway', 'flavonoid biosynthetic pathway', and 'phenylpropanoid biosynthetic pathway' and 'amino acid derivative metabolic process' were already induced 6 hours after JA treatment, indicative of a faster response in secondary metabolite biosynthesis in genotype 8 than in genotype 29. In both genotypes, JA treatment resulted in repression of 'response to light stimulus' and 'photosynthesis' after 24-hour. The magnitude of JA-repressed photosynthesis was smaller in genotype 8 compared to genotype 29 in terms of both gene number and expression fold change of these genes. For example, Capana00g002801, Capana00g002799 and Capana00g002794, homologues of the chlorophyll a/b binding protein encoding gene, LIGHT-HARVESTING COMPLEX b1 (LHCb1) in S. tuberosum (AAA80593.1, E value 0, 0, 0), which is the subunit of the LHC involved in light harvesting and biochemical energy conversion (Fernandez and Staneloni, 1996), were 6.6-, 13.1- and 23.0-fold (Log 2-transformed) repressed by 24-hour JA induction in genotype $8 \mathrm{com}$ pared with 23.3-, 72.6- and 128.7-fold, respectively in genotype 29. 
A

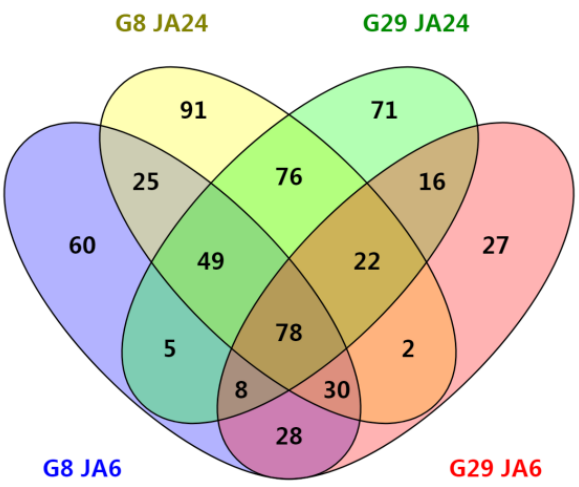

B

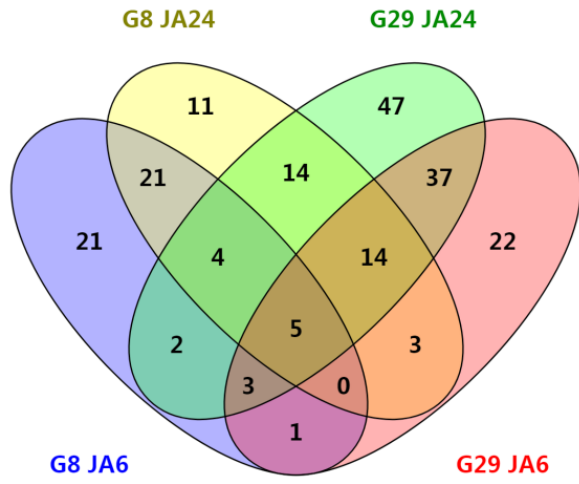

Figure 7. Venn-diagram showing mutual and different differentially expressed genes (DEGs) in two genotypes upon JA induction for 6 or $\mathbf{2 4}$ hours. $A$ and B show DEGs that were induced and repressed upon JA, respectively.

\section{Spider-mite induced responses in Capsicum}

DEGs upon spider-mite infestation in both genotypes showed overrepresentation of processes associated with 'responses to fungus', 'wounding', 'response to jasmonic acid' and 'response to salicylic acid' as well as 'protein phosphorylation' (Figure 6; Supplemental Table 2). Up-regulation of JA biosynthetic genes encoding LOX2 (Capana01g001577), AOS (Capana08g002494) and JA/ET responsive genes including PR4 (PATHOGENESIS-RELATED 4; Capana08g001234, Capana08g002211, Capana08g001236), CHIB (Capana02g002478, Capana02g002477, Capana02g002479, Capana02g002482, Supplemental Table 3) indicate that spider mites induced the JA signaling pathway in Capsicum. Furthermore, spider mites also induced genes associated with SA signaling, including genes with homology to transcription factors WRKY40 (Capana08g000683) and WRKY70 (Capana03g002635, Capana10g001220, Capana10g001548) as well as the SA inducible gene Glutaredoxin GRX480 (Capana10g000465) (Ndamukong et al., 2007) and SA positive regulator RLK (Receptor Lectin Kinase, Capana09g001638) (Luo et al., 2017). Fungal defense related genes such as genes encoding for protease inhibitors which are important components of insect and pathogen defenses especially in the Solanaceae family (Capana01g000500, Capana01g000544, Capana01g000501, Capana01g000502, Capana01g000547) (Kim et al., 2009) and PR4 (Capana08g001234, Capana08g002211, Capana08g001236) were also induced by spider-mite infestation. 
A

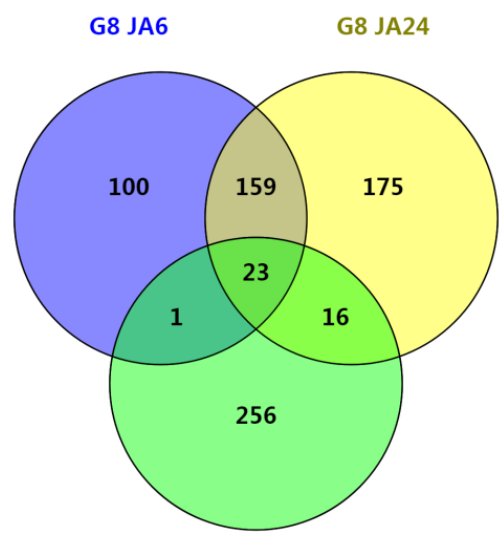

G8 TSSM

C

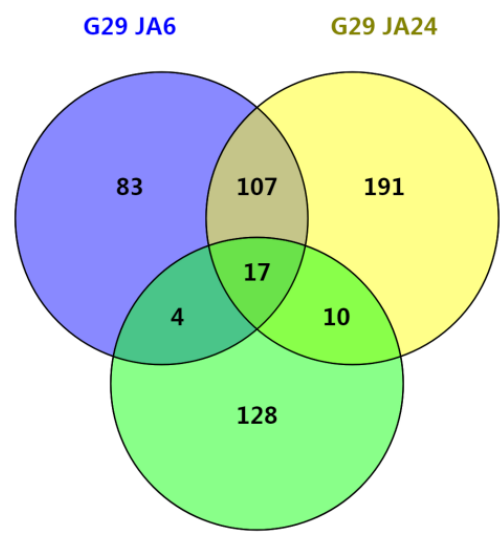

G29 TSSM
B

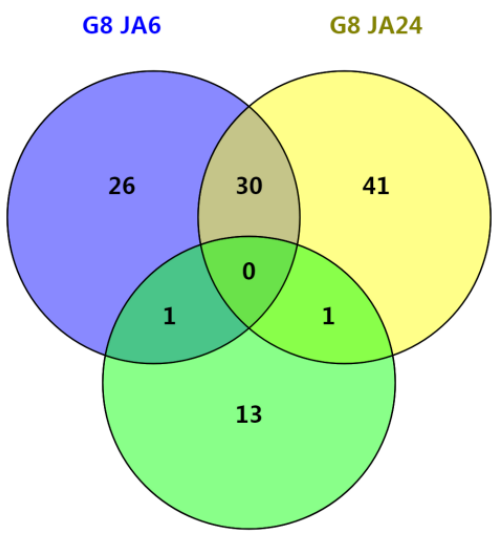

G8 TSSM

D

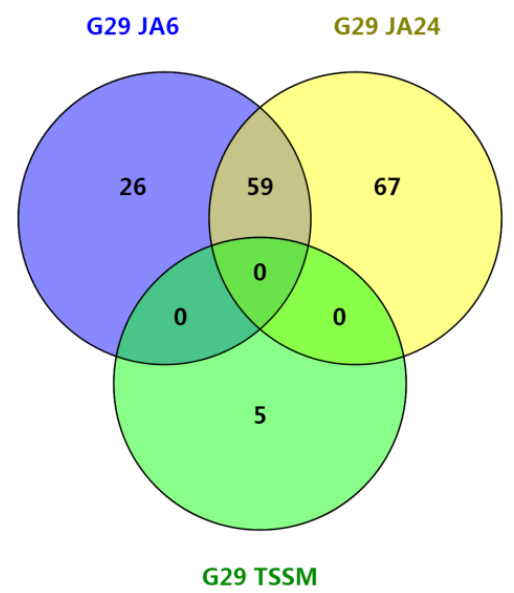

Figure 8. Differentially expressed genes (DEGs) in two genotypes upon spider-mite infestation and early or late JA-induction. A. Upregulated DEGs in genotype 8; B. Downregulated DEGs in genotype 8; C. Upregulated DEGs in genotype 29; D. Downregulated DEGs in genotype 29; Venn diagrams show the numbers of DEGs overlapping in each of the conditions

In contrast to the strong upregulation of metabolic processes by JA, spider-mite infestation resulted in up-regulation of a limited number of metabolic processes including lipid metabolism and MYB transcription factors regulated 'phenylpropanoid biosynthetic pathway' (Liu et al., 2015), which probably led to the production of SA instead of flavonoids that are predominantly induced by JA (Supplemental Table 2, Figure 6). Nevertheless, a number of JA-induced Terpene synthase (TPS) genes were also induced by spider mites, including Capana05g000800, a homologue of the tomato Geranylgeranyl diphosphate synthase 1 (GGPS1) (S. lycopersicum; NP_001234087.1; E value 0) (Ament et al., 2006), Capana00g000219 and Capana02g002126 
which are homologues of $\alpha$-Farnesene synthase (AFS1) from S. lycopersicum (AEP82777.1; E value 0) (Falara et al., 2011) and N. attenuata (OIT31173; E value $9 \mathrm{e}-108)$. Furthermore, multiple protein kinases especially leucine-rich repeat transmembrane protein kinase, were up-regulated suggesting the induction of several different signal transduction pathways known to be related to abiotic and biotic stresses (Gou et al., 2010).

In genotype $29,19.5 \%$ of the genes induced by spider mites were in common with JA induced genes (Figure 8), of which five genes revealed an overrepresentation of lipid metabolic process and 6 were characterized as stress defense related genes based on $\mathrm{GO}$ enrichment. Five genes were repressed by spider mites but none of these were enriched in any GO term, such as Capana02g002739 with homology to a tomato abscisic acid and environmental stress-inducible protein TAS14 (S. lycopersicum, NP_001234038.1, E value 5e-27) and Capana09g000202, a JA-dependent disease resistant zinc finger $\mathrm{CCCH}$ domain-containing protein encoding gene $\mathrm{C} 3 \mathrm{H} 12$, (Deng et al., 2012).

In genotype $8,13.5 \%$ of genes induced by spider mites were also induced by JA (Figure 8 ). Eleven of those commonly induced genes showed overrepresentation for 'stress-responsive processes', including genes with putative functions as THIONIN-LIKE PROTEIN (Thi) in N. tabacum (Capana10g000171, E value 4e-31) (Wawrzynska et al., 2005), PATHOGENESIS-RELATED PROTEIN $P R-1$ in Capsicum annuum (Capana08g002192; E value 5e-131) (Hong et al., 2005) and $P R-4 b$ (Capana08g001236, E value 9e-135). Upon spider-mite infestation, Capsicum plants showed JA-related responses by increased expression of JA-regulated genes including PLEIOTROPIC DRUG RESISTANCE 12 (PDR12, Capana12g000032), CHIB (Capana02g002478) and JA biosynthesis genes, AOS (Capana08g002494) and LOX2 (Capana01g001577). However, none of the metabolic processes induced by JA were found enriched upon spider-mite infestation except the 'fatty acid metabolic process' (Figure 6, Supplemental Table 2). There were two genes repressed by both JA and spider mites with putative homology to TAS14 from S. lycopersicum (Capana02g002739, E value 0.007) (Parra et al., 1996) and putative RHODANESE-LIKE DOMAIN-CONTAINING PROTEIN from Capsicum chinense (Capana10g000843, E value 0.0) (Kim et al., 2017). Even though spider mites induced the JA signaling pathway, photosynthesis-related genes were not repressed by spider-mite infestation for three days.

\section{Genotypic variation in spider-mite induced responses}

To explain the variation in spider-mite susceptibility based on the transcriptional changes, spider-mite induced DEGs of both genotypes were com- 
pared. We detected 296 DEGs up-regulated and 15 DEGs down-regulated in genotype 8 while 159 DEGs were up-regulated and 5 DEGs down-regulated in genotype 29 by spider mites compared with the corresponding control plants (Figure 8). Thus, the extent of transcriptional changes was almost twice higher in genotype 8 than in genotype 29. Interestingly, a relative large portion of DEGs was specific for each genotype, with 60\% (178 of 296) of up-regulated DEGs that were specifically induced in genotype 8 while $25 \%$ (41 of 159) of up-regulated DEGs found in genotype 29 were not detected in genotype 8 (Supplementary Figure 2). To compare transcriptional changes quantitatively, we compared transcriptomes of spider-mite infested leaves between both genotypes directly. Upon spider-mite infestation, in genotype 8 more genes were found enriched in 'response to SA' (Supplementary Figure 3) including genes with homology to SA responsive transcription factor WRKY70 (Capana10g001220, Capana10g001548, Capana03g002635), SA-inducible genes encoding GRX480 (Capana10g000465) and RLK (Capana09g001638) while genotype 29 showed more enrichment in 'secondary metabolic processes' including phenylpropanoid biosynthetic pathway gene 4CL3 (Capana03g001732) encoding 4-coumarate-CoA ligase (NP_001333794.1; S. lycopersicum, E value 0), flavonoid biosynthetic pathway gene TT7 (Capana03g000102) encoding a cytochrome P450 (ABG74350.1; Capsicum chinense; E value 0) and a lignan biosynthetic gene (Capana02g002450) encoding dirigent protein (XP_021602373.1, Manihot esculenta; E value 3e-82). With the hypothesis that spider mites induced SA signaling, which in turn repressed JA signaling, we particularly examined JA-induced genes that were not induced or even repressed by spider mites. In genotype 29 , genes enriched in 'amino acid metabolic process' and 'wound response' were detected while in genotype 8 , genes enriched in 'lipid metabolic process' and secondary metabolic processes including 'isoprenoid biosynthetic pathway', 'phenylpropanoid biosynthetic pathway', 'Iignin metabolic process', 'terpenoid metabolic process', 'amino acid metabolic process' and 'wound response' were found (Supplementary Figure 3). In genotype 8, more genes responsive to JA were repressed or not induced upon spider-mite infestation than in genotype 29 , which could support the hypothesis that there is a stronger suppression of JA responses in genotype 8.

\section{Transcriptome profiling of non-infested plants}

As the observed defense responses towards spider mites are determined by the combination of induced defenses and the basal defense level, we also compared the transcriptomes of both genotypes in non-infested plants. No GO term was found significantly $(F D R<0.05)$ enriched in genes with a 
higher expression level in genotype 29 (which was relatively resistant) compared to those in genotype 8 (relatively more susceptible) $(\log 2(\mathrm{FC})>1.5$, $P<0.05)$. In contrast, GO terms 'response to biotic stimulus' and 'response to stress' were enriched in genes with a higher expression level in genotype 8, including genes Capana01g000284 encoding OSMOTIN-LIKE PROTEIN (OSML13) precursor (NP_001311827.1, C. annuum, E value 4e-180) (Kim et al., 2002), Capana05g001701 encoding ETHYLENE-RESPONSIVE FACTOR 1 (ERF1) (AAK95688.1, S. lycopersicum, E value 1e-101) (Huang et al., 2004) and Capana10g002242 encoding ZEATIN O-GLUCOSYLTRANSFERASE-LIKE (XP_016543732.1, C. annuum, E value 0). Apparently these constitutively expressed genes do not play an important role in the defense as genotype 8 is more susceptible, while inducible defense responses, such as JA induced secondary metabolite biosynthesis, as are induced in genotype 29 are more effective.

\section{Spider-mite infestation induced defensive related metabolites}

To verify metabolic processes described by transcriptional changes, we performed an untargeted analysis of endogenous metabolites of the same samples that were analyzed for transcriptomes. In addition, emitted volatile metabolites of spider-mite infested plants of both genotypes were analyzed.

PCA on endogenous metabolites suggested that the largest variation in the semi-polar metabolites was present between JA-induced and non JA-induced samples along the first PC (22.1\%) while genotypic variation appeared along the second PC (18.0\%). JA-induced metabolome profiles diverted stronger from non-induced profiles than did spider-mite induced metabolomes. This difference in the metabolome is consistent with the responses in transcriptome analysis, which together suggests that JA induced extensive changes in metabolism while spider mites only induced several genes involved in lipid metabolic process and the phenylpropanoid pathway. 

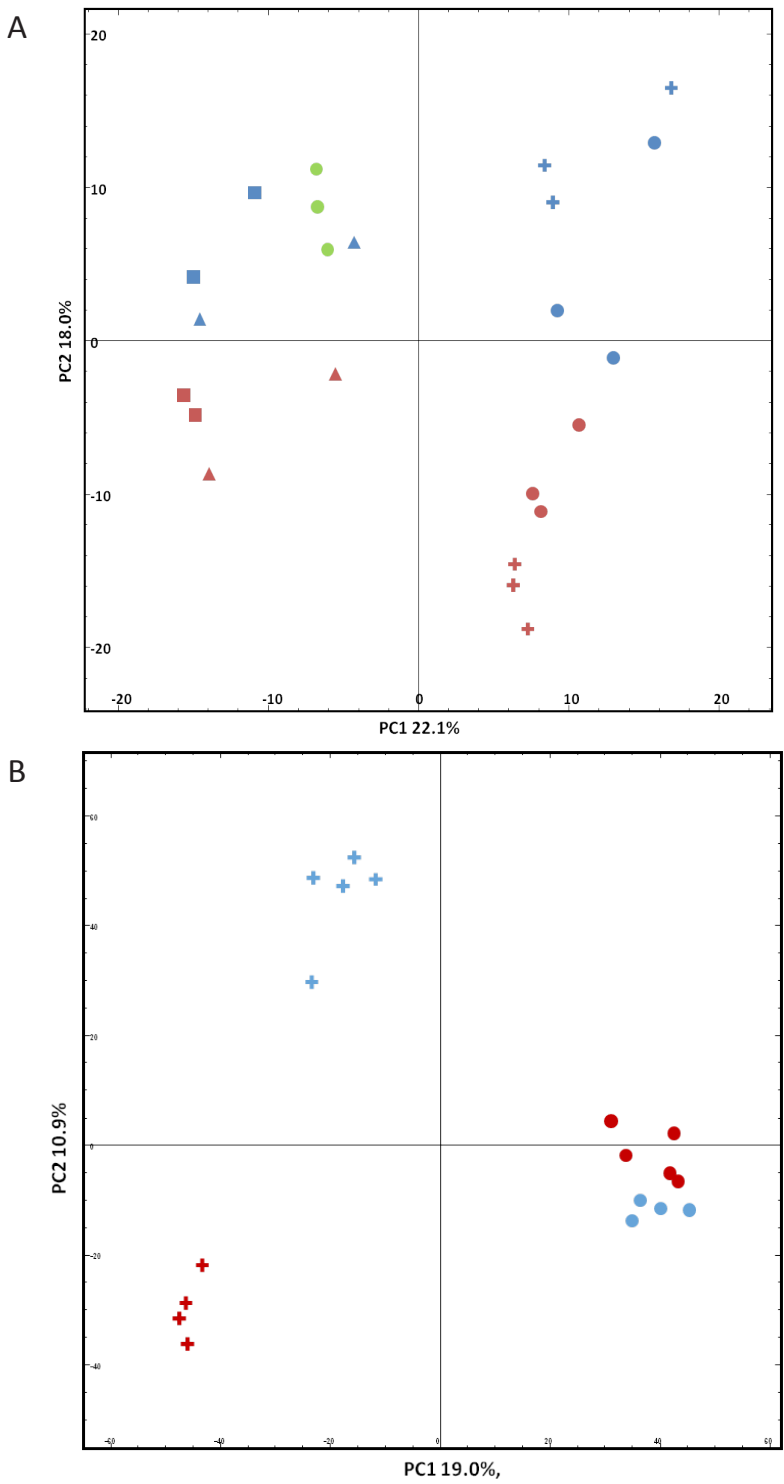

Figure 9. Principle Component Analysis of metabolomes in C. annuum genotype 8 and 29. A. Score plot of endogenous metabolites in leaves (PC1 explained 22.1\%, PC2 explained $18.0 \%$ of total variation). B. Score plot of volatile metabolites emitted by spider-mites infested and non-infested plants (PC1 explained 19.0\%, PC2 explained $11.6 \%$ of total variation). Data points represent each sample. Blue color represents $\mathrm{G} 8$, red color represents G29. Circles represent non-treated plants, crosses represent plants infested by spider mites for 3 days; Squares and triangles represent plants induced by JA for 6 and 24 hours, respectively, green circles represent quality controls (only for endogenous metabolites). 
Table 1. Metabolites that were significantly induced or repressed in leaves of two C. annuum genotypes upon TSSM infestation or JA-induction. Putative annotation was done by comparing accurate masses and retention times with in-house databases and with the KEGG (http://kanaya.naist.jp/knapsack_jsp/top.html). Significance is depicted by * $(\mathrm{P}<0.05), * *$ $(\mathrm{P}<0.01)$ or $* * *(\mathrm{P}<0.001)$ using the two-tailed $\mathrm{T}$-Test with equal variance. Metabolites with absolute fold change (FC, treatment/non-treatment or non-treatment/treatment) $>1.5$ are shown.

\begin{tabular}{|c|c|c|c|c|c|c|}
\hline & $\begin{array}{l}\text { Biochemical } \\
\text { class }\end{array}$ & FC & CAS RN & Putative Metabolite & Chemical Formula & $\begin{array}{c}\text { Molecular } \\
\text { Weight }\end{array}$ \\
\hline \multirow{18}{*}{$\begin{array}{c}\mathrm{G} 2 \\
9 \\
\mathrm{JA6} \\
/ \mathrm{CO} \\
\mathrm{N}\end{array}$} & Alkaloids & $\infty$ & - & Antibiotic SF $2425 * *$ & $\mathrm{C} 25 \mathrm{H} 54 \mathrm{~N} 10 \mathrm{O} 2$ & 526.44 \\
\hline & Diterpenoids & $\infty$ & $189368-20-5$ & Taxumairol C $*$ & $\mathrm{C} 26 \mathrm{H} 38011$ & 526.24 \\
\hline & Flavonoids & $\infty$ & 215176-98-0 & $\begin{array}{c}\text { Cyanidin 3-(6- } \\
\text { malonyglucoside)-7- } \\
\text { (6-feruloylglucoside)- } \\
\text { 3'-glucoside * }\end{array}$ & $\mathrm{C} 46 \mathrm{H} 51027$ & 1036.55 \\
\hline & Flavonoids & 20.94 & $38953-85-4$ & Isovitexin $*$ & $\mathrm{C} 21 \mathrm{H} 20010$ & 432.11 \\
\hline & - & 2.87 & $\begin{array}{c}1137584-36- \\
1\end{array}$ & Micropeptin C* & C53H69N7O14 & 1027.49 \\
\hline & $\begin{array}{l}\text { Triterpene } \\
\text { Glycosides }\end{array}$ & 2.84 & 259747-95-0 & Assamsaponin A** & C57H88O25 & 1172.56 \\
\hline & $\begin{array}{c}\text { Triterpene } \\
\text { saponin }\end{array}$ & 2.36 & 929877-79-2 & Theasaponin $\mathrm{C} 1 * *$ & C57H90O25 & 1174.58 \\
\hline & - & 2.36 & Unknown & - & - & - \\
\hline & - & 2.36 & Unknown & - & - & - \\
\hline & Carotenoids & 2.34 & $640-03-9$ & Antheraxanthin * & $\mathrm{C} 40 \mathrm{H} 56 \mathrm{O} 3$ & 584.42 \\
\hline & $\begin{array}{c}\text { Phenylpropa } \\
\text { noids } \\
\text { (tannins) } \\
\end{array}$ & 2.23 & - & Pterocarinin A * & $\mathrm{C} 46 \mathrm{H} 36030$ & 1068.13 \\
\hline & $\begin{array}{c}\text { cyclic } \\
\text { depsipeptide }\end{array}$ & 2.14 & $136634-57-6$ & Plusbacin A1 * & $\mathrm{C} 48 \mathrm{H} 79 \mathrm{~N} 11020$ & 1129.55 \\
\hline & $\begin{array}{c}\text { Triterpene } \\
\text { saponins }\end{array}$ & 1.9 & 288153-05-9 & TR-Saponin ** & C51H78O2O & 1010.51 \\
\hline & - & 1.58 & Unknown & - & - & - \\
\hline & Pyrans & 0.69 & $63023-59-6$ & Costatone ${ }^{*}$ & $\mathrm{C} 10 \mathrm{H} 12 \mathrm{Br}$ & 391.86 \\
\hline & - & 0.41 & $7545-84-8$ & Neoclauxin ** & $\mathrm{C} 26 \mathrm{H} 1609$ & 472.08 \\
\hline & $\begin{array}{c}\text { Alkaloids/Ph } \\
\text { enols }\end{array}$ & 0.37 & $137793-81-8$ & Michellamine A $* * *$ & $\mathrm{C} 46 \mathrm{H} 48 \mathrm{~N} 2 \mathrm{O} 8$ & 756.34 \\
\hline & Carotenoids & 0.15 & $472-70-8$ & beta-Cryptoxanthin * & $\mathrm{C} 4 \mathrm{OH} 56 \mathrm{O}$ & 552.43 \\
\hline \multirow{15}{*}{$\begin{array}{c}\mathrm{G} 2 \\
9 \\
\mathrm{JA} 2 \\
4 / \mathrm{C} \\
\mathrm{ON}\end{array}$} & Diterpenes & $\infty$ & $51330-30-4$ & Stevioside $* * *$ & $\mathrm{C} 38 \mathrm{H} 60 \mathrm{O} 18$ & 804.38 \\
\hline & Diterpenoids & $\infty$ & $189368-20-5$ & Taxumairol C ** & $\mathrm{C} 26 \mathrm{H} 38011$ & 526.24 \\
\hline & Alkaloids & $\infty$ & $76282-39-8$ & Pandicine $* *$ & C44H50N4O7 & 746.37 \\
\hline & Alkaloids & $\infty$ & - & Antibiotic SF $2425 *$ & $\mathrm{C} 25 \mathrm{H} 54 \mathrm{~N} 10 \mathrm{O} 2$ & 526.44 \\
\hline & Flavonoids & 11.95 & 38953-85-4 & Isovitexin $* *$ & $\mathrm{C} 21 \mathrm{H} 20010$ & 432.16 \\
\hline & $\begin{array}{c}\text { Steroid } \\
\text { glycoside }\end{array}$ & 3.73 & 26151-14-4 & Saponoside A** & $\mathrm{C} 54 \mathrm{H} 84 \mathrm{O} 25$ & 1132.53 \\
\hline & $\begin{array}{c}\text { Steroid } \\
\text { Glycosides, }\end{array}$ & 3.48 & $276680-60-5$ & Anguivioside B * & $\mathrm{C} 48 \mathrm{H} 74 \mathrm{O} 20$ & 970.48 \\
\hline & $\begin{array}{l}\text { Triterpene } \\
\text { Glycosides }\end{array}$ & 2.57 & $259747-95-0$ & Assamsaponin A $* * *$ & $\mathrm{C} 57 \mathrm{H} 88 \mathrm{O} 25$ & 1172.56 \\
\hline & - & 2.34 & Unknown & - & - & - \\
\hline & $\begin{array}{c}\text { Triterpene } \\
\text { saponin }\end{array}$ & 2.23 & $929877-79-2$ & Theasaponin C1 $* *$ & C57H90O25 & 1174.58 \\
\hline & - & 2.23 & Unknown & - & - & - \\
\hline & - & 2.23 & Unknown & - & - & - \\
\hline & Triterpene & 2.2 & $259748-74-8$ & Assamsaponin E* & $\mathrm{C} 59 \mathrm{H} 92 \mathrm{O} 26$ & 1216.59 \\
\hline & $\begin{array}{c}\text { Phenylpropa } \\
\text { noids } \\
\text { (tannins) }\end{array}$ & 2.17 & - & Pterocarinin A * & $\mathrm{C} 46 \mathrm{H} 36 \mathrm{O} 30$ & 1068.13 \\
\hline & $\begin{array}{c}\text { cyclic } \\
\text { depsipeptide }\end{array}$ & 2.03 & $136634-57-6$ & Plusbacin A1 * & $\mathrm{C} 48 \mathrm{H} 79 \mathrm{~N} 11020$ & 1129.55 \\
\hline
\end{tabular}




\begin{tabular}{|c|c|c|c|c|c|c|}
\hline & $\begin{array}{l}\text { Triterpene } \\
\text { saponins }\end{array}$ & 1.81 & 288153-05-9 & TR-Saponin * & C51H78O2O & 1010.51 \\
\hline & Tannins & 1.62 & - & Quisqualin A* & $\mathrm{C} 39 \mathrm{H} 28 \mathrm{O} 25$ & 896.09 \\
\hline & Pyrans & 0.59 & $63023-59-6$ & Costatone $* *$ & $\mathrm{C} 10 \mathrm{H} 12 \mathrm{Br}$ & 391.86 \\
\hline & $\begin{array}{c}\text { Alkaloids/Ph } \\
\text { enols }\end{array}$ & 0.54 & 137793-81-8 & Michellamine A** & $\mathrm{C} 46 \mathrm{H} 48 \mathrm{~N} 2 \mathrm{O} 8$ & 756.34 \\
\hline & Carotenoids & 0.13 & $472-70-8$ & $\begin{array}{l}\text { beta-Cryptoxanthin } \\
* *\end{array}$ & $\mathrm{C} 40 \mathrm{H} 56 \mathrm{O}$ & 552.43 \\
\hline & - & 0 & $7545-84-8$ & Neoclauxin $* * *$ & $\mathrm{C} 26 \mathrm{H} 1609$ & 472.08 \\
\hline & Carotenoids & 0 & $144-68-3$ & Zeaxanthin * & $\mathrm{C} 40 \mathrm{H} 56 \mathrm{O} 2$ & 568.43 \\
\hline \multirow{21}{*}{$\begin{array}{c}\text { G2 } \\
9 \\
\text { TSS } \\
\text { M }\end{array}$} & Triterpenes & $\infty$ & $5563-70-2$ & $\begin{array}{c}3 \beta, 11 \alpha \text {-Diacetoxy-12- } \\
\text { ursene * }\end{array}$ & C34H54O4 & 526.40 \\
\hline & $\begin{array}{l}\text { Triterpene } \\
\text { Glycosides }\end{array}$ & 2.34 & $259747-95-0$ & Assamsaponin A * & C57H88O25 & 1172.56 \\
\hline & $\begin{array}{l}\text { Triterpene } \\
\text { saponins }\end{array}$ & 2.2 & 288153-05-9 & TR-Saponin * & $\mathrm{C} 51 \mathrm{H} 78 \mathrm{O} 20$ & 1010.51 \\
\hline & $\begin{array}{c}\text { Triterpene } \\
\text { saponin }\end{array}$ & 2.19 & $929877-79-2$ & Theasaponin $\mathrm{C} 1 *$ & C57H90O25 & 1174.58 \\
\hline & - & 2.19 & Unknown & - & - & - \\
\hline & - & 2.19 & Unknown & - & - & - \\
\hline & Peptides & 2.14 & $36528-64-0$ & $\begin{array}{c}\text { Ilamycin B1 } \\
\text { Rufomycin B1 * }\end{array}$ & C54H77N9O10 & 1011.58 \\
\hline & - & 2.1 & Unknown & - & - & - \\
\hline & $\begin{array}{l}\text { Steroid } \\
\text { glycoside }\end{array}$ & 2.09 & 26151-14-4 & Saponoside A * & C54H84O25 & 1132.53 \\
\hline & $\begin{array}{c}\text { Steroid } \\
\text { Glycosides, }\end{array}$ & 1.98 & $276680-60-5$ & Anguivioside $B * *$ & $\mathrm{C} 48 \mathrm{H} 74 \mathrm{O} 20$ & 970.48 \\
\hline & $\begin{array}{c}\text { Depsipeptid } \\
\text { es }\end{array}$ & 1.82 & 189757-91-3 & Fusaricidin $\mathrm{D}^{* *}$ & C46H76N10O12 & 960.56 \\
\hline & Flavonoids & 1.71 & 107668-77-9 & $\begin{array}{c}\text { Tricetin 3'-methyl } \\
\text { ether 7,5'- } \\
\text { diglucuronide * }\end{array}$ & $\mathrm{C} 28 \mathrm{H} 28 \mathrm{O} 19$ & 668.12 \\
\hline & Ceramides & 1.65 & $346425-30-7$ & Calyceramide ${ }^{*}$ & C34H67NO7S & 633.46 \\
\hline & $\begin{array}{c}\text { cyclic } \\
\text { depsipeptide }\end{array}$ & 1.6 & $136634-57-6$ & Plusbacin A1 * & C48H79N11O20 & 1129.55 \\
\hline & Phenols & 0.39 & $4299-57-4$ & Plastoquinone $9 *$ & $\mathrm{C} 53 \mathrm{H} 80 \mathrm{O} 2$ & 748.62 \\
\hline & - & 0.01 & $7545-84-8$ & Neoclauxin $* *$ & $\mathrm{C} 26 \mathrm{H} 16 \mathrm{O} 9$ & 472.08 \\
\hline & Carotenoids & 0 & $472-70-8$ & $\begin{array}{l}\text { beta-Cryptoxanthin } \\
\qquad * * *\end{array}$ & $\mathrm{C} 40 \mathrm{H} 56 \mathrm{O}$ & 552.43 \\
\hline & Diterpenes & 0 & $63550-99-2$ & Rebaudioside $\mathrm{C}^{* * *}$ & $\mathrm{C} 44 \mathrm{H} 70 \mathrm{O} 22$ & 950.44 \\
\hline & Phenols & 0 & - & $\begin{array}{l}\text { 2-Octaprenylphenol } \\
\qquad * *\end{array}$ & $\mathrm{C} 38 \mathrm{H} 54 \mathrm{O}$ & 526.42 \\
\hline & $\begin{array}{c}\text { Phenylpropa } \\
\text { noids } \\
\text { (tannins) }\end{array}$ & 0 & - & Pterocarinin A * & $\mathrm{C} 46 \mathrm{H} 36030$ & 1068.13 \\
\hline & Akaloids & 0 & 309963-07-3 & Lissoclinamide $9 *$ & $\mathrm{C} 35 \mathrm{H} 45 \mathrm{~N} 705 \mathrm{~S} 2$ & 707.29 \\
\hline \multirow{5}{*}{$\begin{array}{l}\mathrm{G} 8 \\
\mathrm{JA} 6 \\
\mathrm{COO} \\
\mathrm{N}\end{array}$} & Flavonoids & $\infty$ & ( & $\begin{array}{l}\text { Isoscutellarein } 4^{\prime}- \\
\text { methyl ether7-(6"'- } \\
\text { acetylallosyl)(1->2)- } \\
\text { glucoside }{ }^{* *}\end{array}$ & С30H34O17 & 666.18 \\
\hline & Alkaloids & $\infty$ & - & Antibiotic SF $2425 *$ & $\mathrm{C} 25 \mathrm{H} 54 \mathrm{~N} 10 \mathrm{O} 2$ & 526.44 \\
\hline & Akaloids & 2.91 & $185750-71-4$ & $\begin{array}{c}\text { Dibromophakellstatin } \\
*\end{array}$ & $\mathrm{C} 11 \mathrm{H} 10 \mathrm{Br} 2 \mathrm{~N} 4 \mathrm{O} 2$ & 387.92 \\
\hline & - & 2.69 & 270926-87-9 & Abutiloside D * & $\mathrm{C} 50 \mathrm{H} 84022$ & 1036.55 \\
\hline & - & 2.39 & Unknown & - & - & - \\
\hline
\end{tabular}




\begin{tabular}{|c|c|c|c|c|c|c|}
\hline & Xanthones & 2.28 & - & $\begin{array}{l}\text { Bijaponicaxanthone } \\
* *\end{array}$ & - & - \\
\hline & - & 2.23 & $346425-30-7$ & Calyceramide $* *$ & C34H67NO7S & 633.46 \\
\hline & $\begin{array}{l}\text { Depsipeptid } \\
\text { es }\end{array}$ & 2.2 & $189757-91-3$ & Fusaricidin D * & $\mathrm{C} 46 \mathrm{H} 76 \mathrm{~N} 10 \mathrm{O} 12$ & 960.56 \\
\hline & Flavonoids & 2.17 & $38953-85-4$ & Isovitexin * & $\mathrm{C} 21 \mathrm{H} 20010$ & 432.11 \\
\hline & $\begin{array}{l}\text { Hemiterpen } \\
\text { e glycosides }\end{array}$ & 1.9 & $394212-42-1$ & Hymenoside $\mathrm{H}^{*}$ & $\mathrm{C} 35 \mathrm{H} 38 \mathrm{O} 17$ & 730.21 \\
\hline & $\begin{array}{c}\text { cyclic } \\
\text { depsipeptide }\end{array}$ & 1.73 & $136634-57-6$ & Plusbacin A1 * & C48H79N11O20 & 1129.55 \\
\hline & Flavonoids & 1.69 & - & $\begin{array}{c}\text { Cyanidin 3,5- } \\
\text { diglucoside (6",6"'- } \\
\text { malyldiester) *** }\end{array}$ & - & 709.16 \\
\hline & Akaloids & 1.66 & $309963-07-3$ & Lissoclinamide $9 *$ & C35H45N7O5S2 & 707.29 \\
\hline & Carotenoids & 0.41 & $472-70-8$ & beta-Cryptoxanthin * & $\mathrm{C} 40 \mathrm{H} 56 \mathrm{O}$ & 552.43 \\
\hline & $\begin{array}{c}\text { Triterpenoid } \\
\mathrm{s}\end{array}$ & 0.38 & $19057-60-4$ & Collettiside III ** & $\mathrm{C} 45 \mathrm{H} 72 \mathrm{O} 16$ & 868.48 \\
\hline & Diterpenes & 0.09 & $63550-99-2$ & Rebaudioside C* & $\mathrm{C} 44 \mathrm{H} 70 \mathrm{O} 22$ & 950.44 \\
\hline & Phenols & 0 & - & $\begin{array}{l}\text { 2-Octaprenylphenol } \\
* *\end{array}$ & $\mathrm{C} 38 \mathrm{H} 54 \mathrm{O}$ & 526.42 \\
\hline & Carotenoids & 0 & $144-68-3$ & Zeaxanthin $* *$ & $\mathrm{C} 40 \mathrm{H} 56 \mathrm{O} 2$ & 568.43 \\
\hline & Furans & $\infty$ & $21453-69-0$ & $(+)$-Lirioresinol $\mathrm{B} * * *$ & $\mathrm{C} 22 \mathrm{H} 26 \mathrm{O} 8$ & 418.16 \\
\hline & Alkaloids & $\infty$ & - & Antibiotic SF $2425^{* *}$ & $\mathrm{C} 25 \mathrm{H} 54 \mathrm{~N} 10 \mathrm{O} 2$ & 526.44 \\
\hline & Flavonoids & $\infty$ & 59952-97-5 & Carlinoside ${ }^{*}$ & $\mathrm{C} 26 \mathrm{H} 28 \mathrm{O} 15$ & 580.14 \\
\hline & $\begin{array}{l}\text { Steroidal } \\
\text { Glycosides }\end{array}$ & 4.66 & 929701-99-5 & Isotubocaposigenin * & $\mathrm{C} 30 \mathrm{H} 44 \mathrm{O} 6$ & 500.31 \\
\hline & Akaloids & 3.46 & 185750-71-4 & $\begin{array}{l}\text { Dibromophakellstatin } \\
*\end{array}$ & $\mathrm{C} 11 \mathrm{H} 10 \mathrm{Br} 2 \mathrm{~N} 4 \mathrm{O} 2$ & 387.92 \\
\hline G8 & Akaloids & 2.6 & $309963-07-3$ & Lissoclinamide $9 *$ & C35H45N7O5S2 & 707.29 \\
\hline JA2 & - & 2.42 & Unknown & - & - & - \\
\hline $\begin{array}{l}4 / \mathrm{C} \\
\text { ON }\end{array}$ & Xanthones & 2.38 & - & $\begin{array}{l}\text { Bijaponicaxanthone } \\
* *\end{array}$ & - & - \\
\hline & - & 2.09 & $346425-30-7$ & Calyceramide * & C34H67NO7S & 633.46 \\
\hline & Tannins & 1.9 & - & Quisqualin A* & $\mathrm{C} 39 \mathrm{H} 28025$ & 896.09 \\
\hline & $\begin{array}{l}\text { Depsipeptid } \\
\text { es }\end{array}$ & 1.85 & $189757-91-3$ & Fusaricidin D * & $\mathrm{C} 46 \mathrm{H} 76 \mathrm{~N} 10 \mathrm{O} 12$ & 960.56 \\
\hline & $\begin{array}{c}\text { cyclic } \\
\text { depsipeptide }\end{array}$ & 1.74 & $136634-57-6$ & Plusbacin A1 * & C48H79N11O20 & 1129.55 \\
\hline & Carotenoids & 0 & $144-68-3$ & Zeaxanthin * & $\mathrm{C} 40 \mathrm{H} 56 \mathrm{O} 2$ & 568.43 \\
\hline & Diterpenes & $\begin{array}{c}377.1 \\
8\end{array}$ & $51330-30-4$ & Stevioside $* * *$ & $\mathrm{C} 38 \mathrm{H} 60018$ & 804.38 \\
\hline & Flavonoids & $\begin{array}{c}256.4 \\
7\end{array}$ & $32769-01-1$ & Tricin 7-glucoside * & $\mathrm{C} 23 \mathrm{H} 24 \mathrm{O} 12$ & 492.13 \\
\hline G8 & $\begin{array}{l}\text { Steroidal } \\
\text { Glycosides }\end{array}$ & 2.96 & 929701-99-5 & $\begin{array}{l}\text { Isotubocaposigenin } \\
* *\end{array}$ & $\mathrm{C} 30 \mathrm{H} 44 \mathrm{O} 6$ & 500.31 \\
\hline $\begin{array}{c}\text { TSS } \\
M\end{array}$ & $\begin{array}{l}\text { Flavonoid } \\
\text { glycosides }\end{array}$ & 1.88 & 205584-37-8 & $\begin{array}{l}\text { Vitexin 6"-O-malonyl } \\
\text { 2"-o-xyloside * }\end{array}$ & $\mathrm{C} 29 \mathrm{H} 30017$ & 650.15 \\
\hline & Flavonoids & 0.66 & $167774-88-1$ & $\begin{array}{c}\text { Pelargonidin 3- } \\
\text { glucoside-5-(6"'-- } \\
\text { malonylglucoside) * }\end{array}$ & $\mathrm{C} 30 \mathrm{H} 33 \mathrm{O} 18$ & 681.17 \\
\hline & Phenols & 0.43 & $4299-57-4$ & Plastoquinone $9 * * *$ & $\mathrm{C} 53 \mathrm{H} 80 \mathrm{O} 2$ & 748.62 \\
\hline & Akaloids & 0.33 & 309963-07-3 & Lissoclinamide $9 *$ & C35H45N7O5S2 & 707.29 \\
\hline
\end{tabular}


To reveal metabolic changes in detail, relative amounts of endogenous metabolites were compared under different conditions relative to non-treated samples in both genotypes using T-test. In genotype 29, 21 metabolite features were significantly different between spider mite-infested and control plants of which 7 features were suppressed by spider mites and 14 were induced (Table 1). Genotype 8 showed 7 metabolite features significantly different between spider mite-infested and control samples of which 4 were induced and 3 were repressed. Most of the metabolites induced upon spider-mite feeding are terpenes and their glycoside conjugates. A diterpenoid conjugate and a flavonoid-O-glucoside were strongly increased upon spider-mite infestation in genotype 8 , specifically. Only a single metabolite, the putative plastoquinone 9 , was repressed by spider mites in both genotypes. JA-induction resulted in 23 metabolite features that were induced and 5 that were repressed after 24 hours in genotype 29 while in genotype 8 , the number of induced and repressed metabolite features was 14 and 1 , respectively. In both genotypes, JA induced higher fold changes in more metabolites than did infestation with spider mites, including in terpenoids, flavonoids and alkaloids (Table 1). In addition, JA significantly repressed the production of metabolites with putative annotation to carotenoids $\beta$-cryptoxanthin and zeaxanthin in both genotypes while spider mites only repressed $\beta$-cryptoxanthin in genotype 29 and had no effect on any carotenoids in genotype 8 . Xanthophylls are accessory pigments for photosynthesis and assist chlorophylls in light harvesting (Ma et al., 2012, Xu et al., 2015). These findings are consistent with JA repressed photosynthesis found in the transcriptome analysis of both genotypes.

Volatile metabolite changes were estimated by computing the fold changes in metabolite concentrations upon spider-mite infestation relative to non-treated samples in both genotypes. Methyl salicylate (MeSA) was the most distinctive compound present in the volatile blend of spider-mite infested plants of both genotypes while it was absent in the blend of non-infested plants (Table 2).

Upon spider-mite infestation, 70 volatile metabolite features displayed increased emission and 14 were decreased relative to non-treated plants in genotype 8 while there were 96 volatile metabolite features induced and 35 repressed in genotype 29 . In both genotypes, monoterpenes, sesquiterpenes, phenolics, and alkaloids were detected in the induced volatile blend (Table 2, Supplemental Table 3, Supplemental Figure 4 A, B). The concomitant increased emission of MeSA and MeJA confirms the spider-mite induced accumulation of SA and JA. 
Table 2. Volatile metabolites emitted by $C$. annuum plants of genotype 8 and 29 that were by spider mites(TSSM). Table includes volatile metabolites that were significantly induced or repressed by spider mites $(|\log 2(F C)|>0)$ in each genotype compared to by non-infested plants and those different emitted in two genotypes upon spider mites (G29/G8). The top 20 features for each comparison are given.

\begin{tabular}{|c|c|c|c|c|}
\hline & $\begin{array}{l}\text { Retention- } \\
\text { time }\end{array}$ & $\log 2(\mathrm{FC})$ & Volatile Metabolite & $\begin{array}{l}\text { Chemical } \\
\text { Formula }\end{array}$ \\
\hline \multirow{31}{*}{$\begin{array}{l}\text { G29 } \\
\text { TSSM/ } \\
\text { CON }\end{array}$} & 19:00 & 8.40 & $\mathrm{~N}$-(1-Cyano-2-imidazol-1-yl-ethyl) formamide & C7H8N4O \\
\hline & $15: 83$ & 8.20 & Methyl salicylate & $\mathrm{C} 8 \mathrm{H} 8 \mathrm{O} 3$ \\
\hline & $20: 36$ & 8.17 & $\begin{array}{l}\text { [1aS-(1a.alpha.,3a.alpha.,7a.beta.,7b.alpha.)]-1H- } \\
\text { Cyclopropa[a]naphthalene, decahydro-1,1,3a- } \\
\text { trimethyl-7-methylene }\end{array}$ & $\mathrm{C} 15 \mathrm{H} 24$ \\
\hline & $18: 75$ & 8.16 & $\begin{array}{l}\text { 2-Methylene-5-(1-methylvinyl)-8-methyl- } \\
\text { Bicyclo[5.3.0]decane }\end{array}$ & $\mathrm{C} 15 \mathrm{H} 24$ \\
\hline & $20: 10$ & 8.13 & (E,E)-alpha.-Farnesene & $\mathrm{C} 15 \mathrm{H} 24$ \\
\hline & $15: 78$ & 8.09 & trans-p-mentha-1(7),8-dien-2-ol & $\mathrm{C} 10 \mathrm{H} 160$ \\
\hline & $14: 64$ & 8.02 & 1,3,8-p-Menthatriene & $\mathrm{C} 10 \mathrm{H} 14$ \\
\hline & $16: 75$ & 7.97 & Cyclohexene, 6-butyl-1-nitro- & $\mathrm{C} 10 \mathrm{H} 17 \mathrm{NO} 2$ \\
\hline & $18: 66$ & 7.89 & $\begin{array}{l}\text { 4,11,11-trimethyl-8-methylenebicyclo[7.2.0]undec-3- } \\
\text { ene }\end{array}$ & $\mathrm{C} 15 \mathrm{H} 24$ \\
\hline & $21: 60$ & 7.83 & $\begin{array}{l}\text { Tricyclo[7.4.0.0(3,8)]tridec-12-en-2-one, 5,6-epoxy-4- } \\
\text { methyl-1-(2-propynyl)- }\end{array}$ & $\mathrm{C} 17 \mathrm{H} 20 \mathrm{O} 2$ \\
\hline & $14: 46$ & 7.63 & Benzene, 2-ethyl-1,4-dimethyl- & $\mathrm{C} 10 \mathrm{H} 14$ \\
\hline & $18: 59$ & 7.61 & 2-Pentenamide, 4-methyl-N-phenyl- & $\mathrm{C} 12 \mathrm{H} 15 \mathrm{NO}$ \\
\hline & $14: 35$ & 7.42 & cis-Ocimene, 8-oxo- & $\mathrm{C} 10 \mathrm{H} 140$ \\
\hline & $20: 20$ & 7.35 & Dodecanoic acid, methyl ester & $\mathrm{C} 13 \mathrm{H} 26 \mathrm{O} 2$ \\
\hline & $20: 22$ & 7.23 & $\begin{array}{l}\text { (1R,3aS,8aS)-7-Isopropyl-1,4-dimethyl-1,2,3,3a,6,8a- } \\
\text { hexahydroazulene }\end{array}$ & $\mathrm{C} 15 \mathrm{H} 24$ \\
\hline & 19:26 & 7.17 & $\begin{array}{l}\text { Bicyclo[5.2.0]nonane, 4-methylene-2,8,8-trimethyl-2- } \\
\text { vinyl- }\end{array}$ & $\mathrm{C} 15 \mathrm{H} 24$ \\
\hline & $14: 13$ & 7.04 & Benzoic acid, methyl ester & $\mathrm{C} 8 \mathrm{H} 8 \mathrm{O} 2$ \\
\hline & $15: 82$ & 6.96 & Methyl salicylate & $\mathrm{C} 8 \mathrm{H} 8 \mathrm{O} 3$ \\
\hline & $22: 12$ & 6.78 & 1-methylpropyl-Cyclooctane & $\mathrm{C} 12 \mathrm{H} 24$ \\
\hline & $13: 72$ & 6.67 & 1,4-Cyclohexadiene, 3-ethenyl-1,2-dimethyl- & $\mathrm{C} 10 \mathrm{H} 14$ \\
\hline & $16: 77$ & 6.60 & 7-Oxabicyclo[4.1.0]heptane, 3-oxiranyl- & $\mathrm{C} 8 \mathrm{H} 12 \mathrm{O} 2$ \\
\hline & 19:55 & -6.93 & Methanone, (2,3-dihydro-5-benzofuryl)(4-morpholyl) & $\mathrm{C} 13 \mathrm{H} 15 \mathrm{NO} 3$ \\
\hline & $24: 20$ & -6.98 & 2,4-Diphenyl-4-methyl-2(E)-pentene & $\mathrm{C} 18 \mathrm{H} 20$ \\
\hline & $24: 27$ & -7.00 & $\begin{array}{c}\text { 1,2-Benzenedicarboxylic acid, bis(2-methylpropyl) } \\
\text { ester }\end{array}$ & $\mathrm{C} 16 \mathrm{H} 22 \mathrm{O} 4$ \\
\hline & $25: 27$ & -7.27 & $\begin{array}{c}\text { Dibutyl phthalate } \\
\end{array}$ & $\mathrm{C} 16 \mathrm{H} 22 \mathrm{O} 4$ \\
\hline & $22: 65$ & -7.33 & Benzoic acid, 2-ethylhexyl ester & $\mathrm{C} 15 \mathrm{H} 22 \mathrm{O} 2$ \\
\hline & $25: 76$ & -7.70 & Isopropyl palmitate & $\mathrm{C} 19 \mathrm{H} 38 \mathrm{O} 2$ \\
\hline & $24: 84$ & -7.86 & Benzene, (1-methyldodecyl)- & $\mathrm{C} 19 \mathrm{H} 32$ \\
\hline & 19:30 & -9.00 & 1,3-Benzenediol, O,O'-di(2-methylbenzoyl)- & $\mathrm{C} 22 \mathrm{H} 18 \mathrm{O} 4$ \\
\hline & 13:67 & -9.02 & Phenacylidene diacetate & $\mathrm{C} 12 \mathrm{H} 12 \mathrm{O} 5$ \\
\hline & $4: 90$ & -10.41 & Benzene, 1,2-difluoro-4-(trifluoromethyl)- & C7H3F5 \\
\hline \multirow{7}{*}{$\begin{array}{l}\text { G8 } \\
\text { TSSM/ } \\
\text { CON }\end{array}$} & $15: 82$ & 12.68 & Methyl salicylate & $\mathrm{C} 8 \mathrm{H} 8 \mathrm{O} 3$ \\
\hline & $18: 33$ & 12.20 & cis-3-Hexenyl cis-3-hexenoate & $\mathrm{C} 12 \mathrm{H} 20 \mathrm{O} 2$ \\
\hline & $14: 26$ & 12.12 & Cyclohexane, 2-ethenyl-1,1-dimethyl-3-methylene- & $\mathrm{C} 11 \mathrm{H} 18$ \\
\hline & $14: 60$ & 11.32 & $\begin{array}{l}\text { 5-[(Trimethylpyrazol-4-yl)methyl]-1,3,5-triazinane-2- } \\
\text { thione }\end{array}$ & C10H17N5S \\
\hline & 20:90 & 10.75 & (3E,7E)-4,8,12-Trimethyltrideca-1,3,7,11-tetraene & $\mathrm{C} 16 \mathrm{H} 26$ \\
\hline & $21: 60$ & 10.64 & Phenethylamine, 2,4,5-trimethoxy-.alpha.-methyl- & $\mathrm{C} 12 \mathrm{H} 19 \mathrm{NO} 3$ \\
\hline & $18: 66$ & 10.45 & Bicyclo[5.3.0]decane, 2-methylene-5-(1-methylvinyl)-8- & $\mathrm{C} 15 \mathrm{H} 24$ \\
\hline
\end{tabular}




\begin{tabular}{|c|c|c|c|c|}
\hline & & & methyl- & \\
\hline & $19: 22$ & 10.44 & Cycloheptasiloxane, tetradecamethyl- & $\mathrm{C} 14 \mathrm{H} 42 \mathrm{O} 7 \mathrm{Si} 7$ \\
\hline & $20: 68$ & 10.37 & Cyclohexene, 1,5,5-trimethyl-3-methylene- & $\mathrm{C} 10 \mathrm{H} 16$ \\
\hline & $20: 81$ & 10.34 & Hexadecane, 2-methyl- & $\mathrm{C} 17 \mathrm{H} 36$ \\
\hline & $20: 82$ & 10.05 & Cyclohexanepropanol- & $\mathrm{C9H} 180$ \\
\hline & $13: 13$ & 9.82 & 1,3,6-Octatriene, 3,7-dimethyl-, (Z)- & $\mathrm{C} 10 \mathrm{H} 16$ \\
\hline & $14: 64$ & 9.68 & p-Mentha-1,5,8-triene & $\mathrm{C} 10 \mathrm{H} 14$ \\
\hline & $20: 36$ & 9.61 & $\begin{array}{c}\text { 1H-Cyclopropa[a]naphthalene, decahydro-1,1,3a- } \\
\text { trimethyl-7-methylene-, [1aS- } \\
\text { (1a.alpha.,3a.alpha.,7a.beta.,7b.alpha.)]- }\end{array}$ & $\mathrm{C} 15 \mathrm{H} 24$ \\
\hline & $15: 58$ & 9.41 & endo-Borneol & $\mathrm{C} 10 \mathrm{H} 180$ \\
\hline & $14: 27$ & 9.04 & [(4-Hexylbenzene-1,3-diyl)bis(oxy)]bis(trimethylsilane) & $\mathrm{C} 18 \mathrm{H} 34 \mathrm{O} 2 \mathrm{Si} 2$ \\
\hline & $20: 30$ & 8.94 & $\begin{array}{l}\text { Naphthalene, decahydro-4a-methyl-1-methylene-7-(1- } \\
\text { methylethenyl)-, [4aR-(4a.alpha.,7.alpha.,8a.beta.)]- }\end{array}$ & $\mathrm{C} 15 \mathrm{H} 24$ \\
\hline & $16: 12$ & 8.83 & Bicyclo[3.1.1]hept-3-en-2-one, 4,6,6-trimethyl-, (1S)- & $\mathrm{C} 10 \mathrm{H} 140$ \\
\hline & $12: 30$ & 8.82 & Cyclopentene, 3-methyl- & $\mathrm{C} 6 \mathrm{H} 10$ \\
\hline & $15: 15$ & -2.10 & Heptane, 1-chloro- & $\mathrm{C} 7 \mathrm{H} 15 \mathrm{Cl}$ \\
\hline & $12: 36$ & -2.24 & Benzene, 1,2,4-trimethyl- & $\mathrm{C} 9 \mathrm{H} 12$ \\
\hline & $16: 53$ & -2.44 & 1H-Pyrazolo[3,4-d]pyrimidin-4-amine & C5H5N5 \\
\hline & $15: 78$ & -2.49 & Ethanol, 2-[methyl(phenylmethyl)amino]- & $\mathrm{C} 10 \mathrm{H} 15 \mathrm{NO}$ \\
\hline & $22: 00$ & -2.67 & Benzophenone & $\mathrm{C} 13 \mathrm{H} 100$ \\
\hline & $12: 90$ & -2.77 & (E)-3-Caren-2-ol & $\mathrm{C} 10 \mathrm{H} 16 \mathrm{O}$ \\
\hline & $13: 44$ & -3.01 & Ethanone, 1-(4-methylphenyl)- & $\mathrm{C9H} 100$ \\
\hline & 9:96 & -3.02 & Benzene, 1,3-dimethyl- & $\mathrm{C} 8 \mathrm{H} 10$ \\
\hline & $10: 40$ & -3.07 & Styrene & $\mathrm{C} 8 \mathrm{H} 8$ \\
\hline & $20: 10$ & -3.90 & 1-Octadecyne & $\mathrm{C} 18 \mathrm{H} 34$ \\
\hline & $16: 64$ & 8.06 & 2,4-Dimethylamphetamine & $\mathrm{C} 11 \mathrm{H} 17 \mathrm{~N}$ \\
\hline & $6: 78$ & 7.91 & Pentanenitrile & C5H9N \\
\hline & $13: 72$ & 7.71 & Phenol, 4-ethyl- & $\mathrm{C} 8 \mathrm{H} 10 \mathrm{O}$ \\
\hline & $16: 75$ & 7.07 & 2-Octanone, 1-phenyl- & $\mathrm{C} 14 \mathrm{H} 20 \mathrm{O}$ \\
\hline & $20: 10$ & 7.04 & Pentadecanal- & $\mathrm{C} 15 \mathrm{H} 30 \mathrm{O}$ \\
\hline & 11:39 & 6.99 & 2(5H)-Furanone, 5,5-dimethyl- & $\mathrm{C} 6 \mathrm{H} 8 \mathrm{O} 2$ \\
\hline & $16: 16$ & 6.83 & 2-Ethylphenol, methyl ether & $\mathrm{C} 9 \mathrm{H} 12 \mathrm{O}$ \\
\hline & $15: 39$ & 6.72 & 4-(3-Methoxycarbonylpropyl)-4-butanolide & $\mathrm{C} 9 \mathrm{H} 14 \mathrm{O} 4$ \\
\hline & $17: 35$ & 6.71 & Indole & $\mathrm{C} 8 \mathrm{H} 7 \mathrm{~N}$ \\
\hline & $20: 20$ & 6.69 & $\begin{array}{l}\text { (4R,4aS,6S)-4,4a-Dimethyl-6-(prop-1-en-2-yl)- } \\
\text { 1,2,3,4,4a,5,6,7-octahydronaphthalene }\end{array}$ & $\mathrm{C} 15 \mathrm{H} 24$ \\
\hline & $16: 77$ & 6.68 & 2-Hexyne, 4-methyl- & $\mathrm{C} 7 \mathrm{H} 12$ \\
\hline G29(TS & $14: 36$ & 6.61 & cis-Ocimene, 8-oxo- & $\mathrm{C} 10 \mathrm{H} 140$ \\
\hline $\mathrm{SM}) / \mathrm{G}$ & $14: 77$ & 6.55 & 2,4,6-Octatriene, 2,6-dimethyl-, (E,Z)- & $\mathrm{C} 10 \mathrm{H} 16$ \\
\hline $8($ TSS & $14: 64$ & 6.54 & 1,4-Cyclohexadiene, 3-ethenyl-1,2-dimethyl- & $\mathrm{C} 10 \mathrm{H} 14$ \\
\hline M) & $14: 46$ & 6.41 & Unknown & \\
\hline & 19:00 & 6.36 & Furyl hydroxymethyl ketone & $\mathrm{C} 6 \mathrm{H} 6 \mathrm{O} 3$ \\
\hline & $14: 45$ & 6.27 & Benzene, 2-ethyl-1,4-dimethyl- & $\mathrm{C} 10 \mathrm{H} 14$ \\
\hline & $15: 78$ & 6.26 & Carveol & $\mathrm{C} 10 \mathrm{H} 160$ \\
\hline & $20: 00$ & 6.24 & $(\mathrm{E}, \mathrm{E})$-alpha.-Farnesene & $\mathrm{C} 15 \mathrm{H} 24$ \\
\hline & $9: 50$ & 6.22 & (E)-4-Hexen-1-ol, & $\mathrm{C} 6 \mathrm{H} 12 \mathrm{O}$ \\
\hline & $22: 77$ & -2.02 & Benzene, (1-pentylheptyl)- & $\mathrm{C} 18 \mathrm{H} 30$ \\
\hline & $15: 82$ & -2.36 & Methyl salicylate & $\mathrm{C} 8 \mathrm{H} 8 \mathrm{O} 3$ \\
\hline & $17: 31$ & -6.61 & 1-Octadecyne & $\mathrm{C} 18 \mathrm{H} 34$ \\
\hline & $18: 33$ & -6.72 & cis-3-Hexenyl or cis-3-hexenoate & $\mathrm{C} 12 \mathrm{H} 20 \mathrm{O} 2$ \\
\hline & $15: 49$ & -6.87 & $(\alpha, \alpha)$-4-trimethyl-benzenemethanol & $\mathrm{C} 10 \mathrm{H} 140$ \\
\hline & 9:11 & -7.38 & Naphthalene, 2-ethoxy- & $\mathrm{C} 12 \mathrm{H} 12 \mathrm{O}$ \\
\hline & $13: 67$ & -8.71 & Phenacylidene diacetate & $\mathrm{C} 12 \mathrm{H} 12 \mathrm{O} 5$ \\
\hline
\end{tabular}


Benzenoids are the most distinctive group of compounds repressed in the two genotypes. As cinnamoyl-CoA and benzoyl CoA are involved in the biosynthesis of both SA and benzenoids in e.g. petunia flowers (Klempien et al., 2012), it suggests that common precursors are converted to SA and MeSA instead of benzenoids upon spider-mite infestation. Ninety volatile metabolite features exhibited higher production in genotype 29 , including most of the terpenoids and green leaf volatiles, while only 8 volatile metabolites were higher in genotype 8 (Supplemental Table 3, Supplemental Figure 4C.) which is in agreement with transcriptome analysis indicating more secondary metabolite related genes were induced by spider mites in genotype 29. While both genotypes exhibited enhanced attractiveness to predatory mites upon spider-mite infestation, genotype 8 was more attractive than genotype 29 . Genotype 29 had higher induced emission of $(E)$ - $\beta$-ocimene, $(E, E)$ $\alpha$-farnesene, TMTT and (E)-3-hexenol compared to genotype 8 , which are suggested to be involved in the attraction of natural enemies in many plant species (Kappers et al., 2011, Zhang et al., 2009, Schnee et al., 2006, Copolovici et al., 2011). Intriguingly, only two volatile metabolites were induced to a higher level in genotype 8, putatively annotated as 3-methyl-cyclopentene and MeSA. MeSA is extensively reported to be attractive to predatory mites in many plant species (Shimoda, 2010, Ishiwari et al., 2007, De Boer and Dicke, 2004, Kappers et al., 2011). Although, the attractiveness to predatory mites is most likely the result of the blend of volatile metabolites emitted, our data suggest that MeSA is an important compound determining predatory mite preferences.

\section{Discussion}

Many studies have shown that JA plays a prominent role in plant defense against herbivores (Bari and Jones, 2009) and induces the production of metabolites such as terpenoids, alkaloids and proteins that deter herbivorous attackers directly or indirectly (van der Fits and Memelink, 2000, Aerts et al., 1994, Ament et al., 2004, Chen et al., 2005).

Here we found that in $C$. annuum spider mites induce distinctive transcriptional changes different to those in response to JA (Figure 4, 5). JA treatment induced genes enriched in wound responses and JA biosynthesis genes including $L O X, A O C$ and AOS. In multiple plant species it has been described that wound responses are mediated by the COI1-dependent JA signaling (Wasternack et al., 2006, Wang et al., 2008) and that JA regulates JA biosynthesis via a positive feedback loop (Wasternack and Hause, 2013). The expression of genes related to different secondary metabolite biosyn- 
thesis pathways including those of terpenoids, flavonoids and phenylpropanoids were also induced by JA (Figure 6, Supplemental Table 2). Multiple terpenoids, flavonoids and alkaloids were found in a higher abundance in endogenous metabolites upon JA treatment (Table 1). Previous studies showed that JA enhances flavonoid production probably via MYB transcription factors (Pireyre and Burow, 2015, An et al., 2015) in which MYC2 was shown to have a positive role (Dombrecht et al., 2007). Several JA induced terpenoids and alkaloids have been confirmed and multiple biosynthetic genes as well as regulators were identified in tomato Lycopersicon esculentum (Ament et al., 2004), Artemisia annua L (Yu et al., 2012), Catharanthus roseus (Zhu et al., 2015). Although due to the complexity of different metabolic biosynthetic pathways and limited datasets of the current study, it is difficult to precisely connect metabolite production with gene expression, our data provide comprehensive evidence that JA induces multiple secondary metabolite biosynthetic pathways and is responsible for a burst of secondary metabolite production.

It's noteworthy that JA repressed genes functional in the tyrosine biosynthesis pathway (including Capana04g002663, Capana04g002427, Capana08g000468, Capana04g001109, Capana04g002426, Capana04g002800, Supplemental Dataset 1, 2, 4, 5). Tyrosine is generated from chorismate, an intermediate in the biosynthesis of phenylalanine. Phenylalanine is the starting point of the phenylpropanoid biosynthesis pathway (Figure 10) (Vogt, 2010, Chapple, 2011) of which multiple transcripts were shown to be significantly induced by JA (Figure 6) in this study, suggesting that JA represses the production of tyrosine in favor of up-regulation of the phenylpropanoid pathway.

\section{JA induced secondary metabolites are important for Capsicum defense against spider mites}

Based on numbers of spider mites developed in the short time span of the bioassay, genotype 8 is more susceptible than genotype 29. A larger accumulation of SA was detected in genotype 8 , corresponding with the higher expression of SA-responsive genes found in this genotype (Supplemental Dataset). In contrast, the increase in JA upon spider-mite infestation was higher in genotype 29 (Supplemental Figure 1), and more endogenous metabolites were detected in genotype 29 upon spider-mite feeding compared to genotype 8 (Table 1, 2). Transcriptome comparison between the two genotypes in control samples suggests that some stress related genes are higher expressed in genotype 8 under unchallenged conditions, which is consistent with the higher constitutive accumulation of SA and JA in genotype 8. However, upon spider mite feeding, there is a stronger JA response in genotype 
29 , resulting in a higher expression of JA responsive genes and accumulation of various secondary metabolites, which results in a stronger induced defense which correlates with the observed higher resistance for genotype 29.

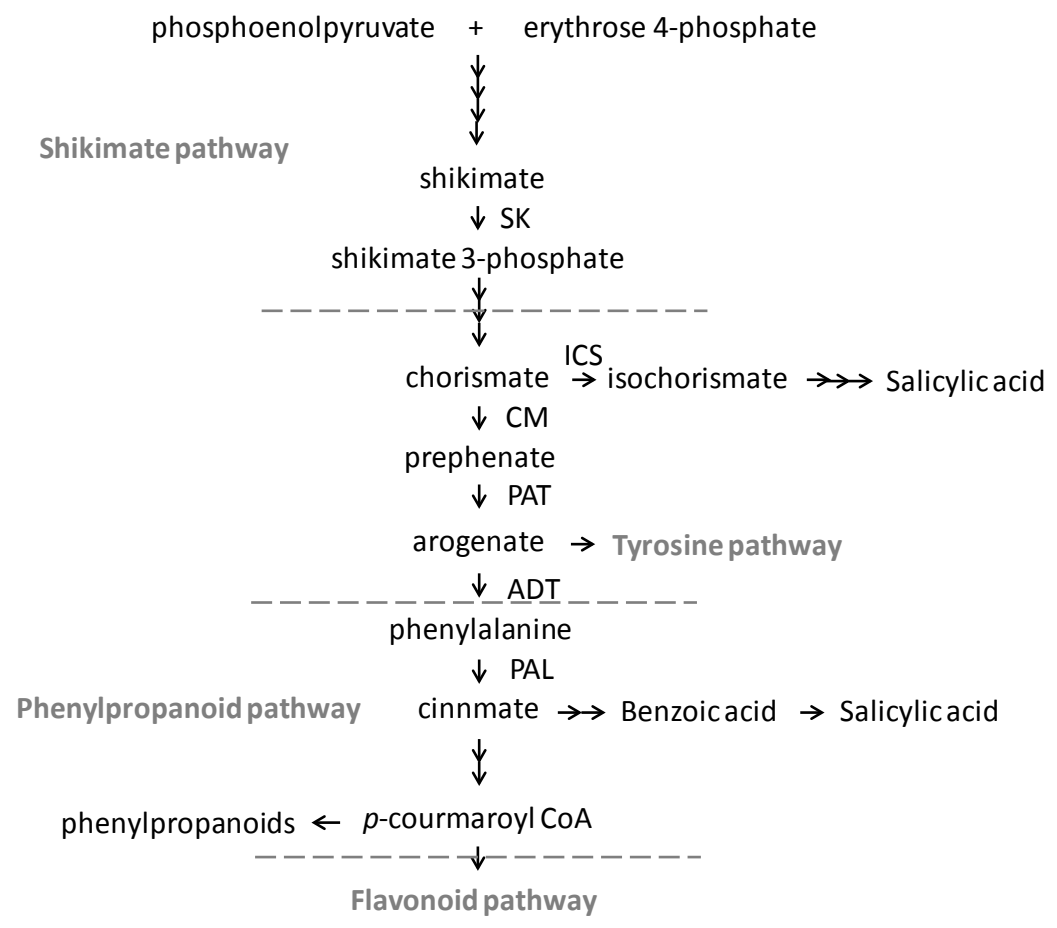

Figure 10. The phenylpropanoid pathway in plants. SK, Shikimate kinase; ICS, Isochorismate synthase; PAT, Prephenate aminotransferase; CM, Chorismate mutase; ADT, Arogenate dehydratase; PAL, Phenylalanine ammonia-lyase.

Spider mites induce both the SA and JA signaling pathways, but not all JA-induced metabolic processes

Spider mites also up-regulated JA biosynthetic genes ( $L O X 2, A O C, A O S$ ) and caused the accumulation of cis-OPDA, JA and JA-lle (Figure 3). Furthermore, JA-responsive genes, CHIB and $P R 4$, regulated by the JA/ET signaling pathway were induced by spider mites (Supplemental Dataset 3,6 ). Together, this confirms that spider mites induced both JA biosynthesis and signaling in C. annuum. However, different from chewing herbivores such as caterpillars (Kawazu et al., 2012), spider mites also induced the SA pathway resulting in an increased SA concentration (Figure 3 ) and the up-regulation of SA responsive genes (Figure 6, Supplemental Dataset 3,6). This result is consistent with studies on spider-mite induced responses in tomato (Martel et al., 2015) and in grape (Díaz-Riquelme et al., 2016). 
Our study shows that spider mites induce a limited number of metabolite pathways compared to JA treatment (Figure 6, Supplemental Table 2). As a result, plants accumulated less secondary metabolites upon spider-mite infestation than plants treated with JA and distinctive metabolic profiles were found for JA induced plants compared with spider-mite infested plants and control plants (Figure 8). However, both JA and spider mites up-regulated genes encoding for 4-coumarate-CoA ligase 2, 4CL2 (Capana03g001733, Log2(FC) 3.63) in Genotype 8, Capana03g001732, Log2(FC) 3.44 in Genotype 29) which are involved in the final step of the phenylpropanoid pathway. Phenylpropanoid biosynthesis can result in the production of SA (Chen et al., 2009) and flavonoids (Vogt, 2010) (Figure 10). The conversion of phenylalanine to trans-cinnamic acid, the precursor of salicylic acid is catalyzed by phenylalanine ammonia-lyase (PAL). JA induced multiple genes in the flavonoid pathway, downstream of the phenylpropanoid pathway and produced more flavonoid metabolites compared with non-treated plants (Supplemental Dataset, Table 1). In contrast, spider mites induced the production of SA and MeSA, but less so of flavonoids and flavones compared to JA treatment (Figure 3, Table 1). This suggests that spider mites induce the phenylpropanoid pathway only, and do not up-regulate the flavonoid pathway as JA does, which results in the production of SA, but not flavanoids. In accordance with our results, overproduction of SA in tobacco plants by bacterial transgenes strongly inhibited the accumulation of the flavonoids quercetin, kaempferol and rutin (Verberne et al., 2000, Nugroho et al., 2002). However, exogenous SA application has been reported to boost the production of flavonoids in several plant species (Xu et al., 2009, Gondor et al., 2016) and SA induced by pathogens resulted in the accumulation of flavonoid phytoalexins in a range of crops from Brassicaceae, Fabaceae, Solanaceae, Vitaceae and Poaceae (Ahuja et al., 2012). Altogether, we hypothesize that JA-induced flavonoid biosynthesis is restricted upon spider-mite herbivory because the production of SA induced by the mites diverts all the precursors available to SA biosynthesis. Even though no GO-terms related with terpenoid pathway metabolic processes were found enriched upon spider-mite infestation, a number of terpene biosynthetic genes were induced and multiple volatile and non-volatile terpenoids also were found to be present in higher amount after spider mite infestation (Table 1, 2). Our results indicate that the terpenoid biosynthetic pathway is mainly induced via JA signaling, while the SA signaling pathway activated by spider mites does not repress this biosynthetic pathway. 


\section{JA-SA crosstalk in spider mites induced defense}

In addition to multiple secondary metabolic pathway genes, there are many other genes that are only responsive to exogenous JA but are not induced by spider-mite infestation even though JA signaling is induced by spider mite feeding. JA-SA antagonism has been demonstrated in many plant species (Thaler et al., 2012) and we propose that in Capsicum the SA pathway suppresses part of the spider-mite induced JA responses. To verify this hypothesis and demonstrate the possible mechanism of antagonizing crosstalk, we identified transcription factors induced by JA and spider mites respectively, as well as genes strongly correlating with those transcription factors.

MYC2 is well-known as the master regulator of JA signaling. Two homologues are identified in the Capsicum annuum genome, Capana01g004352 and Capana01g001098. Since only Capana01g001098 generates strong correlations with DEGs, we predict that Capana01g001098 is the functional homologue of MYC2 in Capsicum. This Capsicum MYC2 homologue is induced by exogenous JA in both genotypes though not statistically significant. Based on correlation analysis, 40 DEGs positively correlate with MYC2 and 24 and 25 of those 40 genes are induced by JA in genotype 8 and 29 respectively while none of them were induced by spider mites in either of the genotypes (Supplemental Table 1, Dataset 2, 3, 5, 6). In A. thaliana, protein levels of MYC2, MYC3 and MYC4 were strongly diminished by Pieris brassicae egg extract in an SA-dependent manner, suggesting that MYC transcription factors are targets of SA/JA antagonism (Schmiesing et al., 2016). Apart from the MYC2 branch of the JA signaling pathway, exogenous JA application also induced transcription factors from the JA/ET branch, including ERF1, ERF2 and ERF13 (Capana05g001701, Capana01g000661, Capana01g003507) in genotype 8 and ERF1 and MYB3 (Capana05g001701 Capana01g000070) in genotype 29. In total, $107 \mathrm{DEGs}$ positively correlated with these JA induced transcription factors in genotype 8 and 51 of these DEGs were induced by JA while 2 were also induced by spider mites. In genotype 29, 28 DEGs positively correlated with these JA induced transcription factors, while 25 of these were induced by JA and 5 also by spider mites. Interestingly, spider mite feeding resulted in the up-regulation of an ERF1 related gene, Capana12g000990, in both genotypes, annotated as TIFY1OB which encodes the $M Y C$ repressor, JAZ. This may suggest a repression of the MYC branch in the JA signaling pathway by spider mites.

As discussed, JA signaling was suppressed by spider-mite induced SA, but our data also show that exogenous JA application represses SA signaling. JA application strongly represses the expression of homologues of WRKY70 in both genotypes (Capana10g001548, Log2(FC) = 3.46 in genotype 8; Cap- 
ana10g001220, $\log 2(F C)=-60.16$ in genotype 29). WRKY70 mediates the SA-dependent signaling pathway in multiple species (Pandey and Somssich, 2009). Overexpression of WRKY70 results in constitutive expression of SA-induced PR genes and enhances resistance to Erysiphe cichoracearum but represses JA responses. Conversely, antisense suppression of WRKY70 activates JA-responsive/COl1-dependent genes in A. thaliana ( $\mathrm{Li}$ et al., 2004, Li et al., 2006).

In this study, we demonstrated the differences in the responses of Capsicum to JA and spider mites by comparing transcriptome changes and corresponding metabolite changes and gave a comprehensive overview of JA-responsive and spider-mite induced genes by coexpression analysis. Based on the data presented in this study, we show that spider mites induce SA biosynthesis and hence SA signaling as well as the JA biosynthesis pathway, resulting in the expression of $S A$ responsive genes and some $J A$ responsive genes. A JA/SA antagonism mechanism seems to be responsible for this. Our data suggest that SA signaling induced upon spider-mite infestation suppresses the $M Y C$ regulated branch in the JA signaling pathway but not the ERF regulated branch. An ERF1 related gene, encoding MYC repressor $J A Z$ was induced by spider mites. Exogenous application of JA up-regulated the flavonoid biosynthetic pathway which may compete with SA biosynthesis and suppressed SA signaling regulator WRKY7O. Further investigation is still needed to reveal the details of this mutual antagonizing JA/SA crosstalk.

\section{Acknowledgements}

We would like to thank Kristyna Flokova for performing plant hormone measurement, Paul Mooijman and Elise Serin for helping with $\mathrm{R}$ script analysis, Bert Schipper for performing endogenous metabolites measurement, Francel Verstappen for performing volatiles measurement. 


\section{References}

ADOLFSSON, L., NZIENGUI, H., ABREU, I. N., SIMURA, J., BEEBO, A., HERDEAN, A., ABOALIZADEH, J., SIROKA, J., MORITZ, T., NOVAK, O., LJUNG, K., SCHOEFS, B. \& SPETEA, C. 2017. Enhanced Secondary- and Hormone Metabolism in Leaves of Arbuscular Mycorrhizal Medicago truncatula. Plant Physiology, 175, 392-411.

AERTS, R. J., GISI, D., DECAROLIS, E., DELUCA, V. \& BAUMANN, T. W. 1994. Methyl Jasmonate Vapor Increases the Developmentally Controlled Synthesis of Alkaloids in Catharanthus and Cinchona Seedlings. Plant Journal, 5, 635-643.

AHUJA, I., KISSEN, R. \& BONES, A. M. 2012. Phytoalexins in defense against pathogens. Trends in Plant Science, 17, 73-90.

AMENT, K., KANT, M. R., SABELIS, M. W., HARING, M. A. \& SCHUURINK, R. C. 2004. Jasmonic acid is a key regulator of spider mite-induced volatile terpenoid and methyl salicylate emission in tomato. Plant Physiology, 135, 2025-2037.

AMENT, K., VAN SCHIE, C. C., BOUWMEESTER, H. J., HARING, M. A. \& SCHUURINK, R. C. 2006. Induction of a leaf specific geranylgeranyl pyrophosphate synthase and emission of $(E, E)-4,8,12$-trimethyltrideca-1,3,7,11-tetraene in tomato are dependent on both jasmonic acid and salicylic acid signaling pathways. Planta, 224, 1197-1208.

AN, X.-H., TIAN, Y., CHEN, K.-Q., LIU, X.-J., LIU, D.-D., XIE, X.-B., CHENG, C.-G., CONG, P.-H. \& HAO, Y.-J. 2015. MdMYB9 and MdMYB11 are Involved in the Regulation of the JA-Induced Biosynthesis of Anthocyanin and Proanthocyanidin in Apples. Plant and Cell Physiology, 56, 650-662.

BANDOLY, M., HILKER, M. \& STEPPUHN, A. 2015. Oviposition by Spodoptera exigua on Nicotiana attenuata primes induced plant defence against larval herbivory. Plant Journal, 83, 661-672.

BARI, R. \& JONES, J. D. G. 2009. Role of hormones in plant defense responses. Plant Molecular Biology, 69, 473-488.

BENJAMINI, Y. \& HOCHBERG, Y. 1995. Controlling the false discovery rate: a practical and powerful approach to multiple testing. Journal of the Royal Statistical Society Series $B$-Methodological, 57, 289-300.

BLEECKER, A. B. \& KENDE, H. 2000. Ethylene: A gaseous signal molecule in plants. Annual Review of Cell and Developmental Biology, 16, 1-+.

BOLGER, A. M., LOHSE, M. \& USADEL, B. 2014. Trimmomatic: a flexible trimmer for Illumina sequence data. Bioinformatics, 30, 2114-2120.

BOUCHEZ, O., HUARD, C., LORRAIN, S., ROBY, D. \& BALAGUE, C. 2007. Ethylene is one of the key elements for cell death and Defense response control in the Arabidopsis lesion mimic mutant vad1. Plant Physiology, 145, 465-477.

CARRIZO GARCÍA, C., BARFUSS, M. H. J., SEHR, E. M., BARBOZA, G. E., SAMUEL, R., MOSCONE, E. A. \& EHRENDORFER, F. 2016. Phylogenetic relationships, diversification and expansion of chili peppers (Capsicum, Solanaceae). Annals of Botany, 118, 35-51.

CHAPPLE, C. M. F., CLINT 2011. The Phenylpropanoid Pathway in Arabidopsis. Arabidopsis Book, 9, e0152.

CHEN, H., WILKERSON, C. G., KUCHAR, J. A., PHINNEY, B. S. \& HOWE, G. A. 2005. Jasmonate-inducible plant enzymes degrade essential amino acids in the herbivore midgut. Proceedings of the National Academy of Sciences of the United States of America, 
102, 19237-19242.

CHEN, Z., ZHENG, Z., HUANG, J., LAI, Z. \& FAN, B. 2009. Biosynthesis of salicylic acid in plants. Plant Signal Behav, 4, 493-6.

CHEYNIER, V., COMTE, G., DAVIES, K. M., LATTANZIO, V. \& MARTENS, S. 2013. Plant phenolics: Recent advances on their biosynthesis, genetics, and ecophysiology. Plant Physiology and Biochemistry, 72, 1-20.

COBURN, R. A., GRIFFIN, R. H. \& SMITH, S. D. 2015. GENETIC BASIS FOR A RARE FLORAL MUTANT IN AN ANDEAN SPECIES OF SOLANACEAE. American Journal of Botany, $102,264-272$.

COPOLOVICI, L., KANNASTE, A., REMMEL, T., VISLAP, V. \& NIINEMETS, U. 2011. Volatile Emissions from Alnus glutionosa Induced by Herbivory are Quantitatively Related to the Extent of Damage. Journal of Chemical Ecology, 37, 18-28.

CREELMAN, R. A., TIERNEY, M. L. \& MULLET, J. E. 1992. JASMONIC ACID METHYL JASMONATE ACCUMULATE IN WOUNDED SOYBEAN HYPOCOTYLS AND MODULATE WOUND GENE-EXPRESSION. Proceedings of the National Academy of Sciences of the United States of America, 89, 4938-4941.

DE BOER, J. G. \& DICKE, M. 2004. The role of methyl salicylate in prey searching behavior of the predatory mite phytoseiulus persimilis. J Chem Ecol, 30, 255-71.

DE VOS, R. C., MOCO, S., LOMMEN, A., KEURENTJES, J. J., BINO, R. J. \& HALL, R. D. 2007. Untargeted large-scale plant metabolomics using liquid chromatography coupled to mass spectrometry. Nature Protocols, 2, 778-91.

DENG, H. Q., LIU, H. B., LI, X. H., XIAO, J. H. \& WANG, S. P. 2012. A CCCH-Type Zinc Finger Nucleic Acid-Binding Protein Quantitatively Confers Resistance against Rice Bacterial Blight Disease. Plant Physiology, 158, 876-889.

DÍAZ-RIQUELME, J., ZHUROV, V., RIOJA, C., PÉREZ-MORENO, I., TORRES-PÉREZ, R., GRIMPLET, J., CARBONELL-BEJERANO, P., BAJDA, S., VAN LEEUWEN, T., MARTÍNEZ-ZAPATER, J. M., GRBIC, M. \& GRBIC, V. 2016. Comparative genome-wide transcriptome analysis of Vitis vinifera responses to adapted and non-adapted strains of two-spotted spider mite, Tetranyhus urticae. BMC Genomics, 17, 74.

DIAZ, J., TEN HAVE, A. \& VAN KAN, J. A. L. 2002. The role of ethylene and wound signaling in resistance of tomato to Botrytis cinerea. Plant Physiology, 129, 1341-1351.

DICKE, M., SABELIS, M. W. \& TAKABAYASHI, J. 1991. Do plants cry for help? evidence related to a tritrophic system of predatory mites, spider mites and their host plants. Symposia Biologica Hungarica, 127 - 134.

DO, C. T., POLLET, B., THEVENIN, J., SIBOUT, R., DENOUE, D., BARRIERE, Y., LAPIERRE, C. \& JOUANIN, L. 2007. Both caffeoyl Coenzyme A 3-O-methyltransferase 1 and caffeic acid O-methyltransferase 1 are involved in redundant functions for lignin, flavonoids and sinapoyl malate biosynthesis in Arabidopsis. Planta, 226, 1117-1129.

DOHERTY, H. M., SELVENDRAN, R. R. \& BOWLES, D. J. 1988. The wound response of tomato plants can be inhibited by aspirin and related hydroxy-benzoic acids. Physiological and Molecular Plant Pathology, 33, 377-384.

DOMBRECHT, B., XUE, G. P., SPRAGUE, S. J., KIRKEGAARD, J. A., ROSS, J. J., REID, J. B., FITT, G. P., SEWELAM, N., SCHENK, P. M., MANNERS, J. M. \& KAZAN, K. 2007. MYC2 differentially modulates diverse jasmonate-dependent functions in Arabidopsis. 
Plant Cell, 19, 2225-45.

DU, Z., ZHOU, X., LING, Y., ZHANG, Z. H. \& SU, Z. 2010. agriGO: a GO analysis toolkit for the agricultural community. Nucleic Acids Research, 38, W64-W70.

DURRANT, W. E. \& DONG, X. 2004. SYSTEMIC ACQUIRED RESISTANCE. Annual Review of Phytopathology, 42, 185-209.

ERB, M., MELDAU, S. \& HOWE, G. A. 2012. Role of phytohormones in insect-specific plant reactions. Trends in Plant Science, 17, 250-259.

EULGEM, T. \& SOMSSICH, I. E. 2007. Networks of WRKY transcription factors in defense signaling. Curr Opin Plant Biol, 10, 366-71.

FALARA, V., AKHTAR, T. A., NGUYEN, T. T., SPYROPOULOU, E. A., BLEEKER, P. M., SCHAUVINHOLD, I., MATSUBA, Y., BONINI, M. E., SCHILMILLER, A. L. \& RL, L. 2011. The tomato terpene synthase gene family. Plant Physiology, 157, 770-789.

FALARA, V., ALBA, J. M., KANT, M. R., SCHUURINK, R. C. \& PICHERSKY, E. 2014. Geranyllinalool Synthases in Solanaceae and Other Angiosperms Constitute an Ancient Branch of Diterpene Synthases Involved in the Synthesis of Defensive Compounds. Plant Physiology, 166, 428-441.

FAN, X. T., MATTHEIS, J. P. \& ROBERTS, R. G. 2000. Biosynthesis of phytoalexin in carrot root requires ethylene action. Physiologia Plantarum, 110, 450-454.

FASULO, T. R. \& DENMARK, H. A. 2016. Twospotted Spider Mite, Tetranychus urticae Koch (Arachnida: Acari: Tetranychidae)1. Entomology \& Nematology.

FERNANDEZ-CALVO, P., CHINI, A., FERNANDEZ-BARBERO, G., CHICO, J. M., GIMENEZ-IBANEZ, S., GEERINCK, J., EECKHOUT, D., SCHWEIZER, F., GODOY, M., FRANCO-ZORRILLA, J. M., PAUWELS, L., WITTERS, E., PUGA, M. I., PAZ-ARES, J., GOOSSENS, A., REYMOND, P., DE JAEGER, G. \& SOLANO, R. 2011. The Arabidopsis bHLH transcription factors MYC3 and MYC4 are targets of JAZ repressors and act additively with MYC2 in the activation of jasmonate responses. Plant Cell, 23, 701-15.

FERNANDEZ, S. V. \& STANELONI, R. J. 1996. Characterization and regulation of the expression of the Solanum tuberosum LHCB1 genes. Cellular and Molecular Biology, 42, 577-587.

FLOKOVÁ, K., TARKOWSKÁ, D., MIERSCH, O., STRNAD, M., WASTERNACK, C. \& NOVAK, O. 2014. UHPLC-MS/MS based target profiling of stress-induced phytohormones.

FU, Z. Q. \& DONG, X. N. 2013. Systemic Acquired Resistance: Turning Local Infection into Global Defense. Annual Review of Plant Biology, Vol 64, 64, 839-863.

FURSTENBERG-HAGG, J., ZAGROBELNY, M. \& BAK, S. 2013. Plant defense against insect herbivores. Int J Mol Sci, 14, 10242-97.

GLAZEBROOK, J. 2005. Contrasting mechanisms of defense against biotrophic and necrotrophic pathogens. Annual Review of Phytopathology, 43, 205-227.

GOLS, R. 2014. Direct and indirect chemical defences against insects in a multitrophic framework. Plant Cell and Environment, 37, 1741-1752.

GONDOR, O. K., JANDA, T., SOÓS, V., PÁL, M., MAJLÁTH, I., ADAK, M. K., BALÁZS, E. \& SZALAI, G. 2016. Salicylic Acid Induction of Flavonoid Biosynthesis Pathways in Wheat Varies by Treatment. Frontiers in Plant Science, 7, 1447.

GOU, X., HE, K., YANG, H., YUAN, T., LIN, H., CLOUSE, S. D. \& LI, J. 2010. Genome-wide clon- 
ing and sequence analysis of leucine-rich repeat receptor-like protein kinase genes in Arabidopsis thaliana. BMC Genomics, 11, 19.

GRENNAN, A. K. 2008. Ethylene response factors in jasmonate signaling and defense response. Plant Physiology, 146, 1457-1458.

GUNDLACH, H., MULLER, M. J., KUTCHAN, T. M. \& ZENK, M. H. 1992. Jasmonic acid is a signal transducer in elicitor-induced plant-cell cultures. Proceedings of the National Academy of Sciences of the United States of America, 89, 2389-2393.

HENDRIKS, M. M. W. B., CRUZ-JUAREZ, L., BONT, D. D. \& HALL, R. D. 2005. Preprocessing and exploratory analysis of chromatographic profiles of plant extracts. Analytica Chimica Acta, 545, 53-64.

HONG, J. K., LEE, S. C. \& HWANG, B. K. 2005. Activation of pepper basic PR-1 gene promoter during defense signaling to pathogen, abiotic and environmental stresses. Gene, 356, 169-80.

HOWE, G. A. \& JANDER, G. 2008. Plant immunity to insect herbivores. Annual Review of Plant Biology, 59, 41-66.

HUANG, P. Y., CATINOT, J. \& ZIMMERLI, L. 2016. Ethylene response factors in Arabidopsis immunity. Journal of Experimental Botany, 67, 1231-1241.

HUANG, Z. J., ZHANG, Z. J., ZHANG, X. L., ZHANG, H. B., HUANG, D. F. \& HUANG, R. F. 2004. Tomato TERF1 modulates ethylene response and enhances osmotic stress tolerance by activating expression of downstream genes. Febs Letters, 573, 110-116.

ISHIWARI, H., SUZUKI, T. \& MAEDA, T. 2007. Essential Compounds in Herbivore-Induced Plant Volatiles that Attract the Predatory Mite Neoseiulus womersleyi. Journal of Chemical Ecology, 33, 1670-1681.

KANG, J. H., WANG, L., GIRI, A. \& BALDWIN, I. T. 2006. Silencing threonine deaminase and JAR4 in Nicotiana attenuata impairs jasmonic acid-isoleucine-mediated defenses against Manduca sexta. Plant Cell, 18, 3303-20.

KAPPERS, I. F., AHARONI, A., VAN HERPEN, T., LUCKERHOFF, L. L. P., DICKE, M. \& BOUWMEESTER, H. J. 2005. Genetic engineering of terpenoid metabolism attracts, bodyguards to Arabidopsis. Science, 309, 2070-2072.

KAPPERS, I. F., HOOGERBRUGGE, H., BOUWMEESTER, H. J. \& DICKE, M. 2011. Variation in Herbivory-induced Volatiles Among Cucumber (Cucumis sativus L.) Varieties has Consequences for the Attraction of Carnivorous Natural Enemies. Journal of Chemical Ecology, 37, 150-60.

KAWAZU, K., MOCHIZUKI, A., SATO, Y., SUGENO, W., MURATA, M., SEO, S. \& MITSUHARA, I. 2012. Different expression profiles of jasmonic acid and salicylic acid inducible genes in the tomato plant against herbivores with various feeding modes. Arthropod-Plant Interactions, 6, 221-230.

KAZAN, K. \& MANNERS, J. M. 2013. MYC2: The Master in Action. Molecular Plant, 6, 686703.

KIELKIEWICZ, M. 2002. Influence of carmine spider mite Tetranychus cinnabarinus Boisd. (Acarida: Tetranychidae) feeding on ethylene production and the activity of oxidative enzymes in damaged tomato plants. Acarid Phylogeny and Evolution: Adaptation in Mites and Ticks: Proceedings of the IV Symposium of the European Association of Acarologists. Dordrecht: Springer Netherlands. 
KIM, J. Y., PARK, S. C., HWANG, I., CHEONG, H., NAH, J. W., HAHM, K. S. \& PARK, Y. 2009. Protease inhibitors from plants with antimicrobial activity. Int J Mol Sci, 10, 2860-72.

KIM, S., PARK, J., YEOM, S. I., KIM, Y. M., SEO, E., KIM, K. T., KIM, M. S., LEE, J. M., CHEONG, K., SHIN, H. S., KIM, S. B., HAN, K., LEE, J., PARK, M., LEE, H. A., LEE, H. Y., LEE, Y., OH, S., LEE, J. H., CHOI, E., CHOI, E., LEE, S. E., JEON, J., KIM, H., CHOI, G., SONG, H., LEE, J., LEE, S. C., KWON, J. K., LEE, H. Y., KOO, N., HONG, Y., KIM, R. W., KANG, W. H., HUH, J. H., KANG, B. C., YANG, T. J., LEE, Y. H., BENNETZEN, J. L. \& CHOI, D. 2017. New reference genome sequences of hot pepper reveal the massive evolution of plant disease-resistance genes by retroduplication. Genome Biology, 18, 11.

KIM, Y. S., PARK, J. Y., KIM, K. S., KO, M. K., CHEONG, S. J. \& OH, B. J. 2002. A thaumatin-like gene in nonclimacteric pepper fruits used as molecular marker in probing disease resistance, ripening, and sugar accumulation. Plant Molecular Biology, 49, 125135.

KLEMPIEN, A., KAMINAGA, Y., QUALLEY, A., NAGEGOWDA, D. A., WIDHALM, J. R., ORLOVA, I., SHASANY, A. K., TAGUCHI, G., KISH, C. M., COOPER, B. R., D'AURIA, J. C., RHODES, D., PICHERSKY, E. \& DUDAREVA, N. 2012. Contribution of CoA Ligases to Benzenoid Biosynthesis in Petunia Flowers. The Plant Cell, 24, 2015-2030.

KLOTH, K. J., WIEGERS, G. L., BUSSCHER-LANGE, J., VAN HAARST, J. C., KRUIJER, W., BOUWMEESTER, H. J., DICKE, M. \& JONGSMA, M. A. 2016. AtWRKY22 promotes susceptibility to aphids and modulates salicylic acid and jasmonic acid signalling. Journal of Experimental Botany, 67, 3383-3396.

KUBIGSTELTIG, I., LAUDERT, D. \& WEILER, E. W. 1999. Structure and regulation of the Arabidopsis thaliana allene oxide synthase gene. Planta, 208, 463-71.

LAUDERT, D., SCHALLER, F. \& WEILER, E. W. 2000. Transgenic Nicotiana tabacum and Arabidopsis thaliana plants overexpressing allene oxide synthase. Planta, 211, 163-165.

LEON-REYES, A., VAN DER DOES, D., DE LANGE, E. S., DELKER, C., WASTERNACK, C., VAN WEES, S. C. M., RITSEMA, T. \& PIETERSE, C. M. J. 2010. Salicylate-mediated suppression of jasmonate-responsive gene expression in Arabidopsis is targeted downstream of the jasmonate biosynthesis pathway. Planta, 232, 1423-1432.

LI, J., BRADER, G., KARIOLA, T. \& PALVA, E. T. 2006. WRKY70 modulates the selection of signaling pathways in plant defense. Plant J, 46, 477-91.

LI, J., BRADER, G. \& PALVA, E. T. 2004. The WRKY70 transcription factor: A node of convergence for jasmonate-mediated and salicylate-mediated signals in plant defense. Plant Cell, 16, 319-331.

LITTLE, D., GOUHIER-DARIMONT, C., BRUESSOW, F. \& REYMOND, P. 2007. Oviposition by pierid butterflies triggers defense responses in Arabidopsis. Plant Physiology, 143, 784-800.

LIU, J. Y., OSBOURN, A. \& MA, P. D. 2015. MYB Transcription Factors as Regulators of Phenylpropanoid Metabolism in Plants. Molecular Plant, 8, 689-708.

LOMMEN, A. 2009. MetAlign: Interface-Driven, Versatile Metabolomics Tool for Hyphenated Full-Scan Mass Spectrometry Data Preprocessing. Analytical Chemistry, 81, 3079-3086.

LORENZO, O., CHICO, J. M., SANCHEZ-SERRANO, J. J. \& SOLANO, R. 2004. Jasmonate-insensitive1 encodes a MYC transcription factor essential to discriminate between different jasmonate-regulated defense responses in Arabidopsis. Plant Cell, 16, 
1938-1950.

LORENZO, O., PIQUERAS, R., SANCHEZ-SERRANO, J. J. \& SOLANO, R. 2003. ETHYLENE RESPONSE FACTOR1 integrates signals from ethylene and jasmonate pathways in plant defense. Plant Cell, 15, 165-178.

LUO, X., XU, N., HUANG, J., GAO, F., ZOU, H., BOUDSOCQ, M., COAKER, G. \& LIU, J. 2017. A Lectin Receptor-Like Kinase Mediates Pattern-Triggered Salicylic Acid Signaling. Plant Physiol, 174, 2501-2514.

MA, G., ZHANG, L., KATO, M., YAMAWAKI, K., KIRIIWA, Y., YAHATA, M., IKOMA, Y. \& MATSUMOTO, H. 2012. Effect of Blue and Red LED Light Irradiation on $\beta$-Cryptoxanthin Accumulation in the Flavedo of Citrus Fruits. Journal of Agricultural and Food Chemistry, 60, 197-201.

MARTEL, C., ZHUROV, V., NAVARRO, M., MARTINEZ, M., CAZAUX, M., AUGER, P., MIGEON, A., SANTAMARIA, M. E., WYBOUW, N., DIAZ, I., VAN LEEUWEN, T., NAVAJAS, M., GRBIC, M. \& GRBIC, V. 2015. Tomato Whole Genome Transcriptional Response to Tetranychus urticae Identifies Divergence of Spider Mite-Induced Responses Between Tomato and Arabidopsis. Molecular Plant-Microbe Interactions, 28, 343361.

MEMELINK, J., VERPOORTE, R. \& KIJNE, J. W. 2001. ORCAnization of jasmonate - responsive gene expression in alkaloid metabolism. Trends in Plant Science, 6, 212-219.

MORTAZAVI, A., WILLIAMS, B. A., MCCUE, K., SCHAEFFER, L. \& WOLD, B. 2008. Mapping and quantifying mammalian transcriptomes by RNA-Seq. Nature Methods, 5, 621-628.

NDAMUKONG, I., ABDALLAT, A. A., THUROW, C., FODE, B., ZANDER, M., WEIGEL, R. \& GATZ, C. 2007. SA-inducible Arabidopsis glutaredoxin interacts with TGA factors and suppresses JA-responsive PDF1.2 transcription. Plant J, 50, 128-39.

NUGROHO, L. H., VERBERNE, M. C. \& VERPOORTE, R. 2002. Activities of enzymes involved in the phenylpropanoid pathway in constitutively salicylic acid-producing tobacco plants. Plant Physiology and Biochemistry, 40, 755-760.

PANDEY, S. P. \& SOMSSICH, I. E. 2009. The Role of WRKY Transcription Factors in Plant Immunity. Plant Physiology, 150, 1648.

PARRA, M. M., DEL POZO, O., LUNA, R., GODOY, J. A. \& PINTOR-TORO, J. A. 1996. Structure of the dehydrin tas 14 gene of tomato and its developmental and environmental regulation in transgenic tobacco. Plant Mol Biol, 32, 453-60.

PAUWELS, L., BARBERO, G. F., GEERINCK, J., TILLEMAN, S., GRUNEWALD, W., PEREZ, A. C., CHICO, J. M., BOSSCHE, R. V., SEWELL, J., GIL, E., GARCIA-CASADO, G., WITTERS, E., INZE, D., LONG, J. A., DE JAEGER, G., SOLANO, R. \& GOOSSENS, A. 2010. NINJA connects the co-repressor TOPLESS to jasmonate signalling. Nature, 464, 788-91.

PIREYRE, M. \& BUROW, M. 2015. Regulation of MYB and bHLH Transcription Factors: A Glance at the Protein Level. Molecular Plant, 8, 378-388.

PRE, M., ATALLAH, M., CHAMPION, A., DE VOS, M., PIETERSE, C. M. J. \& MEMELINK, J. 2008. The AP2/ERF domain transcription factor ORA59 integrates jasmonic acid and ethylene signals in plant defense. Plant Physiology, 147, 1347-1357.

SCALA, A., ALLMANN, S., MIRABELLA, R., HARING, M. A. \& SCHUURINK, R. C. 2013. Green Leaf Volatiles: A Plant's Multifunctional Weapon against Herbivores and Pathogens. International Journal of Molecular Sciences, 14, 17781-17811. 
SCHALLER, F. 2001. Enzymes of the biosynthesis of octadecanoid-derived signalling molecules. J Exp Bot, 52, 11-23.

SCHALLER, F., BIESGEN, C., MUSSIG, C., ALTMANN, T. \& WEILER, E. W. 2000. 12-oxophytodienoate reductase 3 (OPR3) is the isoenzyme involved in jasmonate biosynthesis. Planta, 210, 979-984.

SCHMIESING, A., EMONET, A., GOUHIER-DARIMONT, C. \& REYMOND, P. 2016. Arabidopsis MYC Transcription Factors Are the Target of Hormonal Salicylic Acid/Jasmonic Acid Cross Talk in Response to Pieris brassicae Egg Extract. Plant Physiology, 170, 24322443.

SCHNEE, C., KOLLNER, T. G., HELD, M., TURLINGS, T. C. J., GERSHENZON, J. \& DEGENHARDT, J. 2006. The products of a single maize sesquiterpene synthase form a volatile defense signal that attracts natural enemies of maize herbivores. Proceedings of the National Academy of Sciences of the United States of America, 103, 1129-1134.

SHIMODA, T. 2010. A key volatile infochemical that elicits a strong olfactory response of the predatory mite Neoseiulus californicus, an important natural enemy of the two-spotted spider mite Tetranychus urticae. Experimental and Applied Acarology, 50, 9-22.

SNOEREN, T. A. L., KAPPERS, I. F., COLETTE, B., ROLAND, M., MARCEL, D. \& BOUWMEESTER, H. J. 2010. Natural variation in herbivore-induced volatiles inArabidopsis thaliana. Journal of Experimental Botany, 61, 3041-3056.

SPOEL, S. H., KOORNNEEF, A., CLAESSENS, S. M. C., KORZELIUS, J. P., VAN PELT, J. A., MUELLER, M. J., BUCHALA, A. J., METRAUX, J. P., BROWN, R., KAZAN, K., VAN LOON, L. C., DONG, X. N. \& PIETERSE, C. M. J. 2003. NPR1 modulates cross-talk between salicylate- and jasmonate-dependent defense pathways through a novel function in the cytosol. Plant Cell, 15, 760-770.

STASWICK, P. E. \& TIRYAKI, I. 2004. The Oxylipin Signal Jasmonic Acid Is Activated by an Enzyme That Conjugates It to Isoleucine in Arabidopsis. The Plant Cell, 16, 21172127.

TAKABAYASHI, J. \& DICKE, M. 1992. Response of Predatory Mites with Different Rearing Histories to Volatiles of Uninfested Plants. Entomologia Experimentalis Et Applicata, 64, 187-193.

THALER, J. S., HUMPHREY, P. T. \& WHITEMAN, N. K. 2012. Evolution of jasmonate and salicylate signal crosstalk. Trends in Plant Science, 17, 260-270.

THINES, B., KATSIR, L., MELOTTO, M., NIU, Y., MANDAOKAR, A., LIU, G., NOMURA, K., HE, S., HOWE, G. \& BROWSE, J. 2007. JAZ repressor proteins are targets of the SCFCOI1 complex during jasmonate signalling. Nature, 448, 661-5.

THOLL, D. 2015. Biosynthesis and Biological Functions of Terpenoids in Plants. In: SCHRADER, J. \& BOHLMANN, J. (eds.) Biotechnology of Isoprenoids. Cham: Springer Int Publishing Ag.

TIKUNOV, Y. M., LAPTENOK, S., HALL, R. D., BOVY, A. \& DE VOS, R. C. H. 2012. MSClust: a tool for unsupervised mass spectra extraction of chromatography-mass spectrometry ion-wise aligned data. Metabolomics, 8, 714-718.

TORNERO, P., CONEJERO, V. \& VERA, P. 1994. A Gene Encoding a Novel Isoform of the Pr-1 Protein Family from Tomato Is Induced Upon Viroid Infection. Molecular \& General Genetics, 243, 47-53. 
TORNERO, P., GADEA, J., CONEJERO, V. \& VERA, P. 1997. Two PR-1 genes from tomato are differentially regulated and reveal a novel mode of expression for a pathogenesis-related gene during the hypersensitive response and development. Molecular Plant-Microbe Interactions, 10, 624-634.

TURNER, J. G., ELLIS, C. \& DEVOTO, A. 2002. The jasmonate signal pathway. Plant Cell, 14, S153-S164.

VAN DER FITS, L. \& MEMELINK, J. 2000. ORCA3, a jasmonate-responsive transcriptional regulator of plant primary and secondary metabolism. Science, 289, 295-297.

VAN KAN, J. A., COZIJNSEN, T., DANHASH, N. \& DE WIT, P. J. 1995. Induction of tomato stress protein mRNAs by ethephon, 2,6-dichloroisonicotinic acid and salicylate. Plant Mol Biol, 27, 1205-13.

VERBERNE, M. C., VERPOORTE, R., BOL, J. F., MERCADO-BLANCO, J. \& LINTHORST, H. J. M. 2000. Overproduction of salicylic acid in plants by bacterial transgenes enhances pathogen resistance. $18,779-783$.

VERMA, V., RAVINDRAN, P. \& KUMAR, P. P. 2016. Plant hormone-mediated regulation of stress responses. BMC Plant Biol, 16, 86.

VOGT, T. 2010. Phenylpropanoid Biosynthesis. Molecular Plant, 3, 2-20.

WANG, D., AMORNSIRIPANITCH, N. \& DONG, X. N. 2006. A genomic approach to identify regulatory nodes in the transcriptional network of systemic acquired resistance in plants. Plos Pathogens, 2, 1042-1050.

WANG, Z., CAO, G., WANG, X., MIAO, J., LIU, X., CHEN, Z., QU, L.-J. \& GU, H. 2008. Identification and characterization of COI1-dependent transcription factor genes involved in JA-mediated response to wounding in Arabidopsis plants. Plant Cell Reports, 27, 125-135.

WAR, A. R., PAULRAJ, M. G., AHMAD, T., BUHROO, A. A., HUSSAIN, B., IGNACIMUTHU, S. \& SHARMA, H. C. 2012. Mechanisms of plant defense against insect herbivores. Plant Signal Behav, 7, 1306-20.

WASTERNACK, C. \& HAUSE, B. 2013. Jasmonates: biosynthesis, perception, signal transduction and action in plant stress response, growth and development. An update to the 2007 review in Annals of Botany. Annals of Botany, 111, 1021-1058.

WASTERNACK, C., STENZEL, I., HAUSE, B., HAUSE, G., KUTTER, C., MAUCHER, H., NEUMERKEL, J., FEUSSNER, I. \& MIERSCH, O. 2006. The wound response in tomato - Role of jasmonic acid. Journal of Plant Physiology, 163, 297-306.

WAWRZYNSKA, A., LEWANDOWSKA, M., HAWKESFORD, M. J. \& SIRKO, A. 2005. Using a suppression subtractive library-based approach to identify tobacco genes regulated in response to short-term sulphur deficit. Journal of Experimental Botany, 56, 1575-1590.

WEBER, H., VICK, B. A. \& FARMER, E. E. 1997. Dinor-oxo-phytodienoic acid: a new hexadecanoid signal in the jasmonate family. Proc Natl Acad Sci U S A, 94, 10473-8.

WHITE, R. F. 1979. Acetylsalicylic acid (aspirin) induces resistance to tobacco mosaic virus in tobacco. Virology, 99, 410-2.

XIE, D. X., FEYS, B. F., JAMES, S., NIETO-ROSTRO, M. \& TURNER, J. G. 1998. COI1: an Arabidopsis gene required for jasmonate-regulated defense and fertility. Science, 280, 1091-4. 
XU, M., DONG, J., WANG, H. \& HUANG, L. 2009. Complementary action of jasmonic acid on salicylic acid in mediating fungal elicitor-induced flavonol glycoside accumulation of Ginkgo biloba cells. Plant Cell Environ, 32, 960-7.

XU, P., TIAN, L., KLOZ, M. \& CROCE, R. 2015. Molecular insights into Zeaxanthin-dependent quenching in higher plants. 5, 13679.

YAMAWO, A., HADA, Y. \& SUZUKI, N. 2012. Variations in direct and indirect defenses against herbivores on young plants of Mallotus japonicus in relation to soil moisture conditions. Journal of Plant Research, 125, 71-76.

YAN, Y., STOLZ, S., CHETELAT, A., REYMOND, P., PAGNI, M., DUBUGNON, L. \& FARMER, E. E. 2007. A downstream mediator in the growth repression limb of the jasmonate pathway. Plant Cell, 19, 2470-83.

YU, Z.-X., LI, J.-X., YANG, C.-Q., HU, W.-L., WANG, L.-J. \& CHEN, X.-Y. 2012. The Jasmonate-Responsive AP2/ERF Transcription Factors AaERF1 and AaERF2 Positively Regulate Artemisinin Biosynthesis in Artemisia annua L. Molecular Plant, 5, 353-365.

ZHANG, P. J., ZHENG, S. J., VAN LOON, J. J. A., BOLAND, W., DAVID, A., MUMM, R. \& DICKE, M. 2009. Whiteflies interfere with indirect plant defense against spider mites in Lima bean. Proceedings of the National Academy of Sciences of the United States of America, 106, 21202-21207.

ZHU, J., WANG, M., WEN, W. \& YU, R. 2015. Biosynthesis and regulation of terpenoid indole alkaloids in Catharanthus roseus. Pharmacognosy Reviews, 9, 24-28.

ZIEGLER, J., STENZEL, I., HAUSE, B., MAUCHER, H., HAMBERG, M., GRIMM, R., GANAL, M. \& WASTERNACK, C. 2000. Molecular cloning of allene oxide cyclase - The enzyme establishing the stereochemistry of octadecanoids and jasmonates. Journal of Biological Chemistry, 275, 19132-19138.

\section{Supplemental Figures, Tables and Datasets}

Supplemental files to this chapter can be downloaded from:

<http://www.wageningenseedlab.nl/thesis/vuanyuanzhang/>http://www.wageningenseedlab.nl/thesis/vuanyuanzhang/

<http://www.wageningenseedlab.nl/thesis/yuanyuanzhang/Sl/>http://www.wageningenseedlab.nl/thesis/yuanyuanzhang/SI/ 


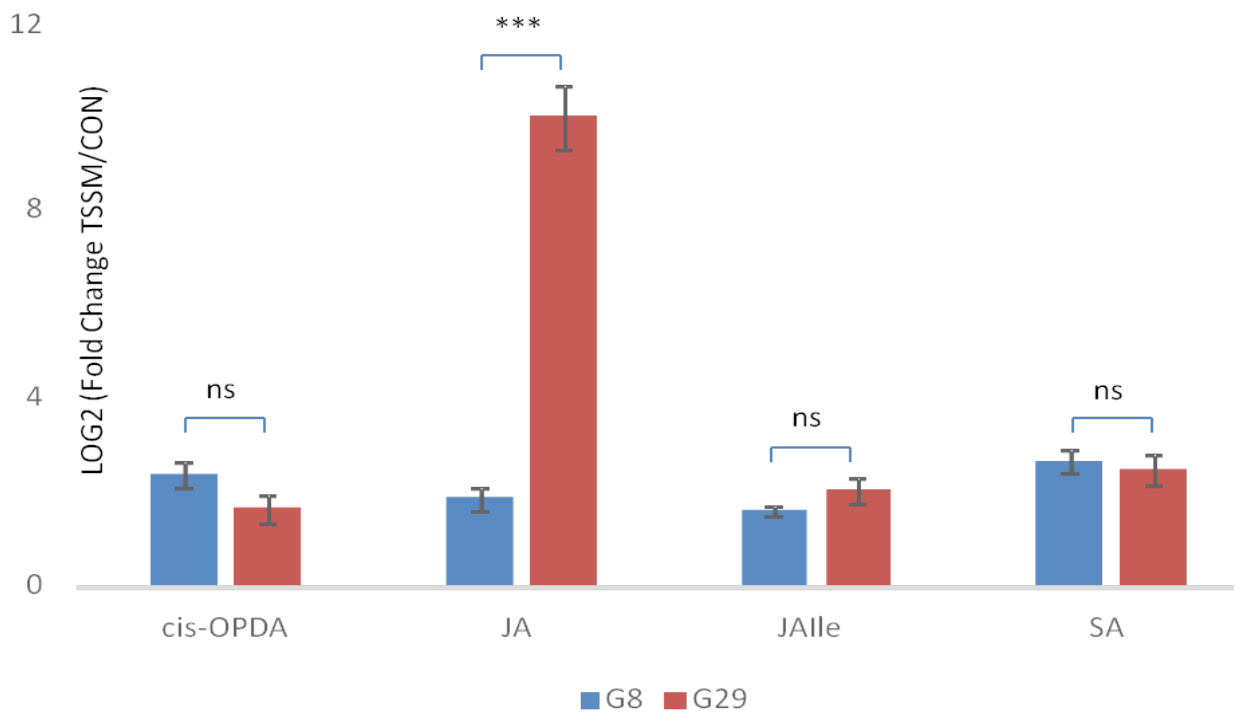

Figure 1. Fold-changes in levels of endogenous cis-OPDA, JA, JA-lle and SA in leaves of Capsicum annuum $\mathbf{G 8}$ and G29 plants that were infested with TSSM for 3 days. Data represent the average \pm SE of three replicate samples, calculated as LOG2 transformed amount in TSSM-infested leaves divided by the amount in non-treated leaves (fold change). Asterisks denote statistically significant differences between both genotypes (**P < 0.01 ; $\mathrm{P}<$ 0.05; ns not significant; two-tailed t-test).

A

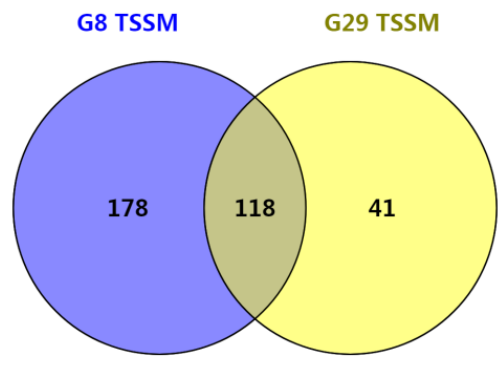

B

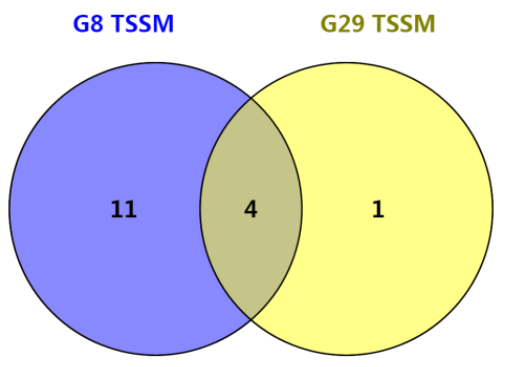

Figure 2. Spider mites induced/repressed DEGs in two genotypes. A represents spider mite induced DEGs in two genotypes; B represents spider mite repressed DEGs in two genotypes. 
A

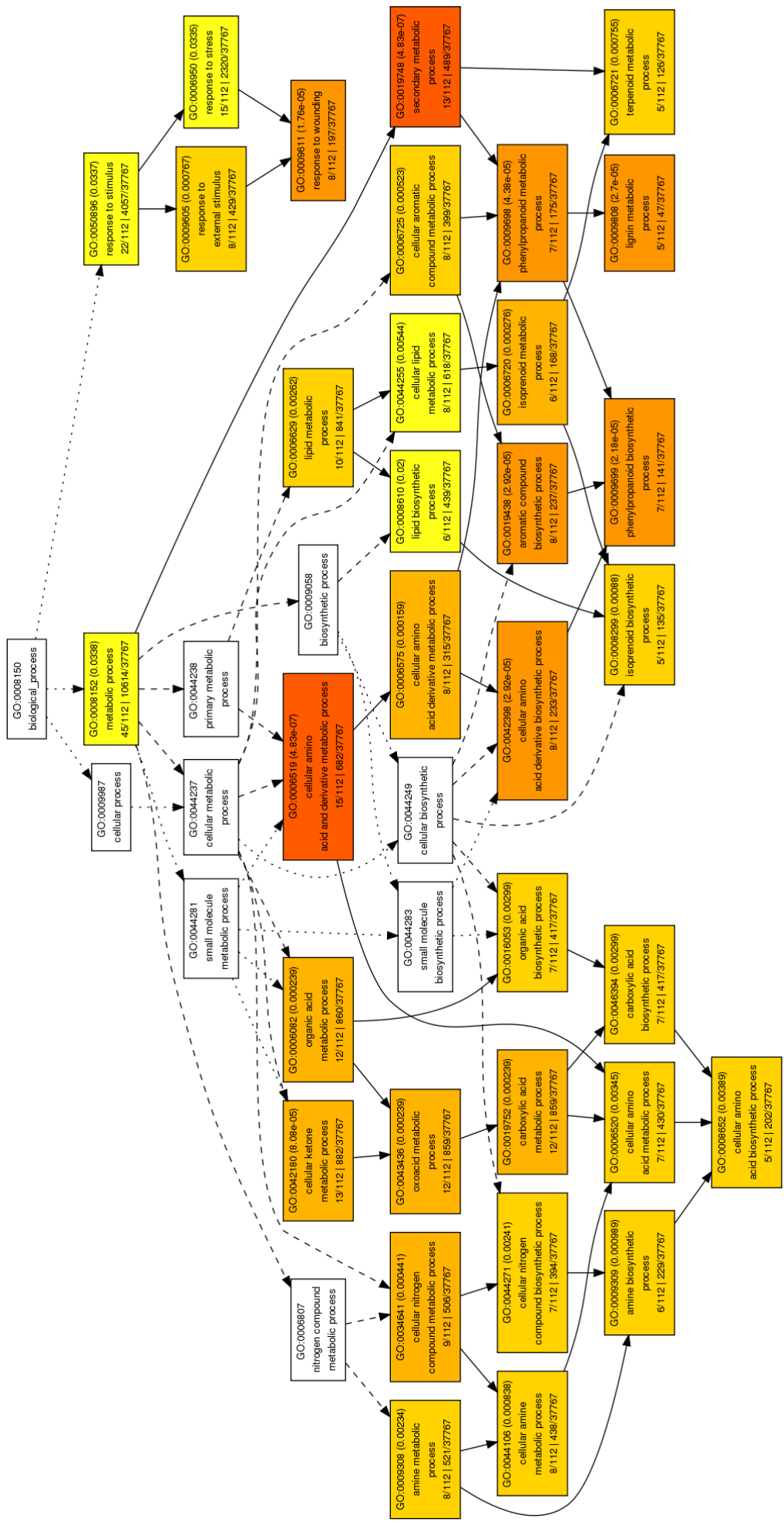


B

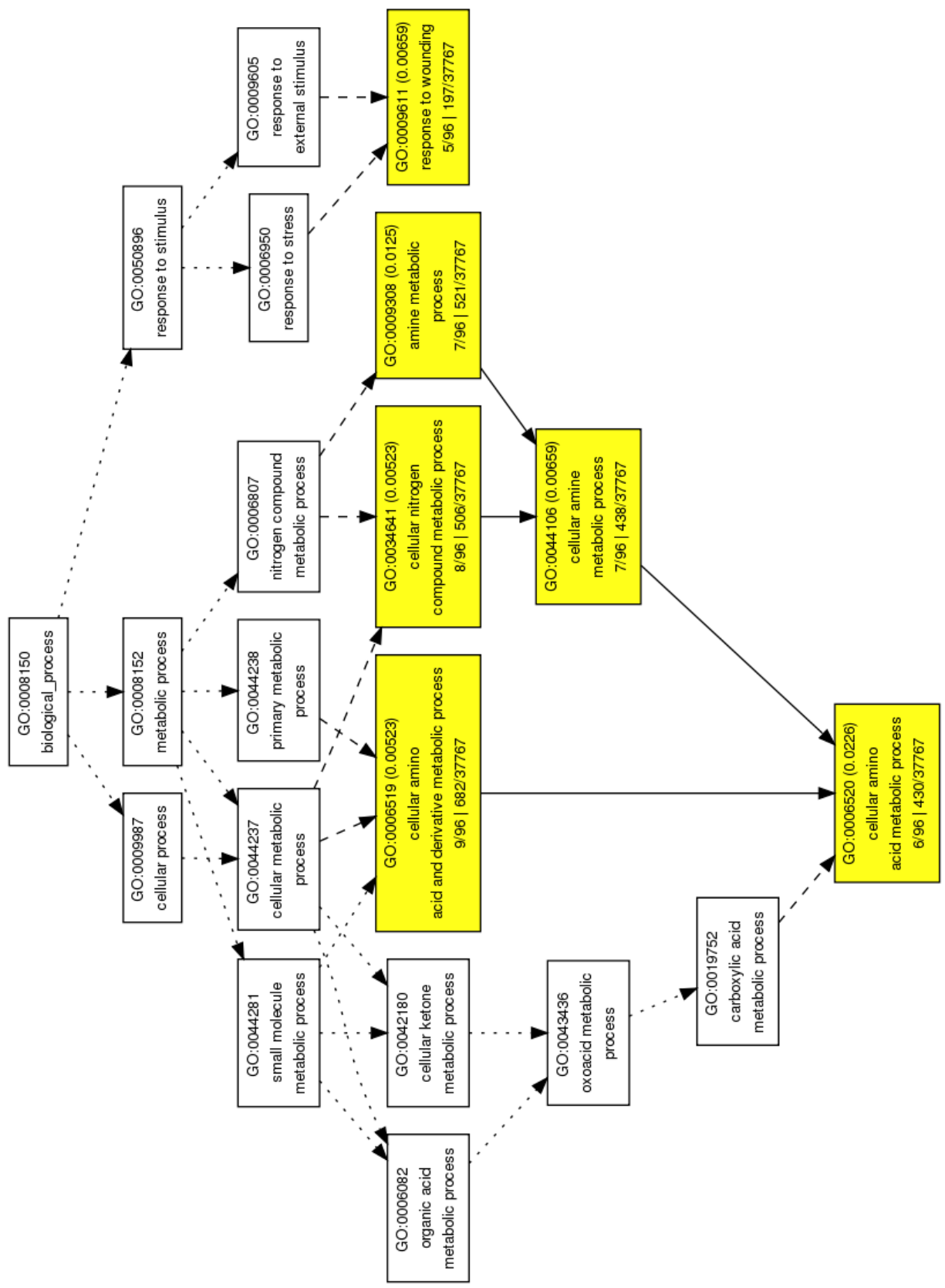

Figure 3. GO enrichment analysis on JA induced genes which were not induced by spider mites in two genotypes. A represents genes in genotype 8 , B represents genes in genotype 29. 
A

(3E,7E)-4,8,12-Trimethyltrideca- Methyl salicylate

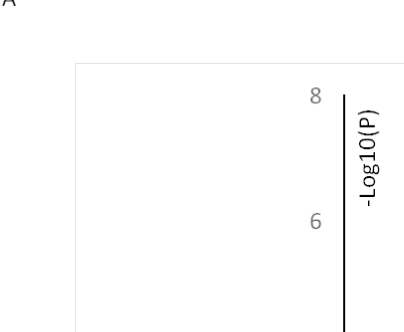

Benzene, 1,3-dimethyl- 4
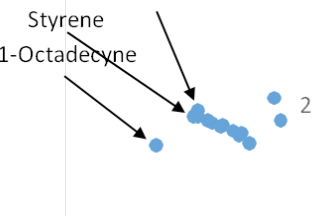

1,3,7,11-tetraene TMTT

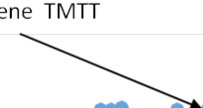

cyclor/exane, 2-ethenyl-

1,1-gimethyl-3-methylene-
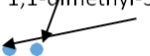

- 000

$+\quad$ 5-[(Trimethylpyrazol-4-yl)methyl]-

8. 1,3,5-trikzinane-2-thione

-

$\bullet$
cis-3-Hexenyl cis-3-

hexenoate

$\log 2(\mathrm{FC})$

\begin{tabular}{lllll}
\hline-5 & 0 & 5 & 10 & 15
\end{tabular}

B

Benzoic acid, 2-ethylhexyl ester

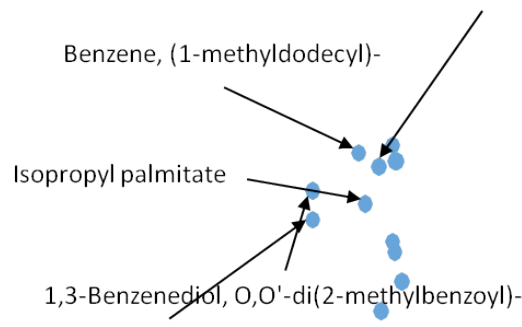

Phenacylidene diacetate

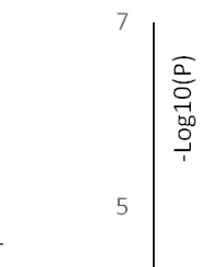

高

$\log 2(\mathrm{FC})$

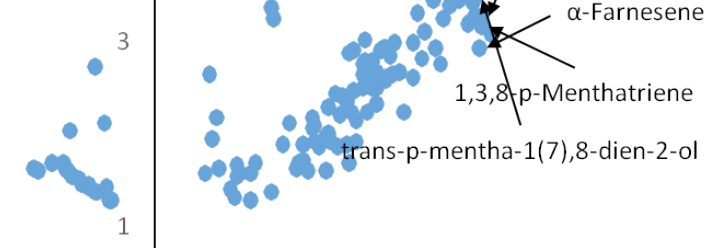

$\alpha$-Farnesene

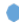

1

$\log 2(\mathrm{FC})$ 


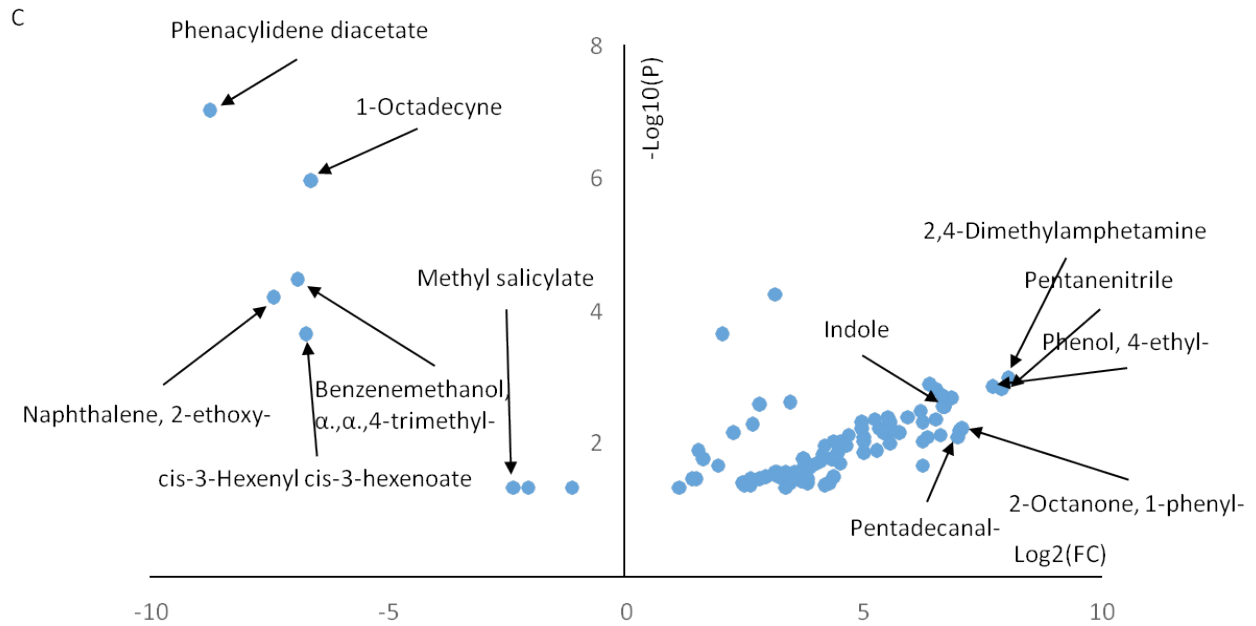

Figure 4. Volcano plot displaying fold-changes (Log2 transformed fold change (FC), $x$ axis) versus statistical significance (-log10 transformed $p$ value, y axis) of volatile metaboites. Dashed line shows where $p=0.005$ and LOG2(FC) $>2$. Metabolite features significantly different between control plants and spider mites infested plants in each genotypes ( $A$, Genotype 8 TSSM/CON; B, Genotype 29 TSSM/CON) and between two genotypes of infested plants (C, Genotype 29 TSSM/Genotype 8 TSSM) $(p<0.05$, LOG2(FC) $>2$ ) are shown. 
Table 1. Pearson correlation values between DEGs, used as input values for the co-expression network

Table 2. Gene Ontology (GO) enrichment of differentially expressed genes $(\log 2 \mathrm{FC}>1.5$; $\mathrm{P}<0.05$ ) between jasmonic acid treated and control plants and of spider-mite infested plants compared to control plants of Capsicum genotypes 8 and 29. Enrichment analysis was performed using AgriGO, taking FDR $\leq 0.05$ as threshold.

Supplemental data set 1. Transcriptome of JA treatment for 6 hours versus non-treated plants, in genotype 29

Supplemental data set 2. Transcriptome of JA treatment for 24 hours versus non-treated plants, in genotype 29

Supplemental data set 3. Transcriptome of spider mites infested for 3 days versus non-treated plants, in genotype 29

Supplemental data set 4. Transcriptome of JA treatment for 6 hours versus non-treated plants, in genotype 8

Supplemental data set 5. Transcriptome of JA treatment for 24 hours versus non-treated plants, in genotype 8

Supplemental data set 6 . Transcriptome of spider mites infested for 3 days versus non-treated plants, in genotype 8

Supplemental data set 7. Transcriptome of non-treated plants of Genotype 8 versus non-treated plants of Genotype 29. 


\section{Chapter 5 Characterization of the TPS gene family and transcriptomic insight into terpenoid biosynthesis upon spider-mite feeding in Capsi- cum annuum}

Yuanyuan Zhang, Arman Beyraghdar Kashkooli, Suze Blom, Harro J. Bouwmeester and Iris F. Kappers

Laboratory of Plant Physiology, Wageningen University, P.O. Box 16, 6700 AA Wageningen, The Netherlands

Plant Hormone Biology group, Swammerdam Institute for Life Sciences, University of Amsterdam, Postbus 94215, 1090 GE Amsterdam, The Netherlands 
Abstract Pepper (Capsicum annuum) is a global economically important crop in which the incidence of herbivorous pests can result in severe damage and losses in fruit production. In response to herbivory, C. annuum leaves produce secondary metabolites that may protect the plant against feeding either directly as repellent or anti-feedant or are released as volatiles that are cues for natural enemies of the herbivore. The volatile blend of two-spotted spider mite challenged leaves differs from non-challenged leaves predominantly by a higher contribution of mono- and sesquiterpenes, suggesting that these are biosynthetically induced by spider mite feeding. Genome-wide analysis by sequence homology, synteny and Hidden-Markov-Modeling of the $C$. annuum genome resulted in the annotation of a terpene synthase gene family (TPS) of 103 putative members of which structural analysis revealed that 27 seem to encode functional enzymes. Phylogenetic analysis of these 27 CaTPS gene members with known TPS genes from other species suggested that there are 5 subclades within the CaTPS gene family. Transcriptome analysis showed that 44 TPS loci (so including a number of pseudo-genes) were expressed under two-spotted spider-mite infestation and/or jasmonic acid induction in two $C$. annuum genotypes. Co-expression analysis revealed that most members of the TPS-a subfamily co-express with upstream biosynthetic genes from the mevalonate pathway while several gene members of the TPS-b subfamily co-express with methylerythritol phosphate pathway genes. In addition, the expression of multiple potential downstream biosynthetic genes, including cytochrome P450 monooxygenases and UDP-glycosyl transferases and multiple transcription factors, strongly correlated with herbivore/JA-induced TPS genes. The herbivory/JA-induced TPS genes were functionally characterized by in-vitro enzyme assays with recombinant enzymes produced in $E$. coli. The products that these enzymes make match with the diterpene glycoside conjungates and the monoterpenes and sesquiterpenes - $(E)$ - $\beta$-pinene, $(E)$ - $\beta$-ocimene, $(E, E)$ - $\alpha$-farnesene and $(E)$-nerolidol - that are produced upon spider mite herbivory/JA treatment. 


\section{Introduction}

The terpenoids represent a large class of chemical compounds with an extensive diversity in chemical structures and a wide range of functions. In plants, the terpenoids harbor various phytohormones involved in plant growth regulation, including gibberellins, abscisic acid, strigolactones and cytokinins as well as metabolites that are involved in important physiological processes such as membrane stabilization (sterols), photosynthesis (carotenoids, the phytol side chain of chlorophyll and plastoquinone) and respiration (ubiquinone) (Tholl and Lee, 2011). However, a substantial larger number of terpenoids contribute to broader physiological and ecological functions, including plant defense and plant communication (Singh and Sharma, 2015).

Terpenoids are formed from C5 isoprene unit precursors, isopentenyl diphosphate (IPP) and its isomer dimethylallyl diphosphate (DMAPP) that are produced through either the mevalonate pathway (MVA) in the cytosol/peroxisomes or the methylerythritol phosphate pathway (MEP) in the plastids. The condensation of these building blocks into the primary precursors of all terpenoids is catalyzed by prenyl diphosphate synthases (Wang and Ohnu$\mathrm{ma}, 2000)$. The condensation of one IPP with one DMAPP molecule produces geranyl diphosphate (GPP) (trans-configuration), or neryl diphosphate (NPP) (cis-configuration), depending on the prenyl diphosphate synthase. The sequential condensation of two molecules of IPP and one DMAPP molecule leads to the formation of trans- or cis-farnesyl diphosphate (FPP), while the condensation of two molecules of IPP and two molecules of DMAPP results in the formation of geranylgeranyl diphosphate (GGPP) (Takahashi and Koyama, 2006). Prenyl diphosphates are substrates of plant terpene synthases (TPSs) - monoterpene synthases, sesquiterpene synthases and diterpene synthases - that generate monoterpenes (C10), sesquiterpenes (C15) and diterpenes (C20), respectively (Singh and Sharma, 2015). Oxygenation of terpenes by cytochrome P450 monooxygenases (CYPs) and further modifications by other biosynthetic enzymes such as glycosyl and acetyl transferases, will generate the diversity of terpenoids present in nature (Boutanaev et al., 2015).

The myriad structures of terpenoids mirror the complexity of properties and functions. Part of this structural diversity is obtained through the variation in cyclization and rearrangement reactions of the prenyl diphosphate substrates (Yang et al., 2012). After formation of the carbocation through dephosphorylation of the prenyl diphosphate substrate catalyzed by TPSs usually a multitude of carbocation attacks and/or quenching through water, double bond rearrangements and hydride shifts occur, which is why a single 
TPS enzyme can sometimes generates multiple products from one substrate (Degenhardt et al., 2009). The structural diversity in these TPS products is subsequently often further increased through the activity of cytochrome P450s, reductases, dehydrogenases, methyl transferases and glycosyl transferases. In general, TPSs consist of 550-850 amino acids, with a molecular mass of 50-100 kDa. Terpene synthases are encoded by gene members of the structurally related TPS gene family that probably has a common phylogenetic origin (Aubourg et al., 2002). TPS gene families have been explored in many species, including Arabidopsis (Arabidopsis thaliana) (Aubourg et al., 2002), citrus (Citrus sinensis) (Dornelas and Mazzafera, 2007, Alquezar et al., 2017), grapevine (Vitis vinifera) (Martin et al., 2010), tomato (Solanum lycopersicum, (Falara et al., 2011), and eucalyptus (Eucalyptus grandis and Eucalyptus globulus) (Külheim et al., 2015). The number of TPS genes within a species ranges from about 20 to 150 (Chen et al., 2011). An exception is the moss Physcomitrella patens (Hayashi et al., 2007) which has only one functional terpene synthase gene, which encodes a bifunctional enzyme catalyzing the conversion of GGPP to ent-kaurene via copalyl diphosphate. Structurally the TPS gene family can be divided into seven subfamilies, TPS- $a$, TPS- $b$, TPS-c, TPS- $d$, TPS-e/f, TPS- $g$ and TPS- $h$. The TPS- $a, b$ and $g$ subfamilies are angiosperm specific while the TPS- $d$ subfamily is gymnosperm specific and TPS- $h$ is specific to the lycopod Selaginalla moellendorffi (Li et al., 2012, Chen et al., 2011). TPS-c and $e / f$ members are present in both angiosperms and gymnosperms; TPS-c members encode copalyl diphosphate synthases and TPS-e/f members encode kaurene synthases (KSs). Most of the TPS- $a$ genes encode sesquiterpene and diterpene synthases while TPS- $b$ and $g$ genes mostly encode monoterpene synthases (Falara et al., 2011).

Terpenoids often play a role in plant-insect interaction, for example as attractants of pollinators or defensive compounds against various pathogens and herbivores (Kappers et al., 2008). For instance, the oleoresin of conifers releases volatile mono- and sesquiterpenoids that insects use to distinguish suitable hosts from non-hosts (Keeling and Bohlmann, 2006). A relatively high dose of the sesquiterpene lactone argophyllone $B$ reduces the larval mass of the sunflower moth Homeosoma electellum in Helianthus spp (Prasifka et al., 2015). In Nicotiana attenuata, 17-hydroxygeranyllinalool diterpene glycosides were demonstrated to be effective defensive metabolites to herbivores (Heiling et al., 2010). Besides their direct effect on herbivores, terpenoids also play an important role in attracting natural enemies of herbivores. Overexpression of a strawberry nerolidol synthase in Arabidopsis resulted in emission of two new terpenoids (3S)-(E)-nerolidol and its derivative (E)-4,8-dimethyl-1,3,7-nonatriene [(E)-DMNT], which resulted in enhanced attraction of predatory mites (Kappers et al., 2005). Transgenic 
Arabidopsis expressing maize TPS10 produced more sesquiterpenes and attracted more female Cotesia mariniventris parasitoids (Schnee et al., 2006).

Capsicum belongs to the nightshade family Solanaceae and consists of approximately 35 species (Carrizog, 2013). Capsicum is native to the Americas and nowadays worldwide cultivated for their sweet or hot chili fruits used as vegetable or spice. Various insect and arthropod species can infest Capsicum resulting in serious yield losses, including western flower thrips (Franklinella occidentalis), aphids (the green peach aphid, Myzus persicae and the potato aphid, Macrosiphum euphorbiae) and two-spotted spider mite (Tetranychus urticae). The biotic stress related phytohormone, jasmonic acid (JA) is the master regulator of plant defense responses against herbivores (Verma et al., 2016) by mediating the expression of defense related genes such as PLANT DEFENSIN1.2 (PDF1.2) and BASIC CHITINASE (CHIB) (Rehrig et al., 2014), as well as the biosynthesis of secondary metabolites (Ferrieri et al., 2015, Machado et al., 2017), especially terpenoids in multiple plant species (Zhang et al., 2009, Hong et al., 2012). In Chapter 3, 4 we showed that JA plays a major role in the early signaling events of spider-mite induced defenses in Capsicum and exogenous application of JA results in notably higher emission of various terpenoids (Chapter 2,4). The initial sequencing and assembly of the genome of a Capsicum inbred line (C. annuum var Zunla) enables us to predict the Capsicum TPS (CaTPS) gene family, which will help to understand the mechanism of terpenoid formation and metabolism under herbivory in $C$. annuum.

Here, we report the genome-wide identification of the TPS gene family and the annotation of 27 putative functional TPS genes in the $C$. annuum genome. To study how herbivory, in general, and specifically spider-mite infestation, affect terpene production and emission in $C$. annuum, we treated plants with JA and spider mites and studied the changes in CaTPS gene expression. Several CaTPS genes of which the expression was induced by spider mites and/or by JA were subsequently isolated and functionally characterized. Analysis of transcriptional and metabolic changes upon herbivory revealed co-expression patterns between TPS genes and upstream biosynthetic genes from the MVA and MEP pathway as well as with genes downstream of TPS that may be involved in the creation of the large structural diversity in herbivory related $C$. annuum terpenoids. 


\section{Materials and methods}

\section{Plant and arthropod material}

Capsicum seeds (Capsicum annuum, genotype 8 and genotype 29) were incubated on wet filter paper in a Petri dish for 6 to 7 days at $23^{\circ} \mathrm{C}$ until the cotyledons had emerged. Then seedlings were transferred into $7 \times 7 \times 8 \mathrm{~cm}$ plastic pots filled with soil (Lentse potgrond, Katwijk, The Netherlands) and grown for 4 weeks in a greenhouse $\left(23 / 18^{\circ} \mathrm{C}, 16 / 8 \mathrm{~h}\right.$; day : night; $50-60 \%$ relative humidity) of Wageningen University, Wageningen, The Netherlands. Two-spotted spider mites Tetranychus urticae Koch were obtained from Koppert BV (Berkel en Rodenrijs, The Netherlands) and maintained on lima bean (Phaseolus vulgaris) for multiple generations.

\section{JA treatment and spider-mite infestation}

For spider-mite infestation, plants were infested with approximately 300 spider mites per plant by placing similar pieces of heavily infested lima bean leaves on top of the Capsicum leaves. For metabolite analysis and RNA sequencing, 5 to 6 leaves from different ontogenic positions of five-week-old plants were pooled together and powdered in liquid nitrogen after 6 or 24 hours of JA (100 $\mu \mathrm{M}, 0.1 \%$ Tween-20) treatment, three days of spider-mite infestation or from non-treated plants respectively. For each treatment, three biological replicates were used.

\section{Volatile collection and analysis}

To analyze the volatile emission of Capsicum leaves upon herbivory, plants that were infested with spider mites for three days, treated with JA for 6 or 24 hours or were left untreated, were enclosed in a glass jar for two hours as described in (Kappers et al., 2011) with adaptations. Purified air supplemented with $\mathrm{CO}_{2}$ to $400 \mathrm{ppm}$ and $50 \%$ relative humidity was introduced into the jar with a flow of $300 \mathrm{ml} \cdot \mathrm{min}^{-1}$ and volatiles were collected on a Tenax cartridges (23/35 mesh, Grace-Alltech, Deerfield, MI, USA) at a flow rate of $200 \mathrm{ml} \cdot \mathrm{min}^{-1}$ for 2 hours. After collection, Tenax cartridges were dried under a stream of nitrogen for $20 \mathrm{~min}$ at ambient temperature to remove water. Volatiles were resorbed from the cartridges with a Thermal Desorber TD100-xr (Unity, MARKES International) connected to a GC/Q-ToF (Agilent Technologies, CA, USA). Analytes were focused at $0^{\circ} \mathrm{C}$ on an electronically-cooled sorbent trap (Unity, Markes, Llantrisant, UK). Volatiles were transferred with split flow of $99 \mathrm{ml} \mathrm{min}^{-1}$ to the analytical column by rapid heating of the cold trap to $260^{\circ} \mathrm{C}$ for 3 minutes using a 7890B GC-system for separation with a DB-5MS column of $30 \mathrm{~m}$ 
long a 0.250 diameter, $1 \mu \mathrm{m}$ film and a constant Helium flow of $1.2 \mathrm{ml} \mathrm{min}^{-1}$. (Agilent J\&W CC columns, Agilent Technologies, CA, USA). For each sample, the oven temperature was set at $40^{\circ} \mathrm{C}$ for 2 minutes to $280^{\circ} \mathrm{C}$ for 4 minutes followed by a linear thermal gradient of $10^{\circ} \mathrm{C} \mathrm{min}^{-1}$ and held for $2.5 \mathrm{~min}$. The column effluent was ionized by electron impact ionization at $70 \mathrm{eV}$ and got detected with an Agilent Technologies 7200 accurate mass Q-Tof GC/MS. Mass spectra were acquired by scanning from $50-350 \mathrm{~m} / \mathrm{z}$ with a scan rate of 5 scans. $\mathrm{min}^{-1}$. For each treatment, five replicates were analyzed.

Chromatograms were analyzed for the presence of plant terpenoid compounds using the Software Agilent MassHunter Qualitive analyses B0700, NIST MS Search 2.2, version June 2014, library and comparing retention indices with literature Adams, 1995. (Adams et al., 1995).

\section{Endogenous terpenoids extraction and analysis}

Semi-polar endogenous metabolites were extracted with aqueous methanol according to De Vos and co-workers (De Vos et al., 2007) and analyzed by LC-Orbitrap-MS. Leaf samples were ground into a fine powder in liquid nitrogen. $20 \mathrm{mg}$ of lyophilized leaf material from each sample was extracted with $2 \mathrm{ml} 75 \% \mathrm{MeOH}$ (0.1\% formic acid) solution. Samples were homogenized for 5 seconds and sonicated for $15 \mathrm{~min}$ at maximum frequency (40 $\mathrm{kHz}$ ) in a water bath at ambient temperature and centrifuged for $10 \mathrm{~min}$ at $5000 \mathrm{rpm}$. The supernatant was filtered using a $0.45 \mu \mathrm{m}$ inorganic membrane filter (Millipore, USA) using a disposable syringe (Omnifix, Germany) and transferred into a $0.3 \mathrm{ml}$ LC-MS plastic vial. Ten $\mu \mathrm{l}$ of the supernatant was taken from each sample of the series and combined to make a quality control sample (QC) that was analysed every 20 samples to control for machine stability.

The LC-Orbitrap-MS consisted of an Accela U-HPLC equipped with a $1.7 \mu \mathrm{m}$ AQUITY UPLC BEH C18 column ( $2.1 \times 150$ mm; Waters), an Accela photodiode array (PDA) detector and an lon trap-Orbitrap FTMS hybrid mass spectrometer (Thermo Fisher Scientific) using the negative electrospray ionization mode at a source voltage of $4.5 \mathrm{kV}$. Five $\mu \mathrm{L}$ of extract was injected and separated with a linear 20 min gradient of 5 to $35 \%$ acetonitrile (acidified with $0.1 \mathrm{FA})$ at a flow rate of $400 \mu \mathrm{L} \mathrm{min}$. The column was washed and equilibrated before the next injection (van Duynhoven et al., 2014).

The Metalign software (Lommen, 2009) was used for baseline correction, mass spectra extraction and mass signal alignment. MSClust (Tikunov et al., 2012) was used for data reduction by unsupervised clustering and extracting of putative metabolite mass spectra from ion-wise chromatographic align- 
ment data. Significantly altered metabolites were semi-quantified by comparing characterized ion intensity between non-treated plants and treated plants (Criteria for selection: Fold Change [Treated/Non-treated] $>1.5$ or $<-1.5$, two-tailed Student t-test $p<0.05)$. Putative annotation of non-volatile terpenoid compounds was done based on comparison of accurate masses with the KNApSAcK database (http://kanaya.naist.jp/knapsack jsp/top.

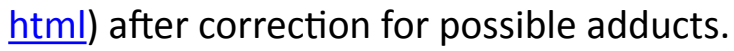

\section{RNA isolation}

About $100 \mathrm{mg}$ of tissue of each sample was used for total RNA extraction with TriPure (Roche, Mannheim, Germany). The extracted total RNAs were cleaned with the RNeasy Plant Mini Kit (Qiagen, USA) and genomic DNA was digested using RNase-Free DNase Set (Qiagen, USA) according to the manufacturer's instructions. RNA integrity was estimated by agarose $(1.0 \%)$ gel electrophoresis. Total RNA for RNA-seq library construction was quantified (Thermo scientific Nanodrop 2000, Wilmington, USA) and samples with a concentration above $300 \mathrm{ng} / \mu \mathrm{l}, \mathrm{A}_{260} / \mathrm{A}_{280}$ values between 1.8 to 2.0 and $\mathrm{A}_{260} /$ $A_{230}$ values between 2.0 to 2.2 were send used for CDNA library construction and sequencing (Laboratory of Bioinformatics, Plant Research International, WUR, Wageningen, The Netherlands).

\section{RNA sequencing and transcript assembly}

Transcriptome libraries were constructed using the TruSeq ${ }^{\text {TM }}$ RNA sample Prep Kit (Illumina, CA, USA). Sequencing was conducted using Illumina HiSeq TM 2500 (Illumina, CA, USA) platform and produced 9 to 20 million-bp pairedend reads per sample. Reads were filtered with the program Trimmomatic version (Bolger et al., 2014) to remove the adaptor sequences, empty reads, short reads $(<25 \mathrm{bp})$, reads with an $\mathrm{N}$ ratio greater than $10 \%$ and low quality sequences, all of which negatively affect the bioinformatics analysis (as also described in Chapter 4 of this thesis). Assembly of full length TPS transcripts was performed using the Trinity method (Grabherr et al., 2011).

\section{Identification of TPS genes in Capsicum}

To identify putative Capsicum TPS genes, a BLAST search against the $C$. annuum (Zunla-1) genome database (http://peppersequence.genomics.cn/ page/species/index.jsp) using the protein sequence of known terpene synthases from Arabidopsis (A. thaliana), tomato (S. lycopersicum), medicago (Medicago truncatula), grapevine ( $V$. vinifera), and spruce (Picea glauca) (Supplemental Data 1) was performed (blast hits with e-value lower than e-5), in combination with lines of evidence provided by synteny and Hid- 
den-Markov-Modeling (Hofberger et al., 2015).

\section{Phylogenetic tree reconstruction and gene model analysis}

Deduced TPS genes from Capsicum were aligned using the program ClustalX2.1 (Larkin et al., 2007) with standard parameters. The phylogenetic tree was built with Maximum Likelihood method in MEGA 5 (Tamura et al., 2007). The intron-exon structure of CaTPS genes was determined by comparing the coding sequences and genomic sequences (http://peppersequence. genomics.cn/page/species/index.jsp) using Gene Structure Display Server (GSDS2.0) (Hu et al., 2015). Putative plastid transit peptides were predicted using the TargetP1.1 server (Emanuelsson et al., 2000). Motifs were visualized using Jalview (Troshin et al., 2011).

\section{Network construction and transcript data analysis}

Pearson correlation coefficients were calculated between 18 expressed TPSs and 35336 transcripts assembled from the RNA sequencing. Correlation coefficients above a threshold of 0.85 (either positive or negative) were used to create a co-expression network visualized using Cytoscape v.3.3.0 (Shannon et al., 2003). Functional annotation of studied transcripts was based on homology with annotated $A$. thaliana and $S$. lycopersicum genes. Multivariate analysis of gene transcripts was done using principal component analysis and hierarchical cluster analysis (www.metaboanalyst.ca).

\section{Heterologous expression of CaTPS in E.coli}

Selected full length TPS genes were amplified from cDNA obtained from spider-mite damaged or JA-treated leaves of $C$. annuum. Primer sequence information is available in Supplemental Data 2. PCR products of open reading frames were cloned into the pACYC-Duet vector and transformed in $E$. coli strain BL21. Single colonies were grown in $5 \mathrm{ml} \mathrm{LB}$ to an OD600 of 0.6 and 0.8 , induced with $50 \mu \mathrm{l} 1 \mathrm{M} \mathrm{IPTG}$ and grown for another $24 \mathrm{hrs}$ at $18{ }^{\circ} \mathrm{C}$. Subsequently, cells were collected by centrifugation, re-suspended in icecold extraction buffer ( $50 \mathrm{mM}$ Tris, pH7.5, $300 \mathrm{mM} \mathrm{NaCl}, 1.4 \mathrm{mM} \beta$-mercapto ethanol) and disrupted using a sonicator (4 times 15 seconds). Cell fragments were removed by centrifugation and the supernatant containing the heterologous protein was used for enzymatic assays.

To determine the catalytic activity of TPSs, $150 \mu \mathrm{l}$ of the crude protein solution was added to $1340 \mu \mathrm{l}$ assay buffer with $5 \mu \mathrm{l} 10 \mathrm{mM}$ GPP or FPP in a screw-capped vial with an overlay of $100 \mu$ pentane and incubated for 1 hour at $30{ }^{\circ} \mathrm{C}$ with gentle shaking. For analysis of the captured reaction products, the pentane layer was carefully filtered over a Pasteur's-pipet 
filled with $\mathrm{Na}_{2} \mathrm{SO}_{4}$ and analyzed using GC-MS. As a negative control, crude protein extract from E. coli expressing the empty vector pACYC-Duet incubated with substrate, was used.

One $\mu \mathrm{l}$ of the pentane extract was injected splitless in the injector at a temperature of $250^{\circ} \mathrm{C}$ at an initial column temperature of $40^{\circ} \mathrm{C}$. The temperature was held for 3.5 minutes, then increased with $10^{\circ} \mathrm{C} / \mathrm{min}$ to $280^{\circ} \mathrm{C}$ and a hold for $2.5 \mathrm{~min}$ at a helium flow of $1 \mathrm{ml} / \mathrm{min}$. The ion source of the DSQ quadrupole mass spectrometer was directly coupled with the analytical column and operated in the $70 \mathrm{eV} \mathrm{El} \mathrm{ionization} \mathrm{mode.} \mathrm{Masses} 45$ to $350 \mathrm{~m} / \mathrm{z}$ were scanned. Compound identification was performed using Wiley (http://www. sisweb.com/software/wiley-ffnsc.htm), NIST11 (http://chemdata.nist.gov/), and Adams mass spectra databases and retention indices (Adams, 2007) and an in-house data base in which authentic standards from Sigma were used to identify compounds. For each TPS enzyme and substrate combination, assays were repeated at least once but most often three times. 


\section{Results}

\section{Genome-wide identification of the TPS gene family in Capsicum annuum}

We identified 103 loci in the Capsicum genome with sequence homology to previously identified TPS genes from Arabidopsis, tomato, Medicago, grapevine or spruce (E-value < e-5) using the second version of the Capsicum genome and confirmed with synteny and Hidden-Markov-Modeling (HMM) (Hofberger et al., 2015). Most of the predicted TPS proteins contain at least one or more TPS characteristic domains, IPR008930, IPR001906, IPR008949, IPR005630 as described in the InterPro database. These homologous hits of CaTPS genes encode putative proteins with sizes ranging from 102 to 852 amino acids (Supplemental Data 3).

Gene sequences predicted to encode for proteins of less than 500 amino acids are considered to be translated products of partial genes or pseudogenes, and will most likely not encode functional enzymes (Bohlmann et al., 1998). Consequently, 27 gene models which encode protein sequences of more than 500 amino acids were assumed to represent full length genes while 76 gene models are considered to be non-functional because of their short length (Table 1). Forty-four of the 103 detected putative CaTPS genes had transcripts present in leaves of which 27 are putatively non-functional genes and 17 are putatively functional (Supplemental Data 4).

\section{Genomic organization of CaTPS}

The 103 loci exhibiting significant similarity with known TPS genes are distributed across all 12 chromosomes of Capsicum (Figure 1). Chromosome VII contains the highest density of TPS genes including 16 TPS-like gene models. Ten of these TPS-like gene models (CaTPS92, CaTPS93, CaTPS94, CaTPS95, CaTPS96, CaTPS97, CaTPS98, CaTPS99, CaTPS100, CaTPS101) are physically located close to each other and show high sequence similarity with each other, suggesting multiple (partial) duplication and recombination events. Thirteen TPS-like genes are located on chromosome VIII of which most are arranged in two nearby clusters. Of these genes, 4 out of 5 show high sequence similarity with sesquiterpene synthase encoding genes and cluster in a sequential repeat (CaTPS54, CaTPS55, CaTPS56, CaTPS57) with one gene (CaTPS58) located not within but close to the repeat. Another 8 genes with high sequence similarity to monoterpene synthases form a three-gene repeat (CaTPS59, CaTPS60, CaTPS61) and a four-gene repeat (CaTPS62, CaTPS63, CaTPS64, CaTPS65), together with a single scattered gene, CaTPS66. There are 11 TPS-like genes on chromosome III of which 4 are located next to each other (CaTPS32, CaTPS33, CaTPS34, CaTPS35). An- 
other two genes on this chromosome (CaTPS37 and CaTPS38) are located in a tandem repeat. Eleven TPS genes are located on chromosome $\mathrm{XI}$ and nine of them have high sequence homology. Respectively 9, 9, 7, 5 and 2 TPS genes were annotated to chromosome IX, chromosome IV, chromosome $\mathrm{I}$, chromosome $\mathrm{VI}$ and chromosome $\mathrm{VII}$ respectively, while chromosome $\mathrm{V}$ and chromosome $X$ have a single TPS locus. Eight TPS genes could not be anchored to any specific position during genome sequencing and were assigned to an artificial chromosome and two of them are suggested to be part of the TPS-a clade.

In general, CaTPS genes are located compactly on the chromosomes with a high tandem repeat structure. Most tandem repeated genes show high similarity in sequence but with diverse gene sizes. It most likely indicates a recent evolutionary tandem duplication of which some are non-completed (Figure 1).

\section{Phylogenetic analysis and gene structure}

To analyze the phylogenetic distribution of CATPS and predict their gene function based on homology with known functional TPS genes from other species, a phylogenetic tree was constructed based on the 27 putative functional CaTPSs and 41 TPS protein sequences from 13 other species (Figure 2 ). The selected plant species include both gymnosperms (Abies grandis, $P$. glauca, Mentha. piperita, Mentha. longifolia) and angiosperms (S. lycopersicum, A. thaliana, M. truncatula, V. vinifera, Clarkia. breweri, Croton. sublyratus, C. sativus, Cucurbita. maxima, Solanum. habrochaites). The phylogenetic analysis indicated that 6 out of the 8 designated subfamilies (Bohlmann et al., 1998) are present in the CaTPS family. Only the S. moellendorffi specific TPS-h and gymnosperm specific TPS- $d$ subfamilies are missing. Eighteen CaTPS genes cluster with TPS-a subfamily members from other species all encoding sesquiterpene synthases. Five CaTPS genes cluster with previously identified TPS-b family members which mainly encode cyclic monoterpene and hemiterpene synthases. Among them, CaTPS66 shared the highest similarity of $92.7 \%$ with a monoterpene synthase from S. Iycopersicum (SITPS8) which catalyzes the formation of 1,8-cineole from both GPP and NPP (Falara et al., 2011). CaTPS76 clusters with TPS-g subfamily members of other species, which include acyclic monoterpene synthases and is phylogenetically most related to SITPS37 and SITPS39 with similarities of $89.0 \%$ and $86.5 \%$ respectively. Both SITPS37 and SITPS39 encode monoterpene synthases catalyzing the conversion of GPP to linalool but also accept FPP as substrate to produce (E)-nerolidol (Falara et al., 2011). The TPS-c subfamily contains one TPS member, CaTPS42, with high homology with copalyl diphosphate synthases from other species. Also the TPS-e and TPS- $f$ subfamilies both contain 
Table 1. Characteristics of deduced full length TPS genes identified in the Capsicum annuum genome. cTP, predicted chloroplast transit peptide (for details of predicted N-terminal presequences see Supplemental Table 2.)

\begin{tabular}{|c|c|c|c|c|c|c|c|c|}
\hline $\begin{array}{c}\text { CaTPS } \\
\text { ID }\end{array}$ & $\begin{array}{l}\text { Pro- } \\
\text { tein } \\
\text { size }\end{array}$ & $\begin{array}{c}\text { Chro- } \\
\text { mo- } \\
\text { some }\end{array}$ & Start code & End code & Strand & $\begin{array}{c}\text { Genomic } \\
\text { sequence } \\
\text { length }\end{array}$ & $\begin{array}{l}\text { CaTPS } \\
\text { Sub- } \\
\text { family }\end{array}$ & $\begin{array}{c}\text { Predicted } \\
\text { N-termina } \\
\text { prese- } \\
\text { quences }\end{array}$ \\
\hline TPS5 & 560 & 0 & 400335448 & 400337809 & + & 2361 & a & _ \\
\hline TPS6 & 560 & 0 & 400364995 & 400367460 & + & 2465 & $a$ & _ \\
\hline TPS18 & 559 & 2 & 109682722 & 109685096 & - & 2374 & a & _ \\
\hline TPS29 & 516 & 3 & 47294276 & 47301851 & - & 7575 & $b$ & _ \\
\hline TPS30 & 551 & 3 & 57221196 & 57227028 & - & 5832 & a & _ \\
\hline TPS35 & 504 & 3 & 246086802 & 246090906 & - & 4104 & $a$ & _ \\
\hline TPS37 & 588 & 3 & 250104138 & 250108596 & - & 4458 & a & _ \\
\hline TPS39 & 852 & 4 & 207815899 & 207828461 & - & 12562 & $f$ & _ \\
\hline TPS42 & 823 & 6 & 950241 & 957838 & + & 7597 & c & cTP \\
\hline TPS49 & 560 & 7 & 19879360 & 19882249 & + & 2889 & a & _ \\
\hline TPS50 & 530 & 7 & 181643803 & 181647182 & + & 3379 & $\mathrm{a}$ & _ \\
\hline TPS53 & 719 & 7 & 222027433 & 222032024 & + & 4591 & e & _ \\
\hline TPS54 & 553 & 8 & 134509287 & 134511524 & + & 2237 & a & _ \\
\hline TPS55 & 556 & 8 & 134514999 & 134517439 & + & 2440 & $a$ & _ \\
\hline TPS61 & 620 & 8 & 141131924 & 141134817 & + & 2893 & $b$ & cTP \\
\hline TPS62 & 647 & 8 & 141195405 & 141199514 & + & 4109 & $b$ & cTP \\
\hline TPS63 & 579 & 8 & 141201146 & 141204029 & + & 2883 & $b$ & cTP \\
\hline TPS66 & 520 & 8 & 141425323 & 141427845 & + & 2522 & $b$ & _ \\
\hline TPS67 & 552 & 9 & 12430842 & 12433433 & + & 2591 & $a$ & _ \\
\hline TPS76 & 551 & 10 & 23962352 & 23969183 & + & 6831 & $\mathrm{~g}$ & cTP \\
\hline TPS87 & 542 & 11 & 211209518 & 211212055 & - & 2537 & a & _ \\
\hline TPS91 & 524 & 12 & 172790869 & 172793329 & + & 2460 & a & _ \\
\hline TPS92 & 519 & 12 & 215123920 & 215126190 & + & 2270 & a & _ \\
\hline TPS93 & 561 & 12 & 215155419 & 215157731 & - & 2312 & a & _ \\
\hline TPS94 & 558 & 12 & 216482592 & 216484978 & - & 2386 & a & _ \\
\hline TPS96 & 559 & 12 & 216588216 & 216590578 & - & 2362 & a & _ \\
\hline TPS98 & 552 & 12 & 217625229 & 217627603 & + & 2374 & $a$ & _ \\
\hline
\end{tabular}




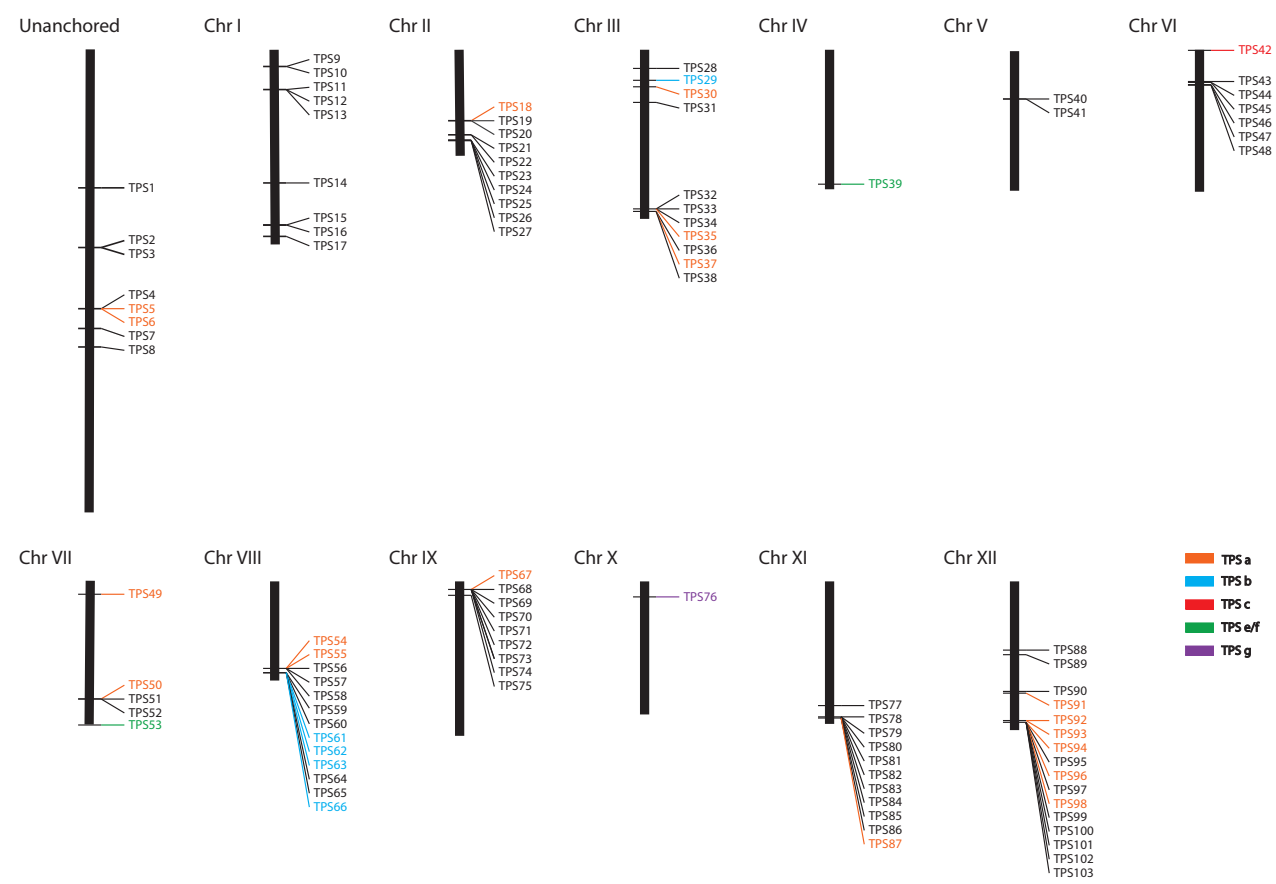

Figure 1. Genomic localization of CaTPS genes. The numbered black bars represent the twelve Capsicum chromosomes. Unanchored TPSs are depicted on an artificial chromosome. Deduced functional TPSS of six subfamilies are highlighted with different colors. For gene identifiers of the different genes, see Supplemental Table 1.

a single full length gene member. TPS-e subfamily member CaTPS53 shows $94.4 \%$ similarity with SITPS24 which is a KS (Falara et al., 2011) while CaTPS39 is closely related to AtTPS04 (geranyl linalool synthase), MtTPS18 ((E)-nerolidol / $(E, E)$-geranyl linalool synthase) and CbS-linalool synthase in the TPS- $f$ clade (Aubourg et al., 2002, Parker et al., 2014, Dornelas and Mazzafera, 2007).

The genomic structure of CaTPS gene members suggests that TPS-a, $-\mathrm{b}$ and -g subfamily members have 6 to 7 exons while the exon number of TPS-c, -e and - $f$ subfamily members ranges from 11 to 15 , consistent with previous research (Trapp and Croteau, 2001) (Table 1, Supplemental Figure 1). 


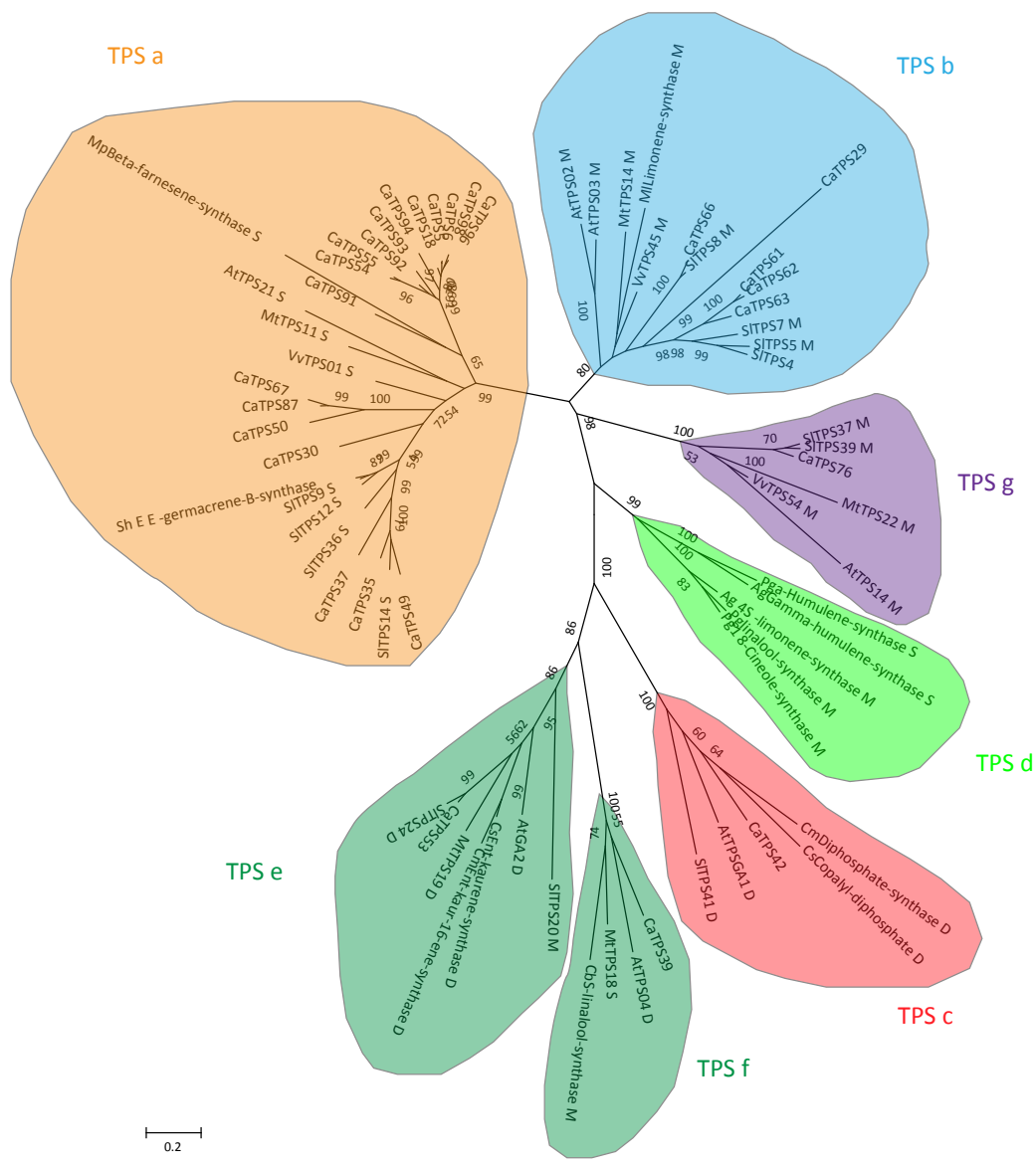

Figure 2. Phylogenetic relationships of TPS proteins. The phylogenetic tree is based on sequences of 27 TPS proteins from Capsicum annuum (Ca) and TPS proteins with known function from other plants species including $A$. grandis $(\mathrm{Ag})$, P. glauca $(\mathrm{Pg}), \mathrm{M}$. piperita (Mp), M. longifolia (MI), S. lycopersicum (SI), A. thaliana (At), M. truncatula (Mt), V. vinifera (Vv), C. breweri (Cb), C. sublyratus (Cs), C. sativus (Cs), C. maxima (Cm), S. habrochaites (Sh) by Maximum likelihood method. Numbers at each node represent bootstrap values, and only values higher than $50 \%$ are shown. Phylogenetic clades are designated with different colors; M represents monoterpene synthases, $\mathrm{S}$ sesquiterpene synthases; D diterpene synthases.

Three of the five TPS-b subfamily members, CaTPS61, CaTPS62 and CaTPS63, the TPS-c subfamily member CaTPS42 and the TPS-g subfamily member CaTPS76, were predicted to contain an N-terminal chloroplast transit peptide (Table 1). The presence of a plastid transit peptide in three TPS-b subfamily members further supports their role as monoterpene synthases. In contrast, no signal peptide was found in the other TPS-b members, CaTPS29, and CaTPS66. The putative function as diterpene synthase of the TPS-c subfamily member CaTPS42 is supported by the presence of a plastid transit 
peptide. The TPS- $f$ member CaTPS39 is also predicted to be a diterpene synthase, but lacks a chloroplast signal peptide. The TPS-g subfamily member CaTPS76 could be either a monoterpene or diterpene synthase.

Conserved motifs were identified after the complete alignment of 27 full length predicted proteins. Three putative monoterpene synthases of the TPS-b subfamily with predicted plastid transit peptide contain the $R R(X)_{8} W$ motif near the $\mathrm{N}$-terminus. Variation in the $\mathrm{RR}(\mathrm{X})_{8} \mathrm{~W}$ motif as $(\mathrm{R} / \mathrm{P})(\mathrm{S} / \mathrm{A} / \mathrm{Y} / \mathrm{V} /$ $\mathrm{I} / \mathrm{E})(\mathrm{X}) 8 \mathrm{~W}$ was found in 16 TPS-a members (Figure 3 ). This motif may be involved in the initiation of the isomerization cyclization reaction or stabilizing the protein through electrostatic interactions (Martin et al., 2010, Aubourg et al., 2002).

The RXR motif was found to be conserved in most CaTPS members and in CaTPS35, CaTPS49, CaTPS53, CaTPS39, CaTPS76 with variation as $R X(R / K / Q)$ but not conserved in TPS-c member CaTPS42. The aspartate-rich DDXXD motif is about 35 amino acids downstream of the RXR motif. Residues of the active-site DDXXD motif are responsible for the divalent metal ion-assisted binding and cleavage of the prenyl diphosphate substrate (Davis and Croteau 2000). The DDXXD motif is highly conserved in the CaTPS family except for the TPS-c member, CaTPS42, a putative copalyl diphosphate synthase. In $A$. thaliana, copalyl diphosphate synthase initiates ionization of GGPP by protonation rather than by diphosphate ester cleavage (Aubourg et al., 2002) (Bohlmann et al., 1998). Another aspartate-rich motif (DIDDTA) which initiates cyclization by protonation of GGPP (Peters et al., 2001) is indeed present in CaTPS42 (aa 384-389).

The (N/D)DXX(S/T/G)XXXE (NSE/DTE) motif is present in all TPS-b, TPS-e/f, TPS-g members and most of the TPS-a members but not in TPS-c member, CaTPS42, nor in three of the TPS-a members, CaTPS98, CaTPS91 and CaTPS37 (Figure 3). Together with the DDXXD motif, the NSE/DTE motif is also required for metal ion dependent ionization of the prenyl diphosphate substrate which is the activity not present in a monofunctional copalyl diphosphate synthase (Chen et al., 2011). 


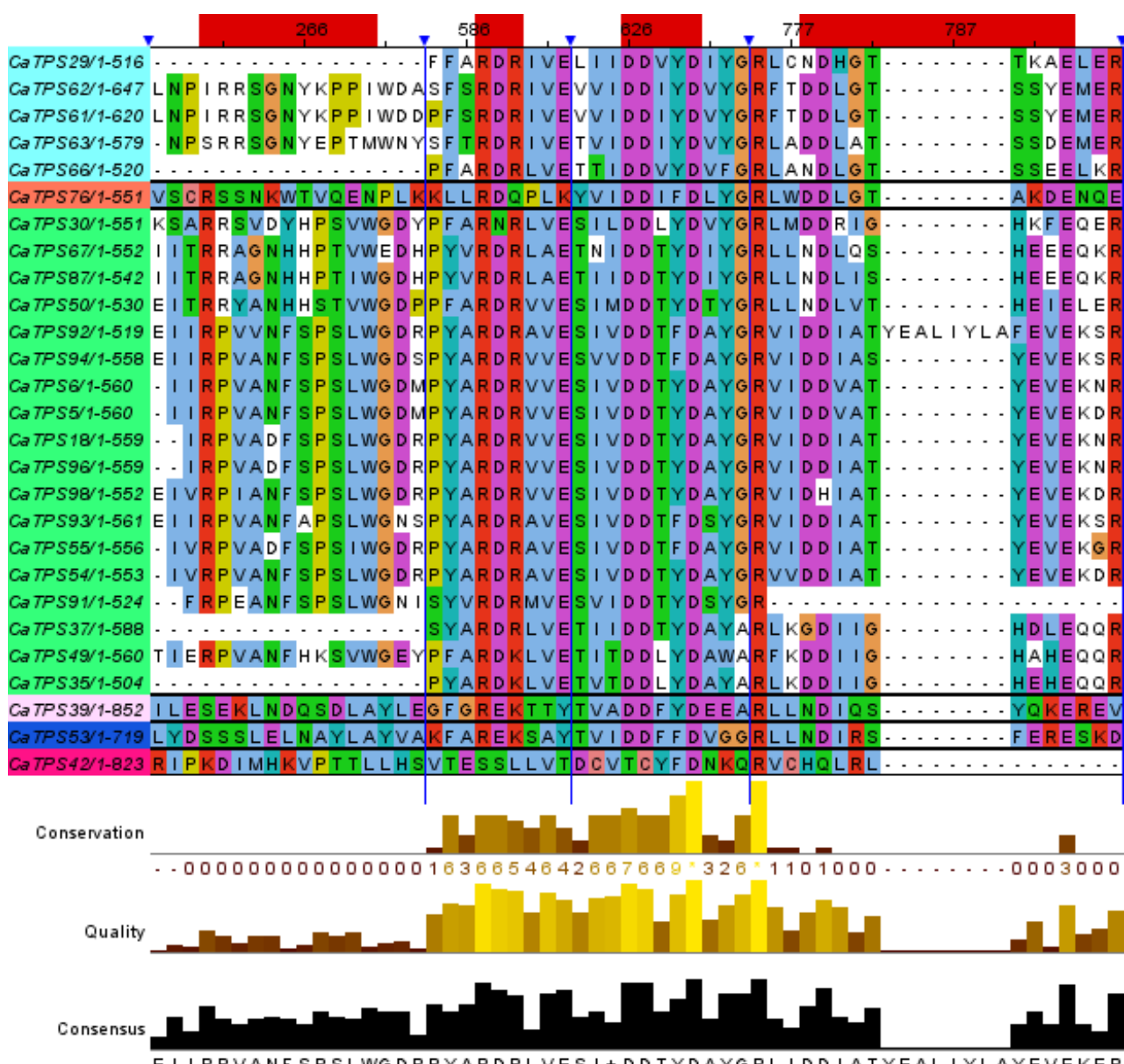

Figure 3. Conserved motifs in CaTPS proteins. Regions with conserved motifs are indicated with red highlight and the separation between different regions is indicated with a blue arrow. Classification of the TPSs in different subfamilies is indicated using colors: TPS-b (light blue), TPS-g (brown), TPS-a (green), TPS f (pink), TPS e (dark blue), TPS c (fuchsia).

\section{Expression profiles of Capsicum annuum TPS genes and upstream biosyn- thetic genes under biotic stress}

To study which CaTPS genes within the Capsicum genome are involved in the response of Capsicum to herbivory, we examined the expression pattern of all CATPS loci after spider-mite infestation and after JA treatment in two C. annuum genotypes. In addition, transcript levels of upstream genes including IPP isomerases, prenyltransferases (PTF), genes from the MVA and the MEP pathway and triterpene-specific synthases were analyzed. These genes were identified by sequence homology, Hidden-Markov-Modeling 
(HMM) and genomic context as described by Hofberger et al. (Hofberger et al., 2015).

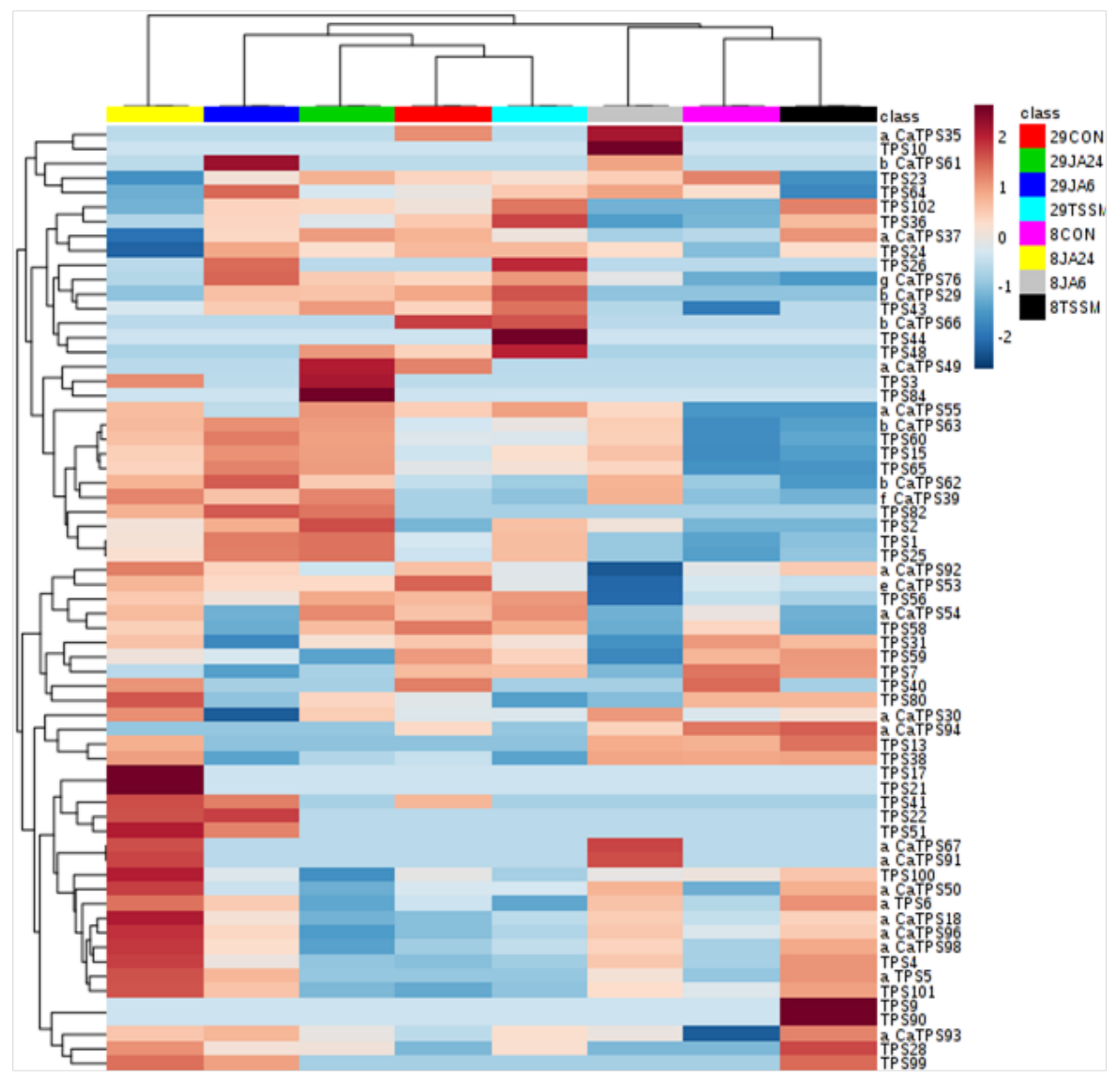

Figure 4. Expression profiles of CaTPS genes upon spider mite infestation for 3 days (TSSM), JA treatment for 6 (JA6) or $24 \mathrm{hrs} / 24 \mathrm{hrs}$ (JA24) or left un-treated (CON) in two Capsicum genotypes, G8 and G29. The expression profiles were obtained by RNA-seq. The average expression levels of TPS genes under each condition were used for hierarchical clustering analyses by UPGMA method based on Euclidean distance. Putative TPS loci are indicated as TPSxx, and putative full length terpene synthase genes are indicated as CaTPSxx, including the sub-family (a-g).

Among the 103 putative CaTPS loci, at least 44 transcripts were found present in Capsicum leaves in either genotype or experimental condition (Figure 4). Most TPS- $a$ and $-b$ subfamily members were induced by spider mites or by JA, except for 3 TPS- $a$ subfamily members (CaTPS49, CaTPS87, CaTPS94) and 2 TPS- $b$ members (CaTPS29, CaTPS66).

CaTPS53, a gene member of the TPS-e clade was constitutively expressed in Capsicum leaves regardless of genotype or treatment, probably due to 
its importance for primary metabolite (gibberellin) production, but its expression was slightly repressed by spider mites and JA in both genotypes. Members of the TPS- $f$ and $g$ clade, CaTPS39 and CaTPS76, were expressed in control plants and induced by both JA and spider mites (Figure 4, Supplemental Data 4). In addition, all four IPP isomerases, 11 out of 13 MEP pathway genes, 16 out of 18 MVA pathway genes, 12 out of 13 PTFs and 9 out of 15 triterpene synthases were expressed in at least one experimental condition (Supplemental Data 4). Most of the expressed MEP/MVA pathway genes and PTFs were induced by spider-mite infestation and JA treatment while IPP isomerases showed comparable expression levels across all samples.

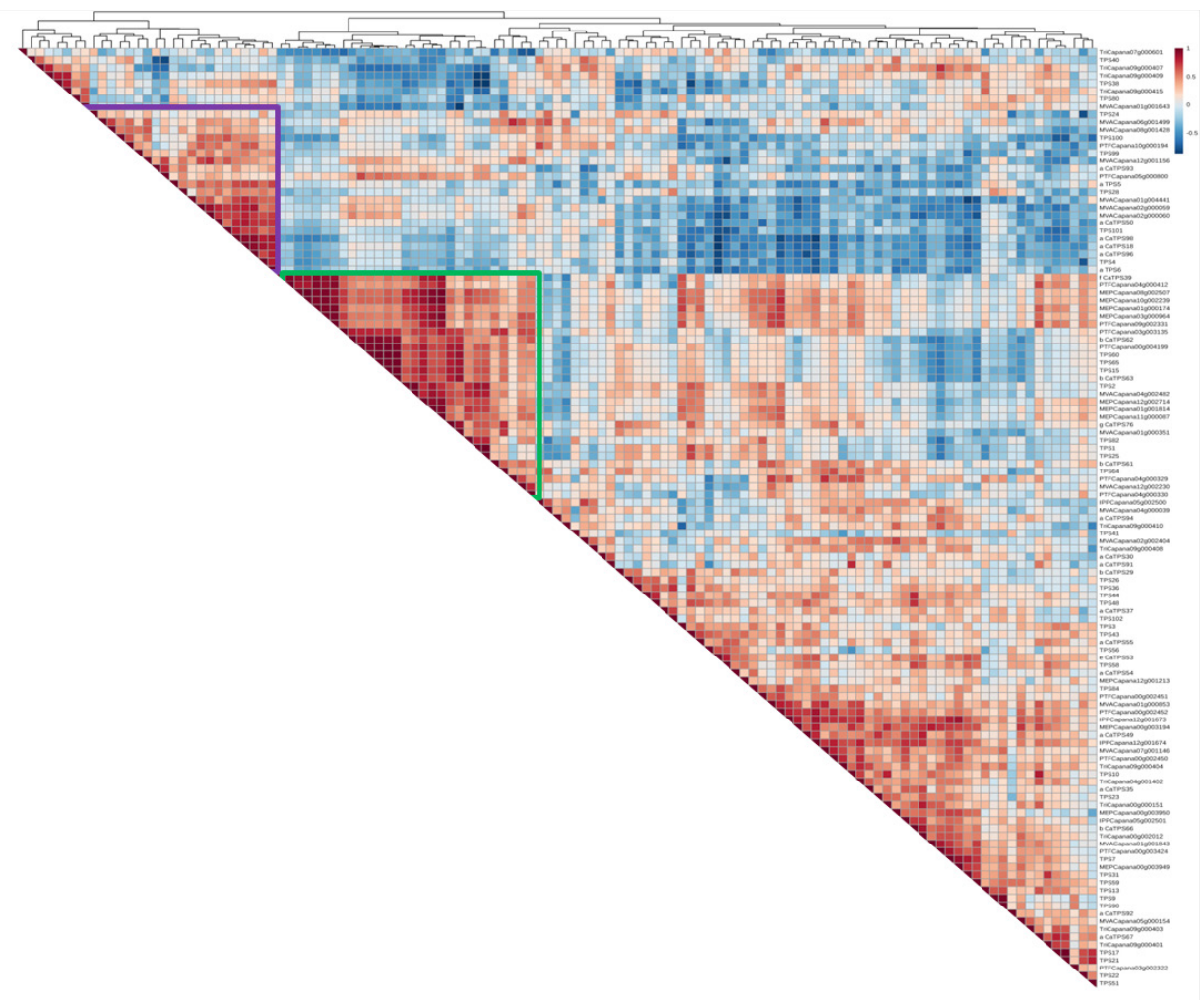

Figure 5. Correlation (Pearson r) matrix of CaTPSs, IPP isomerases, prenyl transferases (PTFs) and genes involved in MVA and MEP pathways. High correlations were found between TPS-a clade genes and IPP isomerases, PTFs and MVA pathway genes (purple frame); TPS-b clade genes and MEP pathway genes (green frame). Gene expression profiles of TPSs and terpene biosynthesis upstream genes were selected from RNA seq data described in Chapter 4. Data represent the relative number of Reads per Kilobase of transcript per Million mapped reads (RPKM) for each selected gene. 
To obtain insight in the relationship between TPS expression and the expression of genes encoding the pathways that provide substrate for terpene biosynthesis, we performed co-expression analysis (Figure 5). The TPS- $a$ subfamily mainly encodes sesquiterpene synthases. Seven out of 17 TPS-a clade genes that were expressed in the leaves, strongly correlated with IPP isomerases, PTFs and MVA pathway genes supporting the idea that substrate for the production of sesquiterpenes is obtained from the MVA pathway (Figure 5 , purple frame). The expression of about half of the expressed MVA genes correlated with the expression of PTF genes, indicating that the biosynthesis of sesquiterpenes through the MVA pathway requires the assistance of PTFs for FPP production (Wang and Ohnuma, 2000). Furthermore, 7 of 11 expressed MEP pathway genes correlated with 6 out of 8 TPS loci that show sequence similarity with monoterpene synthase encoding genes located on chromosome VIII supporting their putative function as monoterpene synthase (Figure 5, green frame). A less strong but visible correlation was found between a number of triterpene synthases with MEP and MVA pathway genes. However, tripterpenes are not within the scope of this study and therefore we did not perform any more in-depth analysis.

\section{Transcriptome co-expression analysis on terpenoid biosynthesis genes}

To discover other genes possibly involved in Capsicum terpene biosynthesis or its regulation, the expression profiles of seventeen expressed and putatively functional TPS genes were used as baits in a co-expression analysis using the RNA-seq data. Differentially expressed (upon JA treatment or spider mite infestation) gene pairs with correlation coefficients $|r|>0.9$ were selected to create a network (Figure 6).

Among 17 expressed TPS genes, 13 showed strong co-expression with other genes resulting in 1606 correlation pairs with 512 genes in total (Figure 6, Supplemental Data 5). The co-expression network was visualized as modules in which nodes represent correlated genes that are connected by edges depicted in blue (negative correlation) or red (positive correlation). This analysis revealed that TPS genes segregate into distinct modules containing multiple classes of genes. 


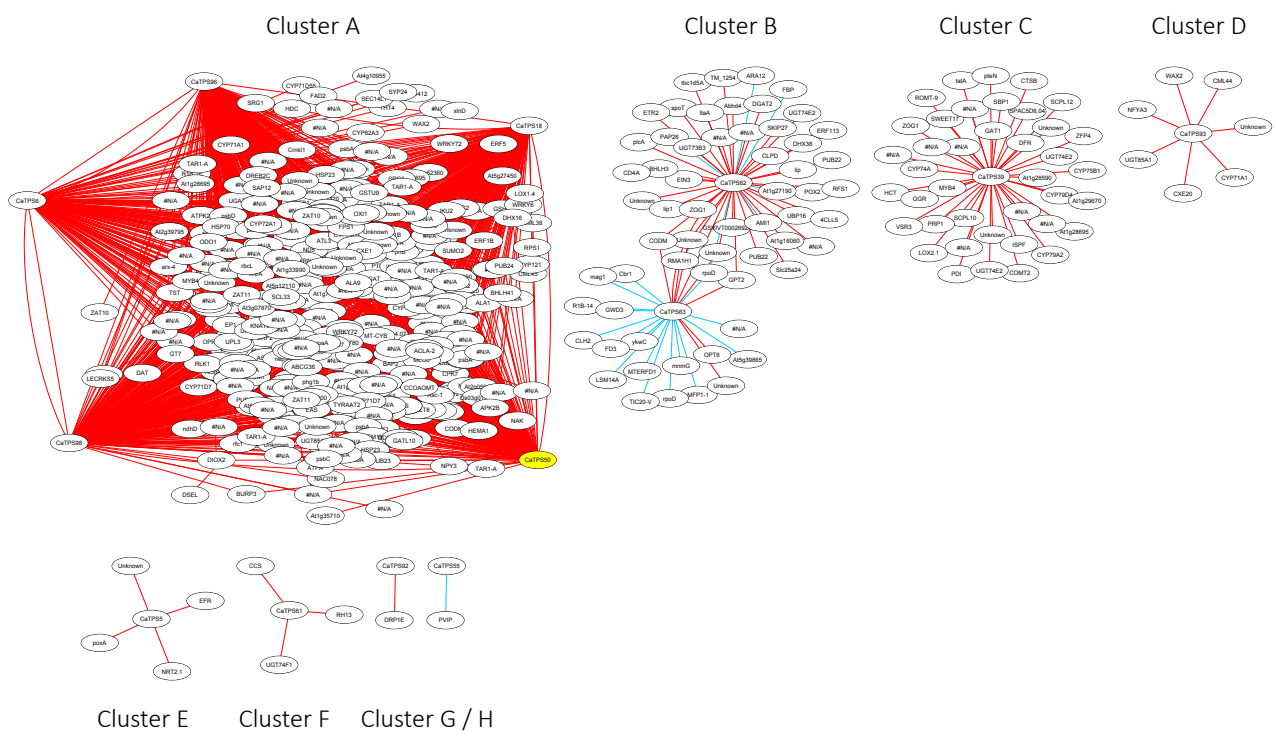

Figure 6. Gene co-expression network of transcripts correlated with $C$. annuum TPS genes that were significantly altered in their expression upon spider-mite infestation or JA induction. The network is visualized using an yGraph Organic layout in Cytoscape 3.3.0. Nodes represent genes labeled with gene annotation based on the Pepper Genome Database (release 2.0). Red lines represent positive correlations; blue lines represent negative correlations. Only gene pairs with correlation coefficient $|r|>0.9$ are shown. For a high resolution version of the figures, see Supplemental Figure 2.

Five TPS-a clade genes, CaTPS6, CaTPS18, CaTPS50, CaTPS96, CaTPS98 and their co-expressed genes formed a module with the highest number of nodes and edges (cluster A in Figure 6). Within this sub-cluster, TPS- $a$ subfamily member CaTPS18 had the highest correlation (0.998) with a cytochrome P450, CYP71D7 homologue. CaTPS18 displayed high co-expression with multiple putative cytochrome P450s and a gene with homology to the rate-limiting MVA pathway enzyme, 3-hydroxy-3-methylglutaryl-coenzyme A reductase, HMGR2 (correlation coefficient 0.949). Co-expressed putative transcription factors included homologues of Arabidopsis/tomato WRKY33 (0.985), WRKY72 (0.983), ERF2 (0.979), WRKY75 (0.931) and MYB4 (0.928), suggesting that CaTPS18 expression is tightly regulated.

Another TPS- $a$ clade gene member, CaTPS50 co-expressed in a similar fashion as CaTPS18, including with multiple cytochrome P450s, CYP71D7s (correlation coefficients varying from 0.974 to 0.988 ) and HMGR2 (0.967). The expression of putative transcription factors with homology to Arabidopsis/ tomato WRKY33, ERF2, MYB4, WRKY72, and WRKY75 also significantly correlated with CaTPS50 expression. 
Among genes co-expressed with the five TPS- $a$ clade members mentioned above, 111 genes overlapped. Genes putatively encoding HMGR2, galacturonosyl and glutathione transferases, and multiple P450s showed high correlations. Highly correlated candidate transcription factors include MYB4, WRKY75, ERF2, WRKY33 and ERF1B (Supplemental Data 5).

The expression of TPS- $b$ clade members CaTPS62 and CaTPS63 highly correlated (correlation coefficient 0.915 , Figure 6 . cluster B) and both of them correlated with other TPS genes (TPS60, TPS65) that have high sequence similarity and are relatively closely located on chromosome VIII. An explanation could be that both TPS genes and the other co-expressed genes localized closely to them on chromosome VIII are under regulation of the same transcription factor. Furthermore, several UDP-glycosyltransferase and glutathione S-transferase genes co-expressed with CaTPS62 and CaTPS63. No WRKY nor $M Y B$ transcription factors were found in these two network modules, but a single ERF113 transcription factor (0.938) co-expressed with CaTPS62. In contrast to the sub network cluster containing TPS-a gene members, negative correlations were found for TPS- $b$ gene member CaTPS63 with two putative cytochrome P450s (Capana01g000486, -0.858; Capana01g000368, -0.862). The strongest negative correlation with both CaTPS62 and CaTPS63 was found for Capana08g000288, a putative RNA polymerase sigma factor, which is important to RNA biosynthesis (Ellermeier, 2012).

In network cluster $\mathrm{C}$, positive co-expression relations were found for TPS-f member, CaTPS39 with multiple UDP-glycosyltransferases and with genes that likely belong to the JA biosynthetic pathway including a linoleate 13S-lipoxygenase 2-1 (LOX2.1) and an allene oxide synthase (AOS). Furthermore, a putative transcription factor, with homology to AtMYB4, highly correlated (0.923) with CaTPS39.

In general, the co-expression network of Capsicum TPS genes that are responsive to spider-mite infestation and/or JA treatment revealed that TPS- $a$ subfamily members predominantly co-express with multiple P450s and most of them (except CaTPS93) also with the MVA pathway gene, HMGR2. In addition, multiple transcription factors including WRKYs, MYBs, and EFRs correlated with these putative sesquiterpene synthases. Several Capsicum TPS- $a$, TPS- $b$ and TPS-e/f gene members co-expressed with multiple UDP-glycosyltransferases. Negative gene correlations were predominant among the putative monoterpene synthases suggesting that biosynthesis of monoterpenes is more affected by interaction with other biological processes in plants, while sesquiterpene biosynthesis is more regulated by signaling pathways or external biotic/abiotic stresses. 


\section{Functional characterization of recombinant TPS enzymes}

Transcriptional analysis suggests that multiple TPSs are responsive to biotic stresses. To further characterize the gene functions and their ecological roles in plant defense, nine full-length TPS ORFs of genes from Capsicum that were induced by spider mites or JA were expressed in E. coli and the recombinant TPS proteins analyzed for enzymatic activity. Consistent with sequence analysis, six TPS-a subfamily members were identified as sesquiterpene synthases as CaTPS6, CaTPS18, CaTPS37, CaTPS96 and CaTPS98 all accepted FPP as substrate to form 4,5-di-epi-aristolochene. In addition, CaTPS93 catalyzed the conversion of FPP into germacrene A. None of these enzymes accepted GPP nor GGPP, earmarking them as monofunctional sesquiterpene sythases. The TPS-f subfamily member CaTPS39 was characterized as a bifunctional enzyme accepting both FPP and GGPP to produce $(E)$-nerolidol and geranyl linalool, respectively. Unfortunately, none of the expressed TPS-b subfamily members could be cloned or characterized (Table 2).

Table 2. Functional characterization of selected recombinant CaTPS proteins. Description of assay conditions and chromatograms are presented in Supplemental Figure 2.

\begin{tabular}{|c|c|c|c|c|}
\hline CaTPS ID & Class & $\begin{array}{c}\text { Accepted } \\
\text { substrate }\end{array}$ & $\begin{array}{c}\text { Product } \\
\text { Formed }\end{array}$ & $\begin{array}{c}\text { Molecular } \\
\text { Formula } \\
\text { product }\end{array}$ \\
\hline TPS6 & a & FPP & $\begin{array}{c}\text { 4,5-di-epi- } \\
\text { Aristocholene }\end{array}$ & C15H24 \\
\hline TPS18 & a & FPP & $\begin{array}{c}4,5 \text {-di-epi- } \\
\text { Aristocholene }\end{array}$ & C15H24 \\
\hline TPS37 & a & FPP & $\begin{array}{c}4,5 \text {-di-epi- } \\
\text { Aristocholene }\end{array}$ & C15H24 \\
\hline TPS39 & f & FPP & Nerolidol & C15H260 \\
\cline { 2 - 5 } & G & None & Geranyllinalool & C20H340 \\
\hline TPS76 & a & FPP & Germacrene A & \\
\hline TPS93 & a & FPP & $\begin{array}{c}4,5 \text {-di-epi- } \\
\text { Aristocholene }\end{array}$ & C15H24 \\
\hline TPS96 & a & FPP & $\begin{array}{c}4,5 \text {-di-epi- } \\
\text { Aristocholene }\end{array}$ & C15H24 \\
\hline TPS98 & & & &
\end{tabular}

\section{Induced terpenoids in Capsicum in response to biotic stresses}

To characterize terpenoid metabolites in Capsicum leaves produced upon biotic stress, both volatile and endogenous terpenoids were analyzed in two genotypes in response to spider mites or JA. Compared to untreated plants, more monoterpenes and sesquiterpenes were detected in the volatile blends of both genotypes in response to spider mite feeding and at least 24 terpenoid volatiles were detected in total, including $(E)-\beta$-pinene, $(E)-\beta$ - 
ocimene, (Z)- $\beta$-ocimene, limonene and 11 other monoterpenoids in minor amounts, as well as caryophyllene oxide, (E)-nerolidol, $(E, E)$ - $\alpha$-farnesene and 7 other sesquiterpenoids (Table 3 ). The monoterpene limonene and sesquiterpene $(E)$ - $\beta$-elemene/germacrene $A$ were commonly present in the blend of non-treated plants of both genotypes. (E)- $\beta$-Pinene, 7-epi- $\alpha$-eudesmol, $(E, E)$-4,8,12-trimethyltrideca-1,3,7,11-tetraene (TMTT) and (E)- $\beta$-elemene/ germacrene A were commonly induced by spider mites in both genotypes.

Untargeted UPLCT/QToF-MS analysis revealed that 13 metabolites in Capsicum leaves, which were putatively annotated as terpenoids, significantly changed $(P<0.05, \mathrm{FC}>1.5$ or $<-1.5)$ upon JA treatment and/or spider-mite infestation in both genotypes. JA reduced the production of two metabolites that were putatively identified as carotenoids, namely $\beta$-cryptoxanthin and zeaxanthin in both genotypes. Most endogenous terpenoids that increased in response to spider mites and/or JA are putative diterpene-glycosides and hemiterpene glycosides. Furthermore, a number of metabolites were detected with putative identification as triterpene that were mostly induced in genotype 29 and were tentatively identified as triterpene saponins and steroid terpenoids conjugated with glycosides (Table 4). Among those, anguivioside B and collettiside III have been identified in Solanum sodomaeum and Solanum anguivi (KNApSAcK database). Although the coexpression network revealed a strong correlation between TPS- $a, b$, e/f members with multiple UDP-glycosyltransferases, no monoterpene- or sesquiterpene-glycoside conjugates were detected upon $\mathrm{JA} /$ spider mite treatment. 
Table 3. Differentially emitted volatile terpenoid metabolites (Met) in the blends of two genotypes of spider-mite (TSSM)-infested Capsicum annuum plants. Ret=Retention time in min. $\mathrm{CF}=$ Chemical formula. Data shows base peak deconvoluted area (PA).gram of leaf fresh weight ${ }^{-1}$ and is the mean $\pm S E$ of three replicates.

\begin{tabular}{|c|c|c|c|c|c|c|c|c|c|c|}
\hline \multirow[b]{2}{*}{ Ret } & \multirow[b]{2}{*}{ CF } & \multirow[b]{2}{*}{ Met } & \multicolumn{2}{|c|}{$\begin{array}{l}\text { Genotype } 29 \\
\text { TSSM-infested }\end{array}$} & \multicolumn{2}{|c|}{$\begin{array}{l}\text { Genotype } 29 \\
\text { Non-infested }\end{array}$} & \multicolumn{2}{|c|}{$\begin{array}{c}\text { Genotype } 8 \\
\text { TSSM-infested }\end{array}$} & \multicolumn{2}{|c|}{$\begin{array}{c}\text { Genotype } 8 \text { Non- } \\
\text { infested }\end{array}$} \\
\hline & & & $\begin{array}{l}\text { PA/g. } \\
\text { F.W. }\end{array}$ & SE & $\begin{array}{c}\text { PA/g.F. } \\
\text { W. }\end{array}$ & SE & PA/g.F.W. & SE & $\begin{array}{c}\text { PA/g.F. } \\
W\end{array}$ & SE \\
\hline 12.10 & $\begin{array}{c}\mathrm{C} 10 \mathrm{H} 1 \\
6\end{array}$ & $\begin{array}{l}\text { (E)- } \beta- \\
\text { Pinene }\end{array}$ & $\begin{array}{l}1141 \\
79.60\end{array}$ & $\begin{array}{c}24756 . \\
38\end{array}$ & - & - & 12070.25 & $\begin{array}{c}3377 . \\
02\end{array}$ & - & - \\
\hline 12.16 & $\begin{array}{c}\mathrm{C} 10 \mathrm{H} 1 \\
6\end{array}$ & 3-Carene & - & - & - & - & 4245.34 & $\begin{array}{c}1829 . \\
39\end{array}$ & - & - \\
\hline 12.55 & $\begin{array}{c}\mathrm{C} 10 \mathrm{H} 1 \\
4\end{array}$ & $\begin{array}{c}\text { 1,3,8-p- } \\
\text { Menthatri } \\
\text { ene }\end{array}$ & - & - & - & - & 2753.00 & $\begin{array}{c}1007 . \\
39\end{array}$ & - & - \\
\hline 12.77 & $\begin{array}{c}\mathrm{C} 10 \mathrm{H} 1 \\
6\end{array}$ & $\begin{array}{c}\text { Y- } \\
\text { Terpinene }\end{array}$ & $\begin{array}{c}6632 . \\
94\end{array}$ & $\begin{array}{c}1787.4 \\
8\end{array}$ & - & - & - & - & - & - \\
\hline 12.90 & $\begin{array}{c}\mathrm{C} 10 \mathrm{H} 1 \\
60\end{array}$ & $\begin{array}{c}\text { (E)-3- } \\
\text { Caren-2-ol }\end{array}$ & - & - & - & - & 20735.19 & $\begin{array}{c}7573 . \\
68\end{array}$ & - & - \\
\hline 12.90 & $\begin{array}{c}\mathrm{C} 10 \mathrm{H} 1 \\
6\end{array}$ & $\begin{array}{c}(E)-\beta- \\
\text { ocimene }\end{array}$ & $\begin{array}{l}3548 \\
77.54\end{array}$ & $\begin{array}{c}80056 . \\
99\end{array}$ & - & - & - & - & - & - \\
\hline 13.00 & $\begin{array}{c}\mathrm{C} 10 \mathrm{H} 1 \\
6\end{array}$ & Limonene & - & - & 8867.85 & $\begin{array}{c}1069.8 \\
8\end{array}$ & 24583.8 & $\begin{array}{c}6169 . \\
02\end{array}$ & 28192.2 & $\begin{array}{c}6813.3 \\
0\end{array}$ \\
\hline 13.10 & $\begin{array}{c}\mathrm{C} 10 \mathrm{H} 1 \\
6\end{array}$ & $\begin{array}{c}(Z)-\beta- \\
\text { ocimene }\end{array}$ & $\begin{array}{c}1503 \\
823.1 \\
0 \\
\end{array}$ & $\begin{array}{c}61250 . \\
659\end{array}$ & - & - & - & - & - & - \\
\hline 13.44 & $\begin{array}{c}\mathrm{C} 10 \mathrm{H} 1 \\
4\end{array}$ & $\begin{array}{l}\text { 1,3,8-p- } \\
\text { Menthatri } \\
\text { ene }\end{array}$ & - & - & - & - & 1888.58 & 57.85 & - & - \\
\hline 13.70 & $\begin{array}{c}\mathrm{C} 10 \mathrm{H} 1 \\
8 \mathrm{O} 2\end{array}$ & $\begin{array}{l}\text { (E)-Linalool } \\
\text { oxide }\end{array}$ & $\begin{array}{c}7884 . \\
21\end{array}$ & $\begin{array}{c}2810.4 \\
2\end{array}$ & - & - & - & - & - & - \\
\hline 14.34 & $\begin{array}{c}\mathrm{C} 10 \mathrm{H} 1 \\
40\end{array}$ & $\begin{array}{c}\text { (Z)- } \\
\text { Ocimene, } \\
\text { 8-oxo- }\end{array}$ & $\begin{array}{l}6924 \\
75.05\end{array}$ & $\begin{array}{c}39220 . \\
86\end{array}$ & - & - & - & - & - & - \\
\hline 14.63 & $\begin{array}{c}\mathrm{C} 10 \mathrm{H} 1 \\
4\end{array}$ & $\begin{array}{c}\text { p-Mentha- } \\
\text { 1,5,8- } \\
\text { triene }\end{array}$ & - & - & - & - & 32282.80 & $\begin{array}{c}5325 . \\
60\end{array}$ & - & - \\
\hline 18.75 & $\begin{array}{c}\mathrm{C} 15 \mathrm{H} 2 \\
4\end{array}$ & $\begin{array}{c}\text { (E)- } \beta- \\
\text { Elemene/G } \\
\text { ermacrene } \\
\text { A }\end{array}$ & $\begin{array}{l}4703 \\
39.80\end{array}$ & $\begin{array}{c}23418 \\
3.6\end{array}$ & 987.93 & 485.11 & $\begin{array}{c}664556.2 \\
0\end{array}$ & $\begin{array}{l}2266 \\
25.60\end{array}$ & 1436.02 & 710.74 \\
\hline 20.01 & $\begin{array}{c}\mathrm{C} 15 \mathrm{H} 2 \\
4\end{array}$ & $\begin{array}{c}\alpha- \\
\text { Farnesene }\end{array}$ & $\begin{array}{l}7141 \\
52.15 \\
\end{array}$ & $\begin{array}{c}22839 \\
4.77\end{array}$ & - & - & - & - & - & - \\
\hline 20.53 & $\begin{array}{c}\mathrm{C} 15 \mathrm{H} 2 \\
4\end{array}$ & $\alpha$-Guaiene & $\begin{array}{c}4960 . \\
46\end{array}$ & $\begin{array}{c}2458.1 \\
9\end{array}$ & - & - & - & - & - & - \\
\hline 20.62 & $\begin{array}{c}\mathrm{C} 15 \mathrm{H} 2 \\
40\end{array}$ & $\beta$-Santalol & $\begin{array}{c}9483 . \\
18 \\
\end{array}$ & $\begin{array}{c}1555.5 \\
3\end{array}$ & - & - & - & - & - & - \\
\hline 20.69 & $\begin{array}{c}\mathrm{C} 15 \mathrm{H} 2 \\
60\end{array}$ & $\begin{array}{c}\text { 7-epi-a- } \\
\text { Eudesmol }\end{array}$ & $\begin{array}{l}2752 \\
3.181\end{array}$ & $\begin{array}{c}10888 . \\
80\end{array}$ & - & - & 40615.58 & $\begin{array}{l}3420 \\
6.37\end{array}$ & - & - \\
\hline 20.78 & $\begin{array}{c}\mathrm{C} 15 \mathrm{H} 2 \\
4\end{array}$ & $\begin{array}{c}\text { (E)- } \\
\text { Nerolidol }\end{array}$ & $\begin{array}{l}3684 \\
8.637\end{array}$ & $\begin{array}{c}16721 . \\
38\end{array}$ & - & - & - & - & - & - \\
\hline 20.78 & $\begin{array}{c}\mathrm{C} 16 \mathrm{H} 2 \\
6\end{array}$ & $\begin{array}{l}\text { Elemene } \\
\text { isomer }\end{array}$ & - & - & - & - & 6855.90 & $\begin{array}{c}4920 . \\
16\end{array}$ & - & - \\
\hline
\end{tabular}




\begin{tabular}{|c|c|c|c|c|c|c|c|c|c|c|}
\hline 20.91 & $\begin{array}{c}\mathrm{C} 16 \mathrm{H} 2 \\
6\end{array}$ & TMTT & $\begin{array}{c}2752 \\
3.181\end{array}$ & $\begin{array}{c}10888 . \\
80\end{array}$ & $\begin{array}{c}22958.1 \\
5\end{array}$ & $\begin{array}{c}4694.5 \\
0\end{array}$ & $\begin{array}{c}1106466 . \\
20\end{array}$ & $\begin{array}{c}2110 \\
75.96\end{array}$ & - & - \\
\hline 21.38 & $\begin{array}{c}\mathrm{C} 15 \mathrm{H} 2 \\
40\end{array}$ & $\begin{array}{c}\text { Caryophyll } \\
\text { ene oxide }\end{array}$ & $\begin{array}{c}7043 . \\
9805\end{array}$ & $\begin{array}{c}1928.4 \\
4\end{array}$ & - & - & - & - & - & - \\
\hline 22.13 & $\begin{array}{c}\mathrm{C} 15 \mathrm{H} 2 \\
60\end{array}$ & $\begin{array}{c}\text { Ledene } \\
\text { oxide-(II) }\end{array}$ & - & - & - & - & 2052.80 & $\begin{array}{c}1493 . \\
58\end{array}$ & - & - \\
\hline 24.03 & $\begin{array}{c}\mathrm{C} 15 \mathrm{H} 2 \\
0\end{array}$ & $\begin{array}{c}\alpha- \\
\text { Dehydroar } \\
\text { himachale } \\
\text { ne }\end{array}$ & $\begin{array}{c}1079 . \\
34\end{array}$ & 118.61 & - & - & - & - & - & - \\
\hline
\end{tabular}

Both monoterpenoids and sesquiterpenoids showed increased production coordinated with upregulated TPS gene expression encoding monoterpene and sesquiterpene synthases upon infestation (Figure 4). Interestingly, among induced terpenoids, there were more monoterpenoids than sesquiterpenoids in the induced volatiles. For example, the emission of the monoterpene $(E)$ - $\beta$-pinene was induced by spider mites in both genotypes and 5 times higher in genotype 29 than in genotype 8 which is nicely corresponding to a similar transcript change of TPS63, which shows high sequence similarity with a (-)-camphene/tricyclene synthase encoding gene in S. lycopersicum (E value 0.0) (Falara et al., 2011) that produces (-)-camphene, an isomer of $\beta$-pinene. Multiple monoterpenes such as $(E)$ - $\beta$-ocimene, linalool and 3-carene displayed increased production in response to spider mites in at least one of the genotypes. Based on transcript expression and sequence homology, TPS62, TPS63 and TPS65 would be the most likely candidates to encode enzymes for the formation of those monoterpenes, but unfortunately we were not able to characterize the function of these genes. 
Table 4. Differentially produced non-volatile terpenoid compounds in leaves of two Capsicum annuum genotypes upon spider-mite (TSSM) infestation or JA treatment. Putative annotation was done by comparing accurate masses with the KNApSAcK database (http:// kanaya.naist.jp/knapsack_jsp/top.html). $=$ TSSM= Two Spotted Spider Mites, JA= Jasmonic acid, $\mathrm{CON}=$ Control plants; $\mathrm{FC}=$ Fold Change $(\mathrm{TSSM} / \mathrm{CON}) \mathrm{OR}(\mathrm{JA} / \mathrm{CON})$; The metabolites analysis was based on three replicates of each sample (Student-T-Test with equal variation; $\mathrm{P}<0.05, \mathrm{FC}>1.5$ or $<-1.5)$.

\begin{tabular}{|c|c|c|c|c|c|c|}
\hline $\begin{array}{l}\text { Genotype } \\
\text { \& } \\
\text { Treatment }\end{array}$ & FC & Chemical class & $\begin{array}{c}\text { Putative } \\
\text { identification }\end{array}$ & $\begin{array}{l}\text { Chemical } \\
\text { Formula }\end{array}$ & $\begin{array}{c}\text { Parental } \\
\text { ion [ M- } \\
\mathrm{H}]-\end{array}$ & CAS RN \\
\hline \multirow{7}{*}{$\begin{array}{c}\text { G29 } \\
\text { JA6/CON }\end{array}$} & $\infty$ & Diterpenoids & Taxumairol C & $\mathrm{C} 26 \mathrm{H} 38011$ & 525.24 & $189368-20-5$ \\
\hline & 2.84 & $\begin{array}{l}\text { Triterpene } \\
\text { Glycosides }\end{array}$ & Assamsaponin A & $\mathrm{C} 57 \mathrm{H} 88 \mathrm{O} 25$ & 1171.53 & $259747-95-0$ \\
\hline & 2.36 & $\begin{array}{c}\text { Triterpene } \\
\text { saponins }\end{array}$ & Theasaponin C1 & C57H9OO25 & 1173.54 & $929877-79-2$ \\
\hline & 2.34 & Carotenoids & Antheraxanthin & $\mathrm{C} 40 \mathrm{H} 56 \mathrm{O} 3$ & 583.28 & $640-03-9$ \\
\hline & 1.9 & $\begin{array}{c}\text { Triterpene } \\
\text { saponins }\end{array}$ & TR-Saponin & C51H78O2O & 1009.48 & 288153-05-9 \\
\hline & 1.23 & $\begin{array}{l}\text { Hemiterpene } \\
\text { glycosides }\end{array}$ & Hymenoside $\mathrm{H}$ & C35H38O17 & 729.23 & $394212-42-1$ \\
\hline & 0.15 & Carotenoids & $\begin{array}{c}\text { beta- } \\
\text { Cryptoxanthin }\end{array}$ & $\mathrm{C} 40 \mathrm{H} 56 \mathrm{O}$ & 651.16 & $472-70-8$ \\
\hline \multirow{11}{*}{$\begin{array}{c}\text { G29 } \\
\text { JA24/CON }\end{array}$} & $\infty$ & $\begin{array}{l}\text { Diterpene } \\
\text { glycosides }\end{array}$ & Streptovirudin B1 & $\begin{array}{c}\text { C36H60N4O16O } \\
18\end{array}$ & 803.37 & $51330-30-4$ \\
\hline & $\infty$ & Diterpenoids & Taxumairol C & $\mathrm{C} 26 \mathrm{H} 38 \mathrm{O} 11$ & 525.24 & $189368-20-5$ \\
\hline & 3.73 & $\begin{array}{c}\text { Steroid } \\
\text { glycoside }\end{array}$ & Saponoside A & $\mathrm{C} 54 \mathrm{H} 84 \mathrm{O} 25$ & 1131.53 & 26151-14-4 \\
\hline & 3.48 & $\begin{array}{c}\text { Steroid } \\
\text { Glycosides, }\end{array}$ & Anguivioside B & $\mathrm{C} 48 \mathrm{H} 74 \mathrm{O} 20$ & 969.48 & $276680-60-5$ \\
\hline & 2.57 & $\begin{array}{l}\text { Triterpene } \\
\text { Glycosides }\end{array}$ & Assamsaponin A & C57H88O25 & 1171.53 & $259747-95-0$ \\
\hline & 2.23 & $\begin{array}{l}\text { Triterpene } \\
\text { saponin }\end{array}$ & Theasaponin C1 & C57H90O25 & 1173.53 & $929877-79-2$ \\
\hline & 2.2 & $\begin{array}{c}\text { Triterpene } \\
\text { saponin }\end{array}$ & Assamsaponin $\mathrm{E}$ & С59H92O26 & 1215.53 & $259748-74-8$ \\
\hline & 1.81 & $\begin{array}{l}\text { Triterpene } \\
\text { saponins }\end{array}$ & TR-Saponin & $\mathrm{C} 51 \mathrm{H} 78020$ & 1009.48 & 288153-05-9 \\
\hline & 1.13 & $\begin{array}{l}\text { Hemiterpene } \\
\text { glycosides }\end{array}$ & Hymenoside $\mathrm{H}$ & $\mathrm{C} 35 \mathrm{H} 38017$ & 729.23 & $394212-42-1$ \\
\hline & 0.13 & Carotenoids & $\begin{array}{c}\text { beta- } \\
\text { Cryptoxanthin }\end{array}$ & $\mathrm{C} 40 \mathrm{H} 56 \mathrm{O}$ & 651.16 & $472-70-8$ \\
\hline & 0 & Carotenoids & Zeaxanthin & $\mathrm{C} 40 \mathrm{H} 56 \mathrm{O} 2$ & 567.21 & $144-68-3$ \\
\hline \multirow{8}{*}{$\begin{array}{c}\text { G29 } \\
\text { TSSM/CON }\end{array}$} & $\infty$ & Triterpenes & $\begin{array}{c}3 \beta, 11 \alpha- \\
\text { Diacetoxy-12- } \\
\text { ursene }\end{array}$ & $\mathrm{C} 34 \mathrm{H} 54 \mathrm{O} 4$ & 525.49 & $5563-70-2$ \\
\hline & 2.34 & $\begin{array}{l}\text { Triterpene } \\
\text { Glycosides }\end{array}$ & Assamsaponin A & C57H88O25 & 1171.53 & $259747-95-0$ \\
\hline & 2.2 & $\begin{array}{l}\text { Triterpene } \\
\text { saponins }\end{array}$ & TR-Saponin & $\mathrm{C} 51 \mathrm{H} 78 \mathrm{O} 20$ & 1009.48 & 288153-05-9 \\
\hline & 2.19 & $\begin{array}{c}\text { Triterpene } \\
\text { saponin }\end{array}$ & Theasaponin C1 & $\mathrm{C} 57 \mathrm{H} 90 \mathrm{O} 25$ & 1173.53 & $929877-79-2$ \\
\hline & 2.09 & $\begin{array}{l}\text { Steroid } \\
\text { glycoside }\end{array}$ & Saponoside A & $\mathrm{C} 54 \mathrm{H} 84 \mathrm{O} 25$ & 1131.53 & 26151-14-4 \\
\hline & 1.98 & $\begin{array}{c}\text { Steroid } \\
\text { Glycosides, }\end{array}$ & Anguivioside B & $\mathrm{C} 48 \mathrm{H} 74 \mathrm{O} 20$ & 969.48 & $276680-60-5$ \\
\hline & 0 & Carotenoids & $\begin{array}{c}\text { beta- } \\
\text { Cryptoxanthin }\end{array}$ & $\mathrm{C} 40 \mathrm{H} 56 \mathrm{O}$ & 651.16 & $472-70-8$ \\
\hline & 0 & Diterpenes & Rebaudioside C & $\mathrm{C} 44 \mathrm{H} 70 \mathrm{O} 22$ & 949.42 & $63550-99-2$ \\
\hline
\end{tabular}




\begin{tabular}{|c|c|c|c|c|c|c|}
\hline \multirow{5}{*}{$\begin{array}{c}\text { G8 } \\
\text { JA6/CON }\end{array}$} & 1.9 & $\begin{array}{c}\text { Hemiterpene } \\
\text { glycosides }\end{array}$ & Hymenoside $\mathrm{HC}$ & $35 \mathrm{H} 380177$ & 29.23 & $394212-42-1$ \\
\hline & 0.41 & Carotenoids & $\begin{array}{c}\text { beta- } \\
\text { Cryptoxanthin }\end{array}$ & $\mathrm{C} 40 \mathrm{H} 560$ & 651.16 & $472-70-8$ \\
\hline & $0.38 \mathrm{~T}$ & riterpenoids & Collettiside III C & $45 \mathrm{H} 72 \mathrm{O} 16$ & 867.90 & $19057-60-4$ \\
\hline & $0.09 \mathrm{D}$ & iterpenes & Rebaudioside C C & $44 \mathrm{H} 70 \mathrm{O} 22$ & 949.42 & $63550-99-2$ \\
\hline & 0 & Carotenoids & Zeaxanthin & $\mathrm{C} 40 \mathrm{H} 56 \mathrm{O} 2$ & 567.21 & $144-68-3$ \\
\hline \multirow{2}{*}{$\begin{array}{c}\mathrm{G} 8 \\
\mathrm{JA} 24 / \mathrm{CON}\end{array}$} & 4.66 & $\begin{array}{c}\text { Steroidal } \\
\text { Glycosides }\end{array}$ & $\begin{array}{c}\text { Isotubocaposigeni } \\
\text { n }\end{array}$ & $\mathrm{C} 30 \mathrm{H} 44 \mathrm{O} 6$ & 499.26 & 929701-99-5 \\
\hline & 0 & Carotenoids & Zeaxanthin & $\mathrm{C} 40 \mathrm{H} 56 \mathrm{O} 2$ & 567.21 & $144-68-3$ \\
\hline \multirow{2}{*}{$\begin{array}{c}\text { G8 } \\
\text { TSSM/CON }\end{array}$} & $377.18 \mathrm{D}$ & iterpenes & Streptovirudin B1 & $\begin{array}{c}\text { C36H60N4O16O } \\
18 \\
\end{array}$ & 803.37 & 51330-30-4 \\
\hline & 2.96 & $\begin{array}{l}\text { Steroidal } \\
\text { Glycosides }\end{array}$ & $\begin{array}{c}\text { Isotubocaposigeni } \\
\text { n }\end{array}$ & $\mathrm{C} 30 \mathrm{H} 44 \mathrm{O} 6$ & 499.26 & 929701-99-5 \\
\hline
\end{tabular}

Recombinant TPS6, TPS18, TPS37, TPS96 and TPS98 catalyzed the formation of 4,5-di-epi-aristolochene from FPP but no products were formed from GPP nor GGPP. While their expression was clearly induced upon spider-mite infestation or JA-treatment, 4,5-di-epi-aristolochene was not detected in the headspace of neither genotype 8 nor 29. 5-Epi-aristolochene is a precursor of a dihydroxylated sesquiterpenoid phytoalexin capsidiol which is produced by several Solanaceous species in response to a variety of environmental stimuli (Whitehead et al., 1989, Lee et al., 2017). The oxidation of 5-epi-aristolochene to capsidiol has been shown to be mediated by elicitor-inducible cytochrome P450 hydroxylases, CYP71D in tobacco (Nicotiana tabacum) (Ralston et al., 2001). Indeed, also in C. annuum TPS18 and TPS98 exhibited the highest correlation with putative CYP71 gene members, which are thus likely candidates for the oxidation of 4,5-di-epi-aristolochene in Capsicum. Upon spider mite infestation and JA treatment, a compound with a similar accurate mass as capsidiol was found in genotype 8 , suggesting that in $C$. annuum 4,5-di-epi-aristolochene is converted into a structural homolog of capsidiol (Supplemental Figure 3).

CaTPS93 was found to produce germacrene A from FPP, while it did not accept GPP nor GGPP and its thermal rearrangement product, $(E)$ - $\beta$-elemene, was detected upon GC-MS analysis of the headspace of challenged plants.

Expression of CaTPS39 was induced by JA in both genotypes and was characterized to catalyze the formation of $(E)$-nerolidol and geranyllinalool from FPP and GGPP, respectively, while it did not accept GPP. This gene would be a logical candidate to explain the presence of nerolidol in the induced volatile blend. Furthermore, TPS39 strongly co-expressed with a putative CYP82G2, which was shown to convert geranyllinalool into DMNT and TMTT, respectively in Zea mays and Arabidopsis (Richter et al., 2016, Lee et al., 2010). The presence of (E)-nerolidol and TMTT in the headspace of $C$. ann- 
uUm upon spider mite feeding is likely due to the expression of these TPS39 and CYP82G2 gene candidates. However, nerolidol and TMTT emission were significantly induced in genotype 29 and in both genotypes, respectively, by spider mites while expression of TPS39 was only found to be significantly enhanced upon JA treatment (Figure 4). The likely explanation for this is that a transient TPS39 gene expression increase was missed in the single time-point RNA-seq analysis. Further qPCR in time series would be needed to verify the expression level of TPS39.

\section{Discussion}

Secondary metabolites play important roles in plant physiology and ecology. Terpenoids are the most widely occurring secondary metabolites in nature and show enormous diversity across the plant kingdom. Many of them have biological activity, for example acting as direct or indirect defense compounds to protect plants against microbes and insects (Bohlmann, 2008, Singh and Sharma, 2015). As Capsicum is an economically important crop with a long history of cultivation, a study on the TPS gene family in Capsicum and how these are related to biotic stress responses not only enhances the understanding of TPS functions in plants but could also give more insight in the role that these genes have in direct and direct defenses to arthropod herbivores in this important crop.

In this study, we identified 103 loci in the $C$. annuum genome based on sequence similarity with TPSs from other species. Twenty-seven of them encode enough amino acids to form potentially functional proteins. These 27 TPS genes belong to TPS clades TPS-a, TPS- $b$, TPS-c, TPS-e, TPS-f and TPS-g. Compared with TPS gene families of other species, including one full length gene out of 4 gene models in P. patens (Hayashi et al., 2007), 32 full length genes out of 40 gene models in Arabidopsis (Aubourg et al., 2002), 10 full length genes out of 55 gene models in apple (Nieuwenhuizen et al., 2013), 29 full length genes out of 44 gene models in tomato (Falara et al., 2011) and 69 full length genes out of 152 gene models in V. vinifera (Martin et al., 2010), the TPS gene family in Capsicum is a relatively middle-sized gene family with a high proportion of pseudogenes and short gene fragments. This is probably due to a relatively high speed of duplication and accompanying gene degradation and loss of function. 


\section{The Capsicum TPS gene family plays a role in the response to biotic stress}

Eighteen CaTPS genes fall into the TPS-a subfamily forming the biggest TPS clade in Capsicum and closely cluster on chromosomes with multiple loci with high sequential homology, likely the result of local duplication events. Despite the high frequency of duplication and gene degradation, all TPS-a family members have conserved DDXXD and RXR domains. The angiosperm-specific TPS-a subfamily is highly divergent across all the seed plants and TPSs in this clade are either sesquiterpene synthases or diterpene synthases (Chen et al., 2011). Many of the volatile and endogenous terpenoid metabolites found in Capsicum can be explained by expression of TPS genes. Seven of the heterologously expressed genes from the CaTPS-a subfamily show high homology to 5-epi-aristolochene synthase that catalyzes the formation of 5-epi-aristolochene from FPP, and 4 of them were characterized as 4,5-di-epi-aristolochene synthase, an isomer of 5-epi-aristolochene, by in vitro enzyme assays. 5-Epi-aristolochene is precursor for the production of the antimicrobial sesquiterpenoid capsidiol which is only produced upon stress (Bohlmann et al., 2002, Zavalapáramo et al., 2000). The upregulated expression of the putative 4,5-di-epi-aristolochene synthases fits well with the increased production of a capsidiol-like compound (based on molecular weight) in infested as well as JA challenged Capsicum plants of genotype 8 (Supplemental Figure 2).

Five CaTPS genes were classified into the TPS- $b$ subfamily. All characterized TPSs in this subfamily are either monoterpene or isoprene synthases (Chen et al., 2011). Except CaTPS29, the other 4 CaTPS- $b$ subfamily members had the conserved RRW8R domain and three of them were predicted to have a transit peptide which would direct the protein to the chloroplasts. Interestingly, only the genes predicted to have a transit peptide were found to have transcripts in the RNA-seq data. These expressed genes all show high similarity to a (-)-camphene/tricyclene synthase from C. baccatum (Kim et al., 2017). Although we did not manage to characterize any of these enzymes in vitro, 14 different monoterpenoids were detected in the headspace of our two genotypes of $\mathrm{C}$. annuum of which 12 were specific in response to spider-mite infestation, which seems consistent with the upregulated expression of these TPS- $b$ members.

There is a single gene in each of the subclasses TPS-c, TPS-e, TPS- $f$ and TPS- $g$. Only TPS- $f$ member CaTPS39, which was shown to catalyze the production of both $(E)$-nerolidol and geranyllinalool in vitro, was induced by both spider mites and JA. Indeed, both nerolidol and geranyllinalool-derived TMTT are detectable in spider-mite induced volatile blends of $C$. annuum and TPS39 expression correlates well with a putative CYP82, suggesting that this cy- 
tochrome P450 could be responsible for the conversion of geranyllinalool to TMTT. It suggests an important role of nerolidol, geranyllinalool and the homoterpenes derived from them in the response to herbivory. The expression of a nerolidol synthases in Arabidopsis resulted in the enhanced emission of nerolidol which improved attraction of parasitoid wasps, Diadegma semiclausum (Houshyani et al., 2013) as well as predatory mites Phytoseiulus persimilis (Kappers et al., 2005). Silencing geranylgeranyl diphosphate synthase in $N$. attenuata dramatically impaired resistance to tobacco hornworm (Jassbi et al., 2008).

Based on sequence similarity TPS-g clade member, CaTPS76 showed high similarity with TPS37 and TPS39 from the tomato SITPS-g clade both of which catalyze the formation of linalool from GPP and nerolidol from $(E, E)$ FPP (Falara et al., 2011). Hence, although we were not successful in its functional characterization, CaTPS76 might be the responsible enzyme for the production of linalool present in the volatile blend upon spider-mite feeding. Full length TPS-c member CaTPS42 likely encodes an ent-copalyl diphosphate synthase but no transcripts were found by RNA sequencing. Six other gene loci were identified as putative ent-copalyl diphosphate synthases, while the other 5 are not predicted to encode functional proteins due to the too short length. Only CaTPS13 was expressed in leaves, albeit at low levels. Probably a low expression level of ent-copalyl diphosphate synthase is sufficient for gibberellin production and RNA sequencing is not sensitive enough to detect this low level of transcripts. It also can be that the low-quality genome annotation did not reveal the complete sequence of all genes and that there is another gene encoding a functional ent-copalyl diphosphate synthase. For example, 3 genes have a predicted putative function as ent-copalyl diphosphate synthase in Carrot (Daucus carota L.)(Keilwagen et al., 2017). To have a more comprehensive idea of which products are encoded by all the $C$. annuum TPSs, a more extensive in vitro analysis would be required.

\section{CaTPS evolution}

Based on phylogenetic analysis, TPS-a and b subfamilies consist of 18 and 5 members, respectively, forming the two largest clades in the CaTPS family (Fig. 2). Many of the members of these families that have high sequence similarity also closely co-localize on the chromosomes. This clustered localization is prominent for TPS-a members on chromosome II, III, VIII , IX, XI, XII and for TPS-b members on chromosome VIII. Many TPS genes of the TPS- $a$ and TPS- $b$ clade seem to have resulted from gene duplication (Aubourg et al., 2002). Those gene copies tend to be retained because their products are secondary, specialized metabolites and will not affect the development and 
survival of the plant. Therefore, this high speed of duplication may not be restricted too much by selection pressures (Heidel-Fischer and Vogel, 2015, Pichersky and Gang, 2000). The rapid evolution of TPS genes has resulted in species-specific paralogous TPS gene clusters. In the TPS-a clade, CaTPS members are more closely related to each other than to TPS genes from other species in the same subfamily.

In contrast to the above mentioned subfamilies, TPS genes from TPS-c, TPSe/f and TPS-g are maintained as a single copy. The low ratio of divergence and slow speed of duplication indicate a strong selection. Sequence analysis suggested that CaTPS53, the only gene member in the TPS-e clade, encodes ent-kaur-16-ene synthase. Together with CaTPS42, these genes are probably responsible for the production of gibberellin in Capsicum (Prisic et al., 2004, Xu et al., 2007).

\section{Terpenoid biosynthesis gene clusters in the Capscium genome}

Genes encoding biosynthetic enzymes for specialized metabolites are often located physically close on chromosomes, forming clusters in the plant genome (Nützmann et al., 2016), such as the biosynthetic genes of tirucalla-7,24-dien-3b-ol (triterpene) in Arabidopsis (Boutanaev et al., 2015), cucurbitacin C (triterpene) in Cucumis sativus (Shang et al., 2014) and the diterpenoid casbene in Euphorbia peplus (King et al., 2014). Combinations of terpenoid synthases with cytochromes P450s are found clustered together in plant genomes far more commonly than would be expected by chance and this gene pairing likely has evolved from a common ancestral pairing in eudicots (Boutanaev et al., 2015).

In Capsicum, we detected multiple genes, including P450s, prenyltransferases, and MVA and MEP pathway genes that were located physically close to TPS genes, suggesting putative specialized gene-clusters. For example, an unknown MEP pathway gene, Capana08g002507, is co-localized with monoterpene synthases CaTPS61, CaTPS62 and CaTPS63 and these genes are co-expressed upon herbivory, suggesting that they are under control of a shared promoter and/or transcription factor. CaTPS62 also co-localized and co-expressed with putative UDP-glucose flavonoid 3-O-glucosyltransferases Capana08g002330 and Capana08g002333 and UDP-glycosyltransferase, Capana08g002334. Especially members of the TPS-a subfamily tend to cluster with cytochrome P450 genes. CaTPS18 is physically close to Capana02g001090 and Capana02g001094 - both of which encode a P450 - and highly correlates with them in expression pattern. CaTPS93 is located close to cytochrome P450s genes, Capana12g002421 while CaTPS98 clusters with cytochrome P450s genes, Capana12g002424 and Capana12g002441. The 
clustering of TPSs with glycosyl transferases and with cytochrome P450s possibly matches with the fact that multiple monoterpene glycosides, oxygenated sesquiterpenes, diterpene glycosides and triterpene glycosides were found to be increased upon spider mite feeding and/or JA treatment.

Biosynthetic genes of both parallel and consecutive steps of specialized metabolites are often clustered in the genome (Boycheva et al., 2014, Shang et al., 2014, Schneider et al., 2016). Many of metabolites formed as result of genes within such plant metabolic gene clusters appear to provide protection against pathogens and herbivores. Clustering genes and coinheritance of optimized gene combination that confer selective advantage is probably beneficial for plants (Yeaman and Whitlock, 2011, Takos and Rook, 2012). Besides, co-localization of metabolic pathway genes increases the likelihood of co-regulating gene expression and prevents the accumulation of toxic/ bioactive intermediates (Field et al., 2011, Xu et al., 2012, Nutzmann et al., 2016).

In conclusion, we identified the TPS gene family in the Capsicum genome and analyzed their phylogeny, gene structure and expression profile upon spider mite feeding and JA treatment. Upstream biosynthetic genes from the MEP, MVA pathway and downstream modification genes including cytochrome P450s, UDP-glycosyl transferases and transcription factors that under herbivory display co-expression with the CaTPS genes were discussed. Finally, recombinant proteins of nine selected TPSs were functionally characterized in vitro. Together, these data to a large extent shed light on the production of volatile and non-volatile defense terpenoids in Capsicum annuum.

\section{Acknowledgements}

We would like to thank Johannes Hofberger for performing terpenoid pathway gene identification, Jun He and Tao Zhao for giving advises on genomic analysis, Francel Verstappen for performing volatile measurement, Bert Schipper for endogenous metabolites measurement. 


\section{References}

ADAMS, R.P. 1995. Identification of essential oil components by gas chromatography/mass spectrometry. Allured Publishing Corporation, Carol Stream. ISBN: 0-931710-421.

ALQUEZAR, B., RODRIGUEZ, A., DE LA PENA, M. \& PENA, L. 2017. Genomic Analysis of Terpene Synthase Family and Functional Characterization of Seven Sesquiterpene Synthases from Citrus sinensis. Frontiers in Plant Science, 8, 20.

AUBOURG, S., LECHARNY, A. \& BOHLMANN, J. 2002. Genomic analysis of the terpenoid synthase (AtTPS) gene family of Arabidopsis thaliana. Molecular Genetics and Genomics, 267, Issue 6, pp 730-745.

BOHLMANN, J. 2008. Insect-Induced Terpenoid Defenses in Spruce, Springer Netherlands.

BOHLMANN, J., MEYER-GAUEN, G. \& CROTEAU, R. 1998. Plant terpenoid synthases: molecular biology and phylogenetic analysis. Proceedings of the National Academy of Sciences of the United States of America, 95, 4126-33.

BOHLMANN, J., STAUBER, E. J., KROCK, B., OLDHAM, N. J., GERSHENZON, J. \& BALDWIN, I. T. 2002. Gene expression of 5-epi-aristolochene synthase and formation of capsidiol in roots of Nicotiana attenuata and N. sylvestris. Phytochemistry, 60, 109-16.

BOLGER, A. M., LOHSE, M. \& USADEL, B. 2014. Trimmomatic: a flexible trimmer for Illumina sequence data. Bioinformatics (Oxford, England), 30, 2114.

BOUTANAEV, A. M., MOSES, T., ZI, J., NELSON, D. R., MUGFORD, S. T., PETERS, R. J. \& OSBOURN, A. 2015. Investigation of terpene diversification across multiple sequenced plant genomes. Proceedings of the National Academy of Sciences of the United States of America, 112, E81.

BOYCHEVA, S., DAVIET, L., WOLFENDER, J. L. \& FITZPATRICK, T. B. 2014. The rise of operon-like gene clusters in plants. Trends in Plant Science, 19, 447-459.

CARRIZOG, C. 2013. Wild Capsicums: identification and in situ analysis of Brazilian species.

CHEN, F., THOLL, D., BOHLMANN, J. \& PICHERSKY, E. 2011. The family of terpene synthases in plants: a mid-size family of genes for specialized metabolism that is highly diversified throughout the kingdom. Plant Journal, 66, 212-229.

DE VOS, R. C., MOCO, S., LOMMEN, A., KEURENTJES, J. J., BINO, R. J. \& HALL, R. D. 2007. Untargeted large-scale plant metabolomics using liquid chromatography coupled to mass spectrometry. Nat Protoc., 2, 778-791.

DEGENHARDT, J., KÖLLNER, T. G. \& GERSHENZON, J. 2009. Monoterpene and sesquiterpene synthases and the origin of terpene skeletal diversity in plants. Phytochemistry, 70, 1621-1637.

DORNELAS, M. C. \& MAZZAFERA, P. 2007. A genomic approach to characterization of the Citrus terpene synthase gene family. Genetics and Molecular Biology, 30, 832-840.

ELLERMEIER, T. D. H., CRAIG D. 2012. Extra Cytoplasmic Function $\sigma$ Factor Activation. Current Opinion in Microbiology, 15, 182-188.

EMANUELSSON, O., NIELSEN, H., BRUNAK, S. \& VON HEIJNE, G. 2000. Predicting Subcellular Localization of Proteins Based on their N-terminal Amino Acid Sequence. Journal of Molecular Biology, 300, 1005-1016.

FALARA, V., AKHTAR, T. A., NGUYEN, T. T., SPYROPOULOU, E. A., BLEEKER, P. M., SCHAUVINHOLD, I., MATSUBA, Y., BONINI, M. E., SCHILMILLER, A. L. \& RL, L. 2011. The tomato 
terpene synthase gene family. Plant Physiology, 157, 770-789.

FERRIERI, A. P., ARCE, C. C. M., MACHADO, R. A. R., MEZA-CANALES, I. D., LIMA, E., BALDWIN, I. T. \& ERB, M. 2015. A Nicotiana attenuata cell wall invertase inhibitor (NaCWII) reduces growth and increases secondary metabolite biosynthesis in herbivore-attacked plants. New Phytologist, 208, 519-530.

FIELD, B., FISTONLAVIER, A. S., KEMEN, A., GEISLER, K., QUESNEVILLE, H. \& OSBOURN, A. E. 2011. Formation of plant metabolic gene clusters within dynamic chromosomal regions. Proceedings of the National Academy of Sciences of the United States of America, 108, 16116.

GRABHERR, M. G., HAAS, B. J., YASSOUR, M., LEVIN, J. Z., THOMPSON, D. A., AMIT, I., ADICONIS, X., FAN, L., RAYCHOWDHURY, R. \& ZENG, Q. 2011. Full-length transcriptome assembly from RNA-Seq data without a reference genome. Nature Biotechnology, 29, 644.

HAYASHI, K. I., KAWAIDE, H., NOTOMI, M., SAKIGI, Y., MATSUO, A. \& NOZAKI, H. 2007. Corrigendum to "Identification and functional analysis of bifunctional ent -kaurene synthase from the moss Physcomitrella patens " [FEBS Lett. 580 (2006) 6175-6181]. Febs Letters, 581, 2748-2748.

HEIDEL-FISCHER, H. M. \& VOGEL, H. 2015. Molecular mechanisms of insect adaptation to plant secondary compounds. Current Opinion in Insect Science, 8, 8-14.

HEILING, S., SCHUMAN, M. C., SCHOETTNER, M., MUKERJEE, P., BERGER, B., SCHNEIDER, B., JASSBI, A. R. \& BALDWIN, I. T. 2010. Jasmonate and ppHsystemin regulate key Malonylation steps in the biosynthesis of 17-Hydroxygeranyllinalool Diterpene Glycosides, an abundant and effective direct defense against herbivores in Nicotiana attenuata. Plant Cell, 22, 273-92.

HOFBERGER, J. A., RAMIREZ, A. M., VAN DEN BERGH, E., ZHU, X., BOUWMEESTER, H. J., SCHUURINK, R. C. \& SCHRANZ, M. E. 2015. Large-Scale Evolutionary Analysis of Genes and Supergene Clusters from Terpenoid Modular Pathways Provides Insights into Metabolic Diversification in Flowering Plants. PLoS ONE, 10, e0128808.

HONG, G. J., XUE, X. Y., MAO, Y. B., WANG, L. J. \& CHEN, X. Y. 2012. Arabidopsis MYC2 Interacts with DELLA Proteins in Regulating Sesquiterpene Synthase Gene Expression. Plant Cell, 24, 2635-2648.

HOUSHYANI, B., ASSAREH, M., BUSQUETS, A., FERRER, A., BOUWMEESTER, H. J. \& KAPPERS, I. F. 2013. Three-step pathway engineering results in more incidence rate and higher emission of nerolidol and improved attraction of Diadegma semiclausum. Metabolic Engineering, 15, 88-97.

HU, B., JIN, J., GUO, A., ZHANG, H., LUO, J. \& GAO, G. 2015. GSDS 2.0: an upgraded gene feature visualization server. Bioinformatics (Oxford, England), 31, 1296.

JASSBI, A. R., GASE, K., HETTENHAUSEN, C., SCHMIDT, A. \& BALDWIN, I. T. 2008. Silencing geranylgeranyl diphosphate synthase in Nicotiana attenuata dramatically impairs resistance to tobacco hornworm. Plant Physiology, 146, 974-986.

KAPPERS, I. F., AHARONI, A., VAN HERPEN, T., LUCKERHOFF, L. L. P., DICKE, M. \& BOUWMEESTER, H. J. 2005. Genetic engineering of terpenoid metabolism attracts, bodyguards to Arabidopsis. Science, 309, 2070-2072.

KAPPERS, I. F., DICKE, M. \& BOUWMEESTER, H. J. 2008. Terpenoids in plant signaling, chemical ecology. Wiley Encyclopedia of Chemical Biology John Wiley \& Sons Inc. 
KAPPERS, I. F., HOOGERBRUGGE, H., BOUWMEESTER, H. J. \& DICKE, M. 2011. Variation in herbivory-induced volatiles among cucumber (Cucumis sativus L.) varieties has consequences for the attraction of carnivorous natural enemies. Journal of Chemical Ecology, 37, 150-160.

KAPPERS, I. F., VERSTAPPEN, F. W. A., LUCKERHOFF, L. L. P., BOUWMEESTER, H. J. \& DICKE, M. 2010. Genetic Variation in Jasmonic Acid- and Spider Mite-Induced Plant Volatile Emission of Cucumber Accessions and Attraction of the Predator Phytoseiulus persimilis. Journal of Chemical Ecology, 36, 500-12.

KEELING, C. I. \& BOHLMANN, J. 2006. Genes, enzymes and chemicals of terpenoid diversity in the constitutive and induced defence of conifers against insects and pathogens. New Phytologist, 170, 657.

KEILWAGEN, J., LEHNERT, H., BERNER, T., BUDAHN, H., NOTHNAGEL, T., ULRICH, D. \& DUNEMANN, F. 2017. The Terpene Synthase Gene Family of Carrot (Daucus carotaL.): Identification of QTLs and Candidate Genes Associated with Terpenoid Volatile Compounds. Frontiers in Plant Science, 8, 1930.

KIM, S., PARK, J., YEOM, S.-I., KIM, Y.-M., SEO, E., KIM, K.-T., KIM, M.-S., LEE, J. M., CHEONG, K., SHIN, H.-S., KIM, S.-B., HAN, K., LEE, J., PARK, M., LEE, H.-A., LEE, H.-Y., LEE, Y., OH, S., LEE, J. H., CHOI, E., CHOI, E., LEE, S. E., JEON, J., KIM, H., CHOI, G., SONG, H., LEE, J., LEE, S.-C., KWON, J.-K., LEE, H.-Y., KOO, N., HONG, Y., KIM, R. W., KANG, W.H., HUH, J. H., KANG, B.-C., YANG, T.-J., LEE, Y.-H., BENNETZEN, J. L. \& CHOI, D. 2017. Multiple reference genome sequences of hot pepper reveal the massive evolution of plant disease resistance genes by retroduplication. bioRxiv.

KING, A. J., BROWN, G. D., GILDAY, A. D., LARSON, T. R. \& GRAHAM, I. A. 2014. Production of bioactive diterpenoids in the euphorbiaceae depends on evolutionarily conserved gene clusters. Plant Cell, 26, 3286-98.

KRUGNER, R., WALLIS, C. M. \& WALSE, S. S. 2014. Attraction of the egg parasitoid, Gonatocerus ashmeadi Girault (Hymenoptera: Mymaridae) to synthetic formulation of a ( E )- $\beta$-ocimene and ( E , E )- $\alpha$-farnesene mixture. Biological Control, 77, 23-28.

KÜLheIM, C., PAdOVAN, A., HEFER, C., KRAUSE, S. T., KÖLlNER, T. G., MYBURG, A. A., DEGENHARDT, J. \& FOLEY, W. J. 2015. The Eucalyptus terpene synthase gene family. BMC Genomics, 16, 450.

LARKIN, M. A., BLACKSHIELDS, G., BROWN, N. P., CHENNA, R., MCGETTIGAN, P. A., MCWILLIAM, H., VALENTIN, F., WALLACE, I. M., WILM, A., LOPEZ, R., THOMPSON, J. D., GIBSON, T. J. \& HIGGINS, D. G. 2007. Clustal W and Clustal X version 2.0. Bioinformatics, 23, 2947-2948.

LEE, H.-A., KIM, S., KIM, S. \& CHOI, D. 2017. Expansion of sesquiterpene biosynthetic gene clusters in pepper confers nonhost resistance to the Irish potato famine pathogen. New Phytologist, 215, 1132-1143.

LEE, S., BADIEYAN, S., BEVAN, D. R., HERDE, M., GATZ, C. \& THOLL, D. 2010. Herbivore-induced and floral homoterpene volatiles are biosynthesized by a single P450 enzyme (CYP82G1) in Arabidopsis. Proceedings of the National Academy of Sciences of the United States of America, 107, 21205-21210.

LI, G., KÖLLNER, T. G., YIN, Y., JIANG, Y. L., CHEN, H., XU, Y., GERSHENZON, J., PICHERSKY, E. \& CHEN, F. 2012. Nonseed plant Selaginella moellendorffi [corrected] has both seed plant and microbial types of terpene synthases. Proceedings of the National 
Academy of Sciences of the United States of America, 109, 14711-5.

LOMMEN, A. 2009. MetAlign: Interface-Driven, Versatile Metabolomics Tool for Hyphenated Full-Scan Mass Spectrometry Data Preprocessing. Analytical Chemistry, 81, 3079-3086.

MACHADO, R. A. R., BALDWIN, I. T. \& ERB, M. 2017. Herbivory-induced jasmonates constrain plant sugar accumulation and growth by antagonizing gibberellin signaling and not by promoting secondary metabolite production. New Phytologist, 215, 803-812.

MARTIN, D. M., AUBOURG, S., SCHOUWEY, M. B., DAVIET, L., SCHALK, M., TOUB, O., LUND, S. T. \& BOHLMANN, J. 2010. Functional Annotation, Genome Organization and Phylogeny of the Grapevine (Vitis vinifera) Terpene Synthase Gene Family Based on Genome Assembly, FLcDNA Cloning, and Enzyme Assays. BMC Plant Biology, $10,226$.

NIEUWENHUIZEN, N. J., GREEN, S. A., CHEN, X., BAILlEUL, E. J. D., MATICH, A. J., WANG, M. Y. \& ATKINSON, R. G. 2013. Functional Genomics Reveals That a Compact Terpene Synthase Gene Family Can Account for Terpene Volatile Production in Apple. Plant Physiology, 161, 787-804.

NÜTZMANN, H. W., HUANG, A. \& OSBOURN, A. 2016. Plant metabolic clusters - from genetics to genomics. New Phytologist, 211, 771-789.

NUTZMANN, H. W., HUANG, A. C. \& OSBOURN, A. 2016. Plant metabolic clusters - from genetics to genomics. New Phytologist, 211, 771-789.

PARKER, M. T., ZHONG, Y., DAI, X. \& WANG, S. 2014. Comparative genomic and transcriptomic analysis of terpene synthases in Arabidopsis and Medicago. Systems Biology let, 8, 146-153.

PETERS, R. J., RAVN, M. M., COATES, R. M. \& CROTEAU, R. B. 2001. Bifunctional abietadiene synthase: free diffusive transfer of the (+)-copalyl diphosphate intermediate between two distinct active sites. Journal of the American Chemical Society, 123, 8974-8.

PICHERSKY, E. \& GANG, D. R. 2000. Genetics and biochemistry of secondary metabolites in plants: an evolutionary perspective. Trends in Plant Science, 5, 439-445.

PRASIFKA, J. R., SPRING, O., CONRAD, J., COOK, L. W., PALMQUIST, D. E. \& FOLEY, M. E. 2015. Sesquiterpene Lactone Composition of Wild and Cultivated Sunflowers and Biological Activity against an Insect Pest. Journal of Agricultural \& Food Chemistry, 63, 4042-9.

PRISIC, S., XU, M. M., WILDERMAN, P. R. \& PETERS, R. J. 2004. Rice contains two disparate ent-copalyl diphosphate synthases with distinct metabolic functions. Plant Physiology, 136, 4228-4236.

RALSTON, L., KWON, S. T., SCHOENBECK, M., RALSTON, J., SCHENK, D. J., COATES, R. M. \& CHAPPELL, J. 2001. Cloning, Heterologous Expression, and Functional Characterization of 5-epi-Aristolochene-1,3-Dihydroxylase from Tobacco (Nicotiana tabacum). Archives of Biochemistry and Biophysics, 393, 222-235.

REHRIG, E. M., APPEL, H. M., JONES, A. D. \& SCHULTZ, J. C. 2014. Roles for jasmonate- and ethylene-induced transcription factors in the ability of Arabidopsis to respond differentially to damage caused by two insect herbivores. Frontiers in Plant Science, $5,14$. 
RICHTER, A., SCHAFF, C., ZHANG, Z., LIPKA, A. E., TIAN, F., KÖLLNER, T. G., SCHNEE, C., PREIß, S., IRMISCH, S., JANDER, G., BOLAND, W., GERSHENZON, J., BUCKLER, E. S. \& DEGENHARDT, J. 2016. Characterization of Biosynthetic Pathways for the Production of the Volatile Homoterpenes DMNT and TMTT in Zea mays. The Plant Cell, 28, 2651-2665.

SCHNEE, C., KÖLLNER, T. G., HELD, M., TURLINGS, T. C. J., GERSHENZON, J. \& DEGENHARDT, J. 2006. The products of a single maize sesquiterpene synthase form a volatile defense signal that attracts natural enemies of maize herbivores. Proceedings of the National Academy of Sciences of the United States of America, 103, 1129-1134.

SCHNEIDER, L. M., ADAMSKI, N. M., CHRISTENSEN, C. E., STUART, D. B., VAUTRIN, S., HANSSON, M., UAUY, C. \& WETTSTEINKNOWLES, P. V. 2016. The Cer-cqu gene cluster determines three key players in a $\beta$-diketone synthase polyketide pathway synthesizing aliphatics in epicuticular waxes. Journal of Experimental Botany, 67, 2715.

SHANG, Y., MA, Y. S., ZHOU, Y., ZHANG, H. M., DUAN, L. X., CHEN, H. M., ZENG, J. G., ZHOU, Q., WANG, S. H., GU, W. J., LIU, M., REN, J. W., GU, X. F., ZHANG, S. P., WANG, Y., YASUKAWA, K., BOUWMEESTER, H. J., QI, X. Q., ZHANG, Z. H., LUCAS, W. J. \& HUANG, S. W. 2014. Biosynthesis, regulation, and domestication of bitterness in cucumber. Science, 346, 1084-1088.

SHANNON, P., MARKIEL, A., OZIER, O., BALIGA, N. S., WANG, J. T., RAMAGE, D., AMIN, N., SCHWIKOWSKI, B. \& IDEKER, T. 2003. Cytoscape: A Software Environment for Integrated Models of Biomolecular Interaction Networks. Genome Res, 13, 2498-504.

SINGH, B. \& SHARMA, R. A. 2015. Plant terpenes: defense responses, phylogenetic analysis, regulation and clinical applications. Biotech, 5, 129-151.

SNOEREN, T. A. L., KAPPERS, I. F., COLETTE, B., ROLAND, M., MARCEL, D. \& BOUWMEESTER, H. J. 2010. Natural variation in herbivore-induced volatiles inArabidopsis thaliana. Journal of Experimental Botany, 61, 3041-3056.

TAKAHASHI, S. \& KOYAMA, T. 2006. Structure and function of cis-prenyl chain elongating enzymes. Chemical Record, 6, 194-205.

TAKOS, A. M. \& ROOK, F. 2012. Why biosynthetic genes for chemical defense compounds cluster. Trends in Plant Science, 17, 383.

TAMURA, K., DUDLEY, J., NEI, M. \& KUMAR, S. 2007. MEGA4: Molecular Evolutionary Genetics Analysis (MEGA) software version 4.0. Molecular biology and evolution, 24, 1596.

THOLL, D. \& LEE, S. 2011. Terpene Specialized Metabolism in Arabidopsis thaliana. The Arabidopsis Book / American Society of Plant Biologists, 9, e0143.

TIKUNOV, Y. M., LAPTENOK, S., HALL, R. D., BOVY, A. \& DE VOS, R. C. H. 2012. MSClust: a tool for unsupervised mass spectra extraction of chromatography-mass spectrometry ion-wise aligned data. Metabolomics, 8, 714-718.

TRAPP, S. C. \& CROTEAU, R. B. 2001. Genomic Organization of Plant Terpene Synthases and Molecular Evolutionary Implications. Genetics, 158, 811.

TROSHIN, P. V., PROCTER, J. B. \& BARTON, G. J. 2011. Java bioinformatics analysis web services for multiple sequence alignment-JABAWS:MSA. Bioinformatics (Oxford, England), 27, 2001-2.

VAN DUYNHOVEN, J., VAN DER HOOFT, J. J. J., VAN DORSTEN, F. A., PETERS, S., FOLTZ, M., 
GOMEZ-ROLDAN, V., VERVOORT, J., DE VOS, R. C. H. \& JACOBS, D. M. 2014. Rapid and Sustained Systemic Circulation of Conjugated Gut Microbial Catabolites after Single-Dose Black Tea Extract Consumption. Journal of Proteome Research, 13, 2668-2678.

VERMA, V., RAVINDRAN, P. \& KUMAR, P. P. 2016. Plant hormone-mediated regulation of stress responses. Bmc Plant Biology, 16, 86.

WANG, K. C. \& OHNUMA, S. 2000. Isoprenyl diphosphate synthases. Biochimica et biophysica acta, 1529, 33.

WHITEHEAD, I. M., THRELFALL, D. R. \& EWING, D. F. 1989. 5-epi-aristolochene is a common precursor of the sesquiterpenoid phytoalexins capsidiol and debneyol. Phytochemistry, 28, 775-779.

XU, M., GALHANO, R., WIEMANN, P., BUENO, E., TIERNAN, M., WU, W., CHUNG, I. M., GERSHENZON, J., TUDZYNSKI, B. \& SESMA, A. 2012. Genetic evidence for natural product-mediated plant-plant allelopathy in rice (Oryza sativa). New Phytologist, 193, 570-575.

XU, M. M., WILDERMAN, P. R., MORRONE, D., XU, J. J., ROY, A., MARGIS-PINHEIRO, M., UPADHYAYA, N. M., COATES, R. M. \& PETERS, R. J. 2007. Functional characterization of the rice kaurene synthase-like gene family. Phytochemistry, 68, 312-326.

YANG, G., HONZATKO, R. B. \& PETERS, R. J. 2012. Terpenoid synthase structures: a so far incomplete view of complex catalysis. Natural Product Reports, 29, 1153-1175.

YEAMAN, S. \& WHITLOCK, M. C. 2011. The genetic architecture of adaptation under migration-selection balance. Evolution; international journal of organic evolution, 65, 1897-911.

ZAVALAPÁRAMO, G., CHÁVEZMOCTEZUMA, M. P., GARCÍAPINEDA, E., YIN, S., CHAPPELL, J. \& LOZOYAGLORIA, E. 2000. Isolation of an elicitor-stimulated 5-epi-aristolochene synthase gene (gPEAS1) from chili pepper (Capsicum annuum). Physiologia Plantarum, 110, 410-418.

ZHANG, P. J., ZHENG, S. J., VAN LOON, J. J. A., BOLAND, W., DAVID, A., MUMM, R. \& DICKE, M. 2009. Whiteflies interfere with indirect plant defense against spider mites in Lima bean. Proceedings of the National Academy of Sciences of the United States of America, 106, 21202-21207.

\section{Supplemental Tables/Figures/Datasets}

\section{Supplemental files to this chapter can be downloaded from:}

<http://www.wageningenseedlab.nl/thesis/yuanyuanzhang/>http://www.wageningenseedlab.nl/thesis/yuanyuanzhang/

<http://www.wageningenseedlab.nl/thesis/yuanyuanzhang/Sl/>http://www.wageningenseedlab.nl/thesis/yuanyuanzhang/SI/

Supplemental Data 1. Sequences of TPS proteins from Capsicum annuum and other 13 plant species including A. grandis (Ag), P. glauca $(\mathrm{Pg})$, M. piperita $(\mathrm{Mp})$, M. longifolia $(\mathrm{Ml})$, S. Iycopersicum (SI), A. thaliana (At), M. truncatula (Mt), V. vinifera (Vv), C. breweri (Cb), C. sublyratus copalyl (Cs), C. sativus (Cs), C. maxima (Cm), S. habrochaites (Sh). 
Supplementary Data 2. Primer sequences and annealing temperatures for amplification of TPS genes from Capsicum annuum cDNA

Supplemental Data 3. List of 103 TPS loci in the Capsicum genome

Supplemental Data 4. Gene transcript levels of 44 expressed TPS genes, upstream genes and triterpene synthase genes in Capsicum annuum leaves of non-treated plants, infested with spider mites for 3 days or JA sprayed for 6 hours/24 hours in two genotypes.

Supplemental Data 5. Gene pairs of expressed functional TPS genes and co-expressed genes with correlation coeffiency $>0.9$ or $<-0.9$

Supplemental Table 1. Signal peptides predictio 


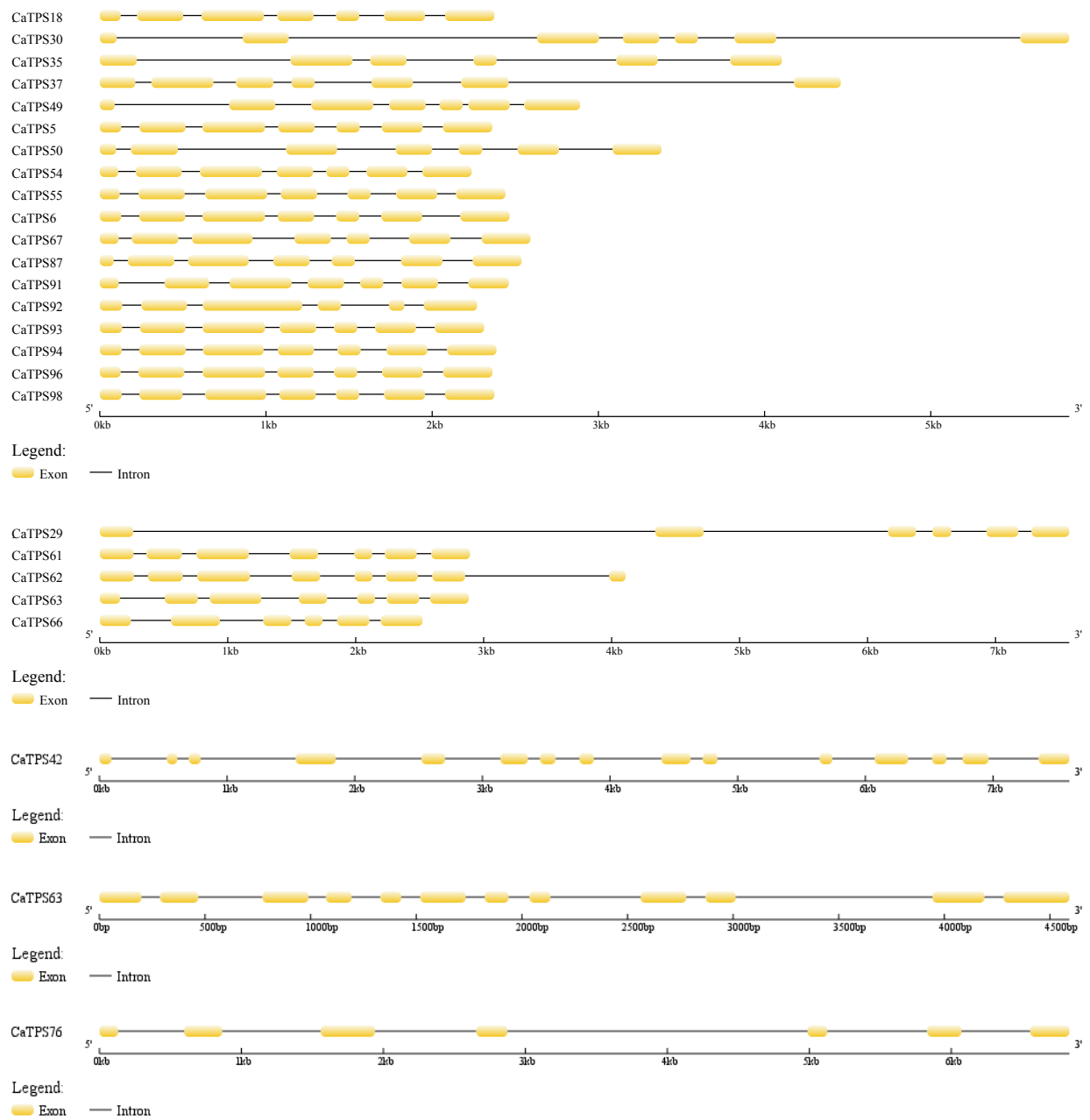

Supplemental Figure 1. Intron-exon structures of CATPS genes in different subfamilies. Yellow boxes and gray lines represent exons and introns, respectively 


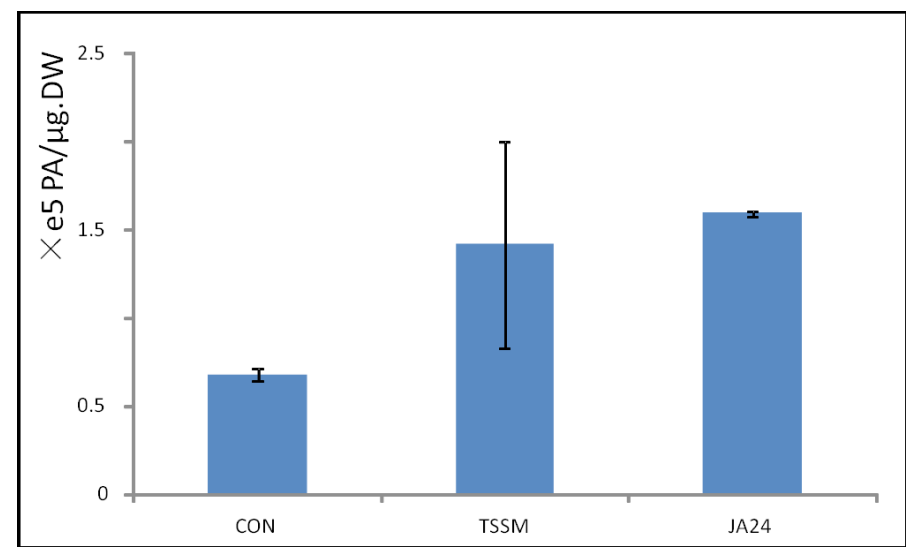

Supplemental Figure 2. Capsidiol-like compound (C15H24O2, Molar mass $236.35 \mathrm{~g} / \mathrm{mol}$ ) induced upon spider-mite infestation (TSSM) and JA treatment for 24 hours (JA24). RT=27 $\min$. 


\title{
General discussion
}

\author{
Yuanyuan Zhang
}


The interaction between plants and arthropod herbivores is a highly complex and dynamic process. Herbivores use various strategies to feed on host plants and plants have evolved a range of different defense strategies to protect themselves during millions of years of coevolution (Howe and Jander, 2008). However, most studies on plant-herbivore interactions are done in a limited number of model species, including e.g. Arabidopsis, Nicotiana spp., maize and tomato. Far less is known on other crop species that are of importance for feeding the world population, such as Capsicum spp. Capsicum has a long history of cultivation and represents a large economic value. However, damage by herbivorous arthropods is one of the biggest threats reducing Capsicum fruit production and thus enhancing resistance to herbivores is important. Classical breeding usually uses a bottom up strategy to introduce and maintain desired traits which makes it have limited power in improving defensive traits, because these are usually controlled by multiple genes that can easily be separated during genetic recombination. In addition, it does not help that the mechanisms underlying defense strategies are often not known. To reveal some of these mechanisms of plant defense and further facilitate resistance breeding approaches, in my thesis I applied several -omics as well as targeted approaches to explore the genetic diversity (Chapter 2 ), dynamic regulation (Chapter 3 ) and detailed molecular processes (Chapter 4) underlying the response of Capsicum to biotic stresses (JA and spider mites). In addition, because of the importance of terpenoids in plant direct and indirect defense, the terpene synthase gene family in Capsicum (CaTPS) was studied using a genome-wide approach and multiple family members were functionally characterized (Chapter 5). In this General discussion, I will discuss the obtained findings and how they can assist Capsicum resistance breeding programs.

\section{Secondary metabolites drive differences in defense in plants}

Due to gene/genome duplication and recombination and evolution under environmental and breeding selection pressure, natural variation arose, providing polymorphisms for multiple plant physiological and genetic aspects. A variety of secondary metabolites is known to have a critical role in plant defense (Bennett and Wallsgrove, 1994, Kliebenstein, 2012). Considering the importance of metabolites in interactions with other organisms such as herbivores and microbes, elucidating the metabolites underlying defense traits is crucial in terms of plant ecology and breeding. Correspondingly, the interaction of plants with herbivores is an important selection pressure to shape plant metabolism. Genetic variation within a certain species provides good resources for targeted and untargeted metabolite profiling in relation with herbivory defenses (Matsuda et al., 2015, Luo, 2015). Both 
direct defense and indirect defense are affected by quantity and quality of those metabolites. For example, tallow tree Triadica sebifera genotypes that showed variation in their response to caterpillars, Grammodes geometrica, Cnidocampa flavescens and Gadirtha inexacta also showed variation in the concentration of selected flavonoids and tannins (Wang et al., 2012). Both qualitative and quantitative variation in glucosinolates influenced plant-insect interaction in Arabidopsis ecotypes (Kliebenstein et al., 2001).

To build the first connection between Capsicum leaf secondary metabolites and defensive traits, I measured both the endogenous and volatile metabolome of 22 Capsicum genotypes in response to spider mites and JA, respectively, as well as the corresponding relative level of direct defense to spider mites and attractiveness towards predatory mites. I found variation in the metabolomes as well as in the defensive traits that I analyzed (Chapter 2). The defense level to spider mites (and herbivores in general) is the outcome of multiple morphological and biochemical traits. Trichomes, which may function as a hindering physical deterrent (Tian et al., 2012) and toxic proteins which may kill the herbivores, were not in the scope of the analyses that I did, but may also play an important role affecting spider mite survival and oviposition. For example, in the genotype collection of this thesis, all three included pubescens and a few chinense genotypes have a distinct volatile blend compared to other genotypes which can be directly related to the presence of typical glandular trichomes. In particular, genotype 33 (Chapter 2) has a high density of trichomes, which may repel spider mites due to physical hindering of spider mite movement and/or as consequence of the deterrent volatiles. In this thesis, I did not further explore the direct defense effects of trichomes (nor of potential toxic proteins), but focused on defense variation that correlated with endogenous and volatile metabolites in leaves. Multivariate analysis suggested that the induced Capsicum leaf metabolome profiles cannot fully explain the level of direct defense nor that of indirect defense. This can possibly be explained by other factors, such as trichomes and proteins, as discussed above, or by the variation in the constitutive metabolome of the genotypes (Chapter 2). For a more in-depth analysis of the relation between metabolites and spider mite resistance and susceptibility, it might be good to focus on for example $C$. annuum genotypes only (and exclude other Capsicum spp.). Nevertheless, several metabolites were identified as defense related including triterpenoid saponins, flavonoids, alkaloids and lignans (Chapter 2). Tocopherol and an unknown phytosterol were reported to be correlated with resistance to thrips (Frankliniella occidentalis) in Capsicum spp., while some alkanes were correlated with susceptibility to thrips (Maharijaya et al., 2012). In my study, instead of alkanes, I identified several other metabolites possibly related to susceptibility in- 
cluding depsipeptides, triterpene glycosides, a withanolide-type steroid and several saponins that all accumulated as spider mite infestation developed and positively correlated with spider mite offspring. Consistent with these accumulated metabolites, transcriptome analysis (Chapter 4 ) revealed that spider mites induced genes enriched in 'secondary metabolic process'. On the other hand, multiple flavonoid and terpene biosynthetic genes were stronger induced in the genotype that was relatively more resistant to spider mites. The flavonoid rutin and chlorogenic acid were found to be defensive to spider mites in tomato (Hoffland et al., 2000). Carmine spider mite (Tetranychus cinnabarinus) infestation in cotton seedlings upregulated the expression of defensive genes encoding phenylalanine ammonia-lyase (PAL), peroxidase (POD), lipoxygenase (LOX), and polyphenol oxidase (PPO) and increased the contents of gossypol and condensed tannin, resulting in enhanced resistance to cotton aphids (Aphis gossypii) (Ma et al., 2018).

\section{The dynamics of plant defense}

Plant defense is regulated in a temporal and spatially dynamic way (Gatehouse, 2002, Herrmann et al., 2012). During the defense response a series of different processes occur after signal perception and transduction, including regulation of gene expression and production of toxic proteins and compounds, which mostly rely on changes in phytohormones and their balance (Furstenberg-Hagg et al., 2013). The timing of these processes in terms of hormone balance and subsequent adaptation of the metabolome varies considerably according to the species involved in the plant-herbivore interaction and affects behavior of both herbivores as well as their natural enemies (Sun et al., 2015, Kant et al., 2004). In many studies, in which the metabolome is studied with respect to a certain plant-herbivore interaction only a single or just a few time points are included, thus ignoring the temporal dynamics of the metabolome adaptation in response to the specific herbivore. In this thesis, I showed that volatile and non-volatile metabolomes adapt with progressing infestation and that this has consequences for e.g. the attractiveness to predatory mites depending on the duration of the infestation.

In chapter 3, I observed metabolome changes as result of spider-mite infestation in time in two genotypes, that differed in their relative spider-mite resistance (selection based on the results described in Chapter 2). In the relative resistant genotype more green leaf volatiles were detected in the volatile blend in the early time points of infestation. These findings are consistent with volatile emission from maize (Zea mays) in response to caterpillars Spodoptera littoralis (Turlings et al., 1998) in which green leaf volatiles were emitted immediately after feeding started while sesquiterpenoids were re- 
leased after 4 hours. And with the response of maize to aphids (Tzin et al., 2015). The latter authors showed that most transcriptional and metabolic changes occurred in the first few hours after infestation and reverted to being more similar to control plants after 4 days of infestation. Defense related metabolites identified in Capsicum in my thesis include alkaloids, flavonoids and a range of (glycosylated) terpenoids, including volatile mono- and sesquiterpenes and non-volatile di- and triterpenoids. On the other hand, a decrease of several carotenoids and diterpenes was detected in multiple time points.

The concentrations of JA and JA-lle responded to spider mites within 3 hours after infestation (Chapter 3 ). SA accumulated with progressing time of presence of spider mites and reached the highest abundance in the late stages of observation. It suggests that JA provides the first signal of herbivore infestation to the plants and subsequently was repressed as SA accumulated. Multiple secondary metabolites showed alterations in their abundance corresponding with the increment in JA and JA-lle, suggesting the involvement of the JA pathway in secondary metabolite production. In addition, multiple $\mathrm{JA}$ biosynthetic and responsive genes were found to be regulated upon spider mite infestation. JA transiently accumulated in response to treatment with a fungal elicitor and triggered the biosynthesis of secondary defensive compounds including flavonoids, sesquiterpene lactones and various classes of alkaloids as well as the upregulation of the defense related enzyme, phenylalanine ammonia lyase (PAL) in cell suspensions of 36 different plant species (Gundlach et al., 1992).

In the susceptible genotype, there is an obvious trend that JA decreased as SA kept accumulating. This suppression of JA could explain the susceptibility of this genotype. Indeed, in a subsequent analysis, the induction of JA in the resistant genotype upon spider-mite infestation was almost 5-fold higher than in the susceptible genotype (Chapter 4). Furthermore, application of JA resulted in induction of genes with function in secondary metabolite biosynthesis including terpenoids and flavonoids and resulted in higher production of corresponding volatile and non-volatile secondary metabolites. Hence, JA plays an important role in the onset of induced defenses and the longer it takes before JA signaling is repressed (by SA), the higher the chance that the plant is successfully defended. The balance between JA and SA appears to be a decisive factor in determining the outcome of the Capsicum-spider mite interaction. 


\section{JA regulates secondary metabolite production}

Many studies show a key role for JA in regulating plant inducible defenses against herbivores mainly including modulating the production of secondary metabolites (Campos et al., 2014, Wasternack, 2015, Hickman et al., 2017). These induced metabolites include nicotine, vinblastine, artemisinin, glucosinolates, anthocyanin, and benzylisoquinoline alkaloids as reviewed by (De et al., 2012, Memelink et al., 2010, Wasternack and Hause, 2013). As previously discussed, JA may regulate the production of volatile and endogenous metabolites, with temporal dynamics. In a time series analysis, the increased volatile production was consistent with JA accumulation (Chapter 3 ) and especially, JA induced expression of TPS genes and enhanced production of terpenoids (Chapter 5). To further reveal the function of JA in regulating secondary metabolism, we conducted combined transcriptome and metabolome analysis on two genotypes of Capsicum plants induced by JA (Chapter 4). JA upregulated the expression of genes involved in biosynthesis of terpenoids, phenylpropanoids and flavonoids and this resulted in increased production of these metabolites.

The mechanism of how JA affects induced secondary metabolite biosynthesis is the focus of many studies. A key player is $M Y C 2$, which has been shown to be involved in the regulation of the biosynthesis of nicotine, phenolamides and many other metabolites in $N$. attenuata and enhance the plant resistance against non-adapted herbivores (Woldemariam et al., 2013). Furthermore, myc234 mutants in Arabidopsis became more susceptible to the specialist Pieris brassicae because they became devoid of glucosinolates. Targeted analysis on carrot (Daucus carota) suggested that reactive oxygen species (ROS) play a key role in regulating primary and secondary metabolism, especially of phenolics, and JA was shown to modulate ROS levels in cooperation with ET (Jacobo-Velázquez et al., 2015). The JA-responsive bHLH transcription factors, MYC2 and BIS1/BIS, mediated the monoterpenoid indole alkaloid biosynthesis in Catharanthus roseus (Patra et al., 2017) while an earlier study proved that an octadecanoid-derivative responsive $C$. roseus AP2-domain transcription factor, ORCA2 plays a key role in JA- and elicitor-responsive expression of the terpenoid indole alkaloid biosynthetic gene Strictosidine synthase (Menke et al., 1999).

According to the transcriptome data generated in my thesis, JA induced the expression of a Capsicum MYC2 homologue. CaMYC2 coexpressed with multiple arginine biosynthetic genes, which will lead to the production of pyridine alkaloids (Wiedenfeld, 2013), as well as with genes involved in the isopentenyl diphosphate biosynthetic pathway (MEP pathway) responsible for the generation of substrate for amongst others mono- and diterpene 
biosynthesis. JA induced the terpene synthase CaTPS98 which coexpressed with a putative ERF transcription factor and CYP71 gene. The putative oxidized product of CaTPS98, a capsidiol-like compound, was found induced upon spider mites and JA. The ERF2 homologue also positively correlated with a putative caffeoyl-CoA 3-O-methyltransferase encoding gene which in Arabidopsis is associated with phenylpropanoid and lignin production (Yang et al., 2017). Indeed, I found an upregulation of phenylpropanoids and flavonoids upon spider mite/JA treatment. To further underpin these connections, and the role of JA in the regulation of secondary metabolite biosynthesis in Capsicum, further work, for example with mutants, is needed.

\section{JA/SA crosstalk}

In the time series study, JA and JAlle were significantly reduced while SA accumulated as the time of infestation progressed, in a susceptible genotype (Chapter 3). Spider mites induced genes involved in both JA and SA signalling pathways. The induced JA responses were partially repressed by spider-mite induced SA including those of multiple secondary metabolites biosynthetic genes. Compared to the extensive number of genes involved in terpenoid, phenylpropanoid and flavonoid biosynthesis induced by exogenous application of JA, spider-mites induced only a limited number of terpenoid and phenylpropanoid pathway genes. Furthermore, no genes involved in flavonoid biosynthesis were significantly induced by spider mites (Chapter 4). Due to the distinct transcriptome and metabolome profiles induced by JA and spider mites, I propose that there is an antagonism between JA and SA which affects the defensive responses against spider mites in Capsicum, especially in the later stages of infestation.

Interestingly, cis-OPDA levels exhibited a similar pattern as SA, and both these compounds positively correlated with infestation level. This suggests that spider mites did not inhibit the entire JA biosynthetic pathway (cis-OPDA was still produced) but only the production of JA and JA-Ile. According to the transcriptome data, spider mite infestation induced the expression of MYC2 repressor JAZ protein encoding gene TIFY1OB, which likely repressed the JA responsive transcriptional factor $M Y C 2$. In Arabidopsis, SA was suggested to affect JA responsive genes by inducing degradation of the APETALA2/ETHYLENE RESPONSE FACTOR (AP2/ERF) transcription factor, ORA59 (Van der Does et al., 2013). However, a Pieris brassicae egg extract induced SA/JA antagonism independently of ORA59 but also strongly diminished MYC protein levels in an SA-dependent manner (Schmiesing et al., 2016). Both studies suggest that neither the expression nor stability of MYC2 repressor JAZ were affected by SA. 
Not only SA repressed JA responses. JA significantly repressed the expression of a gene with homology to Arabidopsis WRKY7O which was induced by spider mite infestation. Consisted with a study in Arabidopsis, WRKY70 works as an activator of SA inducible genes repressed by JA but also repressing JA responsive genes (Li et al., 2004). Besides, JA may repress SA biosynthesis by inducing the production of flavonoids which share the common upstream biosynthetic phenylpropanoid pathway.

\section{Future perspectives}

For a long breeding history, the selection of cultivated crops tends to maintain traits like high yield and good taste. Plant resistance has been unintentionally neglected during domestication resulting in modern varieties with high yields but with poor defensibility compared to their wild ancestors. Studies on plant resistance mechanisms to herbivores help to identify defense related genes and metabolites and provide the basis for further studies that will help to reduce yield losses using e.g. molecular approaches. Studies on metabolic defense in plants may also facilitate biological control strategies using natural enemies. In this thesis I employed untargeted metabolome analysis using multiple platforms. Metabolome analysis provides comprehensive and direct insight into complex plant traits mediated by multiple metabolites, such as direct defense and indirect defense. However, metabolites are highly plant specific and often difficult to identify and the further development of plant-specific metabolite databases will be required to fully exploit these defense mechanisms. Even though the integration of metabolome and transcriptome data provided hints of how these primary/ secondary metabolite processes are regulated at the gene expression level, it is still difficult to fill in all the details of all the pathways involved. Thus, targeted analysis will still be necessary to improve the accuracy. In addition to the possible defense related metabolites I showed that JA/SA antagonism plays an important role in the interaction of Capsicum with spider mites. Since Capsicum is a non-model species, it is not straight-forward to validate our findings. The development of VIGS and/or CRISPR-CAS in Capsicum would be of great value to create specific mutants. Nevertheless, my work has resulted in several leads that should be followed up and can in the future potentially be used to improve spider mite control in Capsicum. 


\section{References}

BENNETT, R. N. \& WALLSGROVE, R. M. 1994. SECONDARY METABOLITES IN PLANT DEFENSE-MECHANISMS. New Phytologist, 127, 617-633.

CAMPOS, M. L., KANG, J. H. \& HOWE, G. A. 2014. Jasmonate-Triggered Plant Immunity. Journal of Chemical Ecology, 40, 657-675.

DE, G. N., GHOLAMI, A., GOORMACHTIG, S. \& GOOSSENS, A. 2012. Transcriptional machineries in jasmonate-elicited plant secondary metabolism. Trends in Plant Science, 17, 349-359.

FURSTENBERG-HAGG, J., ZAGROBELNY, M. \& BAK, S. 2013. Plant defense against insect herbivores. Int J Mol Sci, 14, 10242-97.

GATEHOUSE, J. A. 2002. Plant resistance towards insect herbivores: a dynamic interaction, LEA.

GUNDLACH, H., MULLER, M. J., KUTCHAN, T. M. \& ZENK, M. H. 1992. JASMONIC ACID IS A SIGNAL TRANSDUCER IN ELICITOR-INDUCED PLANT-CELL CULTURES. Proceedings of the National Academy of Sciences of the United States of America, 89, 23892393.

HERRMANN, I., BERENSTEIN, M., SADE, A., KARNIELI, A., BONFIL, D. J. \& WEINTRAUB, P. G. 2012. Spectral monitoring of two-spotted spider mite damage to pepper leaves. Remote Sensing Letters, 3, 277-283.

HICKMAN, R., VAN VERK, M. C., VAN DIJKEN, A. J. H., MENDES, M. P., VROEGOP-VOS, I. A., CAARLS, L., STEENBERGEN, M., VAN DER NAGEL, I., WESSELINK, G. J., JIRONKIN, A., TALBOT, A., RHODES, J., DE VRIES, M., SCHUURINK, R. C., DENBY, K., PIETERSE, C. M. J. \& WEES, S. C. M. 2017. Architecture and Dynamics of the Jasmonic Acid Gene Regulatory Network. Plant Cell, 29, 2086-2105.

HOFFLAND, E., DICKE, M., VAN TINTELEN, W., DIJKMAN, H. \& VAN BEUSICHEM, M. L. 2000. Nitrogen availability and defense of tomato against two-spotted spider mite. Journal of Chemical Ecology, 26, 2697-2711.

HOWE, G. A. \& JANDER, G. 2008. Plant immunity to insect herbivores. Annual Review of Plant Biology, 59, 41-66.

JACOBO-VELÁZQUEZ, D. A., GONZÁLEZ-AGÜERO, M. \& CISNEROS-ZEVALLOS, L. 2015. Crosstalk between signaling pathways: The link between plant secondary metabolite production and wounding stress response. Scientific Reports, 5, 8608.

KANT, M. R., AMENT, K., SABELIS, M. W., HARING, M. A. \& SCHUURINK, R. C. 2004. Differential timing of spider mite-induced direct and indirect defenses in tomato plants. Plant Physiology, 135, 483.

KLIEBENSTEIN, D. J. 2012. Plant Defense Compounds: Systems Approaches to Metabolic Analysis. In: VANALFEN, N. K., LEACH, J. E. \& LINDOW, S. (eds.) Annual Review of Phytopathology, Vol 50. Palo Alto: Annual Reviews.

KLIEBENSTEIN, D. J., KROYMANN, J., BROWN, P., FIGUTH, A., PEDERSEN, D., GERSHENZON, J. \& MITCHELL-OLDS, T. 2001. Genetic Control of Natural Variation in Arabidopsis Glucosinolate Accumulation. Plant Physiology, 126, 811-825.

LI, J., BRADER, G. \& PALVA, E. T. 2004. The WRKY70 Transcription Factor: A Node of Convergence for Jasmonate-Mediated and Salicylate-Mediated Signals in Plant Defense. Plant Cell, 16, 319. 
LUO, J. 2015. Metabolite-based genome-wide association studies in plants. Current Opinion in Plant Biology, 24, 31-38.

MA, G. M., SHI, X. Y., KANG, Z. J. \& GAO, X. W. 2018. The influence of Tetranychus cinnabarinus-induced plant defense responses on Aphis gossypii development. Journal of Integrative Agriculture, 17, 164-172.

MAHARIJAYA, A., VOSMAN, B., VERSTAPPEN, F., STEENHUIS-BROERS, G., MUMM, R., PURWITO, A., VISSER, R. G. F. \& VOORRIPS, R. E. 2012. Resistance factors in pepper inhibit larval development of thrips (Frankliniella occidentalis). Entomologia Experimentalis Et Applicata, 145, 62-71.

MATSUDA, F., NAKABAYASHI, R., YANG, Z. G., OKAZAKI, Y., YONEMARU, J., EBANA, K., YANO, M. \& SAITO, K. 2015. Metabolome-genome-wide association study dissects genetic architecture for generating natural variation in rice secondary metabolism. Plant Journal, 81, 13-23.

MEMELINK, J., HAUSE, B., WASTERNACK, C. \& STRACK, D. 2010. Regulation of gene expression by jasmonate hormones. Phytochemistry, 41, no-no.

MENKE, F. L. H., CHAMPION, A., KIJNE, J. W. \& MEMELINK, J. 1999. A novel jasmonate- and elicitor-responsive element in the periwinkle secondary metabolite biosynthetic gene Str interacts with a jasmonate- and elicitor-inducible AP2-domain transcription factor, ORCA2. Embo Journal, 18, 4455-4463.

PATRA, B., PATTANAIK, S., SCHLUTTENHOFER, C. \& YUAN, L. 2017. A network of jasmonate-responsive bHLH factors modulate monoterpenoid indole alkaloid biosynthesis in Catharanthus roseus. New Phytologist.

SCHMIESING, A., EMONET, A., GOUHIER-DARIMONT, C. \& REYMOND, P. 2016. Arabidopsis MYC Transcription Factors Are the Target of Hormonal Salicylic Acid/Jasmonic Acid Cross Talk in Response to Pieris brassicae Egg Extract. Plant Physiology, 170, 24322443.

SUN, G. Q., WANG, S. L., REN, Q., JIN, Z. \& WU, Y. P. 2015. Effects of time delay and space on herbivore dynamics: linking inducible defenses of plants to herbivore outbreak. Scientific Reports, 5, 11246.

TIAN, D., TOOKER, J., PEIFFER, M., CHUNG, S. H. \& FELTON, G. W. 2012. Role of trichomes in defense against herbivores: comparison of herbivore response to woolly and hairless trichome mutants in tomato (Solanum lycopersicum). Planta, 236, 1053-1066.

TURLINGS, T. C. J., LENGWILER, U. B., BERNASCONI, M. L. \& WECHSLER, D. 1998. Timing of induced volatile emissions in maize seedlings. Planta, 207, 146-152.

TZIN, V., FERNANDEZPOZO, N., RICHTER, A., SCHMELZ, E. A., SCHOETTNER, M., SCHÄFER, M., AHERN, K. R., MEIHLS, L. N., KAUR, H. \& HUFFAKER, A. 2015. Dynamic Maize Responses to Aphid Feeding Are Revealed by a Time Series of Transcriptomic and Metabolomic Assays. Plant Physiology, 169, 1727-43.

VAN DER DOES, D., LEON-REYES, A., KOORNNEEF, A., VAN VERK, M. C., RODENBURG, N., PAUWELS, L., GOOSSENS, A., KORBES, A. P., MEMELINK, J., RITSEMA, T., VAN WEES, S. C. M. \& PIETERSE, C. M. J. 2013. Salicylic Acid Suppresses Jasmonic Acid Signaling Downstream of SCFCOI1-JAZ by Targeting GCC Promoter Motifs via Transcription Factor ORA59. Plant Cell, 25, 744-761.

WANG, Y., SIEMANN, E., WHEELER, G. S., ZHU, L., GU, X. \& DING, J. Q. 2012. Genetic variation in anti-herbivore chemical defences in an invasive plant. Journal of Ecology, 
100, 894-904.

WASTERNACK, C. 2015. How Jasmonates Earned their Laurels: Past and Present. Journal of Plant Growth Regulation, 34, 761-794.

WASTERNACK, C. \& HAUSE, B. 2013. Jasmonates: biosynthesis, perception, signal transduction and action in plant stress response, growth and development. An update to the 2007 review in Annals of Botany. Ann Bot, 111, 1021-1058.

WIEDENFELD, H. 2013. Alkaloids Derived From Ornithine: Pyrrolizidine Alkaloids, Springer Berlin Heidelberg.

WOLDEMARIAM, M. G., DINH, S. T., OH, Y., GAQUEREL, E., BALDWIN, I. T. \& GALIS, I. 2013. NaMYC2 transcription factor regulates a subset of plant defense responses in $\mathrm{Ni}$ cotiana attenuata. Bmc Plant Biology, 13, 14.

YANG, Q., HE, Y., KABAHUMA, M., CHAYA, T., KELLY, A., BORREGO, E., BIAN, Y., EL KASMI, F., YANG, L., TEIXEIRA, P., KOLKMAN, J., NELSON, R., KOLOMIETS, M., L DANGL, J., WISSER, R., CAPLAN, J., LI, X., LAUTER, N. \& BALINT-KURTI, P. 2017. A gene encoding maize caffeoyl-CoA O-methyltransferase confers quantitative resistance to multiple pathogens. Nature Genetics, 49, 1364. 
Summary 
Plants evolved multiple strategies to defend themselves against herbivores. Compared with constitutive defenses, such as trichomes and wax layers, inducible defenses provide a more cost-efficient and specific protection against different herbivores while both of them can protect plants directly and indirectly. In direct defense, the number of herbivores is reduced by for example toxic metabolites and proteins while in indirect defense, the help of natural enemies of the herbivores is solicited, for example by releasing volatile cues. Secondary metabolites mediate both direct and indirect defense. Phytohormones regulate the defense responses and fine-tune it, for example according to the species that is attacking the plant. In my thesis, I studied the molecular mechanisms of plant defense in Capsicum. I explored the natural variation and dynamic changes in metabolite-based direct and indirect defense against spider mites, analyzed the transcriptomic and metabolic changes upon JA and spider mite treatment and carried out a genome-wide characterization of the Capsicum terpene synthase family.

To explore the natural variation in direct and indirect defense in Capsicum and identify defense related metabolites, in Chapter $\mathbf{2}$ spider mite offspring and JA-induced attractiveness to predatory mites were compared among 19 Capsicum genotypes. In addition, the corresponding spider-mite induced endogenous metabolome and JA-induced volatile metabolome were analyzed. Defense related metabolites were identified by correlation analysis, stepwise regression and PLS-DA.

Upon herbivory, signal transduction mediated by MAPK and $\mathrm{Ca}^{2+}$ signaling, is followed by phytohormone signaling. These phytohormones induce metabolite biosynthesis as one of the downstream defense responses. These responses are dynamic and their timing affects the efficiency of the defense strategy. In Chapter 3, I used two genotypes that vary in their defense level to study the dynamic changes in the endogenous and volatile metabolome, and defense related phytohormones during the progression of spider mite infestation. Many metabolites significantly changed upon spider-mite infestation. JA and JAlle correlated strongly with each other and were induced early during infestation, after which they deceased again. Interestingly, also cis-OPDA and SA showed a strong correlation. They slowly continued to increase during the progression of infestation, corresponding with the spider mite number that also kept increasing during the 15 days of infestation.

In Chapter 4, comparative transcriptome and metabolome analysis were integrated to explain and compare the molecular mechanism underlying JA-induced and spider-mite induced responses in the resistant and susceptible genotypes also used in Chapter 3. Transcriptional changes upon JA induction suggested that JA mainly regulates secondary metabolome reprogramming 
including terpene, flavonoid and phenylpropanoid biosynthesis, while repressing photosynthesis. In contrast to JA, spider mites induced both JA and SA signaling, which resulted in the upregulation of SA inducible genes. There was some upregulation of secondary metabolite pathway genes, but much less than for JA. I suggest that the JA/SA crosstalk plays a key role in regulating defense responses in Capsicum to, but also by, spider mites.

Terpenes constitute a large portion of the plant metabolites that play a role in constitutive as well as induced, direct and indirect, defense. In Chapter 5, based on sequence similarity with characterized TPS genes from other plant species, I identified 103 C. annuum TPS genes, of which 27 encode for putative functional TPSs. These 27 CaTPS genes all belong to the angiosperm specific TPS subfamilies, with 18 and 5 members in the TPS- $a$ and $-b$ subfamilies, and one member each in the TPS- $c,-e,-f$ and $-g$ subfamilies. Transcriptomic data suggested that 7 expressed TPS-a family members positively correlate with isopentenyl diphosphate (IPP) isomerases, prenyltransferases (PTF) and mevalonate (MVA) pathway genes and most of them co-express with cytochrome P450s and the MVA pathway limiting enzyme encoding gene, HMGR2, while TPS-b subfamily members, that mostly encode monoterpene synthases, co-express with methylerithritol phosphate pathway (MEP) pathway genes. Multiple UDP-glycosyltransferases co-expressed with TPS- $a$, TPS- $b$ and TPS-e/f subfamily members. The TPSs and co-expressed genes tend to cluster within close distance on the same chromosome. For example, several TPS- $b$ members co-localized with an unknown MEP pathway gene, and a putative UDP-glucose flavonoid 3-O-glucosyltransferase and UDP-glycosyltransferase gene while several TPS- $a$ members co-localized with cytochrome P450s. Selected TPS genes which were induced by spider mites and/or JA were cloned and functionally characterized in vitro. Together these data shed light on the mechanism underlying the production of volatile and non-volatile terpenoids in response to spider mite infestation and JA in Capsicum.

Finally, the results from the different chapters are integrated in Chapter 6. I discuss the important role of variation in metabolism and dynamic changes in defense and the consequences for direct and indirect defense. I go into more detail on the mechanisms underlying JA regulated metabolic processes and the role of JA/SA crosstalk in this. 


\section{Acknowledgments}


First, Harro, thanks for taking me as your student. For many times, your clear logic and broad professional insight helped me get through bottle necks. I admire your efficient problem identifying and solving ability and benefit from it a lot. Your supervision and help cover the entire process of my PhD.

Iris, thanks for introducing me into the world of plant-insect interaction and plant metabolites. You have given me enough freedom in the research, but also make me being realistic to finish a PhD. You are the first person I turned to whenever I met problems at work during the last six years. Your patience and help contributed a lot!

Maarten, talking with you was a great pleasure! Thanks for making me to realize my problems and seeing things from a different angle, it was important to me!

Harro, Sander, Dick, Henk, Leónie, Wilco and Richard, PPH staff members, your contribution and guidance during PhD meeting and literature discussion created a helpful and secure scientific atmosphere in the group. As a student of PPH, I benefited a lot and would like to take this opportunity to say, thank you!

Ton, thanks for taking care of us in the last year of my PhD!

Dear colleagues in the lab, Francel, Jacqueline, Mariëlle and Leo, I am so grateful that you were there whenever I was in trouble in the lab. Thanks for all your help and patience! Jacqueline, as your neighbor in the office, I am affected by your positive attitude and warm heart!

Rina, I bothered you a lot with tickets, course fee, insurance, visa etc. Thanks for being there for us and together with the activity committee, organizing all those exciting activities every year! Margaret, thanks for helping us too!

Douwe, Ria and Susan, thanks for organizing courses and academic activities!

I would like to thank Robert, Desalegn, Fe, Carmen, Yury and Natalia (Carreno Quintero) for the generous help in metabolites analysis. I barely know any of you when I asked for help, thanks for not turning me down.

Manus, Karen, Feng (Zhu) and Leon, who are from Entomology (or half from Entomology), thank you for giving advises in insect behaviors and insect rearing.

Dear colleagues in PPH, Lidiya, Kristyna, Monica, Emilie, Bas, Juriaan, Johanna, Farzaneh, Cecilia, SangSeok, Esmer, Giovanni, Beatriz, Mahdere, Natalia (Moreno Pachon), Melissa, Arman, Mark, Umidjon, Gonda, Elise, Alexandre, Mariana, Nafiseh, Nikita and many others, I am so happy that we could cross the whole world and get together. With you, all those moments in PhD trip, lab outings, bowling nights, We days, BBQs, Christmas dinners become good memories that I will keep along. 
Dear Lillian, although we didn't find much overlap between your Brazilian passion and my Chinese shyness, we share feelings. We had a lot of fun and I will keep these good memories. Thanks for being such a good friend!

Being abroad is exciting! Being abroad to work on a (long-lasting) PhD is lonely and devastating sometimes. Thanks to my Chinese colleagues and friends, Qing, Ting, Jimmy, Yafen, Yanxia, Hui, Wei, Hanzi, Juwei, Xi, Bo, Jun, Bing, Zhen, Jianhua, Min, Guiling, Yunmeng, Yanting, Shuang, Tingting, $\mathrm{Xu}$, Huchen, Yujuan, Wenkun Zhou, Fengjiao, Tian, Jieyu, Zhichun Yan, Lulu, Yue, Juncai, Yin, Yiqian, Yongfu, Jiacui, Bilaoye and many more, I had great companies during all those Chinese festivals and many weekends. Glad to know you guys! Yunmeng, we fought together, hey, go, bro!

Dear Defeng, thanks for being in my life! Life before you, I was conflicting between the real me and the me facing the world. Since I met you, I become more honest to myself. You are smart, kind-hearted and optimistic. You are the best friend and a family to me.

My dear parents, sorry that I haven't been by your side since I left home twelve years ago. Thank you for bringing me up and being supportive no matter when and where. You are home I can always go back. 爱你们。 
About the author 


\section{Curriculum Vitae}

Yuanyuan Zhang was born on $20^{\text {th }}$ June, 1987 , in Heilongjiang, China. In 2010, She received a bachelor degree in Chemistry and a second bachelor degree in Business Administration in China Agricultural University (CAU), Beijing.

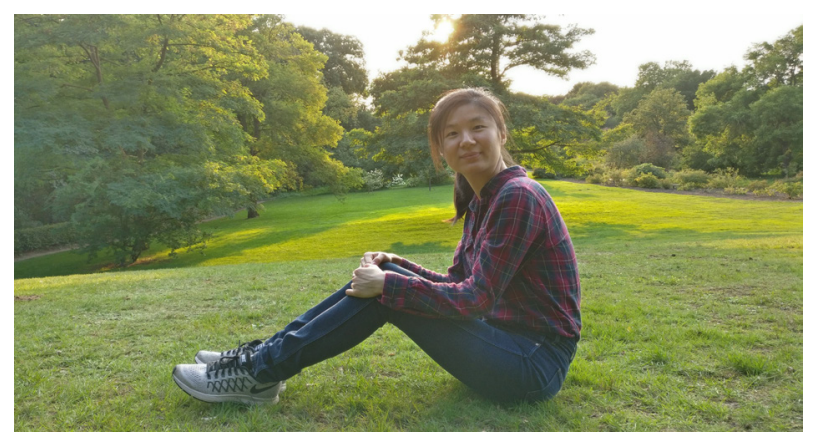
In 2012, she finished her

master study in genetic engineering and insect resistance in poplar and received the master degree in Plant Protection (Pesticide Science) under the supervision of Prof. Yuxia Hou in CAU. In the same year, with the financial support of a China Scholarship Council fellowship, she started her PhD project focusing on plant-herbivore interaction in Capsicum under the supervision of Prof. Harro Bouwmeester and Dr. Iris Kappers, in the Laboratory of Plant Physiology, Wageningen University, The Netherlands. 


\section{Publications:}

Yuanyuan Zhang, Jan van Haarst, Harro Bouwmeester \& Iris Kappers. Combined transcriptome and metabolome analysis reveals induction and suppression of defense responses by JA and two-spotted spider mite herbivory in Capsicum annuum. In prep.

Yuanyuan Zhang, Arman Beyraghdar Kashkooli, Suze Blom, Harro J. Bouwmeester \& Iris F. Kappers. Genome-wide identification of the TPS gene family in Capsicum annuum and its role in the response to biotic stresses. In prep.

Yuanyuan Zhang, Lidiya Sergeeva, Francel W. A. Verstappen, Harro J. Bouwmeester\& Iris F. Kappers. Exploring natural variation in metabolite-based defense against spider mites in Capsicum spp. In prep. 


\title{
Education Statement of the Graduate School \\ Experimental Plant Sciences
}

\author{
Issued to: Yuanyuan Zhang \\ Date: $\quad 13$ September 2018 \\ Group: Plant Physiology \\ University: Wageningen University \& Research
}

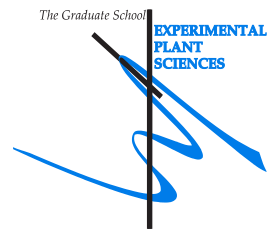

1) Start-up phase

- First presentation of your project

Direct defense and signal-based indirect defense against spider mites in Capsicum

date

- Writing or rewriting a project proposal

Direct and signal-based induced indirect defence against spider mites in Capsicum

- Writing a review or book chapter

- MSc courses

$\checkmark$ Laboratory use of isotopes

18 Mar 2013

Sep 2013

Subtotal Start-up Phase

6.5 *

\section{2) Scientific Exposure}

- EPS PhD student days

EPS PhD student day, Amsterdam, NL

EPS PhD student day, Leiden, NL

EPS PhD Student Days 'Get2Gether', Soest, NL

date

- EPS theme symposia

EPS theme 3 Symposium 'Metabolism and Adaptation', Amsterdam, NL EPS theme 3 Symposium 'Metabolism and Adaptation', Wageningen, NL EPS theme 3 Symposium 'Metabolism and Adaptation', Amsterdam, NL

- National meetings (e.g. Lunteren days) and other National Platforms Annual meeting 'Experimental Plant Sciences', Lunteren, NL Annual meeting 'Experimental Plant Sciences', Lunteren, NL Annual meeting 'Experimental Plant Sciences', Lunteren, NL Annual meeting 'Experimental Plant Sciences', Lunteren, NL

- Seminars (series), workshops and symposia

Symposium: Plant Metabolomics, Wageningen, NL

Symposium: Systems Biology for Food, Feed and Health, Wageningen, NL

Symposium: From Big Data to Biological Solutions, Wageningen, NL

Workshop: 8th Insect-Plant Interactions Workshop, Wageningen, NL

Workshop: iPLANT workshop, Wageningen, NL

Workshop: transPLANT workshop - Exploiting and understanding Solanaceous genomes,

Wageningen, NL

Workshop: 10th Workshop Plant-Insect Interactions, Amsterdam, NL

Workshop: Metabolomics in Chemical Ecology, Wageningen, NL

Seminar: Iridoid glycosides - Biochemistry and role in biotic interactions in ribwort plantain

Seminar: Elucidating the biosynthetic pathway for vibralactone in the basidiomycete fungus Boreostereum vibrans

Seminar: Understanding the molecular mechanisms underlying rice tillering

Seminar: The creation and utility of synthetic genotypes in plants - Boundaries between metabolic engineering and synthetic biology

Seminar: WEES Seminar - Maintaining an ancient balanced polymorphism for resistance amidst diffuse interactions

Seminar: The evolutionary significance of gene and genome duplications

Seminar: The response to cold stress in rice - Signaling, transcriptional and metabolic regulation Seminar: Genomics-enabled natural products discovery

Seminar: Auxin signaling - Inputs and Outputs

Seminar: Evolution of symbiotic gene networks in land plants

Flying Seminar: The rhizomania complex in sugar beet - virus variation and resistance breaking

Flying Seminar: Clocks across taxa - Conserved cellular timekeeping mechanisms in plants, algae and other eukaryotes

Flying Seminar: Highlights of hidden insect-worlds

- Seminar plus

- International symposia and congresses

7th European Plant Science Retreat, Paris, France

Gordon Research Conference, Plant Volatiles, Ventura, USA

30 Nov 2012

29 Nov 2013

29-30 Jan 2015

22 Mar 2013

11 Mar 2014

23 Feb 2016

22-23 Apr 2013

14-15 Apr 2014

13-14 Apr 2015

11-12 Apr 2016

08 Oct 2013

24 Jun 2014

18 Jun 2015

24 Sep 2013

03-04 Mar 2014

13-14 Oct 2014

19 Nov 2015

31 Oct 2016

10 Apr 2013

24 Oct 2013

15 Nov 2013

07 Mar 2014

26 Sep 2014

04 Feb 2015

01 Dec 2015

31 Mar 2016

07 Apr 2016

08 Apr 2016

18 Apr 2017

29 May 2017

02 Oct 2017

10-13 Jul 2015

31 Jan - 5 Feb 2016 
Presentations

Poster: Genetic variation in herbivore-induced indirect defences related with direct defences in Capsicum - Annual meeting 'Experimental Plant Sciences'

Poster: Genetic diversity in spider-mite induced defenses in Capsicum spp. - Annual meeting 'Experimental Plant Sciences'

Poster: Genetic variation in herbivore-induced indirect defences related with direct defences in Capsicum - The European Plant Science Retreat, Paris, France

Poster: Gordon Research Conference, Plant Volatiles - Sesquiterpenes in glandular trichomes of Capsicum and their involvement in direct and indirect defences towards two-spotted spider mites Talk: Plant Physiology PhD trip 2015 in Tübingen University - Direct defense and signal-based indirect defense against spider mites in Capsicum

Excursion to company Rijk Zwaan, Fijnaart, NL

Plant Physiology PhD trip in the Netherlands, Germany and Switzerland

27 Apr 2015

20 Sep 2013

\section{3) In-Depth Studies}

- EPS courses or other PhD courses

Systems Biology: Statistical analysis of omics data

Bioinformatics - A User's Approach, Wageningen, NL

The power of RNA seq, Wageningen, NL

Mixed Linear Models, Wageningen, NL

\section{4) Personal development}

- Skill training courses

The Art of Presenting Science, Wageningen, NL

Scientific Writing, Wageningen, NL

WGS PhD Workshop Carousel, Wageningen, NL

Brain Training, Wageningen, NL

Herewith the Graduate School declares that the PhD candidate has complied with the educational requirements set by the Educational Committee of EPS which comprises of a minimum total of 30 ECTS credits. 
The research was performed at the laboratory of Plant Physiology, Wageningen University. Yuanyuan Zhang was sponsored by a Fellowship from the Chinese Scholarship Council (CSC). The research was partially supported by the STW-funded project "Improved biological control in Capsicum by exploration of genetic diversity" (13551).

Cover Design by Yuanyuan Zhang \& Defeng Shen

Layout by Yuanyuan Zhang

Printed by ProefschriftMaken $\amalg$ DigiForce 